\title{
Achieving Good Governance and Development in Nigeria Through Decentralization: A Case Study of Ondo State
}

\author{
Koledoye, Benedict O
}

How to cite:

Koledoye, Benedict O (2017) Achieving Good Governance and Development in Nigeria Through Decentralization: A Case Study of Ondo State. Doctoral thesis, Swansea University.

http://cronfa.swan.ac.uk/Record/cronfa40712

Use policy:

This item is brought to you by Swansea University. Any person downloading material is agreeing to abide by the terms of the repository licence: copies of full text items may be used or reproduced in any format or medium, without prior permission for personal research or study, educational or non-commercial purposes only. The copyright for any work remains with the original author unless otherwise specified. The full-text must not be sold in any format or medium without the formal permission of the copyright holder. Permission for multiple reproductions should be obtained from the original author.

Authors are personally responsible for adhering to copyright and publisher restrictions when uploading content to the repository.

Please link to the metadata record in the Swansea University repository, Cronfa (link given in the citation reference above.)

http://www.swansea.ac.uk/library/researchsupport/ris-support/ 


\section{Achieving Good Governance and Development in Nigeria through Decentralization: A Case Study of Ondo State}

By

Benedict Oladipo Koledoye

Submitted to Swansea University in fulfilment of the requirements for the

Degree of Doctor of Philosophy

Swansea University

2017 


\section{THESIS SUMMARY}

This summary sheet should be completed after you have read the accompanying notes. The completed sheet should be submitted by you to your Head of School at the time of submission of your work and the supporting documentation.

Candidate's Surname / Family Name: KOLEDOYE

Candidate's Forenames: BENEDICT OLADIPO

Candidate for the Degree of: PhD

Full title of thesis: ACHIEVING GOOD GOVERNANCE AND DEVELOPMENT IN NIGERIA THROUGH DECENTRALISATION: A CASE STUDY OF ONDO STATE.

\section{Summary:}

Decentralization through the political theory of federalism has been at the centre of policy experiments in the last six decades in Nigeria where development and governance institutions have embraced federalism, as a part of the process of political reform, based on the constitutional foundation for its adoption. Federalism is perceived to be the panacea for improvements in efficiencies of the public sector so satisfying the needs of the citizenry, ethnic, religious and political divides notwithstanding.

By transferring decision-making powers closer to the grass roots, federalism improves governance, results in an equitable division of the national wealth and encourages critical development. Whilst the structure and process of government is crucial, it is not the sole determinant of what is considered to be good governance. Other factors that impact include the political culture in which subsidiary features such as corruption and civic activism influence the quality of federal governance.

Federalism has largely failed to engender political stability and socio-economic development in Nigeria. This research examines the major shortcomings in its implementation and a detailed analysis of such factors may help in laying the foundation for improvements in the system. 


\section{Declaration and Statements}

\section{DECLARATION}

This work has not previously been accepted in substance for any degree and is not being concurrently submitted in candidature for any degree.

Signed

(candidate)

Date

\section{STATEMENT 1}

This thesis is the result of my own investigations, except where otherwise stated. Where correction services have been used, the extent and nature of the correction is clearly marked in a footnote(s).

Other sources are acknowledged by footnotes giving explicit references. A bibliography is appended.

Signed (candidate)

Date

\section{STATEMENT 2}

I hereby give consent for my thesis, if accepted, to be available for photocopying and for inter-library loan, and for the title and summary to be made available to outside organisations.

Signed (candidate)

Date 


\section{Table of Contents}

Title Page $\quad$ i

Thesis Summary ii

Declaration and Statements

Table of Contents $\quad$ iv

Acknowledgement viii

Abbreviations and Acronyms $\quad$ ix

List of Tables $\quad$ xi

\section{Chapter One}

\section{Introduction and Background to the Study}

1.0 Introduction of Chapter 1

1.1 Statement of the Problem 5

1.2 Research Objective and Research Questions 12

1.3 Scope and Significance of the Study 13

$\begin{array}{lll}1.4 & \text { Ondo State } & 14\end{array}$

1.5 Guiding Theoretical Framework 16

$\begin{array}{ll}1.6 & \text { Limitation of the Study } \\ 1.7 & 18\end{array}$

1.7 Organisation of the Thesis 19

\section{Chapter Two}

\section{Theoretical and Conceptual Framework}

2.0 Introduction $\quad 21$

2.1 Concepts of Federalism: What is Federalism and Why Federalism? 21

2.2 Decentralisation and Federalism 28

2.3 Types of Decentralisation $\quad 32$

2.4 Forms of Decentralisation $\quad 37$

2.5 Good Governance and Development 40

2.6 Federalism in Nigeria and its Challenges 54

2.7 Local Government System in Nigeria and their Challenges 57

2.8 Fiscal Relations and the Challenge of Nigerian Federalism 61

2.9 Civic Culture and Participation in Governance 66

$\begin{array}{ll}2.10 \text { Conclusion } & 71\end{array}$ 


\section{Chapter Three}

\section{Research Design and Methodology}

$\begin{array}{lll}3.0 & \text { Introduction } & 72\end{array}$

$\begin{array}{lll}3.1 & \text { Research Design } & 72\end{array}$

3.2 Research Method $\quad 75$

3.3 Target Population of the Study 83

$\begin{array}{llr}3.4 & \text { Study Procedure } & 83\end{array}$

3.5 Research Measurement 85

3.6 Data Collection $\quad 86$

$\begin{array}{lll}3.7 & \text { Study Setting } & 88\end{array}$

$\begin{array}{lll}3.8 & \text { Data Analysis } & 90\end{array}$

3.9 Trustworthiness 90

3.10 Ethical Consideration 91

Chapter Four

Political Culture and Governance in Nigeria

4.0 Introduction 93

4.1 Foundational Factors: paths to Nationalism and Federalism 99

4.1.1 The Clifford Constitution 99

4.1.2 The Richards Constitution 100

4.1.3 The Macpherson Constitution 101

4.1.4 The Lyttleton Constitution 101

4.1.5 Transition to Civilian Rule 102

4.1.6 The Second Republic 102

4.1.7 The Third Military Intervention 102

4.1.8 New Democratic Dispensation $\quad 103$

4.2 Consideration of a similar political situation: Indonesia 103

4.3 From Agriculture to Oil: A shift of economic paradigm in Nigeria 108

4.4 Civic Engagement in Nigeria Politics 115

$\begin{array}{llr}4.5 & \text { Political Engagement in Nigeria } & 125\end{array}$

4.6 Specific Factors which erode trust in the Nigerian Political System 126

4.7 The Effects of Social and Cultural Disparities on Politics In Nigeria 129

4.8 Governance: The Role of the Politicians 131

4.9 Infrastructure: Provision and Enhancement of by the distribution of resources 134

4.10 The Creation of States 143

4.11 Politics and Socio-Economic Development 150

4.12 Service Delivery Institutions 155

4.13 Political Parties, Politicians and Elections 156

$\begin{array}{ll}4.14 \text { Conclusion } & 164\end{array}$ 


\section{Chapter Five}

\section{Report on the Field Experiment in Ondo State, Nigeria}

5.0 Introduction 166

5.1 Ondo State; a general description 166

5.2 The Field Survey: subject type, demographics and range 171

5.3 Selection of the Study Respondents and Conduct of Interviews 173

$\begin{array}{lll}5.4 & \text { Findings } & 174\end{array}$

5.4.1 The Constitutional Issues 174

5.4.2 Informal and formal Characteristics of a federal system 175

5.4.3 Imperatives of creation States and Local Government as of good
Governance and Development

5.4.4 Power relations: asymmetrical power and fiscal relations 186

5.4.5 Local government as a means of good governance and development 195

5.4.6 Strength and limitations of Local Government 197

5.4.7 Effectiveness of Local Government personnel: Technocrats and Politicians 199

5.4.8 Level of Participation in Electoral Process 201

5.4.9 Decision-making at the community level 202

5.4.10 Responsiveness of the elected officials 204

5.4.11 Quality of primary health care and primary education 205

5.4.12 Means of improving the function of local government 207

5.4.13 Performance of Local Government between 1998-2015 209

5.4.14 Other community representatives: the role of the traditional

$\begin{array}{lll}5.5 & \text { Conclusion } & 210\end{array}$

\section{Chapter Six \\ Findings and Discussion}

$\begin{array}{lll}6.0 & \text { Introduction } & 212\end{array}$

6.1 Patterns and Themes 213

$\begin{array}{lll}6.1 .1 & \text { Findings } & 213\end{array}$

6.1.2 The de facto federal structure of Nigeria 215

$\begin{array}{ll}\text { 6.1.3 The prevailing political culture } & 220\end{array}$

6.1.4 Extent of Decentralization and the outcomes of
decentralisation

6.1.5 Institutional reforms for Nigeria to transform
poor socio-economic growth

6.1.6 The evolution of federalism in Nigeria 226 
6.2 Key performance indicators by which the progression of de facto federalism to fruition is measured.

6.2.1 Leadership and Political Will

6.2.2 Socio-economic development

6.2.3 Education

6.2.4 Improvements between 1998 to 2014

6.2.5 Institutional Arrangements 234

$\begin{array}{lll}6.3 & \text { Good Governance } & 237\end{array}$

$\begin{array}{lll}6.3 .1 & \text { Accountability } & 237\end{array}$

$\begin{array}{lll}\text { 6.3.2 The Electoral process } & 238\end{array}$

6.3.3 Political instability, civil unrest and violence 239

6.3.4 Government Effectiveness 239

$\begin{array}{lll}\text { 6.3.5 Regulatory Quality } & 240\end{array}$

6.3.6 The Rule of Law 242

6.3.7 Corruption Control 243

$\begin{array}{lll}6.4 & \text { Conclusion } & 244\end{array}$

\section{Chapter Seven: Conclusion}

Summary, and Findings

7.1 Introduction 246

$\begin{array}{lll}7.2 & \text { Summary } & 249\end{array}$

$\begin{array}{lll}7.3 & \text { Findings } & 258\end{array}$

Bibliography 266

$\begin{array}{lr}\text { Appendix } & 289\end{array}$ 


\section{Acknowledgements}

During the course of this study, I enjoyed overwhelming support from many people to whom I owe profound gratitude. First and foremost to God who provided me with means and sustained me with health to successfully complete this study. Special thanks go to the Blessed Virgin Mary, to whom I entrusted all my endeavors and concerns.

Special appreciation goes to the Most Rev. Francis Alonge, the Bishop Emeritus of Ondo Diocese, Nigeria, who approved my further studies and to the incumbent Bishop, the Most Rev. Dr. Jude Arogundade, for his unflinching support. I am very grateful also to Bishop Tom Burns SM, of the Catholic Diocese of Menevia, for his kindness.

I am grateful to the Department of Political and Cultural Studies Swansea University. I am particularly grateful to Dr. Krijn Peters, my first supervisor and Dr. Gerald Clarke, my second supervisor, for their insightful ideas and suggestions all through the period of this study and most especially during its most challenging periods.

Special thanks go to my mother, Eunice Koledoye and my siblings, Dr. Victor Koledoye, Mr. Augustine Koledoye and Fr. Dr. Valentine Koledoye loads of appreciation for their constant prayers, affection and love for me. Very many thanks to Dr. Klaus Peipel, of Misereor Aachen, Germany who facilitated a partial scholarship for me with the Misereor. My special thanks goes to Phillip Rudall for his ideas, suggestions, review, critique and dedication, and to Dr. Christine Abonge, Sr. Dr. Bola Ojo, and Mr. John Davies. I will ever remain grateful to you all. Special thanks to all who stood by me through thick and thin with their prayers and moral support. I also remember with fondest affection, my friend Late Dominic Conway, he was truly a friend. May he rest in peace.

Finally, I am grateful to my former PhD colleagues in the Department of Politics and Cultural studies for their support and kindness, especially Dr. Ola Olateju, Olu Adekola, Dr. Che Afan and Patience Bentu. God bless you all. 


\section{Abbreviations and Acronyms}

AG

ANPP

APC

APGA

AD

$\mathrm{BBC}$

CBN

CIDA

DFFRI

DFID

DPD

EFCC

EITI

FCT

GCR

GDP

HDI

HDR

HRW

ICG

ICPC

IDAs

IMF

INEC
Action Group

All Nigeria People's Party

All Progressive Congress

All Progressive Alliance

Alliance for Democracy

British Broadcasting Corporation

Central Bank of Nigeria

Canadian International Development Agency

Directorate for Food, Roads and Rural Infrastructure

Department for International Development

Regional Representatives Council

Economic and Financial Crimes Commission

Extractive Industries Transparency Initiative

Federal Capital Territory

Global Competitiveness Reports

Gross Domestic Product

Human Development Index

Human Development Report

Human Rights Watch

International Crisis Group

Independent Corrupt Practices and other related offences Commission

International Development Agencies

International Monetary Fund

Independent National Electoral Commission 
LGA

NBS

MAMSER

MDGs.

MPR

NAP

NCNC

NEC

NEITI

NNPC

NYM

NPC

NPC

NPN

NPP

NRC

NNDP

OSOPADEC
Local Government Area

National Bureau of Statistics

Mobilization for Self Reliance, Social Justice and Economic Recovery

Millennium Development Goals

People's Consultative Assembly

Nigeria Advance Party

National Council for Nigeria and Cameroons

National Electoral Commission

Nigerian Extractive Industries Transparency Initiatives

Nigeria National Petroleum Company

Nigerian Youth Movement

National Population Commission

Northern People's Congress

National Party of Nigeria

Nigerian Peoples Party

National Republican Convention

Nigerian National Democratic Party

Ondo State Oil Producing Areas Development Commission 


\section{LIST OF TABLES}

Table 1: Derivation Formula 1960-Till Present 56

Table 2: The Nigerian: Legislative List 63

Table 3: Timeline of Historical Events 95

$\begin{array}{ll}\text { Table 4: Nigerian poverty rates } & 143\end{array}$

$\begin{array}{ll}\text { Table 5: Nigerian States } & 148\end{array}$

$\begin{array}{ll}\text { Table 6: Ondo Population Statistics } & 167\end{array}$

Table 7: Local Government Areas in Ondo State and their headquarters $\quad 170$

\section{LIST OF FIGURES:}

Figure 1: Indicators of good governance 133

Figure 2: Nigerian economic Report 142

$\begin{array}{ll}\text { Figure 3: Map of Nigeria and Map of Ondo State } & 167\end{array}$ 


\section{Chapter One}

\section{Introduction and Background to the Study}

\subsection{Introduction}

It is generally considered that decentralization is an effective and reliable means of achieving good governance, political stability and sustainable development. This view might be corroborated by an examination of the level of governance and development in countries using decentralized systems. Examples include the United States, Australia, Canada, Australia, Switzerland and Indonesia, which can be said to have attained good governance and development. It is likely that the noted achievements of such countries, and the recommendations of development institutions such as the World Bank, informed and influenced the decision of some African countries to attempt decentralisation as its form of governance model; there is however little or no positive evidence to suggest that such attempts have been altogether successful.

A case in point is Nigeria where decentralization is yet to produce the desired results as observed in the USA and Indonesia et al, and various reasons have been advanced for such perceived failures. Whichever approach one adopts in analysing the failure of decentralisation in Nigeria, it is clear that the structure of decentralisation, leadership of the Government, the entire citizenry and the political network of the country have prominent roles to play either in the success or otherwise of decentralisation as a way of bringing about good governance in any country.

This chapter conceptualises decentralisation, outlines the objectives of the study and explains Nigeria's federalism and the challenges to full implementation. In addition there is discussion 
of the statement of the research problem, the research questions, the significance, scope and theoretical framework of the study and limitations of the research; these challenges are discussed under two broad categories of political and economic issues. The organization of the thesis is enumerated at the end.

There is a generally and widely held belief that decentralization stimulates good governance and development because its policy interventions are closer, more responsive and effective in recognising and meeting the local needs of the citizens. Similarly decentralisation is considered to be an important element of participatory democracy. Representing this view is Vansant (1997) who sees decentralisation as an important institutional setting that could enhance good governance. The Word Bank (2001) also supports the view that decentralisation is a global phenomenon that could no longer be ignored by any developmentminded country. However scholars such as Prud'homme et al (1995), Turner and Hulme (1997), Manor (2001) and Smoke (2003) have pointed out that there are also some associated negative aspects of decentralisation. These include political elitism, the hijack of political power and financial resources of the state and inter-regional income, development disparities and an increase in corruption.

In the view of Smoke (2003:7) it is important to stress that decentralisation is not, in itself, an inherently positive or negative concept. The varying outcomes depend on the design and the implementation of the set policies. These include the extent to which political, fiscal and administrative powers are devolved, de-concentrated or delegated. Smoke (ibid) opines that an appropriate design takes into consideration political, institutional, fiscal and cultural characteristics of the particular country implementing decentralisation. The political institutions, particularly the nature and competitiveness of political parties, their power at 
local levels and the strength of civil society play a significant role in the design and implementation of decentralization policies (ibid: 13).

It is essential to emphasise that the design factors identified by Smoke vary from country to country. It therefore becomes compelling for the design of decentralization to be country and context specific. For example what promotes a positive outcome in one country may not necessarily produce the same result in another. It therefore follows that if these contextual factors are not taken into consideration, a poorly designed decentralized system may arise and possibly lead to a fragile or failed state. A classic example is the observation of Brancatti (2005:3-4) that decentralisation was very successful in curbing ethnic conflicts and secessionism in Belgium, India and Spain, but much less successful in curbing similar situations in Nigeria and the former Yugoslavia. What could be deduced from this failure is that the policy makers failed to take into account or give adequate consideration to the sociology of both Nigeria and the former Yugoslavia when designing templates for the future governance of the two countries. Conversely, in the cases of India, Belgium and Spain, full cognisance of the citizenry, its fundamental characteristics and requirements was taken into consideration, resulting in infinitely more successful outcomes.

Major outcomes of any poorly designed decentralisation include the undermining of the state macroeconomic control, worsened inter-regional income disparities and an increase in the risk of political or elite seizure of the government, Smoke (2003:11). Perhaps this is what informed the World Bank on its Decentralization Net to emphasise that decentralisation might not always be efficient if poorly designed. Further the World Bank holds that poorly designed decentralization can also result in the loss of economies of scale and control over scarce financial resources by the central government. Considering the advantages and 
disadvantages of decentralization, and having regard to the submission of Smoke (2003:12), the concept of decentralisation could be seen largely as "... an unambiguously desirable phenomenon that can alleviate many problems of the public sector or, sometimes, as an invariably destructive force that frustrates effective government" (Smoke ibid). Therefore, to reach a conclusion on the merits, or otherwise, of decentralisation, it is imperative to ensure that an appropriate design is in place with leadership commitment to the implementation of its policies and set objectives, and fair share of power between the central and sub tiers of government.

The above submission was largely stressed by Tanzi (1996), Litvack et al. (1998) Wunsch (2001), Peterson (2001) and Smoke (2003) who emphasised that the structure of government and the design of the decentralization arrangement reflective of such design are vital factors to the success or failure of any form of decentralization. This being the case the peculiarity of each country will determine the mode of its decentralisation (Brancatti 2005:3) so that decentralization is not a monolithic concept Smoke (2003: 8). To this extent the context of the state, the rationale for the adoption of decentralisation, the structure of government and the environment and the political network remain critical factors in any decentralisation design so that decentralisation becomes a difficult phenomenon to study especially when a 'grand design' approach is adopted by the study nation. It is with these factors in mind that the political structure of the Nigerian state is examined.

The literature on Nigerian federalism generally claims that the federal system arrangement has not been able to effect and enhance good governance and the pertinent question is why the federal system in Nigeria has failed to engender good governance, poverty reduction and socio-economic development in the country. This question becomes even more significant if 
one considers the example of Indonesia, a country with similar socio-economic and political conditions which has been relatively successful in managing its political and socio-economic problems through decentralisation. This study, in seeking to answer this question, investigates the major challenges facing the Nigerian State through an examination of the institutional factors and political network factors ${ }^{1}$ and how these factors interact and influence the outcome of a federal system of government in the specific context of Nigeria.

There are two approaches to understanding federalism. The first approach is to view the subject federal system in terms of static institutional rules and normative settings. The second is to visualize the federal system as a dynamic system of political networks. This research focuses on federalism as a political process, and how political interactions are embedded in the federal system arrangement in Nigeria. Using Ondo State as a case study, this approach will provide a more much comprehensive explanation of the reasons why the federal system has not generally been instrumental in enhancing social and political development in Nigeria.

\subsection{Statement of the problem}

According to Watts (2002) a federal system is adjudged to be a viable institutional framework that stimulates progress, prosperity, development, better standards of living and long-term economic growth. Underpinning this position Adamolekun and Kincaid (1991) and De Figuerido Jr and Weingast (2005) argue that the federal system creates a consistent, credible,

\footnotetext{
${ }^{1}$ Institutions refer to the legal framework of the federalism which is the constitution and other formal institutions of state. The constitution sets the rules of engagement. Political network factors refers to all the types of political interactions between politicians, between citizens, and all other interactions, which do not always follow existing institutions, but may also be clientelistic in nature or characterized by informal institutional behaviour. These interactions may arise as the result of either too much leeway that federal institutional factors give to political actors (insufficient reach of institutions), or because of other causes to be explored herein. In this sense, institutional and political factors and their respective explanatory power are strongly intertwined.
} 
and financially sensible line of authority between the centre and regions, and ensures efficient allocation of resources capable of promoting political stability and socio-economic development across the whole nation. However, surveys on the federal system and the varying degrees of performance across federal states, suggest that Watts' position is not universally applicable. De Figuerido Jr and Wiengast (2005) argue that whilst some federal systems experience sustained growth (including the richest economies in the world, such as the USA, Australia and Indonesia) others, such as Nigeria, remain economically stagnant, exhibiting persistent recession and poverty. De Figuerido Jr. and Wiengsat (2005) assert that the success or failure of the federal system depends on the context in which it is practiced. It is, therefore, important that each federal state is examined on its own merits in order to determine the issues or factors that enhance political stability and economic growth on the one hand and those that undermine the capacity of the system to engender robust institutions of democratic and economic development on the other. Within that context, this study is based on the context of Ondo State.

The federal system was adopted in Nigeria as a framework for national development, accommodation and peaceful co-existence in a multi-ethnic society. Adebanwi and Obadare (2010) suggest that the federal system is presumed to be a potential solution to the challenges of ethno-regional diversity, resource accumulation and distribution, citizenship, individual rights and collective responsibility. However, from the review of the performance of the Nigerian federal system by Ekeh and Osaghae (1981), Adamolekun (1991), Nnoli (2008), Elaigwu (2007), Suberu (2010), Okpanachi (2010), Osaghae (2010) Adebanwi and Obadare (2010) there seems to be a consensus that the federal system has not sufficiently fulfilled the essential rationale for its adoption as a system of government. 
Based on the findings of Osaghae (2010) the Nigerian federal system is also said to be responsible for the country's political and socio-economic failures. Corroborating this notion, Suberu (2010:249) suggests that "the contemporary debates about Nigeria's political and economic failures have routinely implicated the presumed pathologies, incongruities and liabilities of the country's federalism." In other words, the conception, evolution and practice of Nigerian federalism appear to be defective and unfit for purpose. A general overview of the trends and effects of the defective federal system is summarized by Osaghae (2010) who argues that Nigerian federalism is seen as a long-drawn-out process of decay or decline, whose empirical elements are political instability, a low level of national cohesion, and economic crisis, all of which are mutually reinforcing. Consequently, there have been persistent demands for the restructuring of the Nigerian system, namely:

- restructuring of fiscal arrangements;

- agitation for power rotation amongst the ethnic nationalities;

- agitation for creation of more states and local government autonomy;

- agitation for a loose confederation is predominant;

- agitation for State Police; that each State should maintain and control its Police In the extreme situation, there is also demand for secession.

These issues and agitations have necessitated varied institutional transformation, reforms, and restructuring of the Nigerian federal system before and after Nigerian Independence in 1960. The findings of Elaigwu (2007) and Osaghae (2010) reveal that the many attempts to transform, reform and restructure seem to support the notion that the practice of federalism in Nigeria is at the root of Nigeria's political and economic failure. Regrettably such 
transformations and reforms carried out to date do not seem to have resolved the political and socio-economic challenges of Nigeria. Suberu (2010) too suggests that despite (and often because of) the massive transformation and reorganization it has witnessed since national independence, the Nigerian federal system is often denounced as the source of, rather than a viable solution for, the country's multifaceted crises of poor governance, ethno-political conflict and socio-economic underdevelopment.

Scholars such as Suberu (2010), Elaigwu (2007), and Okpananchi (2010) however have attempted a balanced federalist debate on the performance of the Nigerian federal system and argue that, despite the challenges it faces, it has also recorded some major achievements. These conclusions are premised on the argument that the Nigerian system represents a reasonably viable and successful mechanism for managing inter-ethnic conflict and preventing ethno-political disintegration. Further, despite the numerous challenges and violent conflicts which plague Nigeria, and which includes a thirty month civil war, Nigeria still remains a united country. Both of those conflicts in arguments represent valid standpoints in the context of the economic and political situation in contemporary Nigeria. That duality of debate raises critical questions such as; (1) how long can the present federal system sustain unity and cohesion of Nigeria; and (2) can the present system resolve the lingering socio-economic crisis and offer a robust and conducive environment for future development.

Both questions become even more relevant when considering the present challenges to development and the disruptive activities of the Islamic insurgent group Boko Haram, and underscore the report of the International Crisis Group (2006) which notes that whilst federalism has permitted entitlements to be spread more widely across the society, it has also 
fuelled a proliferation of states and local institutions that has made governance fragmentary and unwieldy. The inability to fairly obtain a fair share of the country's wealth has left most citizens with two choices: fatalistic resignation or greater identification with alternative hierarchies based on ethnicity, religion or other factional identities.

The International Crisis Group report concludes as follows:

"Nigeria's federal system and politics are deeply flawed, contributing to the rising violence that threatens to destabilise one of the Africa's leading countries. Failing to encourage genuine power sharing, they have sparked dangerous rivalries between the centre and the 36 states of the country over revenue from the country's oil and other natural resources; promoted noholds-barred struggles between interest groups to capture the state and its attendant wealth; and facilitated the emergence of violent ethnic militias, while politicians play on and exacerbate inter-communal tensions to cover up their corruption (2006:1)."

The strong inference of this report, coupled with contemporary debate, is that federalism, as practiced in Nigeria, constitutes a great threat to socio-economic growth, national development and national integration and cohesion. It is important, therefore, to examine all the underlying issues which include the structure of central, state and local government, power sharing, fiscal arrangements and the specific tensions which impact on such elements.

According to research by Elaigwu (2007), Adamolekun (1991), Amuwo et al (1998), Falola (1994), Ndibe (1999), Olowu (2001), Osaghae (2010) and Suberu (2010), the Nigerian federalism is, fundamentally a product of three factors, namely:

(1) colonialism and the impact of colonial administrative policies on present political administration; 
(2) the military heritage and its impact on the Nigerian political economy (the transformation of, and centralisation of the Nigerian federation by soldiers; and,

(3) the emergence of oil exports (rent economy) as the dominant source of foreign exchange earnings; in this context the rent economy has a significant effect on the structure and workings of the system.

These three factors are both inter dependant and inter active. They are major contributors to the problems inherent in the Nigerian system and the consequences are largely exhibited in three forms. Firstly Elaigwu (2007), Adamolekun (1991), Suberu (2010), and Olowu (2001) argue that the structure of the federal system tends towards increased centralisation and the concentration of resources and power at the centre. This creates a crisis of fiscal federalism with a negative effect on development. Secondly the perpetuation of reactionary or negative forms of ethnicity and group solidarity promotes the emergence of elite competition for the purpose of power and capital accumulation which is excessively parochial, and reliant on prebendal and patrimonial processes. Thirdly the interaction of these factors has weakened the fiscal cohesiveness and socio-economic development of Nigeria as a whole. This is largely due to the problems arising from intergovernmental relations, such as uncoordinated tax raising powers and the conflict in the responsibilities/ functions of the tiers of government in essential service delivery. Based on the challenges highlighted, this study analyses the institutional and political contexts within which the federal system operates. In doing this, the research specifically examines the four key factors referred to below.

\section{The nature of the federal system}

The nature of the system is relational, based on the constitution. This is the relationship between central government and the sub national units and is defined by the assignment of power, functions and responsibility. However simple this may appear, there is always the problem of the delineation of these functions and it is necessary to determine where the 
boundaries lie as to how much power and responsibility is to be retained by the central government and how much is to be assigned to the sub national units.

\section{Federalism and fiscal arrangements}

Fiscal arrangements are statutorily defined between the tiers of government in a federal arrangement. According to Onimode (2000: 15) they essentially deal with the theoretical and institutional issues of intergovernmental relations and how these relations impinge on sound macroeconomic management. The financial relationship is, equally, tied to expenditure assignment. To this end, Oates (1999) argues that fiscal federalism fundamentally deals with understandings in which functions and instruments are best centralized and which are best placed in the sphere of decentralized levels of government.

This relates largely to how competences and resources are allocated. However, underpinning the fiscal arrangement, particularly as it pertains to the sharing of revenue amongst the tiers of government and the implementation of physical and social programmes, are factors that raise the questions of 'who gets what, when and how?' These are important considerations in the analysis of this research and the equitable division of the national wealth between the citizenry of Nigeria.

The impact of the oil economy

The oil economy is otherwise referred to as rent economy. Scholars have identified the impact of the rent economy in mostly negative terms, i.e. the Dutch disease. This research will examine the impact of the oil economy on the Nigerian federal arrangement

\section{Politics, party system and politicians}

These factors are of critical importance because politics, the party system and the politicians themselves constitute the informal aspects of governance. Given that many attempts to transform, reform, and restructure the Nigerian federal system as a means of engendering good 
governance in Nigeria have failed, there is need for determining the primary reasons leading to such failure and to determine strategies to attain good governance and development.

This study explains why decentralization in Nigeria has failed to engender political stability and socio-economic development and to what extent the current structure and practice of federalism has contributed to the poor governance and underdevelopment. Its aim is to provide an empirical, mostly qualitative contribution that highlights the relevance and importance of what is referred to as the informal factors in the political networks in the workings of decentralisation. Federalism and decentralisation literature typically looks more at the legal frameworks of divisions of responsibilities but perhaps pays less attention to the informal factors referred to above.

\subsection{Research Objective and Research Questions}

The main objective of this study is to reveal the extent that the current structure and practice of federalism has contributed to the current status of governance and development in Nigeria. This is done with the intent to explain that the poor level of governance in Nigeria cannot be excluded from the nature and character of its decentralisation design and political network factors. The overarching question is therefore 'Why the system of decentralization in Nigeria has routinely failed to engender political stability and socio-economic development. In pursuit of a definitive conclusion, this thesis examines:

1. the major shortcomings in the structure of Nigerian federal structure;

2. the institutional and political factors that explain the poor performance of decentralisation in Nigeria; 
3. the problems of encountered in the implementation of decentralisation in Nigeria local government system;

4. the necessary conditions for effective decentralisation for effective decentralisation in the Nigerian local government system; and,

5. the measures to be adopted in improving the decentralisation in the Nigeria local government system.

\subsection{Scope and Significance of the study}

The theoretical significance of this research underscores the importance of effective decentralisation. Its scope is to examine why the system of decentralization in Nigeria has apparently failed to engender good governance and socio-economic development. It investigates the major challenges of Nigerian federalism using Ondo State as a case study. Ultimately this thesis investigates local government as the basis of development and the people's participation in governance at the local level. This is attained through an examination of the Nigerian federal structure and its framework, the relationship between Federal, State and Local Government, the bureaucracy inherent in the process and the system of sharing and managing political, fiscal, and administrative powers.

Analysing decentralisation in Nigeria will contribute to an understanding of the factors that have contributed to the failures of the Nigerian state to produce good governance in the first instance. In principle, this research explores the relationship between political structure and development in Nigeria. It also explores the ways through which an appropriate political structure to support national development could be achieved; the supposition is that an appropriate political structure would, in turn, produce policies and programmes that could engender political stability, economic growth and sustainable development. Invariably there 
is emphasis on the fact that the structure of local government matters in decentralisation but the research progresses to focus attention on the area that is largely ignored in the concept of decentralisation- the political networks.

The first step in the analysis is to determine the nature and character of Nigerian decentralization and review the debate on several aspects of Nigerian federalism that are directly related to development. Although it could be argued that Nigerian federalism has to some extent brought some political stability and socio-economic development, this study critically examines whether such levels of stability and development are commensurate with the natural and human resources available in Nigeria. Against that premise is an assessment of the effect of the nature and character of insurgencies in the Eastern, Southern and Northern parts of the country.

Local government is a product of decentralized administration and in a developing country like Nigeria there is a greater need to strengthen the decentralization in the local government as a means of bringing rapid national development. It is hoped that this study will be of immense contribution to academic research on the central thesis. Furthermore the findings of this study may assist other research in the same or similar topics.

\subsection{Ondo State}

Ondo State was one of the three states created out of the former Western State on 3rd February 1976 by the Federal Military Government of Nigeria (Fatusin, 2015). It covers the total area of the former Ondo Province, which was created in 1915, with Akure as the provincial headquarters. Ondo State officially started its operations on 1st April 1976. Today Ondo State has eighteen local government councils. According to Fatusin (2015) the main local government areas include Owo, Akoko, Okitipupa, Akure and Ondo. Its governance 
structures do not differ from those of other states of the federation and is continually evolving to seek to meet its obligations.

According to Aribigbola, Folami, Williams-Adewinle and Karimu (2013) the need to free local governance from the restraints of the state government has become a challenge to politicians and scholars and citizens alike. For example, between June 2015 and May 2016, the National Economic Intelligence Committee (NEIC) revealed that a total sum of N71 billion has been allocated to Ondo State. However, despite the enormous resources available, people at the grassroots are worse off and are still suffer from poverty. The issues to be considered is therefore is the nature of the responsibilities and duties of the local government to the people, how they are performed and to what extent. If, despite the huge revenue allocation from the centre there is still poverty, the relevance of local governments to the people in terms of good governance must be called into question.

Olowu and Wunsch (2004) provide two methods for evaluating the effectiveness of local governance. The first is to determine whether the transfer of authority, resources, and accountability and the development of an open local political process and local political and administrative institutions are working in ways that suggests local prioritisation. The second is to focus on the output and outcomes to determine whether local governance delivers the expected tangible benefits in terms of better schools, health systems, water supply, or roads, and the intangible benefits inherent in such delivery such as empowerment and social service delivery that enhance people's welfare.

It is also of interest to note that since 1996, the World Bank has made it possible to measure governance performance in a more scientific ways by voice and accountability, political 
stability, absence of violence, government effectiveness, regulatory quality, rule of law, and control of corruption. Some of these six indicators provide the basis for the evaluation of the performance of local governments in Ondo State, Nigeria.

\subsection{Guiding Theoretical Framework}

Recognition of and respect for the political and economic authority among separate levels of government is fundamental to the success of decentralization. National and sub-national governments are entitled to significant autonomy in relation to political administration, expenditure and revenue and initiatives for development. Wildasin (2004) argues that the level of this autonomy enables the levels of government to;

“. . . provide highly-valued public goods and services to their residents, financed by revenue systems that impose little waste through deadweight losses and that distribute the burden of government finance in a manner not offensive to widely-shared notions of equity and fairness."

The presumed outcome of decentralization is effective and efficient governance which, in turn, fulfils the true purpose of government.

The increasing global interest in decentralization and federalism enhances the position of Wildasin (2004). The analysis of the levels of government and their capacity to bring political stability and development however remains a critical issue. The analytical framework of this research is based on two theoretical frameworks, namely functional theory and legislative theory. The two are intertwined in the process and implementation of decentralization design and are considered below.

\section{Functional theory}

This identifies the distinctive areas of competence of each level of government (Oates 1972; Brown and Oates 1986; Paterson, Rabe and Wong 1986; Stein 1990; Elazar 1991Burns1994). 
It divides the economic purpose of government into two aspects namely developmental and redistributive aspects.

\section{Legislative theory}

This postulates that the political incentives that shape the decision of policymakers induce them to make wrong choices. Legislative incentives imply many things but principally that the primary aim of government is for the general good of the society or, alternatively or in addition, for political gain by the politicians or policy makers. Peterson (1995:41) suggests that the primary goal of the political representative is re-election, albeit in support of their bid to satisfy the social demands of their constituents, regardless of the overall benefits to the federal system. He states further that;

$$
\begin{aligned}
& \text { "Constituents easily recognize spatially concentrated costs and } \\
& \text { benefits, but that spatially dispersed costs and benefits are less } \\
& \text { perceptible. Legislators therefore support projects that have } \\
& \text { geographically concentrated benefits but diffuse costs as oppose to } \\
& \text { policies that have diffuse benefits but spatially concentrated costs." }
\end{aligned}
$$

In other words, legislators may allocate more money to projects benefitting their constituency (or, for that matter, their ethnic group) rather than to projects that would benefit the country or region as a whole.

The personal aspirations of politicians and the pressures of their constituency upon them therefore can play a significant role in the policies and working of government. In many cases the goals of politicians are personal and self-serving. It also appears that on occasions the personal aspirations of politicians outweigh constituency needs. Furthermore, the theory holds that whilst incentives are important as a motivation in policy making it is, nevertheless, the successful implementation of projects that is the most important factor in the development of the State. On the issue of the redistribution of resources the legislative theory assumes that redistribution is strongly influenced by the pressure of the constituency legislators (who may 
represent a low-income or needy population/constituency) who are likely to favour the expansion of redistributive programs. Those who represent middle-income constituents are less likely to need government aid and are more likely to resist redistribution on the basis of the social need of others. Political support for redistribution is therefore expected to be greater in cities and states with higher poverty rates.

The sharing of responsibilities for the provision of services is viewed by the legislative theory as lacking in balance. The theory propounds that national government takes on responsibilities it should avoid and imposes unaffordable burdens on lower levels of the system, thereby transferring the burden of responsibility to agencies often less able to manage. This appears to imply the primacy of the legislature over the executive arm of the government and assumes that the preferences of the executive arm have much less effect on domestic public policy than the preferences of the members of the legislative arm (Peterson 1995: 35)

\subsection{Limitations of the study}

This research encountered certain challenges. The main one was the inability to conduct interviews in all eighteen local government areas of the state by the researcher. This was principally due to the limited time within which the second phase of fieldwork was carried out. However, it is considered that the six local government areas covered by the fieldwork did give a balanced representation of the State as a whole. Other challenges included gaining the confidence of the respondents especially having regard to the political situation in Ondo State where the political party in power locally differs from the party at the centre. Additionally the fieldwork was undertaken during a period of gubernatorial elections in the 
state. However this researcher is satisfied that all challenges were satisfactorily overcome and that the validity of the research has not been compromised.

\subsection{Organization of the Thesis}

The thesis is organized into seven chapters.

Chapter one provides an introduction to the study, research problem, research questions and a brief discussion of guiding theories and concepts. It also gives an overview of the literature on politics, governance and the federal system in Nigeria. It also discusses the research design and methods, demonstrating a rigorous approach to the generation of new knowledge.

Chapter two offers a more integrated discussion of federalism, by reference to current literature and its use in development discourse. The review covers the large debates, including governance, development and theories and models of development relevant for a discussion of decentralisation and development in Nigeria.

Chapter three presents and analyses the empirical case study based on significant original empirical research. This includes the methodology used and research designs.

Chapter four discusses the nature and character of governance in Nigerian politics. The chapter explains the relationship between politics, governance, political parties and civic engagement in Nigerian context. The chapter lays a foundation for an understanding of the dynamics of Nigerian politics, and the issues that keep defining the character and nature of the Nigerian federalism.

Chapter five gives the report of the fieldwork conducted.

Chapter six analyses and discusses the findings of the fieldwork. 
Chapter seven summarizes the whole study. It concludes with an exposition of the relative shortcomings of the Nigerian federal model and recommends further decentralisation. 


\section{Chapter Two}

\section{Theoretical and Conceptual Framework}

\subsection{Introduction}

This chapter discusses perspectives of governance, economic development, decentralisation and federalism with emphasis on Nigeria. From the literature review it is apparent that there is a considerable amount of material dedicated to the issues relating to Nigeria's political structure, governance and development and theories and models of development founding an authoritative backdrop to this research. It addresses and is structured in the following order; what is federalism and why federalism: differences between federalism and decentralisation; debates on good governance and development; federalism in Nigeria and its challenges; local governments in Nigeria and the obstacles they represent in the path towards good governance.

\subsection{Concepts of Federalism: what is Federalism and why Federalism?}

Before delving into the issue of good governance, it is apposite to shed light on federalism as a model of government in order to prepare the platform upon which governance would be assessed as either good or bad and the effects of such qualities on development, in this specific context, in Nigeria. In other words, this section examines federalism and decentralisation in relation to policymaking, interactions of institutions, actors in the process and political networks.

The concept of federalism presupposes the fusion of different groups or nations which form a federal state without prejudice to the identities of the discrete and differing groups that come together for such purpose. K.C Wheare (1964) describes federalism as hinging on the association of constituent units of the federation based on principles of justice and equity. It is an aggregation of equals that are being unified by a central federal government. However, 
this does not reduce the autonomy of the sub-units as the powers of the state are not centralised in the federal structure.

Various reasons have been advanced for the formation of federalism and well known federalist academics such as K.C Wheare (1964); Friedrich (1964); Riker (1964); Elazar (1987); Stepan (1985) seem to agree that explanations for federalism are generally based on two theories. The first is the socio-economic theory and the political theory important in the formation of a federal state. Riker (1964) in his Political Theory of Federal Formation however places greater emphasis on the political theory, perhaps influenced by his American milieu, and concludes that every federation is fundamentally a bargain between politicians and between prospective national leaders and officials of constituent governments for the purpose of aggregating territory, the right to levy taxes and raise armies (Riker 1964: 11).

This is largely inapplicable however in respect of Nigeria's federalism which is a product of the colonial administration as reflected in the McPherson 1951 and Lytleton 1954 Constitutions of Nigeria. Federalism in Nigeria cannot therefore be merely the outcome of political bargaining among politicians built on territorial expansionism and militarisation conditions, which Riker advanced as critical conditions for the formation of federalism. The weakness in Riker's argument as it relates to Nigeria was highlighted by Stepan (2005) who considers that Riker's view is predominantly based on the (possibly unique) USA model of federalism. Providing an alternative view Stepan advances theories as to how federalism accrues by 'coming together', 'holding together' and 'putting together' as the typologies that determine the mechanics of peoples living in a federal arrangement. 
Stepan presents the American, Swiss and Australian Federations as typical examples of this 'coming together' model of federalism. He observed that each was comprised of previously separate and independent sovereign units that had voluntarily decided to come together as one political entity while retaining their individual identities. This is quite different from the 'holding together' model, which occurs when an existing unitary state, usually characterized by "historical and political logic" decides to become a federal state. Stepan was close to identifying the beginning of the Nigeria's federalism using his 'putting together' model until he recognised that it came into force through the instrumentality of the colonial administration which merged previously independent regions together through a series of conferences and not so subtle persuasion. The view of Stepan that 'putting together' involves the use of some form of coercion to merge the previously independent states (Stepan, 2005: 257-8) is not entirely inapplicable in Nigeria's federalism because of its roots in some form of unitary system of government. The 'putting together' model forms the basis of arguments in this study for the purpose of explaining why the Nigerian state, in spite of its federal structure, is yet to engage in good governance for the people.

One major factor that might have influenced the putting together of Nigeria's formerly separate regions could be traced to Elaigwu's submission on federalism. He posits that adopting a federal arrangement is to reflect the diverse political, social, cultural and economic interests within a broader framework of unity (2007:6). Elaigwu however might not have given sufficient weight to ethnic identities in this broader framework of unity. The question of identity cannot be ignored in any federal discourse because it is a very significant issue in Nigeria where every ethnic group sees itself as being at the centre of the state. Every such group in Nigeria subscribes to Suberu and Osaghae's assertion on identity, they see identity as a series of group attributes that provide recognition, reference, affinity, coherence and 
meaning for the individual member of the group or the entire group itself (Suberu and Osaghae 2005:5). Identity is core to every ethnic group in Nigeria and their communal lives and the maintenance and preservation of cultural identities in Nigeria serves as integral element of their unity. Any contrary element to such preservation becomes one of the main sources of conflict and crisis in Nigeria's federalism.

Though there have been efforts at stemming crises that often arise from the identity struggles in Nigeria, partly the reason for the adoption of federalism in the first instance, the fusion of these multiple identities is yet to abate the inter-group suspicion in Nigeria's federation and the fear of loss of cultural identity and independence. The essence of federalism is to put in place the means of containing crisis and ensuring peace in a complex heterogynous society, features based on institutionalized structures and the rule of law. This is largely absent in Nigeria's federalism as there is still indigenous resistance to the Nigerian state structure in virtually all the geo-political zones of the federation. The main objection to the state by these various resistant groups is the perceived injustice against their ethnic group inherent in the Nigeria's form of government.

This perception can be contextualised by Elazar (1976) who considers that federalism, in its most limited form, has most to do with distribution and sharing of power. Where such distribution and sharing are inequitable, the objections of insurgent ethnic groups might be the inevitable result. The underpinning factor for the sharing and distribution of power is the conception of justice (Wheare: 1964) which holds among other things, that a distribution of power is necessary and desirable provided that it is achieved fairly. The type of agitation as witnessed in Nigeria is likely to become more intense if the competing groups consider that adoption of federalism amounts to acceptance of a justice system without any right of 
participation in the ensuing political construct, reminiscent of the mantra of the colonies in America 'No taxation without representation' as a preamble to the war of American independence. ${ }^{2}$ Federalism is idealistically about structure, power sharing, group autonomy within the larger federal state, a guarantee of the rights of all groups especially the minority group accommodation and compromise underwritten by justice. In Nigeria however that circumstance is yet to materialise.

As Wheare (1964) submits federalism is a method of dividing powers so that the general and regional governments are within a sphere, coordinated and independent where neither general nor regional is subordinate to the other (Wheare 1964:10). The strength of federalism could therefore be premised on the platform that it lies on the desire for cooperation in some areas and the right to separation in others. According to Shridath (1979) "it is only federalism that fulfils the desire for unity where it coexists with a determination not to smother local identity and local power. ${ }^{, 3}$ Federalism is essentially a compromise solution in a multinational state, between two types of self-determination: one, provided by a national government which guarantees security for all in the nation-state; and two, by self-determination of component groups to retain their individual identities. This research therefore disagrees with the view of Adedeji (1971) who states that what is essential in federalism is union and not unity because it is a result of compromise between centrifugal and centripetal forces that rest on a peculiar attitude on the part of the people of the federating units who desire union and not unity (Adedeji 1971; 103). That opinion fails to deal with one of the central dilemmas in

\footnotetext{
${ }^{2}$ Jonathan Mayhew, Old West Church's Congregational pastor, used the phrase, "No Taxation Without Representation" in a sermon in 1750. The phrase revived a sentiment central to the cause of the English Civil War following the refusal of parliamentarian John Hampden to pay ship money tax.

${ }^{3}$ Ramphal Shridath, The Commonwealth Secretary General, "Keynote Address to the International Conference on Federalism", at the Nigerian Institute of International Affairs, Lagos. Published in A.B Akinyemi, P, Cole, and W. Ofonagoro (eds) Readings on Federalism (Lagos: N.I.I.A., 1979) pp. xiii-xv.
} 
federalism which is the decision-making process which manifests itself most often in the context of the coordination of fragmented resources amongst a multitude of federating units where the question of "Who should do it" is prioritized over the question "What has to be done" (Pierson 1995, 449).

This then brings the focus on the working mechanisms of federalism in respect of which this researcher adopts the characteristics of federalism as espoused by Obinger et al (2005). Obiinger et al, in their study on the impact of federalism on the development of welfare states in the European, North American, and Australian context, seem to compress the normative and theoretical explanations of the early federalists discussed earlier in this section: K.C Wheare (1964); Friedrich (1964); Riker (1964); Elazar (1987); Stepan (1985). Obiinger et al 2005 define federalism as a phenomenon with five crucial characteristics:

(1) institutional arrangements and decision-making rules at the central governmental level with a certain degree of veto power to subordinate other levels/branches of government;

(2) jurisdictional arrangements that allocate policy responsibilities between different levels of government, including policy formulation and policy implementation;

(3) territorially-based actors with ideas and interests that may vary greatly in their number and heterogeneity (for example, municipalities);

(4) inter-governmental fiscal transfer arrangements (depending on the type of fiscal transfers and to which federal level these belong or are passed on to);

(5) informal agreements, both at the vertical and horizontal levels, between governments and other actors.

A critical analysis of these five characteristics suggests that federalism could produce a complex and problematic system of government. This perhaps results in the view of Law 
(2013) who indicates that federalism is a complex system with its characteristics overlapping with one another in various conflicting ways leading perhaps to negative consequences. The relationship of these often-conflicting factors remains contentious and is laden with challenges, all too apparent in Nigeria. Resolution of issues such as how the state institutions, its various actors and the political network relate to each other emphasises the notion that federalism is a continuing and evolving process. This notion is central to this research, because the Nigerian federalism is by definition still evolving, still in its infancy.

It is therefore imperative to examine the relationship between state institutions, actors and political networks. As noted in the functional and legislative theories of federalism (Peterson: 1995) political actors can reinterpret federalism as a polity through their interactions in order to reach individual or collective goals. These interactions will always entail the establishment of different types of relations among political actors. They will be characterized by power, resource, and information asymmetries and either follow, violate, or reinterpret existing federal rules and/or institutions. State and municipal governments, their bureaucrats, politicians, labour unions, elites, and others will fulfil different functions in these relations or networks of relations often involving hard bargaining processes between competing political interests, and overarching goals of macro contexts, such as polity and society.

A fundamental issue that arises from the discussion about politics, institutions, and the political actors engaged in the process, is whether institutions shape the actors or that the actors shape institutions. It raises the issue as to can mechanisms through which institutions shape the behaviour of individuals and through which individuals are able to form and reform institutions, are both envisaged and achieved. This is a complex question to which institutionalism studies have not found a concluding normative answer, despite certain 
agreement that interactions between both are not unidirectional because institutions link individuals with their context and also between one another.

\subsection{Decentralisation and Federalism}

As earlier discussed federalism is about power sharing, group autonomy within the larger federal state, guarantee of the rights of all groups especially the minority and group accommodation and compromise. All these are elements are geared towards socio-economic development of the state with every distinct unit being given the opportunity to adopt backward integration that is, using what they have to secure what they need for the betterment of the citizens.

A pertinent question is whether the power sharing mechanism, and the notional guarantee of everyone's rights and group accommodation and compromise, could be better achieved through decentralisation than federalism. This question arises due to the assumptions of those who confuse decentralisation with federalism. Though the two concepts may look alike they are not the same. Both theories and concepts advocate the devolution of political and economic powers and resources respectively amongst different groups within a state. This perhaps informs the position of Rodden (2004) when he argues that the two concepts are often assumed to be complementary or even interchangeable. Similarly, Ink and Dean (1970:60) say that, "decentralization is an important aspect of an overall effort to streamline federal programmes and to reduce programme management cost to a minimum". Nonetheless, the two concepts as observed by Bretton (2000) and Franceschet and Piscopo (2012), reveal significant disparities in the way that power and authority are distributed among the tiers of government. By means of decentralization central government devolves authority to the lower levels. However the central government can also suspend the powers of the lower 
authority so devolution is not necessarily final even though the lower levels in the government derive their powers primarily from the constitution.

The central government mostly deals with issues on the national scale such as defence, foreign policy and state ideology. The state and the central governments mutually co-exist and operate according to the dictates of the constitution but devoid of any master-servant relationship. The constitution defines power limitations of all the federating units and their tiers and as such, there is established the relationship of fairness in federalism compared to decentralization. The aggrieved party in federalism can challenge power infringement in a competent court of law. However, there are some elements of decentralisation in federalism but not all decentralisations are federalised. Federalism goes beyond power sharing; it includes some degrees of autonomy for the federating units in the areas of resource control, infrastructural development, education, labour, etc. As evident by the submissions of Enikolopoy and Zhuravskava (2007), Tavares de Ameida (2006) and Schneider, (2003) there are several debates surrounding decentralized governance but they all subscribe to its advantages. Such advantages include governmental effectiveness and public policy, democratic representation, participation and accountability as well as accommodation and representation of the territories based on linguistic, cultural and ethnic disparities (Treisman, 2007).

Subjecting Nigeria's federalism to the litmus test of the decentralisation elements confirms the observations of Suberu (2010), Elaigwu (2007), Lewis (2007), Olowu (2001) and Onimode (2000) who posit that the structure of the federal system tends towards increased centralisation and the concentration of resources and power at the centre. It is this concentration therefore that prevents Nigeria as a state from benefitting from the identified advantages of a decentralised federal system particularly as Nigeria's federalism has never been completely 
centralised except during the military regimes. The issue with Nigeria's federalism is that most vital powers necessary for the adoption of backward integration by the federating states are withheld at the centre. This situation perhaps results in the description of Nigeria's federalism by some observers as quasi federalism, pseudo federalism or centralised federalism.

Under a federal constitution, the federating units are fairly independent while the central government coordinates and unites all the units but not with a weak authority as Ames (2001) postulates. The American federal constitution, for example, ensures that the federating states, while coming together, voluntarily combine their authority and safeguard their rights against central government encroachment (Samuels, 2000). In Nigeria a critical examination of the power distribution by the constitution among the government tiers (the central government, the state government and the local governments) is vital in examining good governance and development in Nigeria. It is also vital in explaining why Nigeria's federalism has failed to engender economic development and foster democracy in the country.

Decentralisation has its own challenges, part of which was exploited by the then Eastern region of Nigeria to shake the foundation of Nigeria's federalism to its roots between 1967 and 1970. Challenges associated with decentralisation in the views of Manor (2001), Turner and Hume (1997); and Prud'homme (1995) include intensification of forces for secession and ethnic identity struggles, political instability, power-hijack by local political elites, interregional income disparities, corruption and macro-economic instability caused by budget deficits, local government and fiscal irresponsibility and local government indebtedness. Despite these challenges available evidence shows that the positive outcomes of decentralisation outweigh the challenges of negative elements in those countries where decentralisation has been implemented. Furthermore, analysis of decentralisation shows that 
the challenges are largely due to either poor design of decentralisation, or poor implementation of the process of decentralisation.

All the deficiencies of decentralisation are issues that have been identified by various scholars at different times as factors hindering Nigeria's socio-economic development. Most of these problems are associated with the overbearing influence of the federal government of Nigeria over its federating states. This position tends one to succumb to the view that those challenges are not structural in nature but man-made and which could be avoided if federalism and decentralisation principles are fully applied. The Isle of Man, Guernsey, Jersey and the United Kingdom, comprising of England, Northern Ireland, Wales and Scotland represent various examples of decentralisation though they all belong to what Andrew (2006) Schneider (2003) and Watts (199) refer to as a hybrid union type of federalism.

It is a reasonably drawn conclusion that decentralisation serves as a reaction to problems associated with the centralized system of governance. In most cases it serves as the solution to demand by the minority groups for equal participation and recognition in the political affairs of the state without any hindrance, inability of the government to finance key services and economic decline (Schneider, 2003). Scholars such as Enikopolopov and Zhuravskaya (2007) associate decentralization with democracy, engagement in decision-making, liberty and equality. This is the melting point of federalism and decentralisation because federalism without decentralisation may not fulfil the conditions of engagement with democracy, liberty and equality and, more importantly, the engagement of the citizenry in the economic sector which is most critical in development and governance. Decentralisation could therefore be regarded as a pre-condition for federalism in which public sector decisions could be taken at 
various levels of government with a compromise being reached between the central government and the federating units.

To this extent and citing from Work (2002) and Ebel and Yilmaz (2003) federalism is often accompanied by decentralization though federalism is not a necessary condition for decentralization or decentralization the only condition for federalism. Contextualising this relationship in Nigeria compels an examination of how a decentralised federal system can facilitate delivery of good governance and development and why the federal system could do this better than a unitary or quasi-federal system that Nigeria currently operates.

\subsection{Types of Decentralisation}

As noted earlier in this review, the question at the centre of the contemporary debate of decentralisation is 'how to decentralize?' This involves the designs of decentralisation and how much to decentralize, in other words by way of identified devolved powers. The design for decentralisation will therefore be a mixture of political, administrative and fiscal functions and relationships. A design including these three relationships further raises the question of how to sequence and synchronize them in order for it to produce the desired result of good governance; an example is whether political decentralization should precede or follow fiscal decentralization (Sharma, 2005 c: 40-41). On the issue of proportion it raises the question of how much political decentralization should be combined with what degree of fiscal decentralization. Examining the types of decentralization will illumine our attempt in answering these questions.

\section{Political Decentralization}

In general, political decentralization is understood as an arrangement whereby political power and authority is transferred to the local 'people', 'decision makers' or 'bureaucrats' in the sub 
national levels of government. In this vein it is argued that political decentralization necessitates universal participation and new approaches to community institutions and social capital (Work 2002: 6). It involves the prerogative of the authority to make political decisions among the different tiers in the government. Bird (2000:135) argues that the central question in political decentralization is 'who decides'; the arrangement of decision-making is therefore paramount in decentralization. The prerogative of decision-making determines whether a system is decentralised or not. Treisman argues that: "if authority to decide all questions belongs to the central government, the system is maximally centralised in this sense; if the lowest-tier governments have all decision making rights, it is maximally decentralised" (Treisman 2002: 7). However, this presents some difficulties in practice; for instance: "how rights to decide on specific questions are distributed amongst the tiers, and how decision making takes place on a given question" (Treisman 2002:7). The tendency to contest these issues is high. The issue of inter-governmental relationship is brought to the fore hence the problem of how rights to decide on specific questions are distributed amongst the tiers.

The critical debate in political decentralization is bordered on the process of transfer of the authority and the level or extent of transfer. Such transfer of authority could be by way of the electoral process and/or by appointment (Treisman 2002). Of particular significance in the Treisman argument is the issue of the political parties. For example, the political party controlling the central government has enormous influence on the electoral body. In the same vein the party in government in the state also has enormous influence on the state electoral body. In this manner, political parties largely determine the process and outcomes of 
elections. ${ }^{4}$ This situation questions the independence of the electoral bodies ultimately affects citizen participation and voice.

In as much as there is transfer of power it is noted by the scholars that the most crucial debate in this form of decentralization is the degree of control that the central government exercises over the sub units in development planning and administration. ${ }^{5}$ Political decentralization however requires a constitutional, legal and regulatory framework to ensure accountability and transparency. The legal framework of the political framework of political decentralisation is very important for the outcome of decentralisation. ${ }^{6}$ It also necessitates the restructuring of institutions and developing linkages with civil society and the private sector (Work 2002: 6). Political decentralization is manifested through devolution, which will be discussed later.

\section{Administrative Decentralization:}

Administrative decentralization is the redistribution of authority, responsibility and financial resources among different levels of the government (Rondinelli 1999). It is the transfer of

\footnotetext{
${ }^{4}$ In some of the developing countries, like Zimbabwe, Tunisia and Nigeria, the ruling and dominant parties are very powerful to the extent of emasculating their opposition. One of the reasons adduced for being able to do this is because the ruling parties control the electoral bodies of the countries. The Independence of the electoral bodies is often questioned. For example most of the elections in Nigeria have been characterized by manipulation of the electoral process by the parties in government. This is often made possible by the parties in government through the use of the security apparatus controlled by the Government to intimidate opponents and to rig the elections (Sylvia,Okeke, Idike, 2013).

${ }^{5}$ Ndegwa (2002) presents the findings of a survey on the level of decentralization in Africa, based on the number of elected sub-national tiers, the score for the existence of direct elections for local governments, and the score for turnout and fairness of such elections. Thus a country was likely to score high (i.e. 4) if it had more levels of sub-national government that were elected rather than appointed, where local governments in particular were elected, and where local government elections were adjudged free and fair. The highest score attainable was 4 , while the lowest was 0. Of the 30 countries analyzed, eight scored high (at least a 3 on the index) indicating a high degree of political decentralization (see Figure 1). These were South Africa, Uganda, and Namibia (all above 3.0) and Kenya, Ghana, Senegal, Ethiopia and Cote d'Ivoire. A second set of countries indicated a moderate level of political decentralization, with scores ranging from 2.0 to 2.9; these included 7 countries (i.e. Nigeria, Rwanda, Madagascar, Zambia, Tanzania, Mali and Malawi). The rest of the countries (15) indicated very low levels of political decentralization, although four of these at least held elections in part of the territory.

${ }^{6}$ This research, will explore the importance of legal framework of Nigeria and Indonesia, and asses how legal framework affects the outcome of decentralisation
} 
responsibility for the planning, financing and management of public functions from the central government or regional governments and its agencies to local governments, semiautonomous public authorities or corporations, or area-wide, regional or functional authorities. However, Vito Tanzi (2002) contends that administrative decentralization exists when most taxes are raised centrally but funds are allocated to decentralised sub nationals and the sub units that are more or less the agents of the central government. In this arrangement the central government controls the activities of the sub nationals. Work (2002) contends that administrative decentralization is synonymous with a civil service responsible to central government. Administrative decentralization takes the form of deconcentration and delegation. $^{7}$ Deconcentration is the transfer of authority of sub-national branches of the central state, often to the ministry officials based in local areas while delegation is suggestive of a principal and agent relationship where the principal is the central authority. .

\section{Fiscal Decentralization}

Fiscal decentralization is defined as devolution of authority over public revenue and expenditure to a lower level of government. It also refers to the resource reallocation to subnational levels of government and the capacity of the sub-national government to raise taxes and carry out spending activities within the constitutional provisions. (Enikolopov and Zhuravskaya 2007; Work 2002; Tanzi 2002; Treisman 2002) analyse the basis of sharing and/or redistribution and contends that sharing is based on negotiation between the central and local authorities. It is also based on several other key principles amongst which are: (1) interregional equity; (2) availability of resources at all levels of government and local fiscal management capacity (Work 2002 6). Treisman (2002) argues from the view of fiscal

\footnotetext{
${ }^{7}$ Op.cit. two countries indicated a high degree of administrative decentralization (South Africa and Uganda) while ten others indicated a moderate degree of administrative decentralisation (Nigeria, Rwanda, Tanzania, Zimbabwe, Kenya, Ghana, Ethiopia, Madagascar, Burkina Faso and Eritrea). Of the sixteen countries that showed very low degrees of administrative decentralization, six had practically made no effort to decentralize the administrative systems.
} 
decentralization being the empowerment of sub-units in generating funds through taxation. He argues that, fiscal decentralization deals with the way tax revenues and public expenditure are distributed among the different tiers of government. ${ }^{8}$

Critical issues raised by Treisman (2002) about this form of decentralization are: (1) do subnational governments have rights over specific taxes, defined shares of specific taxes and shares of total revenues, or do they just receive a given sum at the discretion of the central government; (2) are taxation rights defined by the constitution or by federal law; (3) if they have rights over specific taxes, are these only property rights over the revenue or do they also have the right to define tax base and set its rates; and, (4) do they collect the taxes themselves, or are taxes collected by federal bodies and then distributed to them. Some of these issues will be discussed later in this thesis.

The implementation of fiscal decentralization varies. Ebel and Yilmar (2002:3) note that the definition and implementation of fiscal decentralization differ greatly across developing countries due to differences in economic and political structures. They note that the diversity creates challenges of measuring and comparing the degree of decentralization across countries making generalisation difficult. Wang and Di (2010) opine that the debate on fiscal decentralization in developing countries is centred on two sets of questions. The first examines the main driving forces and reasons for fiscal decentralization and how its overall

\footnotetext{
${ }^{8}$ Op.cit In his survey Ndegwa notes that the degree of fiscal decentralization across Africa is best revealed by the fact that in 19 of the 30 countries analyzed, local governments control less than $5 \%$ of the national public expenditure. In fact the highest achievable category indicated in the research ("above 10\%") is lower than the average for decentralized systems elsewhere in the developing world - where an average $14 \%$ of the public expenditure is controlled at the local level.4 Only one country was assessed to have a very high degree of fiscal decentralization (South Africa). The countries that scored high (i.e. where local governments control $5-10 \%$ of public expenditures) are Nigeria, Uganda, and Zimbabwe. Countries with moderate levels of fiscal responsibilities anchored at the local level (i.e. where 3-5\% of public expenditures are controlled by local authorities) included Kenya, Rwanda, Ghana, Senegal, Burundi, and the Congo Republic, and Congo DRC.
} 
benefits can be maximized (Dethier, 2000; Shah and Thompson, 2004). The second assesses the impact of fiscal decentralization on variables of interests such as corruption (Fisman and Gatti, 2002), economic growth (Oates, 1993) and environmental protection (Engel, 1997).

The above analysis of fiscal decentralisation underscores the many faces of the concept of decentralisation and further strengthens the argument of the importance of the design of decentralisation. Thus the extent of decentralization, and its implementation, remains fundamental issues in the concept, theory and practice of decentralization.

\subsection{Forms of Decentralization}

\section{(i) Deconcentration}

This form of decentralization falls under the umbrella of political decentralization and;

“. . . refers to the transfer of authority and responsibility from one level of central government to another whilst maintaining the same hierarchical level of accountability from the local units to the decentralised central government ministry or agency. Deconcentration is the first step in the newly decentralising government to improve service delivery" (Robertson Work 2002: 6).

Rondinelli (1981) defines deconcentration as local administrations in which all subordinate levels of government within a country are agents of the central authority, either appointed or responsible directly to central government. In other words, the local/or sub authorities to which responsibilities are transferred are accountable to the central government. In this context there is no implicit transfer of decision-making authority and financial management to 
other levels of government, merely the transfer of administrative responsibility for specified functions to lower levels within the central government bureaucracy.

\section{(ii) Devolution}

This is viewed as the gold standard of decentralization by means of which the independence of the sub-national units is fully established by legislation. It is said to be;

“...The full transfer of responsibility, decision making, resources and revenue generation to a local level, public authority that is autonomous and fully independent of the devolving authority. Units that are devolved are usually recognised as independent legal entities and, ideally, are elected (although not necessarily)" (Robertson Work 2002: 6).

The features of devolution are; (a) autonomy; (b) the local governments/sub units have constitutional territorial jurisdiction; (c) the local government or sub unit are empowered to secure resources for its functions; and (d) the relationship between the central government and local governments is mutual.

(iii) Delegation

This type of decentralization is considered to be partial or indirect control of the sub units whilst the central government still retains considerable control of the country in general. According to (Robertson Work 2002: 6).the central government effectively, "... redistributes authority and responsibility to local units of government or agencies that are not necessarily branches or local offices of the delegating authority. Whilst some transfer of accountability to the subnational level units to which power is being delegated takes place, the bulk of accountability is still very vertical and to the delegating central unit"

It also creates to some extent the relationship of principal and agent in that the authority to which responsibilities are delegated is ultimately responsible to its principal as agent. 


\section{(iv) Divestment}

According to (Robertson Work 2002:7) this occurs when;

“. . . Planning and administrative responsibility or other public functions are transferred from government to voluntary, private or nongovernmental institutions with clear benefits to and involvement of the public. This often involves contracting out of partial service provision or administrative functions, deregulation or full privatisation"

As simple as these concepts appear to be, Conyers (1985) propounds that the application of decentralization in different countries requires a study of their situations so that the appropriate type of decentralization is applied and so that decentralization will not just be a label of reference. To this extent, she states that each specific situation should be examined by reference to the political structure within which it operates, the functional activities over which authority is transferred, the type of authority or power which is transferred with respect to each functional activity the level(s) or area(s) to which such authority is transferred and the individual, organization or agency to which authority is transferred (Conyer 1985: 89). She also notes that this approach provides a detailed description of government and therefore a better basis for analysis and comparison than a mere label and it allows for the existence of a wide range of models or types of decentralization (by examining each characteristic individually).

It is noted that this classification will further help to measure the degree of decentralization in a meaningful way. Rondinelli notes that political, economic, spatial and administrative concepts of decentralization differ drastically in their meanings, implications and consequences. He observes that governments can deconcentrate central government bureaucracies without promoting political or economic decentralization. Indeed, 
administrative deconcentration can appreciably increase the power of the state by creating an organisational structure for deeper penetration and control, as was achieved by many political leaders of post-colonial African governments (Rondinelli 1990: 493).

\subsection{Good Governance and Development}

Government is an important institution for the development or underdevelopment of any country. This fact is well recognised by various global organisations that are primarily concerned with issues of government, governance and development of every nation. Such organisations include the World Bank, the World Health Organisation, the United Nations Industrial Development Organisation, the International Monetary Fund, the Organisation for Economic Cooperation and Development, the United Nations Development Programme and the African Development Bank. They all subscribe to the fact that governance is an indispensable factor in the developmental process of the state. To these organisations it is the involvement and performance of government in development that is described as governance. In essence there can be no governance without government in either complex or traditional forms.

Governance, and how it works to engender or impede development, is elaborated in the example of the World Bank providing financing support to recipient countries to promote development. An analysis of the link between the donor and the recipient countries shows that some interventions did not yield the expected results for which the World Bank chiefly blamed the recipient governments for the failures. The World Bank (1992) study on governance and development asserts government as being central:

“. . . to creating and sustaining an environment which fosters strong and equitable development, and it is an essential complement to sound 
economic policies. Governments play a key role in the provision of public goods. They establish the rules that make markets work efficiently and, more problematically, they correct for market failure."

This submission is based on an earlier study by the World Bank (1989) on Sub-Saharan Africa, entitled, 'Sub-Saharan Africa - from Crisis to Sustainable Growth: A Long-Term Perspectives Study'. That study demonstrates that the Bank's numerous interventions in facilitating development in Sub- Saharan Africa (through different programmes and projects) failed to deliver the anticipated results for reasons connected to the quality of the recipient government action. For example some economic policies such as the Structural Adjustment Programmes (SAPs) and different forms of aid have not translated into a remarkable socioeconomic development of the Sub-Saharan region. The failures of such economic policies, economic interventions and aids are attributed principally to bad governance.

While the failure of development has been linked to poor governance, the World Bank and the International Monetary Fund (IMF) could not be totally exonerated from the failures in stabilizing global financial markets coupled with what some commentators describe as the arrogant use of aid conditions in developing countries (Lopes 1999: 512). Lopes's assertion brings to the fore the conflict between SAPs in developing countries and globalization and economic integration. Although it is claimed that global integration and SAPs became mutually reinforcing as the adoption of the SAPs reform measures encourage economic interdependence, there are indications that its benefits accrue unequally, resulting in polarisation of income between the rich and the poor (Lopes 1999). In the same vein, it has also widened the gap between developed countries and the developing countries. The developed countries take advantage of the liberalization of privatization policies to the detriment of developing countries. Ajakaiye (2004:55) sees the policies and conditionalities of SAPs as largely responsible for its failures. He buttresses this view with an assertion that: 
“. . . an attribute of SAPs is an aversion to planning and regional integration. SAPs have lessened the capacity of African states and governments to create conditions necessary for economic reforms as they require indiscriminate universal expenditure on health, education, water supply and infrastructure in an environment devoid of social safety nets."

Governance is not a new phenomenon in history; it is as old as the history of government. The concept enjoys critical attention from scholars and policy makers who place much emphasis on the concept of 'good' governance, hence the attempts by various commentators and global agencies to design templates for what constitutes good governance. In the course of such design, the ideal of good governance became exposed to various definitions and understanding. While some associate it with democracy, good civil rights, transparency, rule of law and efficient public services thereby making it synonymous with government, others describe it in a broader notion than government (Olateju: 2013). Good governance remains a prominent factor in measuring the success or failures of governments especially in development in the late 1980s. From this period, the concept of good governance became the yardstick for mostly the third world countries to access opportunities available at the global institutions.

All international funding agencies and governments have placed emphasis more on building and sustaining good governance as the means of attaining development. This view challenges those who believe that some of the third world countries such as Nigeria could not successfully embark on any developmental journey on their own due to some inherent values in their cultures (Huntington and Harrison; 2001). The term 'good governance' thus refers to the quality and standard to which political and administrative authority is exercised at all levels in the management of a country's human and natural resources. In essence good governance could be taken as submitted by the UNDP (1992) as comprising all the mechanisms, processes and 
institutions through which citizens and groups articulate their interests, exercise their legal rights, meet their obligations and mediate their differences. This supports the assertion above that there is no governance without government and reinforces the submission of Olateju (ibid) that governance cannot be judged solely on outcomes, but processes and relationships that produce it must also be considered. Kaufman et al (1991:1) had earlier expressed this view to buttress the relevance of governance to development. It was emphatically stressed by Kaufman and his group that there is a need for us to consider governance as:

“. . . the traditions and institutions by which authority in a country is exercised; the process by which governments are formed, selected, monitored and replaced; the capacity of the government to effectively formulate and implement sound policies; and the respect of citizens and the state for institutions that govern economic and social interactions among them."

To Kaufman et al (ibid), governance represents a robust interaction between the formal and informal institutions of government and the significance of such interaction to economic growth and development. This understanding of governance appears to have significantly influenced the position of development institutions and experts and international policymakers such as The World Bank, and the institutions referred to above, so that good governance is a prerequisite for sustained growth in the living standards of citizens of any country (World Bank 2000; UNDP 2011; Kaufmann et al. 2000; Knack 2003).

It can reasonably be held (for the purpose of this thesis and generally) that good governance means the equitable and consensus orientated exercise of power that represents effective and efficient state mechanisms, bureaucratic capability, accountability, responsiveness, provision of market rights, minimal corruption and overall performance of governments (Manor 1999; Johnson and Start 2001; World Bank and IMF 2006; UNESCAP 2006; Kaufmann et al 
2006). The formal structure that facilitates the core components of governance and overall performance for growth and development, as elucidated by development experts, international policy makers, and development institutions, remains an important topic in development studies.

Perhaps this perception of governance prompts the Canadian International Development Agency to accept governance as the institutions, processes and traditions that determine how power is exercised, how decisions are taken and how citizens have their say (1997). In this context 'good governance' becomes synonymous with the effective, honest, equitable, transparent and accountable exercise of power at various levels of government. Experts in good governance and international affairs such as Wilson (2000) stress that good governance could easily be measured using the relationships between governments and markets, governments and citizens, governments and the private or voluntary sector, elected officials and appointed officials, local institutions and urban and rural dwellers, legislative and executive branches, nation states and institutions etc; Wilson's view aligns with the World Bank Report (1994) where the issue of development was inextricably linked to good governance. Good governance involves:

“. . open and enlightened policymaking (that is, transparent processes); a bureaucracy imbued with a professional ethos; an executive arm of government accountable for its actions; and a strong civil society participating in public affairs; and behaving under the rule of law." (Word Bank 1994: 8)

Further, the World Bank refers to good governance as a ". . public service that is efficient, a judicial system that is reliable, and an administration that is accountable to its public."'(World Bank 1989: xii). The World Bank (2009) provides six parameters for 
evaluating good governance using the following indicators to assess good governance in different countries:

- Regulatory quality: this indicator of governance captures the perceptions of the ability of the government to formulate and implement sound policies and regulations that permit and promote private sector development.

- Government effectiveness: this dimension captures the perceptions of the quality of public services, the quality of the civil service and the degree of its independence from political pressures, the quality of policy formulation and implementation, and the credibility of the government's commitment to such policies.

- Rule of law: this indicator captures perceptions of the extent to which agents have confidence in and abide by the rules of society, and in particular the quality of contract enforcement, property rights, the police, and the courts, as well as the likelihood of crime and violence.

- Control of corruption: this aspect captures perceptions of the extent to which public power is exercised for private gain, including both petty and grand forms of corruption, as well as "capture" of the state by elites and private interests.

- Voice and accountability: this dimension of governance captures the perceptions of the extent to which a country's citizens participate in government and in the policy making process. This includes freedom of expression, press freedom, civil liberty and free and fair elections.

- Political stability in addition to absence of violence or terrorism: this element captures the perception of the likelihood of political instability that may result from, for example, ethnic or religious conflicts, and politically induced violence, the likelihood of a military coup and insurgency or terrorism. 
In evaluating governance those six measures serve as institutions and conventions through which power is exercised. All six indicators contribute to the emerging practical research on governance that has offered advocacy tools for reformers and activists to champion as well as monitor policy reforms in different countries.

It is pertinent to state here that contrary to the World Bank's view it is somehow difficult to measure good governance with a universally acceptable set of criteria and definition of successful delivery. Pierre Landell-Mills and Ismall Serageldin (1991:3) have argued that the concept of good governance is a "highly complex one, and [one that] is surrounded by intense controversy". This impression underscores the varied interpretations of the concept of good governance, which had been earlier stated in this thesis as being subject to difficulties of definition. Stoker (1998) wrestled with the complexity inherent in the universal template for measuring good governance; in his submission, he enunciated five propositions from the assumed universalism of good governance. These include the elements that refer to institutions and actors that are drawn from and, also, beyond government; those elements that illuminate the blurred boundaries between the various actors and responsibility of each actor in dealing with the social and economic issues; those elements that identify the power dependence involved in the relationships between institutions involved in collective action; the elements that deal with the autonomous self-governing networks of the actors and those elements that recognise the capacity to get things done independent of the power of government to command or use its authority. An evaluation of Stoker's propositions reveals that governance is based on both formal and informal institutions. While formal institution represents the structural and legal frameworks of government, the informal institution represents the social-cultural context of the people. 
The state, or government, is central in creating and sustaining an environment that fosters strong and equitable development. It is also an essential and complementary factor leading to sound economic policies. However, the role of government is not limited to the provision of public goods. Government also has the obligation of creating a robust environment that seeks to achieve equity, transparency, participation, responsiveness, accountability and the rule of law. A point is raised by scholars such as Fristchak (1994) and Van Dok (1998) on the usage of the adjective 'good' to qualify governance in that they regard that term to be subjective and relative to the specific context. They argue that the notion of what is good is defined by the desired outcome, which varies from one situation to another. In other words, an objective interpretation of the term 'good governance' could vary on a case-by-case basis. Notwithstanding that point of view, for present purposes there is an acceptable general standard and benchmark of measuring what constitutes good and bad governance as set out herein.

The World Bank study on governance and development (1992) tries to separate symptoms of good from poor governance deserves close scrutiny in order to see whether such classification is sufficient to determine good from poor governance. The World Bank identifies factors such as the failure to make a clear separation between what is public and what is private in this context. Hence there may be a tendency to divert public resources for private gain resulting in a failure to establish a predictable framework of law and government behaviour conducive to development, or arbitrariness in the application of rules and laws; excessive rules, regulations and licensing requirements, which impede the functioning of markets and encourage rent-seeking; priorities inconsistent with development, resulting in a misallocation of resources and excessively narrowly based or non-transparent decision making as signals for poor governance in any country. 
In apparent agreement with the World Bank, the United Nations Development Programme (2012) did not hesitate to capture its own view of good governance as earlier stated in this chapter as the exercise of:

$$
\begin{aligned}
& \text { ". . . economic, political and administrative authority to manage a } \\
& \text { country's affairs at all levels. It comprises the mechanisms, } \\
& \text { processes and institutions, through which citizens and groups } \\
& \text { articulate their interests, exercise their legal rights, meet their } \\
& \text { obligations and mediate their differences." }
\end{aligned}
$$

For the United Nations Development Programme therefore, governance is the way government uses its authority to provide services, to make laws and enforce them.

Good governance, by reference to that serves as both a means and an end. It is a means to achieve the goals of human development, the main elements of which are articulated through the Millennium Development Goals (MDGs). The World Bank and the United Nations Development Programme focus on the mechanisms that promote good governance, the processes used in achieving good governance and the outcomes achieved. The outcomes at least for UNDP are peaceful, stable and resilient societies, where services delivered reflect the needs of communities, including the voices of the most vulnerable and marginalized. Following this definition will reveal that both the World Bank (1992) and the United Nations Development Programme approach to governance and development is purely an institutional approach, which focuses solely on institutional reforms in terms of the intuition of Public Sector Management (PSM). The reforms of the PSM came in various ways to the developing countries. For example, most of the public sector reform programmes that have taken place in developing countries during the last two decades were introduced as part of the Structural Adjustment Programmes (SAPs) of the World Bank in the 1980s. Unfortunately, public 
reforms within this period were deemed to be inefficient and often ineffective, because they led neither to cost containment nor to quality improvement (ibid).

A World Bank study on public sector management notes that: “. . when the capacity of the public sector to manage the economy and deliver public services is weak, the prospects for development are poor" (World Bank 1992:12). Special attention is given to public investments, budget planning and the civil service. Improving public sector management is about developing effective policy processes and systems that enable governments to manage public revenues, expenditure and debt within agreed fiscal targets. It is also about allocating fiscal, administrative and functional authority across levels of government in a way that ensures cooperative and constructive engagement (World Bank: Governance and Public Sector management).

The 1992 World Bank report indicates that the public sector in many developing countries has been characterised by "uneven revenue collection, poor expenditure control and management, a bloated and underpaid civil service...and weaknesses in the capacity of core economic agencies to design and implement policies that would address these problems" (World Bank 1992:12). The issue arising from the problems enumerated by the World Bank report is the need to put in place structures and mechanisms that would enhance effective public sector management. The Governance Indicators of the World Bank define government effectiveness as "measuring the quality of public services, the quality of the civil service and the degree of independence from political pressures, the quality of policy formulation and the implementation and the credibility of the government's commitment to such policies" (Kaufman, Aart and Mastruzzi 2008:7). 
The above analysis shows that the means of achieving of good governance in PSM is predicated on the public servants, politicians and bureaucrats. The failure of the PSM reforms was later attributed to factors such as lack of efficiency, lack of accountability, ineffective management practices, and corruption (ibid). In essence these failures were largely traced to the same public servants, politicians and bureaucrats that were expected to deliver good governance through public sector management in the first instance. This development therefore elicits the need for a new approach to the management of the public sector that would stimulate good governance. In response to that imperative the debate on public sector management shifted to New Public Sector Management (NPSM), the arguments for which arise largely from the political, economic and fiscal pressures on government from the international donor agencies for good governance and development, especially in the developing countries. The economic and fiscal deficits in such countries required a rethink of the structure of government and roles of each tier of government in the management of the public sector. These pressures were stronger in the political sector where calls for full democratisation of the state and decentralisation of responsibilities were very strident, especially in the African countries, Nigeria included. Such demands provided a fertile ground for the emergence and consolidation of NPSM, driven by the combination of economic, social, political and technological factors. These factors, as mentioned above, were mostly triggered by the pressures from the international agencies on state governments for efficiency and reduced cost of delivering public services. Unfortunately the pressures for change were all within the neo-liberal economic and political context.

Achieving the objectives of the NPSM requires both or any of Larbi's (2003) submission. Larbi highlights the paths that the affected countries must follow as management decentralisation, desegregation and downsizing of government, creating leaner and flexible 
organisational structures and systems, and giving managers more freedom to manage on a local or central basis. The alternative is the path that emanates from new institutional economics, which emphasizes market and competition as a way of giving choice and 'voice' to users and promoting efficiency in service delivery. Larbi's strategies constitute a fundamental plank of investigation in this study, in particular the first strategy as he enunciates.

This study investigates the extent to which the structure of decentralization engenders or inhibits good governance and development in Nigeria. It is postulated that the state, and the people who were supposed to drive governance, and serve as beneficiaries of the outcomes of such governance, respectively, were largely ignored by the World Bank, UNDP, PSM and NPSM due to their seemingly neo-liberal character. Their institutional approach to governance and development focuses solely on institutional reforms in terms of public sector management. This approach tends not only to take control of the economic sector away from both the state and the people; it also turns the people into passive spectators in the political sector. The state can, in such circumstances, became a tool in the hands of the private sector operators through which policies that were favourable to private maximization became the priorities of the state. The efforts of the state at directing resources to where it considers vital for the stability of the polity was completely eroded by the profit maximization drive of the private organisations whose sole interest is based on large returns from less inputs.

This therefore calls for the alternative paradigm, which this thesis attempts to prove. While it is accepted by the author that there is a need for institutional reinvigoration of the state, particularly in Nigeria, focus on what made such institutions unable to deliver in the first instance is critical. The major challenge in Nigeria doesn't lie in the institutions but mainly in 
the nature of such institutions, which, if modified and empowered, may be able to positively contribute to good governance countrywide. This is where the issue of decentralisation of powers and responsibilities become vital in the search for good governance and development in Nigeria. That alternative paradigm (for the explanation of good governance and development) is necessitated by the belief that development is the main agenda of good governance.

In the view of Soares Jr. and Quintella (2008), countries have differing development levels. Enriching this argument are Bjornskov, Gupta and Pedersen, (2008) with a submission that technical, cultural, economic and social factors influence development in any country. Development issues take a key role in governance and the major yardstick in evaluating the success of governance is development. Consequently the concept of, and the debate about, development becomes a major contention that exerts enormous pressure on the socio-political structure of any nation in particular and world politics in general. Scholars such as Leftwich (2007) and Wunsch and Olowu (1990) hold that many causes and conjectures for the incidences of underdevelopment and uneven developments in the nations are linked not only to the political structures but also to global economic politics. Invariably, development in terms of economic growth, human and social capital is woven around governance and market forces. Growth and decline of development is therefore linked to political considerations and arrangements.

In effect the factors and values that determine the kind of structure of government and institutions equally affect the policies, planning and execution of developmental programmes. To this extent it is noted that in many developing countries local services and infrastructures are either provided by central governments ineffectively and inefficiently, or by community 
organisations and private businesses sporadically (Rondinelli et al 1989: 57). They argue that the inefficiency is caused by the gap between government, which should be responsible for the holistic development of its citizens, and the people themselves. Consequently, the aspirations and desires of the people are not realised.

Although the neo-liberalist approach to governance advocates a shift from the public to the private sector for the provision of goods and services, what has not been demonstrated is the extent to which the free market can efficiently engender development in developing poor economies. The role of government in bringing about development is, therefore, fundamental if the optimum and desired outcome is to be achieved. Development, in the view of Degutis, Urbonavičius and Gaižutis (2010), simply refers to improvement in the quality of life, human welfare and social wellbeing. Assessing development may involve comparing one nation with others or comparing past and present levels in similar countries (Barro, 2000). Development is principally measured in two ways; human development and economic development (Jacobs and Šlaus, 2010; Degutis, Urbonavičius and Gaižutis, 2010). Economic development quantifies the wealth and means of wealth generation in the country (e.g. banking or information indicates more advancement compared to agriculture, fishing and mining). On the other hand the concept of human development quantifies population accessibility to education, wealth, leisure, security, health, employment opportunities, nutrition, cultural and political freedom (Barro, 2000). Leisure and health could be regarded as 'quality of life' indicators while nutrition and wealth are indicators of standards of living. To determine if individual needs and wants are satisfied, there are several social and economic parameters that could be employed to determine the level of satisfaction (Soares Jr and Quintella, 2008; Barro, 2000). 
Bjornskov, Gupta and Pedersen, (2008) and Jacobs and Šlaus, (2010) were of the view that development usually occurs unevenly. Whereas a nation may have high Gross Domestic Product (GDP) derived from petro-dollar exploitation, as in the case of Nigeria, some population segments may still remain in poverty, lacking essential access to decent housing, basic education, good health, a care delivery system and so on. These negative aspects are true reflection of the Nigerian reality, compelling a thorough examination of Nigeria's federalism for the purpose of explaining its impact on the socio-economic development (or lack thereof) of the country. With the foundation laid for what could be considered as good governance using Stoker's assumed universal criteria, efforts are geared towards the navigation of Nigeria's development using key indicators such as social cohesion, poverty level, unemployment rate, infrastructural facilities etc; to see whether the Nigerian governments, especially at the local level, are actually engaged in good governance.

\subsection{Federalism in Nigeria and its Challenges}

Federalism in Nigeria appeared to be successful from 1954 to the end of the first Republic (1960 - 66). In contemporary Nigerian however there are challenges that render the federal arrangement unsuccessful. Olasupo and Fayomi (2012) outline different forms of corruption causing the failure of Nigerian federalism. They include diversions, duplications, multiplications and the withholding of similar resources during project execution by distinct government agencies. The federal government is reported by Olasupo (2005) as having deducted statutory transfer funds allocated to the local government so wiping out local government entitlements thereby causing zero allocations by local governments to local government. Since the local governments rely upon fiscal transfers made by the federal government to finance services, absent such transfers they cannot then provide services to ensure development, the position of "zero allocation". As to diversions of resource, Olasupo 
(2005) reports that state governments, in most cases, withhold statutory contributions made for the local government, depriving them of the required revenue. In other cases, state governments divert statutory allocations for personal use by draining the federal accounts. Duplication during project execution causes inter-agency, inter-nongovernmental and intergovernmental problems (Olasupo and Fayomi 2012).

A study by Abdulhamid and Chima (2016) reveal that the federal system of government was firstly introduced to Nigeria in 1954 through the Lyttleton Constitution within three distinct regions; the western region, the eastern region and the northern region. These regions were free of the grip of the central government especially in the areas of resource control, police and foreign affairs. Every region had its regional flag that served as the identity symbol for their peoples and each had its town councils as opposed to the current system of local government councils. The major functions of the town councils was to collect taxes on behalf of the regional governments and to also ensure quick delivery of government essential services such road maintenance, provision of public water, primary health care and sanitary inspection services etc. As such it delivered services to where they were needed in a straight line, unlike the present system that has added layers of bureaucracy, all of which hampers rather than helps service delivery.

It is important to stress at this point that the structural framework of the Nigerian federal system has evolved over the years, from a highly devolved federal structure to a highly centralised federal structure. The structure of states as against the regional set up has been a consistent feature in the Nigeria federal arrangement. The breakup of the three regions in 1966 necessitated the reorganisation of fiscal relations. The federal government was given the control over the Distributable Pool Account, which consisted of different percentages of each 
state's export revenues. Between 1976 and 1979, the system was further centralised and federal control extended to almost all revenue collected in the Federation account from where it was then distributed to the subsidiary levels of government.

This shift resulted in the gradual movement from the $100 \%$ derivation in the first republic to the present sharing formula, which 'promote[s] inter-ethnic inclusiveness and discourage[s] sectional imbalance and bias in the decision-making process' (Suberu. 1996:71-72). At the inception of the federal arrangement in 1954 there was fiscal autonomy for the regions both over expenditure decisions and the local revenue base. The latter consisted primarily of mining rents, personal income tax and receipts from licenses. Centrally collected revenues, mainly from export, import and excise duties, was distributed to the regions according to the derivation principle. That principle was modified in the national interest when Nigeria attained independence. (See table 1). At that point the economy of the country shifted from the traditional agro base to an oil based economy. Following from this critical juncture, the evolution of Nigerian federal system has taken place along the path the path of fiscal centralisation, in which most federal states depend on the disbursements from the centre that largely draw on the country's oil economy.

Table 1: Derivation Formula 1960-Till Present.

\begin{tabular}{|l|l|l|l|}
\hline Years & Producing States \% & Federal Government \% & Distributable Pool \% \\
\hline $1960-67$ & 50 & 20 & 30 \\
\hline $1967-69$ & 50 & & 50 \\
\hline $1969-71$ & 45 & & 55 \\
\hline $1971-75$ & 45 minus off-shore & & 55 plus off-shore \\
\hline
\end{tabular}




\begin{tabular}{|l|l|l|l|}
\hline & proceeds & & proceeds \\
\hline $1975-79$ & 20 minus off-shore & & 80 plus off-shore \\
& proceeds & & 100 \\
\hline $1979-81$ & $1 \frac{1}{2}$ & & $981 / 2$ \\
\hline $1982-92$ & 3 & & 97 \\
\hline $1992-99$ & 13 & & 87 \\
\hline
\end{tabular}

Source: Adapted from Sagay, 2001: From 1967, the Federal government shares from the distributable pool.

\subsection{Local Government system in Nigeria and their Challenges}

Olowu and Wunsch (2004) reveal that the goal of creating local governments is to bring the government closer to the people at grass root level. Local government changes in Nigeria, as observed by Abdulhamid and Chima (2016) sought to quicken development as well as facilitate participation of the local population in government, holding individuals in authority accountable based on job descriptions. Nonetheless, in spite of broad confirmation of the local government system as potentially having the power to mobilise people in ensuring local participation in governance, this tier of government in Nigeria has not succeeded. A number of scholars have investigated that position and found key challenges hindering the performances of the local government system in Nigeria. The primary challenges are poor funding (George, 2010; Gboyega, 1987), corruption (Adamolekun, 1979; Ekpo and Ndebbo, 1998; Olasupo and Fayomi 2012), poor service delivery and scarcity of human capital and resources (Bamidele, 2013; Oyediran, 2001). 
With regard to the constitutional framework, deficiencies as well as reforms which shape contemporary local government operations, researchers like Abdulhamid and Chima (2016) have focused on studying such deficiencies. According to Aribigbola, Folami, WilliamsAdewinle and Karimu (2013), local government reforms of 1976 and military intervention in state politics explain how the Nigeria's local government system operated in the $20^{\text {th }}$ Century. Abdulhamid and Chima (2016) also agree that military intervention in the state politics changed the roles of the local government system. With the constitution introduced in 1976 serving as the legal model for reforms in 1979, Nigerian local governments have suffered from an identity crisis. Since then the local government has searched for its relevance in the central government having for a long time been subject to federal and state government whims.

According to Abdulhamid and Chima (2016), local government lacks a well-founded constitution even with the benefit of historic constitutional developments. To improve governance in the local government system Aribigbola, Folami, Williams-Adewinle and Karimu (2013) suggest amendments to the constitution by creating guarantees of local government autonomy and identity as a constitutional third tier of government. Such amendments would overcome the mandatory State Joint Local Government Accounts (SJLGA) system, a key factor in the process that ties the operations of local governments to the apron string of the state governments.

Observers such as Adamolekun (1979), Ekpo and Ndebbo (1998), Oyediran (2001), George (2010), Gboyega (1987) and Bamidele (2013) focused much attention on local governments as vehicles for good governance in Nigeria. While government practitioners and scholars have suggested different reasons for the success and failure of federalism in ensuring 
development in Nigeria (Abdulhamid and Chima, 2016), others blame gaps in reforms before 1976that promoted administration but failed to promote local government as the third tier of Nigerian government (Wilson, 2013). When Nigeria gained independence Wilson (2013) asserts that the local governments were reduced to simple regional governance agents but with the 1976 reforms, the local government started to experience changes based on the wish of the federal government operators. For example, in spite of the colonial history and rule in Nigeria, the contemporary local government system that started with the 1976 local government reforms, as Olanipekun (1988) observes, contained good objectives that included attaining uniformity in the local governance system in the Nigerian federation and the extension of the principles of federalism through expanding the reach of government to the grassroots level for participation by the local populations. This view was further corroborated by Abdulhamid and Chima (2016) who explained that the reforms sought to reorganise and modernize the local government system making it the best system of governance in Africa. Abonyi (2010:90) observes that the state governments, alongside the federal government, from thereon had made extensive changes to the local government system, expanding its functions and structure. The collaboration encouraged multiple purpose functions of the local government, a government tier having devolved status, responsible for ensuring rural development, mobilizing development in remote areas by improving communication, infrastructure and empowering participatory democracy (Wilson 2013: 137).

This was quite unlike the position in 1954 when according to Ikeanyibe (2009) each region had complete control over its government structure, government type and local government functions. Even though the ordinance rule of 1950 promoted democratic and participatory elements in local governments, Abdulhamid and Chima (2010) found that the rule also initiated regional or federal dominance over the local government administrative system. 
Federal dominance, according to George (2010) was apparent throughout the British colonial period, and has also endured all the way through post-colonial period to the modern Nigeria. Some researchers agree that federalism was successful in Nigeria previously, especially in the first Republic due to the robust relationship between the regional governments and their local governments. Ekpo and Ndebbio (1998) observe that in 1988 the local government underwent additional changes as the federal military government introduced changes in civil service. The changes, according to Abdulhamid and Chima (2010) were meant to professionalize some of the services delivered by the local government through the establishment of officers (for example the auditor general, treasurer, councillors and secretaries) and mandatory service delivery departments such as supply, finance and personnel. In addition, the Local Government Service Commission was given explicitly defined functions for instance in its monitoring local government.

To encourage good governance through federalism in Nigeria, Wilson (2013) contend that the constitution passed in law in 1979 empowered the local government as the third tier of government with devolved functions. All such reforms gave legal capacity to the local government to use the available resources (funds and humans) in actualizing the function of ensuring democratic governance in Nigeria Abdulhamid and Chima (2016) and Wilson (2013), That the successes of the 1976 reforms couldn't be replicated in successive administrations raised a number of questions such as what happened to a formally successful system and how the federal government in three regions (East, West and Northern Nigeria) operated successfully to enhance good governance and development immediately after the civil war when in theory the conditions that followed might have been more conducive to good governance. Furthermore, issue arises as to the lessons that the current government can adopt from previous implementation of federalism to ensure successful decentralization, thus 
guaranteeing development, answering these questions provides an understanding of the deficiencies in the current federal structure of Nigeria.

Using secondary data to examine several local government reforms to bring about good governance through the local government revealed that although the 1976 reforms and the 1979 constitution formally recognized the local government, the local governments were left without independent political authority. Consequently the unequal correlation between the Nigerian government tiers with the local government hinders effective governance. While suggesting some reforms that might guarantee successful federalism, Wilson (2013) asserts that as a third tier of government. The local governments need to operate as independent authorities with explicitly defined functions and without interference from the state governments, such large scale interference being evident in present day Nigeria. Tonwe (2012) sees such interference as a major contributor to failed federalism and failed decentralisation in Nigeria, a view supported by Onor (2005) who states that such intervention remains more of a problem than a solution to the challenges confronting effective local government and governance. A key observation of this study is that such interference is not the only militating factor against the local governments in delivering good governance at the grassroots. There are other factors such as the problematic fiscal relations and weak civic engagement, poor participation by citizens in governance.

\subsection{Fiscal Relations and the challenge of Nigerian Federalism}

The principle of fiscal relations in Nigeria is significantly based on structures that expropriate and distribute. However, such fiscal policy has legal and functional frameworks that enable each tier of government to generate revenues and a system of intergovernmental fiscal transfers. Intergovernmental transfer is dominant in the Nigerian fiscal federalism, 
when $80 \%$ to $90 \%$ percent of all sub-national revenues are derived from intergovernmental transfers. Fiscal federalism in Nigeria is essentially an intergovernmental fiscal relation as contained in the second and fourth schedules of the 1999 constitution of the federal republic These parts of the constitution provide the legal and functional framework for the tiers of government to generate and expend revenues.

They also determine the jurisdiction and function of each tier of government in terms of powers of revenues collection and responsibilities for provision of goods and services to the citizens $^{9}$ (Dunmoye, 2002: 49; Okunroumu 1997:157-162; Elaigwu 2007: 204).

\section{Table 2. Nigeria: Legislative List}

${ }^{10}$ Assignments Tier of Government

Federal only

\section{Expenditure Category}

Defence; Shipping; Federal trunk roads; Aviation; Railways; Posts, telegraphs and telephones; Police and other security services; Regulation of labour, interstate commerce, telecommunications; Mines and minerals; Social Security; Insurance; National statistical system; National Parks; Guidelines for minimum education standards at all levels; Water resources

\footnotetext{
${ }^{9}$ The current distribution of responsibilities is provided in the Second and Fourth Schedules of the 1999 Constitution-Part I of the Second Schedule contains the exclusive legislative list on which only the federal government can act; Part II contains the concurrent legislative list on which both the federal and state governments can act; the Fourth Schedule provides the list of functions of the Local Government Councils. Hence, strictly speaking, the Constitution does not really provide the list of functions to be executed by the Federal Government of Nigeria and the states (as it does for the Local Government Councils), but only the subjects upon which they can legislate. However, these legislative lists form the guidelines for other legal decrees and sector policy reports that lay out the specific expenditure responsibilities of the different tiers of government.

${ }^{10}$ Source: 1999 Constitution and various sector policy reports
} 
affecting more than one state;

Federal-State (shared)

State-Local (shared)

Local government

\begin{abstract}
Antiquities and monuments; Electricity; Industrial, commercial and agricultural development; Scientific and technological research; Statistics and surveys; University, technological and postprimary education; Health and social welfare;
\end{abstract}

Primary, adult and vocational education; Health services; Development of agriculture and non-mineral natural resources;

Economic planning and development; Cemeteries, burial grounds; Homes for the destitute and infirm; Markets; Sewage and refuse disposal; Roads, streets, street lighting, drains, other public facilities.

States and local government are financed through three sources of revenue; internally generated revenue; revenues shared with the federal government; but, mainly, by transfer from the federal account. States and local governments are highly dependent on revenue sharing arrangements from the federal level with oil revenue currently accounting for $75 \%$ of all consolidated government revenue in Nigeria and under the current formulae, oil revenues are divided according to a rule that first gives $13 \%$ to oil producing states (the derivation principle) and then splits remaining revenues between the Federal Government (53\%), State Governments (27\%), and Local Governments (20\%). Revenues from customs, excise, and corporate income taxes are divided by the same formula but without the derivation principle. 
Revenues from VAT are divided in the following ratio; $15 \%$ to the Federal Government, 50\% to State Governments, and $35 \%$ to Local Governments. In each case, a small part of the federal share is divided among the special funds (The World Bank: Nigeria Economic Report 2003). Federation revenue released to sub-national government rose from $7.4 \%$ of GDP in 1999 to about 15.3\% of GDP in 2001 (Ahmad and Mottu 2002:5). Oil revenues play a dominant role in intergovernmental fiscal relations in Nigeria. Production is concentrated in eight states, mainly in the Niger River delta. The current revenue allocation formula is as follows: Federal Government (52\%), States (26.72\%), and Local Governments (20.60\%).

Fiscal laws in Nigeria tend to give more power to the federal government than the other subfederal units combined. There is an increased dependence of the sub-federal units on the federal government particularly for their finances. State and local governments are neither given any strong fiscal incentive nor encouraged to generate revenue internally. In view of this they are weak financially and a weak financial base of states cannot strengthen or guarantee true federalism. As a result, there is discontent, conflict and agitation by the two lowertiers against the federal government seeking the right to greater self-reliance. It is argued that for any federation to be sustained there must be fiscal decentralization and financial autonomy. However, in contrast, in Nigeria, there is fiscal centralization(Omotoso 2010).

The federal allocations in Nigeria are centrally administered by the National Revenue Mobilization Allocation and Fiscal Commission. The make-up of the Commission is constitutionally defined, comprising the Federal Minister of Finance and representatives of the states, typically the State Finance Commissioners and State Accountants General. The commission meets in the national capital Abuja on a monthly basis to allocate the previous 
month's tax receipts among the recipient governments. However local governments are not directly represented in the Commission (Omotoso 2010). Nigeria's fiscal federalism evolves hand in hand with political federalism. Elaigwu (2008:23) argues that the history of revenue sharing in Nigeria has been one of interregional or inter-state conflicts; that it demonstratesgradual movement from the derivation to a mix of principles for distribution purposes.

The overview of the Nigerian fiscal federalism shows that there is a persistent problem of revenue allocation between the central government and the sub units. Revenue allocation in this sense goes beyond economic imperatives; rather it aligns with the argument of Adeshina (1998) who statesthat Nigerian fiscal federalism is in the midst of thestruggle for political and economic control and domination among various classes and interest groups. In the same vein Elaigwu (2008) argues that the Nigerian fiscal federalism, heralding perhaps more conflict rather than the harmonious and equitable relationship that it set out to achieve.

By his theory of Horizontal Inequality (HI) Stewart (2005) argues that when the socioeconomic difference between the people that make up a multi-ethnic country is pronounced and geographically represented, there is a higher tendency that violent conflicts, sooner or later, will emerge. With marked differences in the socio-economic existence, it becomes easy for unscrupulous politicians and ethnic ideologues to mobilize support across religious and ethnic lines. However, it is important to note that in HI theory, federalism has an in-built capacity to address horizontal inequality through revenue sharing formulas that is designed to take from better endowed states to cater for the poorer states. Writing on the factors that affect Nigerian federalism, Elaigwu (2008) suggests that the Nigerian federalism has been affected by a number of factors, predominant among them being; 
"(1) the numerous changes in the federal structure, especially in the number of sub national units-states and local governments; (2) the nature of military rule; (3) the advent of oil revenue and the attendant politics of derivation (4) the problem of fiscal equalization, vertically and horizontally; (5) persistent review of the legislative list and expansion in the tax powers of sub-national units and (6) the imperatives of equity and national development"(Elaigwu 2008:252).

\subsection{Civic Culture and Participation in Governance.}

As earlier noted institutions and political network matters in how federalism works to bring about good governance and development (Obiinger et al 2005; Kemp and Gibson 2005; Leftwitch 2007; Law 2013). However, scholars, such as Almond and Verba (1963); Chambers and Kymlicka 2002) argue that the level of participation of the citizens is dependent on their political culture. Almond and Verba (1963) maintain that a democratic political culture requires that a substantial proportion of the public follows and is invested in national politics. Without being informed about the national political system, people are likely to remain apathetic to the system.

To this extent political culture deals with citizens' behaviour in relations to political development and governance in society, an issues that produces one of the most intellectually stimulating issues to study in the area of comparative politics. In some other instances, political culture can be conceptualized as the psychological study of the actions of citizens in relations to government and state policies. Political culture, and thus behaviour, affects state democratic development and processes to a larger extent, Baba (2015). Richard (2000) and Axelrod (1997) incline to the view that the political culture in any nation exemplifies how its history affects peoples' thinking about politics and society as a whole. Richard (2000) asserts that politics, being the function of the immediate environment, displays the same key characteristics in any country. However political landscapes differ because of economic, 
cultural, political and social dimensions so that generalisation might be modified according to the context.

Political culture is influenced by 'parochial' and political 'orientations'. Almond and Verba (1963) argue that there are three types of political culture; this is based on their studies in five democratic countries, namely Germany, Mexico, Italy, the United Kingdom and the United States of America. The first element of political culture identified is the 'parochial political culture'. In this type there is no clear differentiation of specific political roles and citizens are mostly uniformed and unaware of their government, typically taking little interest in the political process. An example of this type of political culture is Mexico. The second is 'subject political culture'. This type represents a situation where citizens are to some degree informed and aware of their government occasionally participating in the political process; examples of countries like this include Germany and Italy. The third is the 'participant political culture'. In this type, the relationships between specialized institutions and citizen opinion and activity are interactive; examples of this political culture are the United States of America and the United Kingdom.

Many scholars have categorized developing countries, such as Nigeria, as the first category of typology of political culture, the parochial political culture. Lerner (1958) and Pye and Verba (1965) argue that Almond and Coleman (1960) correctly describe the political culture of many Third World nations as one in which citizens are generally unaware and uninvolved in politics. Why they are so unaware and uninvolved cannot be stereotyped because political culture in itself is not monolithic. The question as to whether people are unaware and uninvolved may no longer be conclusive taking into account new orientations and opportunities which may provide a new culture. This view accords with that of Dalon and 
Shin (2014) that citizens in established democracies now appear less allegiant and more willing to pursue contentious courses of political action to change the status quo. In addition, democracy has spread across the globe, even in nations where the civic culture theory might not expect democratization.

Systematic empirical evidence on political attitudes in developing nations is now quite extensive with the result that such material is range of more people. This position is further advanced by technological advancements referred to by Norris and Inglehart (2009) who suggest that the expansion of a globalized economy and social system touches even rural areas that once might have fit the civic culture's description of a parochial society. That position questions the typology of civic culture of Almond and Verba (ibid) whose views have been questioned for their selection of unrepresentative samples, asking invalid questions, overestimating the stability of attitudes and underestimating the impact of shortterm political events and drawing unwarranted connections between cultural patterns and regimes; in general, for reaching conclusions not justified by the evidence. The emerging question in the civic culture of Nigeria is what kind of orientation can be put in place to enhance civic society where individuals are oriented positively to the input structures and input processes (Almond and Verba). This is done in two areas; (1) support of institutions, this is the attitude towards the political system are central in political culture (these may range from support for leading political actors to general support for the political system itself); and, (2) trust, focussing on the relationship in the polity.

As noted above the political culture which prevails in contemporary African society has been observed by different scholars to be either the parochial, or subject political culture. With a spotlight on Nigeria the political process is characterised by aggressive manipulation of the 
electorate by political actors, especially those in the seat of power. Some commonly experienced manipulative techniques in the Nigerian electoral process include unjust disqualification of candidates, stealing of data capturing machines, supporting politically biased police, to mention but a few; such cynicism has, perhaps understandably, resulted in an increase in electoral apathy. Nuka (2015) identified the following as factors that engender such apathy in civic culture;

1. The belief that a vote does not count in Nigeria: many people dislike voting in elections in Nigeria because of the negative belief that votes do not count in the country.

2. A lack of trust in corrupt politicians: many people have lost trust and faith in government and the so-called elected politicians. Many believe that Nigerian politicians will say anything to get elected but once in office, they quickly turn their back on those who put them there.

3. The absence of Security at voting centres: the use of thugs, cultists, criminals and militants to intimidate political opponents.

4. Hypercritical negative media: negative political news coverage and political criticisms, which in most cases are not always constructive, create cynicism in many Nigerians. Thus, voters are at times over-fed with falsehood and a frightening image of the political environment.

5. Illiteracy and poverty: illiteracy and poverty are two powerful forces that militate against political participation in Nigeria. Victims of these forces have little or no interest in political activities. 
6. Failure of elected political office holders to honour electioneering promises and the imposition of candidates on voters by political parties

Although coined by Almond \& Verba (1963) the term 'civic culture' came to prominence from a survey conducted in five countries (England, Germany, Italy, Mexico and the United States) studying the attitudes of citizens in respect of their political society. This resulted in a paradigm shift from constitutional analysis to the study of comparative behaviour; a culture is a balance of 'participant traits', which incline citizens to take an interest in politics and participate in elections and generally those other activities that make democracy work. From the same source the term 'subject traits' are those which incline citizens to respect the law and the authority of the state and the government. Almond \& Verba (1963) classified 'civil culture' as a subset of political culture, which they defined as a substantial consensus on the legitimacy of political institutions and the direction and content of public policy. They defined 'civic culture' as "an allegiant participant culture. Individuals are not only oriented to political inputs; they are oriented positively to the input structures and input processes" (1963: 31).

Dalton and Shin (2014) in evaluating the submissions of Almond and Verba argue that civic culture is mixture of a number of traits, such as a political culture that is based on an aware, participatory public, although participation is often a potential rather than a reality. Nevertheless, the democratic culture requires a supportive public that identified with the political community and trusted the institutions of government. The submission of Dalton and Shin reinforces the interface of institutions and the actors, and in this instance the 
citizenry. Civic culture is seen as an integral element in the democratisation of a society or a community for its socio-political advancement as it engenders participation.

\subsection{Conclusion}

Through the review of relevant literature, this chapter establishes relationships between governance and development through a specific examination of some key concepts of governance and development to espouse the challenges of the practice of federalism in Nigeria, and the challenges of good governance. There is affirmation that the practice of federalism has not performed optimally because of the inherent structural defects. It is also noted that other factors such as weak civic engagement and poor participation by citizens in governance is an integral part of the challenges of Nigerian federalism. 


\section{Chapter Three}

\section{$\underline{\text { Research Design and Methodology }}$}

\subsection{Introduction}

This chapter sets out details of the methodology used to investigate the governance and development in Nigeria under federalism. It accounts for the choice of the research design methodology used, data collection and management and analysis. It also details the steps taken by the researcher to ensure that the research is conducted in an ethical manner. The purpose of this study is to determine why decentralization has failed to foster good governance and development in Nigeria. The major sections in this chapter are on research design, research method, target population, inclusion and exclusion criteria, sample size, study procedure, research instruments, method of data collection, data analysis, validity and reliability and the key ethical considerations.

\subsection{Research design}

The historical institutionalist approach was employed in the design of the research. In this context Sanders (2006: 43) adds a more institutional interest by raising questions as to who designs institutions, what makes institutions change or collapse and what are the exogenous social forces or internal group dynamics that are responsible. The foregoing normative questions serve two purposes in this research: firstly they subject the research to various investigations and secondly they point to the core aspects of historical institutionalism, namely, construction, maintenance and adaptation of institutions (Sanders (2006: 42).

Interpreting the variable factors of institutions therefore requires reliable analytical tools. It is important to note from the outset that historical institutionalism employs more narrative in 
setting out its causal chains (Sanders 2006). However, it does incorporate analysis of statistical data to further interpret variables. Pierson and Skocpol (2002: 3) highlight three important features that characterize historical scholarship in political science and its ability to be able to sufficiently interpret the variables. Firstly they note that historical institutionalists address substantive questions that are inherently of interest to a broad public as well as to fellow scholars. In other words, historical institutionalism develops explanatory arguments about important outcomes or conundrums. Secondly time is of the essence to historical institutionalism analysis in the sense that it specifies sequences and traces transformations and processes of varying scale and temporality. Thirdly they hold that historical intuitionalism analyses macro contexts and hypothesizes about the combined effects of institutions and processes rather than just examining only one institution or process at a time. This research revolves around substantive questions, the answers to which would be of interest to the broad public. It is period specific and it examines questions arising from similar institutions.

Historical institutionalism analysis does not however follow a singular pattern. Pierson and Skocpol (2002:2) note that historical institutionalism strategies vary in important ways. Some are explicitly comparative whilst others analyse trends within just one macro context. In the same manner some offer suggestive interpretations while others offer explicit models framed in general terms. Some draw extensively from primary sources; others synthesize from secondary publications or adopt culturist modes of explanation. As Pierson and Skocpol (2002: 3 ) posit, taking together the three characteristics of historical intuitionalism, that is, “. .. substantive agenda, temporal arguments and attention to contexts and configurations, add up to a recognisable historical institutional approach that makes a powerful contribution to an understanding of government, politics, and public policies". In effect the historical 
methodology is appropriate in answering the normative questions about the 'goodness' of particular institutions and the struggle to achieve a 'good state' (Sanders 2006).

Additionally a case study approach was applied in this research. The qualitative case study explored the experiences of the participants in civil service regarding development and decentralization in Nigeria (Yin, 2014). A case study was considered as the finest research design to address the primary research question as it sets boundaries for the entire study and delivers a perspective on the primary theories and models to see if Nigerian federalism foster or hinder development (Frost, 2012). Yin (2014) defines a case study as a technique most researchers use while focusing on in-depth understanding of events or entities in a specified time. Case studies depend on diversity of evidence sources, observation, interviews, focus groups and videotaping (Neuman \& Robson, 2012). In detail individuals, organizations, events, school institutions, standards and departments can be examined suitably using a case study. Creswell (2013) suggests that case studies are increasingly being used by multiple researchers to understand the participants' experiences. By that method scholars understand primary characteristics of real life events, including managerial and organizational decisions and processes (Yin, 2014).

A case study will examine specific situations and factors, such as infrastructure development, while providing explanations about the primary concerns that are untraveled within the population of decentralization and development. Moreover this case study method also allowed the researcher to develop a theory, evaluate major factors in Nigerian federalism and develop and propose an intervention that guarantees good governance and development (Suberu, 2009; Suberu, 2010). The case study method is the most appropriate for this research as it (a) deals with the subjective experience of decision makers in civil service; (b) 
accentuates instances of success by referring to individual subjects experiences through listening and observation (so that the data can speak for itself, a powerful feature of qualitative research), and (c) allows for focusing on examples of successful good governance and development arrangements in three government tiers (Yin, 2014).

The primary focus of the study was an analysis as to how federal structures in Nigeria influence governance and development. Rather than depending on the existing standardized measures on the development index, the researcher was more interested in (a) the participants' perspectives as a practical subjective experience, (b) the competence of the participant and his or her experience in federal practices, and (c) the meaningful experience of the participants as interactive, inter-subjective construct extending far beyond the formal government tier projects and corresponding implementation mechanisms. To maximize on good governance and foster development, there is need to account for decision makers' experiences (Suberu, 2010).

\subsection{Research Method}

This study comprises of qualitative data mainly derived from the publicly available data on governance and development from which the researcher compared governance and political and social economic development under federalism. The qualitative narrative is used as it enhances the argument in this research by providing in-depth insights into good governance and development in Nigeria using Ondo state as a case study.

Through qualitative methods, the researcher collects primary data which is then used to corroborate or contest the existing theories, in turn allowing for clarification and understanding of distinct observations (Neuman \& Robson, 2012; Creswell, 2013). In 
qualitative research induction is a process through which data linked to particular study areas is collected then used to create different theories and concepts (Frost, 2012). In this research a qualitative technique was considered the most appropriate as it enables researchers to gain indepth meanings through experiences that individuals narrate (Maxwell, 2013) feelings and beliefs expressed about federal structure in Nigeria, governance, political culture and development, contrary to quantitative technique that is based on descriptions, numerical data, structured and cover broader scales (Neuman \& Robson, 2012).

This research combines two related methodological and analytical tools. The first is the case study approach; the second is the historical institutionalist approach which includes the critical juncture approach with some reference to path dependency. Critical juncture analysis is favoured here due to its use in comparative-historical analysis, since it provides the means of assessing the political origins and development of institutions that exert critical and longlasting influences on their social and political environments (Cappocia, 2016).Analysis by such means arises in the context of the development of institutions, broadly defined as organizations, formal rules, public policies, political regimes, and political economies. Pathdependency institutions do not always develop as a rigid rational-choice solution to certain societal problems Pierson and Skocpol (2002). In this vein, Peters et al, (2005: 1276) argue that the path dependency approach models the policy process as ' $a$ discrete process characterised by extended time periods of considerable stability - referred to as path dependency - interrupted by turbulent formative moments.' The path-dependency approach notes that decisions we are faced with depend on past knowledge trajectory and decisions made, and are thus limited by the current competence base. In other words, history matters for current decision-making situations and has a strong influence on strategic planning. It is within the scope of path-dependency approach that the history of Nigerian federal system is 
examined. For example, Acemoglu et al., $(2001,2012)$ argue that in the case of Nigeria, the nature of institutions promoted by the colonial administration was extractive. Therefore, according to the path dependence theory, societies within Nigeria will become well versed in extractive behaviour (North, 1994; Pierson, 2000). Another fitting example relates to Nigeria's mineral and petroleum legislation. A system fraught with rent seeking tends to be one with minimal checks on the executive, and hence results in a society that extends arbitrary executive powers (Knack and Keefer, 1995; Persson et al., 1997).

Such approaches have generally been the object of critical juncture analysis with the caveat expressed by Capoccia, "As a matter of political science, within comparative-historical analysis, the concept of critical juncture applies only to the analysis of path-dependent institutions and not to all forms of institutional development."'The combined approach therefore of critical junctures and path dependence is considered best as the tools for identifying institutional development. In this analytical context critical junctures are defined (per Cappocia: 2016: 147-179), “...as moments in which uncertainty as to the future of an institutional arrangement allows for political agency and choice to play a decisive causal role in setting an institution on a certain path of development, a path that then persists over a long period of time. "'The combination of these analytical methods is meant to ensure a proper interpretation of the variables in the historical and socio-economic events that have impacted on the institutional framework of the Nigerian state. Furthermore it becomes clear that all actions have corresponding consequences, confirming the potential of collective or individual agency. Based on research findings and existing research on successful attempts made by other countries using a decentralized system of government, comparisons can be made between the position of the United States, Australia and Indonesia against those of the 
Nigerian experience, and identify reasons for failed attempts in decentralization efforts using a sample population from Ondo State

The general literature on institutionalism treats the issues that are crucial to these research namely state institutions, actors and political networks asking what institutions are, how they structure political life, and how they determine political processes and their results. There are three main schools of thought in the 'new institutionalism' namely rational choice, sociological, and historical institutionalism. The first type of institutionalism focuses on the rational choices and individual preferences of different classes of actors towards the rules imposed by institutions. In the second type emphasis is placed on the cognitive and normative account of institutions, with the possibility that institutions are socially constructed by its members, their perceptions, and cognitions, rather than being objective entities (Scott 1987: Peters 2007: 117). Thirdly, historical institutionalism emphasizes that institutions, and the relations of actors within the rules of these institutions, have to be considered in their historical embedding, sequencing, and unfolding.

Capoccia and Kelemen (2007) reinforce the theory that critical juncture analysis helps in identifying the disconnection between small contingent events and unsuitable institutional political and economic dynamics created though micro-decisions. They reveal that in the course of political and social fluidity, key actors make few decisions and choices which are effective in directing development in institutions. In this context, this study was able to capture the dynamics surrounding critical factors influencing institutional selection choices. It does this by the examination of choices and strategies adopted by the political decision makers as against the micro decisions of individuals. This provides a theoretical platform to place the analysis of critical juncture in this study as a suitable tool for the explanation of 
strategies often adopted by the political decision makers which influence the outcome of any decision, which, in this study means good governance.

Adoption of this approach is further reinforced by the submission of Mahoney (2007) who stressed the flexibility of critical juncture to accommodate influencing factors that underpin the strategy of any decision made by the political leaders. There are recent comparative studies illustrating the strength of the critical juncture approach. For instance, Mahoney (ibid) provides an account of change in political regimes using Central America as the sample for analysis. In Mahoney's study, the era of open-minded oligarchic governments at the turn of the $20^{\text {th }}$ century includes the critical juncture in which political progresses shaped the disparity of regimes through Central America in the subsequent decades. The regimes included the old-fashioned dictatorships that developed in Nicaragua and Honduras, democracy in Costa Rica and the military dictatorship in El Salvador and Guatemala (Mahoney, 2007).

Mahoney makes out that the amplified world demand for native Central American agricultural products and technological advances, which endorsed long-distance shipping of perishable goods, created new possibilities for the development of agricultural industries in those countries. Hence the selections the liberal presidents, alongside their political associates, made about agricultural development for the duration of the critical junctures were important in setting political institutions on dissimilar paths of development. Mahoney (2007) also revealed that the early choices, several of which failed to encourage agricultural development due to foreign intervention, in addition to others that thrived but differed based on whether the individual countries sought gradual or rapid development, led to the creation of institutions and policies that influenced class relations in the rural area. In turn, these 
emerging class relations created social populations that reinforced the persistence of earlier institutional choices, organised the political dynamics in foreseeable ways and stimulated the development of states which sustained different agricultural development models. In the theory Mahoney offers, precursor conditions were vital frameworks during the critical juncture period, but never determined the decisions the political actors made. Mahoney (2007) stresses the "historical contingency" of choices made by the liberal presidents, positing that the immediate political authority to maintain or increase power decisions directly influenced their decisions as opposed to their desire to forge some social coalitions that would persist over the long term.

Generally, comparative analyses in political science have different approaches and different methods of gathering and analysing data. Peters (1998: 11) highlights five types of study that are classified as being components of comparative politics. These include:

(1) single country descriptions of politics;

(2) analysis of similar processes and institutions in a limited number of countries;

(3) the study of developing typologies or other forms of classification schemes for countries or sub national units using these typologies to compare groups of countries and reveal the internal politics of each political system;

(4) statistical and descriptive analysis of data from a subset of the world's countries, usually selected on geographical or development grounds, with the aim to test hypotheses about relationship and variables within that 'sample' of countries; and,

(5) statistical analyses of all countries of the world attempting to develop patterns and to test relationships across the entire range of political systems. 
Out of the five types of study, this research study employs the first option, which is a single country description of politics. The approach was used to examine in detail the decentralization aspects of Nigeria based on the sample population from Ondo State. This approach is considered suitable because of the numerous conceptual issues involved in the research and varied characteristics and multi-dimensional nature of institutional designs. The research study seeks to determine why the decentralization system of government in Nigeria has failed to bring good governance and development by an analysis of a possible relationship between decentralization form of government, good governance and development. This relationship is tested through the historical institutionalism approach. The suitability of this approach comes within the normative interrogation of all the variables that constitute and influence governmental institutions.

According to Pierson and Skocpol (2002:4), historical institutionalism interrogates historically situated outcomes of broad interests. It asks questions such as:

- Why something important happened or did not happen?

- Why certain structures or patterns take shape at some times and places, but not others?

- Why have welfare states emerged and developed along various paths?

- Why have some countries become stable democracies, whilst others have not?

- Under what circumstances do ethnic identities become more prominent in national or international politics?

Sanders (2006: 43) adds a more institutional interest to this and raises questions as to who designs institutions, what makes institutions change or collapse and what are the exogenous 
social forces or internal group dynamics that are responsible for such events. The foregoing normative questions serve two purposes in this research. Firstly, they subject the research to various investigations and, secondly, they point to the core aspects of historical institutionalism which are construction, maintenance and adaptation of institutions (Sanders 2006: 42).

Interpreting the variables of institutions therefore requires reliable analytical tools. It is important to note from the outset that historical institutionalism employs more narratives in setting out its causal chains (Sanders 2006). However, it does incorporate analysis of statistical data to further interpret variables. Pierson and Skocpol (2002: 3) highlight three important features that characterize historical scholarship in political science and its ability to be able to sufficiently interpret the variables. Firstly, they note that historical institutionalisms address large, substantive questions that are inherently of interest to a broad public as well as to fellow scholars. In other words, historical institutionalism develops explanatory arguments about important outcomes or conundrums. Secondly, time is of the essence to historical institutionalism analysis in the sense that it specifies sequences and traces transformations and processes of varying scale and temporality. Thirdly, they hold that historical intuitionalism analyses macro contexts and hypothesizes about the combined effects of institutions and processes rather than just examining only one institution or process at a time. This research revolves around substantive questions, the answers to which would be of interest to the broad public. It is period specific and it examines questions arising from similar institutions.

Historical institutionalism analysis, nonetheless, does not follow a singular pattern. As submitted by Pierson and Skocpol (2002:2), historical-institutionalism strategies vary in 
important ways. Some are explicitly comparative, whilst others analyse trends within just one macro context. In the same manner some offer suggestive interpretations, while others offer explicit models framed in general terms. Some draw extensively from primary sources; some synthesize from secondary publications; others adopt culturist modes of explanation-

This research is descriptive, providing in-depth details of a single country and its politics. Since empirical data and data from the existing literature are included, the inferences are drawn from primary and secondary sources.

\subsection{Target Population of the Study}

There were two samples of the interviews. The first sample consisted of questions for the politicians and the policymakers, the civil servants and the academics in the society. The second one consisted of the questions for the community leaders, and local members of the community.

\subsection{Study Procedure}

Interviews were carried out using face-to-face meetings. Interview questions were carefully designed to answer the study research question formulated in the first chapter (Kumar, 2005). Using the literature reviewed and the research question formulated, an interview protocol with open-ended questions was created. As the participants provided information, the researcher (interviewer), being the study representative, and provided directions on major issues to be addressed. As such, the participants expanded their responses without limiting the information. 
Qualitative interviews are useful in revealing how other people think or feel about their experiences (Frost, 2012). Through interviews, participants elaborate their experiences, providing more wide and flexible details (Kumar, 2005). The research, therefore, elicits more details and information (Creswell, 2013). The researcher, therefore, can comprehend experiences and use them to re-construct events he or she never engaged in (Neuman \& Robson, 2012). Qualitative interviews highlight the significance of understanding and relaying meanings to the interviewees, allowing participants to put forward their experiences. Data was collected in between October 2016 to February 2017. Each interview was recorded then transcribed. The participants were contacted through emails, by telephone and through formal and informal connections. The researcher provided research details, particulars and the importance of participants' roles in the research process. The participants opted for carrying out the interview in suitable places, where they felt comfortable sharing information on governance and development. For a smooth interview process, the researcher prepared an interview schedule. Similar question sets linked to general experience in Nigerian governance and development were presented to each participant. Most questions were open-ended. Some questions, such as those about length of employment, gender and age were close-ended. An example of the open-ended question was, 'how do you feel about Nigerian federalism?'; 'do you think there is improvement in governance in local government from 1999-2016?'; 'is there any platform for interaction between the officials of the local government and the community?' This kind of questions permits the interviewee to express more feelings and thoughts freely, particularly in relation to sensitive topics like governance and development (Frost, 2012). 
According to Creswell (2013), qualitative interviewers that follow suitable procedures successfully collect data for comprehensive analysis. Creswell proposes the following process which the researcher followed:

- using purposeful sample process to identify the participants;

- the choice of semi-structured interviews as suitable for the study;

- record all interviews to transcribe them later;

- design an interview protocol form for use;

- conduct a pilot test to test the interview questions and prepare the last script after making necessary adjustments;

- identify the location for interviews; and,

- obtain the consent from each participant.

Prior to actual data collection the researcher carried out a pilot interview which allowed the interviewee to express feelings and thoughts about questions asked. The researcher used feedback provided from that interview to resolve challenges in question structuring and wording, while pinpointing and eliminating questions likely to upset the participants (those issue about which they feel uncomfortable in sharing in an interview). Data from the pilot interview was not however used during analysis.

\subsection{Research Measurement}

The data collections method in this study consisted of semi-structured interviews. The researcher was the instrument in this study and collected the primary data. The one-on-one interview technique can produce a large number of ideas in a short period (Creswell, 2013). The researcher conducted interviews with participants by asking pre-formulated questions 
related to the research topic to promote ideas from participants and collect relevant data. The protocol for the interviews was similar to Maxwell (2013) and Creswell and P (2007) discussion on interview techniques.

\subsection{Data Collection}

Semi-structured interview questions were found to be useful in stimulating open discussions with the participants. The findings from these questions also provide data needed to formulate conclusions relevant to the research questions on decentralization in Nigeria. The researcher worked in partnership with all participants throughout the whole research process. The interviews were classified into five principal categories; political, legal, economic, socioeconomic factors and development. Those five classes relate to issues on good governance within the framework of Nigerian political structure. These classifications, though distinct, they are strongly interwoven. Consideration of each research category is set out below.

\section{Political Research}

This involved principally interviewing the political class (the policy makers). This interview was an exploration into the historical evaluation of the Nigerian State, the political intrigues that are involved in the structural arrangement of Nigeria federalism, the politics of distribution (fiscal federalism) and the role of political parties in the political multi-ethnic nation and development

\section{Legal Research}

This involved interviews with the constitutional lawyers. This aspect of the interview sought an in-depth examination of constitutional framework of Nigerian federalism, dealing concisely with the constitution of the Federal Republic, distribution and separation of power within the framework of Federalism Constitutional Power of the Constituent Federating Units, Local Government and Federal Constitutional Power. 


\section{Economic Research}

This aspect of research dealt with the technical issues of economy of Nigeria. This involved collection of data and documentaries on Nigeria economy, from Agro based economy to oil economy.

\section{Socio-economic research}

This heading included questioning about the perceived benefits accrued to the general population by a distribution of wealth through federalism. In part this crossed over with the development aspect of the research, post

\section{Development Research}

This part of the interviews had three dimensions. Firstly it explored the concept of development among the local people, and their understanding of the term development and its measurement and their assessment of successive governments on development. Specifically, the researcher asked questions concerning the available infrastructure i.e. road; primary education; and primary health care. Secondly, the study explored how citizens understand development and in determining their understanding, the interviewer sought to discover whether the local people understood their role in the quest for good governance. Thirdly, an aspect of research was conducted among some civil servants. The main reason for interviewing the civil servants was to access the bureaucratic complexities in the federal structure, the sub units (States) structure and the issues militating against governance in Nigeria.

This research was also conducted with some civil society groups. The researcher chose to work with the Action Aid Nigeria on this particular research because the non-governmental 
organization (NGO) works in the six geo-political regions of Nigeria, and their five thematic areas of intervention is hinged on development and good governance.

\subsection{Study Setting}

The location used to collect the data was Ondo State which is comprised of eighteen local government areas. The local government areas are grouped into three senatorial districts (six local governments were visited, two per senatorial district). The respondents targeted in this research were civil servants, members of the civil society, politicians and associated policy makers, academics, community leaders, local members of the community (persons living in vulnerable situations, poverty included). This populace composition gives a balanced representation. It is important to note that some of the data are collected, especially from policy makers, academics are obtained outside of Ondo State.

This research extensively examined the practice of federalism in Nigeria, while using one state as a case study. The choice of using only one state out of the thirty states and the federal capital territory of the federation may appear inadequate considering the diversities in Nigeria state. However, there are some very fundamental factors that made Ondo State suitable and adequate in assessing and analysing federal system in Nigeria. A number of the features inherent in the administration of Ondo State are identifiable in and common to all other states. They include; (1) the administrative structure of both state and local governments. There exist uniformed administrative systems of state and local governments. The administrative systems are enshrined in the constitution of the federal republic of Nigeria. The institutional lapses exploited by the politicians in Ondo State are also exploited by politicians in other states. For example, non election into the local government, but using caretaker committees to run the affairs of the local government has been one of the 
challenges of local governance in Nigeria. (2) Vertical and inter-governmental relationship; like many other states in Southwest of Nigeria, Ondo state has been in opposition to the federal government. There is a consistent contention between the powers of the federal government and state. Ondo State offers a more profound example of this relationship. Being a state in opposition to the federal government for many years has attendant consequences, which will be further examined in this research; and (3) the Location; Ondo is one of the Oil producing states in Nigeria, and it is located near one of the recent hotspots of violence, the Niger-Delta. This factor offers a dual advantage for this research. First, it gives opportunity of examining the contentious issue of allocation and utilisation of resources accruing to the state government. Secondly, two local governments in Ondo South Senatorial District, namely Ilaje and Ese Ondo Local Governments experienced the restiveness of Niger Delta Militancy to such extent that these two local government became part of the Federal Government Amnesty Program for ex-militants. It is important to note that being an oil producing state, Ondo State receives $13 \%$ derivation revenue outside of the statutory allocation. This is a significant derivation payment. The struggle for, and the utilisation of the funds from the $13 \%$ derivation revenue among the Ilajes and Apois, offer an insight to how revenue funds can lead to ethnic mobilisation. This research will therefore draw on interviews from officials of Ondo State Oil Producing Areas Development Commission (OSOPADEC). (4) Ethnic and cultural diversity: although Ondo State is predominantly a Yoruba speaking State, it does include some non-Yoruba groups. Within the Yoruba groups there are further diversities which sometimes impact on the politics of the state, and quest for a political space for the purpose of development. 


\subsection{Data Analysis}

Qualitative data analysis began with identifying the emergence of principal patterns and themes and occurred concurrently with the raw data collected. Data analysis for interviews consisted of examining, categorizing and tabulating the patterns of information to address the research questions. During the coding process, the researcher identified, named and grouped the conceptual groups. The theoretical and conceptual analyses were carried out using primary and secondary data. The primary data consisted of interview responses provided by the participants. Secondary data, on the other hand, constituted constitutions and legislative documents, books, journal articles and newspapers.

This approach enables extensive assessment of historical events, conceptual issues on decentralization, governance and development in Nigeria. Furthermore, the research makes extensive use of global aggregated indices of relevant international development organisations to further analyse the causal relationship between institutions, good governance and development. After interviewing all participants, the questions and responses were transcribed. The researcher developed a description of the information collected to create a combined textual and structural description justifying the essence of the participants' experiences. This process allowed the researcher to recognize similarities and developing patterns as well as themes.

\subsection{Trustworthiness}

The face to face interviews withthe participants helped the researcher toestablish trust between him and the respondent interviewees. It also permitted him the opportunity to assess the trustworthiness of the interviewee in providing opinions and expressing views. This active 
engagement by the researcher ensured the quality of the findings and minimized ethical issues.

\subsection{Ethical Considerations}

Scholars tend to place emphasis on the originality and veracity of documentation and interpretation of the procedures leading to the conclusion of the research project. Swazey et al (1993) highlight fundamental categories of ethical problems in academic research, including (i) fabrication, falsification, or plagiarism, in proposing or reporting research; (ii) questionable research practices, such as keeping poor research records or permitting honorary authorship; (iii) behaviour such as sexual harassment and violation of government regulations, which may take place in a research context. To this end, ethical issues are crucial in all the processes involved in academic research. In this research, the main ethical considerations adhered to were informed consent, confidentiality and anonymity and scientific integrity.

\section{Informed Consent}

In order to inform and assure the participants of their role in the research, permissions and informed consents from all participants in the research study were obtained. To gain access to the participants and collect data through interviews, the researcher sent a consent form. Ethical concerns related to participants' recruitment include deception and unequal treatment. The researcher explained the benefits and risks of the study to avoid deceiving the participants. All were treated equally and both genders were included.

\section{Confidentiality and Anonymity}

To ensure confidentiality of the participants, the data collected and relevant information will be stored in a locked computer; the recording gadget and protected by a password and secured in a secured locked coded safe inside. 
The researcher believes therefore that all practices employed throughout the fieldwork aspect of this study accorded with accepted good practice. 


\section{Chapter Four}

\section{Political Culture and Governance in Nigeria}

\subsection{Introduction}

This chapter discusses the nature and character of governance in Nigerian politics. In doing so the author examines and explains the relationship between institutions and political networks, politics and governance, political parties, and civic engagement in the Nigerian context. It lays a foundation for an understanding of the dynamics underlying Nigerian politics with its ethnic rivalries and political clientelism that keep defining the character and nature of Nigerian federalism. For illustrative and comparative purposes, in part 4.1.It references the political system in Indonesia where a version of decentralization was successfully implemented in place of the exiting political structure following three hundred years of colonial rule and thirty years of military rule.

It is widely considered that ethnic rivalries in Nigeria dictate the direction of its politics and governance. As a result keen attention is paid to competing class interests, the interests of the political elites and the religious dichotomy as well as the other varied sub- agendas that drive the political landscape. These other interests spread across the ethnic frontiers; hence an understanding of Nigeria federalism requires an understanding of the dynamics of Nigerian politics with its various political actors and competing interest groups. These actors sometimes form alliances where and when it is convenient and beneficial but unfortunately such alliances are rarely permanent and provide little medium or long term stability in Nigeria's political equation. This factor on its own affects the stability and implementation of Nigeria's federalism. 
Decentralising powers and responsibilities will often depend on the nature of relationship between the centre and the federating units, a relationship usually determined by the political parties controlling each tier. Where the same political party controls both the centre and a unit it is expected that there should be a cordial relationship but unfortunately in Nigerian context, opposition interest groups within the same party remains the ultimate decider of the nature and character of this relationship. In effect, the political elites who control the apparatus of governance seldom consider the interest of the larger society over their own interests. In essence, the ultimate driving force of the Nigerian federalism may not necessarily be the ethnic rivalry as many had averred but the political actors that constantly instigate such rivalry to achieve their group ambitions. This view appears to be in consonance with the view of Bayart (1989), who argues that the patron-client relationship generally defines politics in Africa. Bayart uses the term 'politics of the belly' to describe this kind of relationship. Politics of the belly further highlights the relationship between clientelism, corruption and power. This type of politics points to the propensity of politicians to hoard and greedily consume resources, Thomas (2003: 3). This relationship is established and sustained by the patrons (politicians) through distributing goods or outright buying loyalty and votes during election, as observed in Nigerian electoral processes (Bratton 2008). This phenomenon is what Bayart refers to as the filling of the bellies of client in return for political loyalty, obviating the need for democracy and instituting alternative and sometimes moral forms of accountability. This view can explain why politicians indicted for corruption or larceny always seeks their clients' protection, principally from their ethnic or religious clients.

It is imperative that both observers and participants in the political process of federalism in Nigeria should recognise the critical contributory factors in the apparent failure of equitable and effective implementation. One of the respondents referred to good governance of the 
process of federalism as a mirage and this is very revealing of a widely held view of the political culture and process. The history of Nigeria is set out in Table 2 below.

Table 3: Timeline of Historical Events

\begin{tabular}{|c|c|}
\hline Year & Event \\
\hline 12.000B.C & Stone Age evidence indicates the antiquity of various indigenous people. \\
\hline 500 B.C & $\begin{array}{l}\text { An iron civilization emerged, with one major center at Nok. Technology } \\
\text { was altered, with great consequences on farming, urbanization, and } \\
\text { settlements. }\end{array}$ \\
\hline 200 A.D & $\begin{array}{l}\text { Evidence of a metal age became abundant, indication the spread of cities } \\
\text { and villages. }\end{array}$ \\
\hline 1000-1500 A.D & $\begin{array}{l}\text { Foundation of many kingdoms such as Benin, Oyo, Hausa States and } \\
\text { Kanem Borno. }\end{array}$ \\
\hline 1450-1850 A.D. & $\begin{array}{l}\text { Contacts with Europe and the New World, dominated by the slave trade } \\
\text { which had profound consequences on the people. }\end{array}$ \\
\hline 1804 & $\begin{array}{l}\text { An Islamic revolution took place in northern Nigeria. It created a huge } \\
\text { caliphate and led to the spread of Islam. }\end{array}$ \\
\hline 1842 & $\begin{array}{l}\text { The beginning of success in the spread of Christianity. A new elite emerged } \\
\text { and Christianity and Islam became the two dominant religions in the } \\
\text { country. }\end{array}$ \\
\hline 1861 & $\begin{array}{l}\text { Establishment of a British consulate in Lagos, the beginning of a process } \\
\text { that led to the conquest of Nigeria. }\end{array}$ \\
\hline
\end{tabular}




\begin{tabular}{|c|c|}
\hline 1886 & $\begin{array}{l}\text { Formation of the Royal Niger Company with a charter to trade and enter } \\
\text { into treaties in the Niger basin and its environs. In the same year ended a } \\
\text { prolonged war among the Yoruba in the Southwest. }\end{array}$ \\
\hline 1892 & British attack on the Ijebu. \\
\hline 1893 & Establishment by the British of a protectorate over Yoruba. \\
\hline 1897 & Name "Nigeria" officially adopted. \\
\hline 1900 & Establishment by the British of a protectorate in northern Nigeria. \\
\hline 1914 & Amalgamation of the Northern and Southern Protectorates. \\
\hline 1929 & $\begin{array}{l}\text { Aba riot, a major protest by women against colonial taxation and other } \\
\text { forms of injustice. }\end{array}$ \\
\hline 1936 & $\begin{array}{l}\text { Establishment of the Nigerian Youth Movement, a leading political } \\
\text { association that demanded for major reforms. }\end{array}$ \\
\hline 1946 & $\begin{array}{l}\text { Richards Constitution, with a central legislature and three Regional Houses } \\
\text { of Assembly. This marks the beginning of constitutional reforms that led to } \\
\text { the independence. }\end{array}$ \\
\hline 1954 & Federal system of government introduced \\
\hline 1957 & $\begin{array}{l}\text { Regional Self-government proclaimed in the East and West, a major } \\
\text { transfer of power from the British to Nigerians. }\end{array}$ \\
\hline 1959 & Regional self-government in the North. \\
\hline 1960 & Independence from Britain, October 1. \\
\hline
\end{tabular}




\begin{tabular}{|c|c|}
\hline 1963 & Republic proclaimed. A Nigerian replaced the Queen as the symbolic head. \\
\hline 1966, Jan.,-July & $\begin{array}{l}\text { The first military coup ended the First Republic, but created further political } \\
\text { instability soon after. }\end{array}$ \\
\hline $1966-1975$ & $\begin{array}{l}\text { Administration of General Yakubu Gowon presided over the civil war and } \\
\text { later economic boom. }\end{array}$ \\
\hline 1966 & Beginning of Nigeria Civil war July 3. \\
\hline 1967 & $\begin{array}{l}\text { Creation of twelve states to replace the existing four regions, but demands } \\
\text { for more states continue as various groups see this as an opportunity to } \\
\text { attain rapid development and benefit from federally distributed revenues. }\end{array}$ \\
\hline 1970 & $\begin{array}{l}\text { End of civil war, January } 13 \text {. Nigeria embarked on a program of } \\
\text { reconciliation and reconstruction, partly financed by oil revenues. While the } \\
\text { East was reintegrated, secession demands by various groups have yet to } \\
\text { end, while some outstanding issues of injustice during the war are yet to be } \\
\text { resolved. }\end{array}$ \\
\hline 1973 & $\begin{array}{l}\text { OPEC oil price increase and led to an economic boom and prosperity for } \\
\text { Nigeria. Development project became grandiose. }\end{array}$ \\
\hline $1975-1975$ & $\begin{array}{l}\text { Military regimes of Brigadiers Murtala Mohammed and Olusegun Obasanjo } \\
\text { introduced far reaching reforms in political institutions and became the first } \\
\text { to transfer power to civilians. }\end{array}$ \\
\hline $1979-1983$ & $\begin{array}{l}\text { The Second Republic, with Alhaji Shehu Shagari was president, was unable } \\
\text { to create discipline among the ranks of politicians and was ended by a }\end{array}$ \\
\hline
\end{tabular}




\begin{tabular}{|c|c|}
\hline & military coup. \\
\hline 1983-1985 & $\begin{array}{l}\text { The military rule of Genera Muhammadu Buhari was noted for firmness, } \\
\text { investigation of political figures for corruption and poor economic } \\
\text { performance. }\end{array}$ \\
\hline 1985-1992 & $\begin{array}{l}\text { Nigeria under General Ibrahim Babangida, with both failed economic and } \\
\text { political programs. }\end{array}$ \\
\hline 1991 & $\begin{array}{l}\text { A census put the country's population at } 88.5 \text { million, and this has since } \\
\text { formed the basis or subsequent projections of population increase. }\end{array}$ \\
\hline 1993 & $\begin{array}{l}\text { Presidential election, won by Chief M.K.O Abiola, was annulled by } \\
\text { General Babangida. The country was thrown a prolonged crisis thereafter. }\end{array}$ \\
\hline 1994 & $\begin{array}{l}\text { Short-lived interim National Government, led by Chief E. Shonekan, } \\
\text { characterized by chaos and public distrust. }\end{array}$ \\
\hline 1994-1998 & $\begin{array}{l}\text { Dictatorship of General Sanni Abacha, died June 8,1998. He was replaced } \\
\text { by General Abdusalami Abubakar. }\end{array}$ \\
\hline 1998 & $\begin{array}{l}\text { General Abdusalami Abubakar conducted a general elections and handed } \\
\text { over power to civilians headed by Chief Olusegun Obasanjo. }\end{array}$ \\
\hline 2007 & $\begin{array}{l}\text { Alhaji Umaru Yar Adua was elected the President. He died in } 2010 \text { and was } \\
\text { replaced by the Vice President, Goodluck Jonathan }\end{array}$ \\
\hline 2011 & Dr. Goodluck Jonathan was elected the President. \\
\hline 2015 & General Muhammadu Buhari was elected the President \\
\hline
\end{tabular}

Source: Falola (1999) 


\subsection{Foundational Factors: paths to Nationalism and Federalism}

The introduction of a new political system to a country used only to colonial or perhaps postcolonial rule involving military authority will generally be seismic in its effect on the incumbent government, the political actors involved in the process and most of all the national population. However such process is generally has its roots in history so some background to the present position of Nigeria is critical in understanding how Nigeria has reached this stage in its evolution and development. A review of the pre-independence Nigeria shows that one of the key factors in political change is the agitation by the educated elites to participate in government. Consequently the successive constitutions became the cornerstone of the emerging nation and the independent Federal Republic of Nigeria. These constitutions built on each other so that in theory the successive constitutions picked up the baton for the previous one and moved on. There are four pre-independent constitutions, the Clifford Constitution (1922), the Richards Constitution (1946), the Macpherson Constitution (1951) and the Littleton Constitution (1954).

\subsubsection{The Clifford Constitution 1922}

This was the first constitution and its hallmark was the introduction of party politics and the first opportunity for a democratic election in Nigeria. It provided for the election of four persons into the legislative council; three from Lagos and one from Calabar. It was the first opportunity therefore for Nigerians to elect their own representatives. Although voting was by direct election, the election was based on a very limited franchise. Those who could vote or be voted for were only British citizens residing in the cities and British protected persons with a minimum gross income of one hundred pounds a year. Many if not most Nigerians were thus disenfranchised. This constitution is said to be the bedrock of formation of political parties in the country (Afigbo: 2003:23). 


\subsubsection{The Richards Constitution 1946}

This was a direct response to the agitation of some sections of the country, particularly the more educated south, for either self-government or more participation in the present government (Coleman: 1986; 271). It moved on from the previous constitution by creating a regional House of Assembly with a majority of unofficial members, (though all elected) in each part of the country, along with a House of Chiefs for the North (Kirk-Greene 1997: 315). For the period of 1946 to 1954 , the country moved therefore from Unitarianism to quasi-federalism (Elaigwu 2007).

There were three main objections to the Richards Constitution by Nigerian nationalists: (1) the imposition of the constitution from above without due consultation with the Nigerian people; (2) the ambiguous role of chiefs in politics (nationalists were suspicious of chiefs whom they regarded as colonial government officials and anti-nationalists groups); and (3) the number of political units created in Nigeria (Elaigwu: 2007). The third objection expressed the sentiments that the three regions did not capture the reality of the heterogeneous nature of Nigeria state, taking into consideration the numerous minorities groups within the three regions and the fear of domination and marginalization from the majority ethnic groups. Elaigwu (2007:34) observed that;

“. . . by 1956, the three major leaders had become grafted in their respective region, which has increasingly become centres of power. Nnamdi Azikwe had returned to the Eastern Region as Premier; Awolowo was the Premier of the Western Region; Ahmadu Bello took the title of Chief Minister of Northern Nigeria. Secured in the regions, the leaders jealously guarded any erosion of regional powers; even Nnamdi Azikwe, who had supported a strong centre, equivocated". 


\subsubsection{The Macpherson Constitution 1951}

The Macpherson Constitution was more inclusive of the indigenous people and in fact laid a foundation for an inclusive federal government and the first general elections into the regional and federal assemblies (Kirk Green 1997).

\subsubsection{The Lyttleton Constitution 1954}

This constitutional reform provided the regional governments with broader legislative and fiscal powers. Each was controlled by their leading political party with a seat or seats in the national legislature. Three major parties consolidated their regional bases of control and their leaders attained both local and national prominence; Nnamdi Azikiwe- head of the Igbo dominated National Council of Nigeria and the Cameroons (NCNC) - later renamed the National Convention of Nigerian Citizens) became premier of the Eastern Region. Obafemi Awolowo of the Yoruba-based Action Group (AG) won the Western Region premiership, while Alhaji Ahmadu Bello, who held the traditional title of Sarduana of Sokoto, led the Northern People's Congress (NPC) chiefly based among the Hausa-Fulani.

The constitution brought into existence a federal system within the colonial framework. Elaigwu (2007:31) explains that the regions were given more autonomy in decision-making; not only had the regional assemblies sprung up, regional bureaucracies had also become established. The regions maximized their autonomy at the expense of the centre, which was still under colonial control (Elaigwu 2007:31).The transfer of power from colonial administrators to indigenous rule yielded northern dominance of the first post-independence government. The 1957 constitutional settlement which the British negotiated with the Nigerian nationalists allotted representation in the federal legislature on the basis of regional population. The 1952 census indicated that Northern Region included 53 percent of the total population. The NPC's decisive hold on the Northern Region ensured a polarity in the 
National Assembly and Sir Abubakar Tafawa Balewa deputy leader of the NPC became prime minister in the new national administration. In 1959, the British invited Tafawa Balewa to form the government. With control of the Federal executive and a secure regional base, the leading northern party was in a uniquely advantageous position in Federal politics.

\subsubsection{Transition to civilian rule: July 1975-October 1979}

The government of General Gowon was overthrown by General Murtala Muhammed, promised to return the country to civilian rule (Falola 1994:51). The hallmark of his regime was the centralisation of power back to the central government and the creation of seven additional states, making nineteen in total.

\subsubsection{The Second Republic: October 1979 -December 1983.}

In October 1979the Military returned power to the civilians and a democratic government headed by a new President, Alhaji Shehu Shagari (a Muslim from Sokoto in the northern Nigeria) of the National Party of Nigeria (NPN) was sworn-in. The Second Republic was based on the 1979 constitution which provided for a three tier government, the federal, the state and the local governments, there being a unicameral legislature at both state federal levels. It was aimed at national integration and equitable representation of all the ethnic groups. There were representatives of other Political parties at the state and Federal levels. However public office was again treated as route to personal and ethnic gratification, and contending political factions employed fraud, patronage, and violence to gain advantage (Falola, 1994: 76).

\subsubsection{The third military intervention and successive military Governments: 1983-1999}

The new military government was marred with records of human rights abuse, although dramatic steps were taken to curtail political corruption and impose accountability on the civilian political class; attempts were made to restore a measure of social order and civility to an unruly public arena. The government was overthrown in August 1985 by General Ibrahim 
Babangaida whose military regime lasted eight years during which the military regime controlled and manipulated the political, social and economic life of the entire country. In the historic June 121993 presidential elections, which most observers deemed to be Nigeria's fairest, because for the first time the barriers of ethnicity, religion and other cleavages were broken, early returns indicated that the wealthy Yoruba businessman Moshood Kasimawo Abiola (a Moslem from Abeokuta, South West) had won a decisive victory. ${ }^{11}$

The annulment of this election by the military triggered off another round of ethnic tension in Nigeria; the Yoruba ethnic group perceived the annulment as fulfilment of the north's agenda to rule Nigeria perpetually and the situation nearly degenerated to a state of civil war. General Abacha's rule was adjudged to be the most notorious dictatorship in Nigeria. "Public reaction to this development in the transition programme was apathy and a new-complete boycott of the elections.";Maja-Pearse, A. (1999). ${ }^{12}$ Eventually a credible transition programme to civilian rule was put in place.

\subsubsection{A new democratic Dispensation May 1999-date: The Fourth Republic}

The emergence of the fourth republic was regarded as a consensus to keep the unity of Nigeria as a direct consequence of the annulment of the 1993 election and was a 'power shift' from the north to south in response to the accusation of political marginalisation of the South by the North. The constitution of 1999 provided a new framework for liberal democracy.

\footnotetext{
${ }^{11}$ The recent book of Prof. Humphrey Nwosu on the June 12 election published on the $15^{\text {th }}$ anniversary of June 12 Laying the Foundation for Nigeria's Democracy, confirm that M.K.O. Abiole won by 8,323,305 votes to beat Alhaji Bashir Tofa who got 6,073,612 votes

${ }^{12}$ Maja-Pearse, A. From Khaki to Agbada: a Handbook for the February 1999 Elections in Nigeria, Lagos: CLO, 1999.pg. 17
} 


\subsection{Consideration of a similar political situation: Indonesia}

It is informative to compare the position of Nigerian federalism, which is largely considered to be a failed attempt, against the process in Indonesia which is regarded as a highly successful example of post-colonial government being succeeded by a civil government based on the principles of federalism and decentralisation.

In assessing the political conditions and the institutional structures as a fulcrum for economic growth and development, most of the literature comparing Nigeria with Indonesia seems to agree that the structural and institutional factors that are embedded within the social and political histories of the two countries are vital in the understanding of the process of governance development in both (Lewis 2007; Tirtosudarmo 2008; Akinyoade 2008). This includes the history of colonialism and nationalism, ethnicity and religion, the role of the military, the role of the elites (the elites herein consist of the politicians, the technocrats and the political parties) and international factors (foreign loans, aids and investment).

These factors significantly shape the process of nation building, the formation of the political structure and the economy of the country. For example, the different decolonisation processes and establishment of state sovereignty were critical factors that influenced the perceptions of the political leaders on the concept of the country as a national project (Lewis 2007). To this end, Tirtosudarmo (2008) argues that a state's format and the structure of the government are outcomes of the long process of political development, mostly before independence. Equally, the format and structure of the state are also an institutional manifestation of the country's state ideology. 
As did nearly every other newly independent colony, Indonesia had its own share of postindependence conflicts and crises, especially the self-determination struggles of the various ethnic groups. As expressed by Vickers (2013) Indonesia had to cope with the effects of 300 years of colonisation on the one hand and the effects of the militarised struggle for independence from the Japanese and the Dutch on the other. Vickers (2013:117) explained that:

“. . . colonial rule had created institutional structures that could be converted to Indonesian needs, but had also created massive inequalities and an economic system that drained resources and sent these overseas."

He went on to consider the legacy that the emerging nation state had to contend with, equally applicable to the position of Nigeria;

“. . . the Revolution left legacies of dislocation, division and death, and it would take a huge effort to rebuild broken lives and industries lost in the scorched earth campaigns. Coming out of the revolution, some Indonesians . . . expressed deep bitterness about the effects of the tumult, but others felt a great optimism that, free at last, they could form their own destinies." (Vickers, 2013: 117).

The establishment of independence was set against two contrasting phenomena vis-à-vis Indonesia and Nigeria. Whilst the Indonesian freedom fighters were optimistic about developing an Indonesian nation from the multi-ethnic groups, diverse ethnic groups in Nigeria were concerned that the loss of their own identities would lead to being subsumed into some version of a national identity by a dominant ethnic group. Additionally, in postindependent Nigeria, residual religious and ideological identities became prominent factors in political affiliations. 
For any nation-building project to succeed Vickers (2013: 119) submits that its architects must be able to convince other social forces of its virtue. One such force in Indonesia was the army that had been torn by divided loyalties arising from allegiance to various social groups. As did Tafawa Balewa in Nigeria (1960-1966), Sukarno, who ruled Indonesia from 1949 to 1966, inherited a fragmented Indonesian state from the colonial authority. He then introduced an ideological tone with his policy of 'Guided Democracy', designed to unify the various social groups in the interest of the nation. He took the view that the Indonesian way of resolving important questions was by prolonged deliberation (musyawarah) designed to achieve a consensus (mufakat); this was the procedure at village level and was intended to be the model for the country. In this way he used the 'bottom up' approach which complemented the 'top down' method where the same political theory originated at each end of the spectrum.

The principle of Guided Democracy received the consent of the four main parties and the National Council representing all the social groups such as the urban workers, rural farmers, intelligentsia, national entrepreneurs, religious organizations, the armed services, youth organizations, women's organizations, etc. Decision making for governance henceforth included the inputs of all these social groups and the political parties under presidential guidance for a national consensus to be expressed. In addition, a middle-way strategy of introducing the military into the process of Guided Democracy was also developed by Sukarno. This arrangement weakened the strength of the opposition parties and saw a rise in the military profile and the powers of the President. 
Sukarno also infused the principle of Guided Democracy with an indigenous national ideology christened Pancasila. This was based on five principles declared by Sukarno and his nationalist group in 1945 . They were meant to serve as the guiding philosophy of the, then, anticipated independent state. These principles included structuring a free Indonesia in faithfulness to God Almighty, consensus or democracy, internationalism or humanitarianism, social prosperity and nationalism or national unity (Vickers 2013). All political parties were made to subscribe to these principles that crystallised into a national ideology for the Indonesian state. By contrast there was no such attempt by any Nigerian government to create that national identity and to establish a recognisable set of shared values on which to build a sense of nationalism. In fact the decolonisation process in Nigeria was established against a background of indirect and deliberate fragmentation of the state which did not create any sort of ideal platform for a national ideology. In this context Lewis (2007) and Tirtosudarmo (2008) argue that the travails of development as responses to challenges and opportunities brought about by political independence, more often than not reflect particular circumstances that the country and its leaders have had to confront.

It can be seen therefore that there are distinct differences between the comparative experiences of Indonesia and Nigeria in their arrangements for power devolution. While Nigeria distributes powers among a three-tier arrangement of federal-state-local government structure, Indonesia's political arrangement allows the distribution of powers in a five-tier arrangement of central-province-local-municipality-villages. In addition, social groups are also infused into each tier to allow broader participation and contributions from every segment of Indonesian society. The diffusion of power through this arrangement greatly improves the level of political consciousness of the Indonesians, shapes the characters of their civil societies groups and gives some legitimacy to Indonesian governments irrespective of 
their ideological bents. Though Suharto's autocratic regime only used this arrangement to keep the people busy, rather than really involving them in governance, it nevertheless recognized the sovereignty of the people beyond multi-party elections and remained fundamental to the survival of the government.

While Nigeria's federalism is fraught with controversy and suspicion among the major ethnic groups, Indonesian centralised, but all-inclusive system, of government reduces suspicion and is less controversial. In the context of Indonesian decentralization Aspinall and Fealy (2003) argue that the shifting of authority to the sub-provincial level would promote democratisation because communities had a far greater awareness and sense of engagement with local politics than they did with either provincial or national affairs. District based autonomy was found to bring decision-making to a level where communities were more inclined to participate, and where they could hold politicians accountable for their actions. Further such district level autonomy was seen as the best way to ensure that decentralization did not encourage separatism and the break-up of the country. Such differences of approach between the Nigerian federalism and Indonesian decentralization experiences are relevant in this study and support the view that the experience of federalism is context and country specific.

\subsection{From Agriculture to Oil: a shift of the economic paradigm in Nigeria}

Before oil was discovered in the late 1950s, agriculture was the mainstay of the Nigerian economy. At this time,

"Nigeria is the world's largest exporter of groundnuts, with about 36\% of the world trade, she also ranks as the second largest exporter of cocoa in the world supplying about $20 \%$ of the world trade. Her export of cotton seeds represents about 18\% if the world supply and the country's share for vegetable oil was 11\%. 'Ekundare (1971) 
Agriculture accounted for $70 \%$ of the Nigerian labour force and from agricultural export Nigerian earned between $65 \%$ to $70 \%$ of its foreign exchange (Lewis 1998). However, by the late 1960s, oil had replaced these agricultural products as the country's largest foreign exchange earner. These agricultural commodities transcended the geopolitical regions of the country; the north had the groundnuts while the south produced cocoa and rubber. The revenues accrued facilitated economic growth and concerted efforts were made in establishing industries and human development within the context of the political arrangement at that time (Nnoli 2008)

The 1970s was a period of volatile expansion (Birdsall 2006:86). The revenue from oil rose to $58.01 \%$ of the country's gross domestic product (GDP)(Nnoli 2008; Omeje 2006; Birdsall 2006). At this point there was a leap from agro-based economy to oil economy. There was a downturn in agricultural sector (Aiyede: 2009: 254). Oil revenues fluctuated with the vagaries of world prices, and state expenditures were supplemented by extensive international borrowing. The oil boom and its downturn have altered fiscal federalism, political structure and development (Aiyede 2009).The transition from agro-based economy to oil economy had a fundamental effect on the economic growth and human development. Nnt only did it cripple agriculture, over and above all, oil revenue accruing to the Nigeria state only served to transform the Nigerian economy into a mono-mineral economy, the state into rentier state and the population into consumers (for the most part), rather than producers (Aiyede: 254). The 'Rentier state' is a concept used to describe a political economy of a state that is largely dependent on extractive resources rents, taxes and royalties paid by transnational companies and on profits from its equity stakes in such investments. They are incomes that are not derived from the productive sectors but thrive by courtesy of international capital (Omeje 
2008:5). In other words, in rentier economy and state, resources from rents predominate the sources of income and it is externally derived. However, one of the greatest features of rentier economy is that it is only a few groups that are involved in generating rents, while the majority distributes and utilize the wealth created (Beblawi and Luciani 1987). In effect, this few are the governing elites who Omeje (2008) argues mainly expend the resources for their own benefit rather than the welfare of the society at large. To this extent, the nature of resource acquisition and distribution appears to be problematic in the sense that the rentier economy has,

“. . . the tendency to develop a self-propelling energy capable of reconfiguring the structures of the political economy of a state, peripheralizing and displacing non-rentier productive forces, and generating a convoluted culture of accumulation and politics that confronts to the imperatives of "rents speak'”, (Omeje 2008:5-6).

There are three critical issues/debates that are associated with rentier states:

(i) the extent to which rent economy makes governments less democratic;

(ii) the extent to which rent economy causes government to do a poorer job of promoting economic development.

(iii) the impact of rentier economy on the citizens, i.e. 'rentier behaviour' or 'rentier mentality'.

In 2003 Nigeria ranked second in the index of oil dependent states. There are however attendant consequences of being highly dependent on rent economy which includesthe centralization of the governance in Nigeria. The 1999 constitution of Nigeria, section 44(3) prescribes that, 
"Notwithstanding the foregoing provision of this section, the entire property in the control of all mineral oil and natural gas in, under or upon any land in Nigeria, under or upon the territorial waters and the exclusive economic zones of Nigeria shall be vested in the government of the federation and shall be managed in such manner as may be prescribed by the national assembly."

Omeje (2008:63) indicates the four key distribution mechanisms which include the federal account; (1) rents appropriated directly by the federal state, a state derivation principle; (2) the right of each state to a proportion of the taxes that its inhabitants are assumed to have contributed to the federal exchequer; (3) the federation account (or state joint account) which allocates revenue to the states on the basis of need, population and other criteria; and (4) a special grant account, designated for other considered special needs, for example the Niger Delta development. The sharing of the revenue from oil became the dominant issue in the political struggles throughout successive regimes and they gave rise to negative and bitter competition between ethnic and regional groups for power and access to the country's oil wealth. This is very fundamental in the politics of federalism and the consequences of fragility and underdevelopment. To this extent the history of the post-colonial Nigeria is in a sense the history of the reconfiguration of revenue allocation (Omeje 2008).

Some characteristics have been associated with rentier states. Scholars such as (Karl 2005; Omeje 2008; Collier and Hoefller, 2000; Collier 2009; Shultz 2005) explain the merits and demerits of the rentier state and show that a rentier economy imparts more on negative side than the positive side. The issues range from the effects of overdependence, stagnation of economic growth, crisis of development, elite capture and corruption. Karl, (2005) argues that over dependence on oil revenues results to poor governance and a slow rate in economic 
growth and development. He contends that the overdependence on oil exports is accompanied by weak public institutions with no competence in handling the challenges of oil-led development (Karl, 2005:25). In the rentier state there is no separation between political power and economic influence, public and private, as they all centre on the rulers, and rent seeking becomes their strategy for wealth creation rather than productive use of the revenues (Karl, 2005). Corroborating this view, Collier (2009:15- 17) argues that there is a fundamental relationship and interplay between natural resources and politics. Collier identifies three ways in which there is interplay between natural resources and politics. The first relationship is a situation where the economic development opportunities created by the abundance of natural resources cannot be exploited due to a weak political system. The second is the situation whereby the presence of huge resource revenues leads to the deterioration of governments and its institutions. The third is a political system that has already developed before the inflow of huge resource revenues becomes a major foreign exchange earner.

Accountability, which is a fundamental element in the process of good governance, appears to be compromised or ignored in a rent economy. Peter et al (1998) argue that the easy availability of oil revenue relieves the state of the need of taxation and enables a small group of leaders to undertake public spending and make public policy without accountability. Shultz (2005) identifies corruption as one the greatest challenges associated with a rentier economy and refers to two factors. The first is that multinational corporations themselves encourage non-transparent relationships. They would rather deal with a few high-level government officials than with parliamentary committees. The second is that because oil rents make the government the 'biggest spender' political clients gather around it, influencing government officials to embezzle and spend recklessly irrespective of how and where the 
money is spent. They do this by diverting public funds to their private accounts at home and abroad, through subsidies, protection policies, and the creation of public employment even in government agencies where there are no the vacancies (Karl, 2005:25).

In the case of Nigeria, Peter et al (1998) argue many Nigeria leaders have become rich through politically inspired partnership in oil ventures, misuse or misallocation of funds, and diversion of funds and diversion of revenues, such that corruption has undermined much of Nigeria institutional framework most especially the federal structure. Corroborating the argument of Peter et al, and explaining further the negative impact of rent economy in Nigeria, Omeje (2008:62) notes that:

". . . what is on offer in the name of petro-development is the terrifying and catastrophic failure of secular nationalist development...from the vantage point of Niger-Delta-but to no less from vast slum worlds of Kano or Lagosdevelopment and oil wealth is a cruel joke".

He continued by considering the misappropriation and the value of oil revenues thus;

"In effect, as it is noted, it is neither the case that development is uneven, but basically, the oil wealth has not really transformed any part of the country. It is important examine the performance of Nigeria oil wealth, '85 per cent of oil revenues accrue to 1 per cent of the population; perhaps $\$ 100$ billion of the $\$ 400$ billion in revenues since 1970 have simply gone 'missing' (the anti-corruption chief, Nuhu Ribadu, claimed that in 2003, 70 per cent of oil wealth was stolen or wasted; by 2005 it was 'only' 40 per cent of the country's wealth). Over the period of 1965-2004, the per capital income fell from $\$ 250$ to $\$ 212$; income distribution deteriorated markedly over the same period. Between 1970 and 2000 in Nigeria, the number of 
people subsisting in less than one dollar day grew to more than 70 per cent from 19 million to a staggering 90 million”

From the data and analysis of the contribution of oil wealth to national development, it seems that oil wealth did not add value to human capital development. Omeje (2008:14-15) identifies eight areas in which the rentier economy contributes to the fragility of the national condition. These are:

(i) the struggle over ownership and control of specific natural resources or "extractive spaces' by various stakeholders (the state inclusive) and groups within a state, often compounded by external intervention of support for one of the conflict parties;

(ii) the struggle over distribution and use of public revenues derived from natural resources by various local stakeholders and groups;

(iii) the inability of weak state institutions to cope with large rents from natural resources coupled with prebendal looting, misappropriation and exclusion of the society, leading to violent protest and resistance;

(iv) the use of official and unofficial revenues from natural resources by the state and its governing elites to build up and finance strong repressive security machinery as a means to keep the hegemonic elites against opposition from counter-hegemonic forces;

(v) the use of legal and illegal rent from natural resources by splinter groups, disgruntled factions of the governing elites and opposition forces to sponsor anti-government insurgencies, secession movements and insurrection.

(vi) the organised extortion of big business (extraction and mining companies),creating aggrieved militia groups protesting against issues of resource related misgoverning; 
(vii) the blatant politicization and mismanagement of conflict-issues and legitimate grievances related to natural resources and the rentier economy.

(viii) Interests and intervention of external parties and stakeholders, forces of imperial governance, predatory networks and militarists regimes on extractive economy of a relatively vulnerable state.

\subsection{Civic engagement in Nigerian politics}

Independence was the critical factor in the development of Nigeria as a sovereign state but post-independence actions of the political elites ${ }^{13}$ have undoubtedly left Nigeria a more divided and alienated nation compared to when it was subject to the benevolent despotism of unitary colonial rule (Lewis 2003). One of the models for Nigerian federalism was the US federal system so that its establishment is comprised of lower and upper houses of the bicameral legislature system in which the president serves as the head of government, the state and the multi-party system. Central government therefore exercises executive authority over the Nigerian people. It will be made out therefore that rampant corruption within the state originates from that executive authority (Lewis 2003).

Nigeria is a well-known oil and mineral rich country with many ethnic and religious disparities which, in the view of Lewis (2003), present serious challenge to the Nigerian political system. These differences sometimes reinforce each other mutually, and also generate peculiar voting behaviour, political, social and economic inequalities. Ethnic disparity is not a sufficiently dominating feature however for it to be considered as the sole

\footnotetext{
${ }^{13}$ Within this section the term 'the elites' is used to describe certain political groupings. For the avoidance of doubt it defined as 'a select group that is superior in terms of ability or qualities to the rest of a group or society'. Furtherit includes persons who finds himself/herself in a position of superiority by reason of greater power that his or her contemporaries.
} 
parameter to account for the dysfunctional federalism in Nigeria. There are other social groups and organisations in addition to religious groups that also play vital role in the faltering federalism, to include labour unions, civil liberty associations, student movements, women's movements, the press, political parties and professional associations (Toyo and Aremu, 2003). There is an increased participation by such groups all of whom have a voice, some of them strident, while the somewhat politically disengaged, such as those from the rural areas in particular, or the unemployed, have less of a voice.

Such groups are to a greater or lesser extent all key actors in Nigerian politics with their varying degrees of engagements in the political processes and governance of the process of federalisation. Of all these groups however, it may be said that the political parties and the political elites are perhaps the most influential because, above all others, it is they who dominate space in Nigerian politics. In the view of Agbaje (1997) the involvement of these peripheral groups is largely influenced by the terms dictated by the elites and their political parties. It is generally the elites who control the affairs of state and direction of the political processes simply because the ownership of these parties, as asserted by Musa (2014), solely lies within their grasp. Agbaje (1997) reinforced by Toyo and Aremu (2003) nourished the total control argument of Musa (ibid) with an explanation that these elites principally fund and control the activities of the parties, so that there is no place for the voice of the masses. The aftermath effect of this control is the disconnection between the politicians and the electorate.

Current literature suggests that three largest ethnic groups, which include Yoruba, HausaFulani and Igbo lack a common historical, social or political unifying factor. Such disparate groups also live unconnectedly, some in ethnic reserves within ethnically mixed cities or 
traditional regions. Religion also plays a significant role in the Nigerian mass political culture (Lewis 2003). While religion in the southern parts may have less impact than ethnicity on the political culture, it has a profound influence in the north. For instance, the identification of the Hausa-Fulani is Islam and traditional religious and political leaders have successfully resisted any efforts to introduce westernization.

The patrilineal system that has existed for several decades in the country is also reflected in the political culture where women are marginalised especially in the North where the male dominated regime, based on fundamentalist religious beliefs, segregate women and limit their access to political power almost completely. In fact it is difficult for women to even vote in northern Nigeria (Toyo and Aremu, 2003) where officials aspire to use a distinct legal system built on Islamic laws, a key factor in constitutions drafted for the three regions during federalization efforts. Religion, on the social scale, largely shapes Nigerian political behaviours. For example twelve out of the thirty-six states in the northern part of Nigeria instituted Sharia as the main body of civil and criminal laws. The introduction of Sharia in these states heightened the religious tension particularly between the Christians and the Muslims.

Scholars such as Elaigwu and Galadima (2002); Suberu (2009) have argued that the introduction of Sharia violates the constitution. However, as Elaigwu and Galadima (2002) pointed out, the main debate in this instance is the extension of Sharia from civil matter to criminal matters. Nigeria's various constitutions, that is pre and post-independence, allowed practice of Sharia in personal and civil matters. For example Section 275 of the 1999 Constitution allows for the creation of state Sharia Courts of Appeals so that the Constitution has implicitly reserved discretion to the states to create their own Sharia 
courts to act as courts of first instance. Sharia criminal code prescribes punishment such as decapitation, amputation, and stoning to death, threatening the well-being of non-Muslims, endangering fundamental rights protected by Nigeria's federal Constitution, and posing significant challenges to elected officials and federal courts.

The extension of Sharia Law to criminal law in twelve northern states also has increased inter-communal and intergovernmental conflict, threatening the fabric of Nigerian federalism. The apprehension expressed by Elaigwu and Galadima (2002) and Suberu (2009) are justifiable when the situation is compared to failed federal practices in Africa for example, the case of Eritrea and Ethiopia, or African countries that have convulsed into civil war; such as Liberia, Sierra Leone and the Democratic Republic of Congo. It is very instructive to note that this dangerous trend has been curtailed through what Suberu (2009) described as the Nigerian federation's judicious combination of centrist and autonomy mechanisms this has been effective in managing religious conflict and cauterising potentially disintegrative centrifugal challenges to national stability. However, despite the significance of regional, ethnic and religious considerations Nigeria seems to have cultivated a political culture of sorts.

Underpinning the deliberate polarization of the population, as posited by Olowu (2003); Ndibe (1999) Toyo and Aremu (2003) is the struggle for the distribution of political power and economic resources. Elaigwu (1994) argues that the imbalance in the distribution of power has exacerbated politics of ethnicity, and heightened the struggle for political power and economic resources using ethnic and religious affiliations in achieving this purpose by the politicians. One can therefore deduce from this situation three implications; firstly that the situation creates a political culture amongst the general population; secondly that the situation 
diminishes the collective bargaining power of the general population; and thirdly, that good governance and development is not the main goal of the struggles for political power and economic resources among the political elites. These three deductions perhaps informed the position Suberu and Osaghae (2005:69) when they argued that economic concerns might have been centric in defining the political assumptions and values in Nigeria. Based on the resources accruing to Nigeria state and the Human Development Index of the World Bank, the position of Suberu and Osaghae (2005), that Nigeria has not developed to its full potential because the politicians do not focus on economic development is entirely plausible.

As mentioned above, the approach and mechanisms of politicians in attaining political power and economic resources has produced a specific type of political culture. The analysis of this culture is complex because it has two dimensions due to the dichotomy between urban and rural areas which are also disparate in nature. Two thirds of citizens in Nigeria live in the rural areas which have strong customary value systems and structures. Rural leaders have found it comparatively easy to transform the British administrative system into influential patron-client relationships, equivalents to Indian Jatis or Japanese Oyabun-kobun (Lewis 2003). A study by Miles (1988) on rural Nigerian politics revealed that customary differences between the commoners and the nobles had been passed into modern Nigerian politics. Further, most Nigerians seem instinctively to reject movements that push for equality or opposition for authority (Lewis 2003). In most rural areas therefore, democracy is practiced at low levels due to high illiteracy and poor education. It is not surprising to find authority for the proposition that the majority of the residents from the rural areas have no knowledge of the political processes at national levels or national political concerns. Kehinde (2007) further notes that with isolation, it is clear that countryside residents barely get involved in issues of the national politics. Instead most residents follow initiatives or programmes that local 
leaders propose or are easily persuaded by the politicians who they see only during election campaigns.

The behavioural pattern of the politicians and political elites is examined against the backdrop of their attitude towards the general population. Kehinde (2007) indicates that it is neither uncommon nor surprising that the elites think and act distinctively from the general public. In the Nigerian experience such distinctiveness is considered to be very significant creating a gulf between the top of the pile of political actors and those whose engagement in the political process is very limited. Momoh and Adejumobi (1999); Okotoni (2001) argue that the behavioural pattern of the political elite is equivalent to Marx's bourgeois class in that their wealth comes from their control over the national purse. As such, the resulting class of bureaucratic political leaders popularly called 'lootocrats'(mis)use their political positions for personal gains and use military as well as civilian rule to protect their power and wealth. The elites, as a whole, have therefore become united in subverting democracy in Nigeria by taking advantage of religious, ethnic and regional divisions to mobilize their resources and amass wealth (Adejumobi and Kehinde 2007).

In any discussion on Nigerian political mass culture and elite culture, it is clear that there are three main challenges affecting decentralization and federalism in the Nigerian political system. Firstly, Nigeria's lack national integration or identity; to most citizens, the important thing is to define politics in terms of one's status, concerning the overlapping, polarizing and sub-national cleavages. Secondly, public acceptance and validation of the government is an important element of a stable government but in a very large measure this is missing. In fact Nigerian citizens have no high regard for the elites, an attitude reciprocated by the elites towards the masses. Thirdly, Adejumobi and Kehinde (2007) illustrates that the federal 
government does not entrust other government tiers with resources to foster development because of existing regional boundaries, ethnic groups and religious definitions.

Adejumobi and Kehinde (2007) argue that a nation with such linguistic and cultural assortment presents analytical challenges while examining political and cultural aspects. In the recent years, most scholars and authors such as (Lewis 2003) have attempted to overcome the analytical challenges by advancing various perspectives and methods, including ethnic pluralism, structural, institutional and economic political method, stressing more on class, underdevelopments, clientelistic patronage, materialism and prebendalism politics, where elected officials, and government workers feel they have a right to a share of government revenues, and use them to benefit their supporters, co-religionists and members of their ethnic group.

Generally, Osaghae (2011) argues that there has been political instability over many years, immensely influencing political behaviour in the Nigerian society. Momoh and Adejumobi (1999) point to the manifestations of such instability in frequent regime turnover of institutions, personnel and structure motivated by the military coups, alterations in public policy which often result in poverty, inconclusive as well as disputed electoral outcomes, legitimacy crises and political violence, for instance, six military coups occurred from 1960 to 1999 , some successful others unsuccessful. Similarly Osaghae (2011) cites three civilian governments in Nigeria, led by Shonekan, Tafawa Balewa and Shagari as a proof of a poor and inconsistent political culture. Osaghae (2011) develops this theme by identifying three principal factors which account for such volatile conditions to prevail;

(1) political instability: as manifested in the high turnover of government (regimes, structures and personnel) occasioned by military coups, inconclusive and contested 
electoral outcomes, frequent changes in policy, political violence and crisis of legitimacy;

(2) national cohesion; a low level of national cohesion is evident in frequent and disputed struggles for political power and resources. Such disputes revolve around regional, ethnic and religious interests, within this context being the recurrent issue of minority rights, resource distribution and power sharing.

(3) economic factors; the indices of economic crisis is reflected in the high rate of poverty.

Whilst the third republic, comparatively, seems stable in the sense of its continuity, many of the historic malpractice continues, all of which factors, according to Osaghae (2011:15), are mutually reinforcing.

Economic decline in Nigeria is attributed to mismanagement of the national economy, itself attributable to regime instability, the dis-enablement of rational planning and deployment of resources by centrifugal politics, primitive accumulationist inclinations of state officials and pervasive corruption and the absence or ineffectiveness of institutions of oversight. That characterisation of the state is another factor that contributes to the Nigerian political culture in that there is a dichotomy between the absence of relative independence and the nature of the federal government system with its backdrop of British colonial rule(Lewis 2003).

Whist successive regimes have made efforts to eradicate legacy attitudes and perceptions the reality is that such attitudes are endemic in the political system. The post-colonial state is still based on law and order, a key seal of the colonial heritage. Moreover, the colonial regime employed an authoritarian administration to coerce the population and sustain power. The 
military regimes also relied on the same style of government (Momoh and Adejumobi, 1999). The post-colonial, post military Nigerian state has attempted through the 1999 constitution, to encourage extractive and regulatory roles which found the systems by which natural resources are produced and distributed within the system of state capitalism. However the reality is that the state still accumulates resource wealth, relying on patron-client ties that dominate political relations between central government and the general populace.

In the colonial period, the Nigerian citizens had negative perceptions and attitudes toward the British government as well as the political beneficiaries of the system, such as the local chiefs. By its very nature colonial rule imported key European practices, so that the Nigerian people were effectively serving European interests. Consequently they did not develop an interest in the sustenance and wellbeing of their own country, which would have largely contributed to political notions of responsiveness, accountability and transparency. That legacy is evident in contemporary Nigeria where people lack interest in government businesses (Lewis 2003). Consequently, leaders can, and do, steal government funds with impunity in the pretence that they are acting in the interest of society at large.

It must be acknowledged that previous regimes have made efforts to address the political culture which creates such a negative view of central government. The creation of the 1999 constitution itself is an indicator that while prevailing practice is corrupt the standards of probity and fairness in government were recognised and are the good standard for which honest politicians strive to attain. Other examples include the creation of the Economic and Financial Crimes Commission (EFCC). In 1987, the regime of General Ibrahim Babangida inaugurated a federal directorate of mass mobilisation, Mobilization for Self-Reliance, Social Justice and Economic Recovery, best known by its acronym MAMSER. MAMSER is a 
government machinery for a new political order, meant to "inculcate new values, politically educate the adult, socialise the young and mobilise the masses for participation in the new order” Agbese (2012: 269). According to General Ibrahim Babangida in Agbese (2012: 22) the thrust of MAMSER to Nigerians involves;

“... a radical review of our external dependency, building our production process more on our own natural and human resources, switching our own growth engine from trading to production, avoiding waste and vanity, shedding all pretences about affluence, reversing our past life-styles. We must create social justice aimed at promoting equality of opportunity in all spheres of our national life.... We are convince that self-reliance is the strategy for building a new society, where our people can develop the consciousness of being the matters of their own destiny"

Another agency was inaugurated by the same regime, Directorate of Food Roads and Rural infrastructure also best known by its acronym DFRRI to complement MAMSER. Decree No. 4 of 6 February, 1986, supplement to Official Gazette Extraordinary No. 19, Vol. 74, 10 April, 1987, Part A outline the objectives and objectives of DFRRI, the main objective is to identify, involve and support viable local community organizations in the effective mobilization of the rural population for sustained rural development activities, bearing in mind the need for promoting greater community participation and economic self-reliance of the rural community. These programmes were abandoned by successive regimes so that there was no continuity in these programmes.

The distributive role of the government is a significant element of the Nigerian political behaviour (Lewis 2003). At a fundamental level central government is responsible for the distribution of national resources throughout the state in a fair and equitable manner, having regard the principles of the constitution and natural justice. The tendency not to achieve that 
duty has however hampered and obscured political and social developments related to public finance and according to the perception of most citizens, the government reserves free money for itself. According to Osaghae (1988) the Nigerian state cannot change such societal perceptions and achieve legitimacy without change. According to Graf (1988), Nigeria can only continue operating as one state if it changes and promotes and maintain the federalism system of governance. In 1954 Nigeria adopted federalism as a the most expedient principle of government but it has declined due to the establishment of additional states and the difficulty of governing a more disparate country. Adding to such difficulties comes the call for the creation of even more states so as ensure a more equitable from of authority, resource sharing and local political independence.

Regard must be had also to the Nigerian political culture of 'live and let live' and the apparent tolerance of the culture of competition for a share in resource and wealth development regardless of merit and need (cf 'laissez faire', the equivalent European principle leading to the free market culture of capitalist society). This however in practice leads to political competition being regulated through a dominant state authority (Lewis 2003) so that the elites dominate political life resulting in the real completion being between them and a disgruntled populace. Even so there is a degree of philosophic acceptance of that situation by which the masses acknowledge perhaps unequal competition as normal behaviour in the political climate of the country.

\subsection{Political engagement in Nigerian}

Commonly the generic term 'politics' has to do with power relations (Richard, 2000). Osaghae (2011:13) explains that politics involves, and has to do with, how individuals and groups organise themselves so as to pursue their divergent and often conflicting interests, 
why the state is crucial to this process, how and why domestic and external economic, social, cultural and other forces shape or influence this process, what major issues ensue from power relations and how conflicts are managed and resolved. That position simplified in an alternative view of the definition of the term as in 'who gets what, when and how' (Musa, 2014).

Richard (2000) and Axelrod (1997) suggest that political culture in any nation exemplifies how its history affects peoples' taking politics and society as a whole. Richard (2000) asserts that politics is the function of the immediate environment and are largely the same in any country, basing his view that general principles and theories apply across the political spectrum on the facts. Pieterse (2001) and Jhingan (2007) however offer an insight as to the unique nature of every state, this quality manifesting through different dimensions, namely, those in the political, cultural and social realms. Elaigwu (2007) further elaborates on the scope of those differences when he argues that the disparity in these dimensions makes political practices in different states disparate.

Pieterse (2001)and Jhingan (2007) consider however that Nigeria's political environment has a number of characteristics which distinguish it, for instance from the United Kingdom, so that is difficult to generalize about the prevailing political culture. Those obvious differences are based on the diversity of linguistics, cultures, regional boundaries, ethnicity and religion (Elaigwu, 2007).

\subsection{Specific factors which erode trust in the Nigerian political system}

\section{Authoritarianism and human rights}

Nigeria theoretically functions, in accordance with the constitution, as a federal government that fosters national development, yet when assessed on the specific criteria against which a 
democratic system is evaluated, it is categorized as an 'authoritarian' state; the 2008 Democracy Index (Musa, 2014). While the situation concerning human rights has improved since the era of the military regimes, violations have since been reported (Lawal, 2004). This prompts the question as to how far human rights violations promote or hinder political engagement and good governance in Nigeria.

\section{Corruption}

Corruption contributes to dysfunctional federalism in Nigeria and the elite strangulation of Nigerian politics and state, Susan (2004) and Victor (2002). An examination of how big a problem corruption is in Nigeria, and how significantly it contributes towards economic crises, poor governance and socio-political problems is critical. Kofele-Kale (2006) defines corruption as,

“ . . . 'requesting, offering, giving or accepting directly or indirectly a bribe or any other undue advantage or the prospect thereof, which distorts the proper performance of any duty or behaviour required of the recipient of the bribe, the undue advantage of the prospect thereof".

One of the central flaws of the Nigerian political system is prebendalism (Osaghae 2011) described by (Agbaje 1997) as practice of elected officials, government workers, and members of the ethnic and religious groups misappropriating government revenues believing that they have the right to do so. While the country earns trillions of Nigerian Naira (in \$USD) from its oil exports, corruption sullies the process with the result that revenue doesn't find its way into much needed development projects for the communities at large.. This corruption can therefore be closely associated with dysfunctional federalism as many officials convert the state and federal resources to personal use; 
In an article entitled, "Oil giant that runs on grease of politics," in the San Francisco Chronicle (March 11, 2007) Nigeria was described as a rich nation floating on oil wealth with “. . almost none of it flowing to the people." Nigeria has been described asa 'Kleptocracy', a nation ruled by an administration of thieves, a ruling body or order of thieves that hampers the societal progress (Susan 2004). According to Hali (2003) it will thus take a committed leadership for Nigeria to solve the corruption menace, and create a productive environment to move the nation forward (Hali 2003).

The Transparency International Index shows that Nigeria was at that time the most corrupt country in Africa (Susan 2004). Most administrations have made promises to eradicate corruption during pre-election manifestos but either have never taken sufficient action to honour such pledges or have been unable to do so in face of endemic and corrupt practices, (Daron 2003). The incumbent government's commitment to the maintenance of the rule of law and the 'war on corruption', its oft repeated mantra, would however seem to be extremely questionable as the increasingly high profile of corruption cases weakens the integrity of the existing federal and state institutions and the associated leadership; this has damaging effects on people's trust and interest in administration (Susan 2004).

\section{Deprivation}

The larger population lives in poverty because of widespread corruption and economic mismanagement (Adejumobi 2000). Violent insurgencies and community clashes in several Nigerian regions in protest against corruption (inter alia) threaten economic and political stability (Musa, 2014; Lawal, 2004). That society at large lacks the basic necessities of life is evident from even the simplest incursion into rural areas. Health care services are poor because hospitals in Nigeria are ill equipped and in general there is a shortage of medically qualified staff. People are reported to have died from minor ailments and it is has been 
proven that poor health affects people's productivity and the overall health of the economy (Victor, 2002).

\section{The political culture}

Although discussed extensively elsewhere in this study the scholarly evidence suggests that the Nigerian party administrative systems have not yet done enough to overcome the intricacies of party politics and made the more accessible to the population at large (Sklar 2004; Osaghae 2011; Agbaje 1997: 379). In fact the political parties have become a selfserving venture, unable to create and sustain a credible backdrop for good governance, imperative for socio-economic development (Kampen et al 2006; Adejumobi 2000).

\subsection{The effects of social and cultural disparities on Politics in Nigeria}

Nigerian political culture directly exemplifies religious, social and economic fragmentation as well as the polarization evident in the large populace. For instance the population of the northern states are quite distinct from those in the southern states, creating a culture of national differences. Such serious social separations between the prominent ethnic groups and religious separations between Christians and Muslims have caused enormous political conflicts within the regime since the groups are also divided along social, political and economic lines. As a consequence voting behaviour and political culture lead to inequalities which are rampant.

As with other third world countries, scholars have conducted studies investigating the political culture and for most it is evident that mass political culture is the major cause of unstable and fluid politics in the country Lewis (2003). Whilst the majority of Nigerians may think in national terms, and most consider Nigeria as a progressive country in terms of 
development, there are very diverse and competing groups who think differently. Boko Haran, for instance, militates for Muslim separatism and national cohesion is difficult to maintain in such circumstances. Such optimism for a fully developed Nigeria, so evident in the early years, has however failed to translate into sustained support of the successive Nigerian regimes. Consequently there has developed a climate of disappointment, mistrust and disillusion. Lewis (2003) describes Nigeria's political system as an unstable and overburdened system.

The key question for Nigeria as a whole is whether thee still exists the national will to take Nigeria forward and achieve federalism as provided for in its constitution. In this context the author's observations, perceptions and experience of the respondents in Ondo go some way towards an answer in the affirmative but only if action is taken to remedy perceived faults in the political culture and differences between disparate groups. In this regard it is worth referring to the bedrock of the system, the constitution, and quoting its guiding principles set out in the preamble as follows,

We the people of the Federal Republic of Nigeria

Having firmly and solemnly resolve, to live in unity and harmony as one indivisible and indissoluble sovereign nation under God, dedicated to the promotion of inter-African solidarity, world peace, international cooperation and understanding

And to provide for a Constitution for the purpose of promoting the good government and welfare of all persons in our country, on the principles of freedom, equality and justice, and for the purpose of consolidating the unity of our people

Do hereby make, enact and give to ourselves the following Constitution;- 
When asked, the respondents unanimously replied that achievement of those principles remain the national ambition and are still worth striving for, despite, or perhaps because of, the increasingly disparate nature of their country.

\subsection{Governance: the effect of the politicians}

Nigerian political parties have eroded the goals of good governance (Osaghae, 1988). High levels of corruption have created a culture of competitive business politics (Adejumobi and Kehinde 2007). From 1999 to 2007, Nigerian citizens suffered from governance crisis as they experienced human rights violations, widespread corruption, insecurity, increased democratic crisis, disillusionment, macro-economic instability, thereby losing confidence in the regime (Musa, 2014). It is apparent therefore that political parties contribute very significantly to the success or failure of good governance. Consequently, organization of the political parties in ensuring effective governance becomes important (Adejumobi and Kehinde 2007).

In 1999, Nigeria transformed into a nation with democratic governance (Agbaje and Adejumobi, 2006). The civil rights groups, labour unions and civil societies warmly welcomed the reoccurrence of democracy following persistent dictatorship for fifteen years (Adejumobi and Kehinde 2007). The political parties, accordingly, were expected to realize democracy and good governance since they act as platforms for political leaders to champion peoples' voices (Musa, 2014). Nonetheless, the programs and activities of most political parties have failed to foster good governance, a possible explanation for failed decentralization efforts (Agbaje and Adejumobi, 2006).

Based on the state of political culture in Nigeria, researchers reveal that individuals must affiliate themselves with blocks to succeed (Musa, 2014; Agbaje and Adejumobi, 2006; 
Agbaje, 2004). In shaping the Nigerian social, economic and political dimensions, associations and blocks are powerful influencers. The associations help individuals ready to associate with them (Adejumobi and Kehinde 2007). The ethno block groups, for instance, influence voting behaviour in Nigeria. The children have the tendency to vote based on the beliefs parents provide in affiliated associations.

The state dominant trends are equally significant in shaping the Nigerian political behaviour. The state guarantees accumulation of resources (Suberu 2010). So, majority of the business people join political parties in power to control their interests and amass wealth. Business people can therefore control resource distribution, promote their own interests and misappropriate public resources (Adejumobi and Kehinde 2007; Suberu 2011; Suberu 2010). Dependence on patronage rhetoric aimed at retaining legitimacy and political power, thus, is important as any political party which loses grip with local, state or federal tier loses its power to other parties, and there is no guarantee to win elections (Adejumobi and Kehinde 2007). The National advanced Party (NAP) case in 1979 is a good case example for the context. Several Nigerian segments and institutions, including social organizations, religious groups, politicians, academics, military and government bureaucracies, struggle for power (Momoh and Adejumobi, 1999; Okotoni (2001).

It is the view of Lewis (2003) that the limited participation of the citizenry in the process of governance is attributed to the serious and multitudinous development challenges in the country. This view is corroborated by Elaigwu (2005); and Suberu (2005) who went further in arguing that poor participation, of itself, has produced corruption which in turn creates a very weak economy, inflation, high unemployment, poverty coupled with diminishing educational standards and an increasing crime rate. All of the evidence points to the fact that 
limited engagement in the political process does not foster sustainable socio-economic development and the governance envisaged by the adoption of the constitution. In this regard Dike (2006) noted that.'. . . the political landscape of Nigeria is besieged by myriad of unreasoned policies-those that are hastily put together and poorly implemented.' There is growing evidence to support the widely held belief that crises affecting the nation's political economy is partially attributed to the authoritarian tendencies of the leadership at all levels and which discourages participation in the process of governance, Bolaji Akinyemi (2004).

For instance, almost every facet of the economy is being controlled by the President who by virtue of Section 5. 1. (a) of the Constitution has virtually complete executive authority vested in him. This is strongly suggestive of a lack of good governance, which by ordinary and accepted standards includes those factors referred to Chapter 2.4 of this study, and repeated for emphasis in figure 1 below;

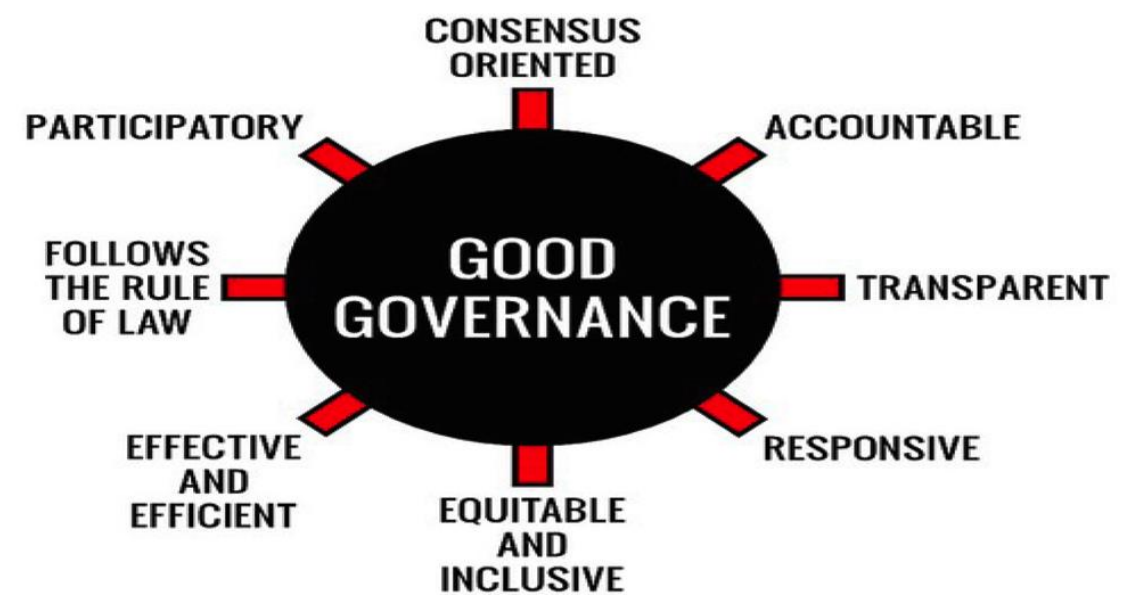

Figure 1: Indicators of good governance

The Nigerian states need transparency, efficiency and accountability, which are so lacking in its public sector (Darma and Ali 2014; Oni, Oni and Gberevbie 2015; Besley and Ghatak 2007). Agbu $(2004 ; 35)$ is of the opinion that there is too much control of the government by the executive to enable governance to be delivered. For instance, the President controls the 
on-going privatization process as well as the decisions in petroleum industry, including the pricing of the petroleum products, a function that stakeholders in the petroleum industry are supposed to address. To support the notion of the domineering role of the president, Suberu and Osaghae (2005:69), Bolaji Akinyemi (2004:4) and Wunch and Olowu (2010:3) note that the president also controls the elections process, determining which individuals take part in the process and who is corrupt and who is not. Moreover, makes decisions about the national budget, often allocating public fund without seeking approval from the National Assembly. Suberu and Osaghae (2005) find that the Nigerian system lacks transparency and the checks and balances generally found in a mature system of government, while at the same time, the people lack the freedom to challenge the autocratic leadership style that prohibit people participation and effective governance.

The discussions of Suberu and Osaghae (2005:69), Bolaji Akinyemi (2004:4) and Wunch and Olowu (2010:3) lead to the inescapable conclusion that the extent to which most of the institutional organs that carry out national functions, such the Independent National Electoral Commission (INEC), more often than not appear not to be independent, so that they lack accountability and transparency, both critical features of governance. Inherent in the notion of governance is that it flourishes only if sufficient opportunities and guarantees for political expression by all the people exist, people expressing themselves as individuals or in associations (Lawal 2004; Kehinde 2007). That implies the existence of all the characteristics comprising good governance as described in detail herein.

\subsection{Infrastructure: provision and enhancement by the distribution of resources}

Consumer and market participation in the economy necessitates durable supply networks frequently supplied by enhancements to the existing physical infrastructure, such as all- 
weather roads, clean water, railroads, ports and plentiful electricity, Bolaji Akinyemi (2004). The means by which the distribution of national wealth is achieved is by its percolation downwards from central government into the states and hence to local government for local projects, is through the political and physical infrastructure designed to achieve full federalism.

Empirical evidence about the way decentralization programs work in practice is scanty (Kampen et al 2006). More recent studies provide new evidence on the way locally elected government's function in delivering essential services to the Nigerian citizens, (Agba, Akwara and Idu 2013). Such evidence suggests limited accountability at the local levels, reflected in poor payment of workers, corruption among other challenges, a tendency that cannot be justified by appealing to the lack of resources the local governments have as provided by governments in higher tier levels (Agba 2006). Faced with the evidence of lack of accountability at all levels of government, there is need to explore some solutions taking into account the on-going policy discussions on high-level fiscal relations in Nigeria (Anazodo, Okoye and Chukwuemeka 2012; Bardhan 2002).

According to Agba, Akwara and Idu (2013), the goal of governments is to offer services likely to make life better for the citizens. Ogunrotifa (2012) also supports the same argument. Gani Fawehinmi as quoted in Anagwonye (2009:184), while analysing the Nigerian economy, point out that unsatisfactory government fails to address poverty in terms of food, health, education, energy and infrastructure. Based on this argument, local governments, as the third tier of government, are established to transform peoples' lives at the grassroots or rural levels (Bardhan 2002; Anazodo, Okoye and Chukwuemeka 2012). Local governments are therefore constitutionally obliged to manage four fundamental functions (Okoli 2000): 
1. equipment for local needs and corresponding services inside the capability and competence of local areas;

2. the provision of equipment for the implementation of federal or regional government policy at the local level;

3. the provision of a mechanism for the resolution of the conflicts of interest at the local level; and,

4. the provision of training grounds for political involvement and vocalization.

Delivering satisfactory, effective, sufficient and timely services to people at grassroots is one of the means to bring the government closer to the people (Anazodo, Okoye and Chukwuemeka 2012; Ogunrotifa 2012). Agba, Akwara and Idu (2013) examined social service delivery by the local governments in Nigeria, and found that the primary constitutional obligations given to the local governments have not yet, in general, been practically realized.

In fact the performance by most public organizations in providing effective service to the general public has lagged behind for decades despite investments made by previous government reforms (Adejumobi and Kehinde 2007, Anazodo, Okoye and Chukwuemeka (2012). Efforts geared towards transformation of public service and other administrative institutions for efficient and effective enactment have undoubtedly become pressing anxieties of the government as evident in the continuing social, economic and administrative reforms by the Obasanjo regime (Agba, Akwara and Idu 2013; Oni, Oni and Gberevbie 2015). The study by Agba (2006) provides a comprehensive analysis of the role of human resource management in effectively delivering under the decentralized regime in Nigeria. He advocates that the refurbishing and alteration of the Nigerian Civil Service to provide 
effective service to the general public does not depend on the continuous formulation of the reforms parameters that are dishonestly applied but rather in the effective human resource management system, complete transformation of citizens' attitudes, change in the value system and the reawakening of a fresh political order considered as foresighted leadership, (Agba 2006).

In any nation, whether developed, or developing, the provision of effective public services is a major factor for determining stability and development (Agba, Akwara and Idu 2013). The reason for this argument is that the public service is the route by which government responsibilities for the implementation of public policies, projects and the provision of indispensable services to the people are conducted (Darma and Ali 2014; Agba 2006). Numerous governmental regimes in Nigeria have endeavoured to reposition the public sector so as to deliver effective and efficient services using several reforms (Oni, Oni and Gberevbie 2015). In spite of all efforts, the Nigerian Public Service still remains inefficient and incompetent in delivering its constitutional responsibilities (Suberu 2010; Suberu 2009; Suberu 2011).

Recent research by Oni, Oni and Gberevbie (2015) adopts descriptive and analytical approach in Nigeria to evaluate the exponential development, usage and the acceptance of Information Communication Technology, arguing for a methodical shift from the outdated approach to electronic administration, which enhances the delivery of public goods and services, The essential role of the public service institutions in Nigeria's development accounts for the several reforms aimed at reviving the state to efficiently and effectively deliver its constructional responsibility (Darma and Ali: 2014). Similar to other African governments, Nigeria has attempted to improve the performance of its public service through 
changes aimed at increasing the capacity for quality public service delivery as well as effective performance of the major governmental functions regarded as fundamental in sustainable socioeconomic development (ECA, 2010; Ayodele and Bolaji 2007).

While improved productivity in the public service has been and is still the main aim, and a decisive factor for the existence and success of any nation, the move to attain improved productivity in the Nigerian Public Service has largely been wishful thinking because bureaucratic disorganisation continues to create obstacles (Okotoni 2001). Bureaucracies destroy the smooth operation of the whole civil service (Oni, Oni and Gberevbie 2015; Okotoni 2001). Consequently, it has adversely affected the delivery of public goods and services (Darma and Ali 2014; Besley and Ghatak 2007). In this context, the question that must be answered is what are the new strategies that could enhance efficiency, productivity and service delivery by the Nigerian Public Service?

Obaro (2005) suggests that poor service delivery in Nigeria reemphasises the significance of quality public services as key determinant of the health of any economy. He posited that the valuation of the strengths and weaknesses of the public service delivery system is important for formulating policies, and designing strategies and plans that foster good governance. For Cuadrado-Ballesteros, García-Sánchez and Prado-Lorenzo (2013) the, essence of public service includes the regime taking action to provide the citizens with definite assistance funded by taxation, and possibly by private and public joint ventures. Whereas the private sector is responsible for efficiently providing private goods and services, the public sector is responsible for the provision of public goods and services (Darma and Ali 2014; Ayodele and Bolaji 2007). The public sector, as a matter of fact, came into being as an instrument to battle 
lack of interest by private initiatives in establishing businesses that offer universal services at affordable prices, as proposed by Besley and Ghatak (2007).

According to Anwar (2005), treating all persons equally and allocating the resources based on the needs are the primary guiding principles delivering services to the public. OECD (1996) consider a more inclusive and broad aspect, and identifies the core components of quality public service delivery, including consultation, transparency, openness, information, satisfying user requirements, participation, accessibility, availability, accountability, timeliness and convenience (cf. the figure on governance in part 4.5 of this Chapter 4). In examining the reasons for failed decentralization, one particular question that may be posed is whether the Nigerian political system does de facto ensure transparency, openness, information, satisfying user requirements, participation, accessibility, availability, accountability, timeliness and convenience while delivering services to the public. The author will conclude (post) that based on the evidence and the literature that the answer is likely to be in the negative.

A point already made in a different context is that of Cuadrado-Ballesteros, García-Sánchez and Prado-Lorenzo (2013) who demonstrates that all regimes have had to address the problem of providing effective public services notwithstanding their financial means, and at a reasonably priced cost. Besley and Ghatak (2007) subscribe to the same position by noting that one of the main challenges universally, is how to improve public service delivery proportionately and most efficiently. Omotosho (2014:119) and Oduwobi (2011) observed that this situation is exacerbated in Africa generally, given the low quality of services provided and the needs of the poorest of people. Globally one of the main challenges is not only how to ensure functional, efficient, flexible and effective public service delivery, but 
also how to make the service providers accountable and ensure that the services are accessible to the citizens, Clarke and Clegg (1999); Omotosho (2014); and Barkan and Gboyega (2001). Therefore for majority of the African countries, Khemani Gauri and Gupta (2004), Cuadrado-Ballesteros, García-Sánchez and Prado-Lorenzo (2013) and Suberu (2010) agree the inequitable distribution of resource, weak governance and poor quality of public services remain unresolved. That this is equally so in Nigeria is overwhelmingly made out by the literature.

The old-fashioned focus of the theoretical government has classically paid either little or no attention to the public service delivery approaches, making effectiveness and efficiency in big bureaucracy progressively sub-standard (Ayodele and Bolaji 2007; Cuadrado-Ballesteros, García-Sánchez and Prado-Lorenzo 2013; Clarke and Clegg 1999; Okotoni 2001). Among the developing nations, (Barkan and Gboyega (2001) regard Nigeria among those that have decentralized services delivered, particularly education and basic health. The research by Khemani Gauri and Gupta provides evidence on how decentralization in Nigeria functions in relation to service delivery institutions in efforts to promote public accountability and good governance. Several scholars (Oni, Oni and Gberevbie 2015) have observed the following defects in contemporary Nigerian service delivery:

a. nepotism where individuals in with influence and power favour their friends and relatives by providing them job opportunities.

b. corruption where individuals in power engage in fraudulent and dishonest activities; it is reported that they both give and receive bribes.

c. delay in decision making and implementation where local leaders cannot take immediate actions to address problems raised by the citizens because of the weight of bureaucracy; 

d. absenteeism is prevalent, particularly in government offices;
e. unresponsiveness to the general public needs and concerns
f. inappropriate supervision and resistance to change;
g. wastage of government resources due to corruption and inefficiency;
h. the violation of codes of ethics.

Musa (2014) posits that there have been numerous attempts by various Nigerian regimes to address such challenges. Such interventions have, however, achieved minimal economic growth that does not significantly improve human development Osaghae (2011). There is generally a lack of continuity in the programs. For example, at the inception of a new government, the programs of development of successive government are frequently abandoned. Rahman and Achi, (2005:113) citing poor coordination by government officials points out that none of the programmes of each political regime aiming at reducing poverty have been able to significantly reduce poverty as well as engender development. For example, the late General Sani Abacha regime's (1993 to 1998) Family Economic Advancement Programme, instituted an anti-poverty strategy aimed at lifting rural families from poverty and spent an estimated NIO billion of oil revenues without any major positive impact on reducing poverty incidence in the country (Osaghae, 2011).

The 2013 USAID report affirms that Nigeria has enjoyed relatively strong economic growth over the past seven years, but that poverty is still a major concern. In the same vein, the World Bank Economic Report of Nigeria states that the size of the Nigerian economy is $170 \%$ times larger today than at the beginning of the decade. Reported growth in the non-oil economy has been even higher, implying that the Nigerian non-oil economy is now $240 \%$ times higher than a decade ago. However, the same report notes that economic and human 
capital development are still constrained by inadequate infrastructure, electricity, incentives, and policies that promote private sector development, and poor access to quality education (World Bank, 2013). See figure 2.

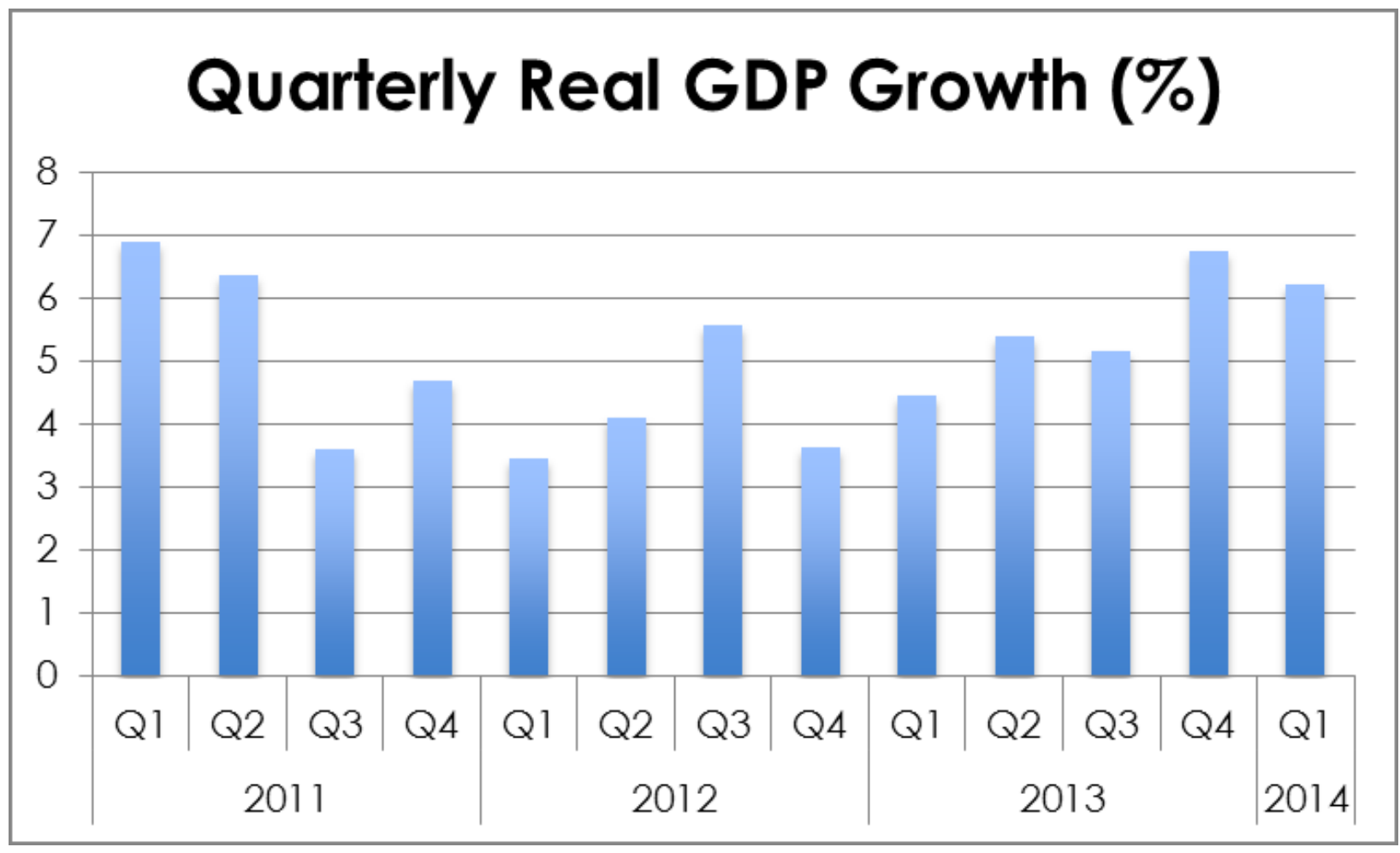

\section{Figure 2: Nigerian economic report of 2013}

Source: Nigeria Bureau of Statics.

Figure 2shows that in the first quarter of 2014, Nigeria's Nominal Gross Domestic Product, GDP (at basic prices) was estimated at N20, 169,778.04 million. In the corresponding quarter of 2013, nominal GDP was estimated N18, 295, 631.91. As a result, the growth rate of real GDP was recorded at $6.21 \%$ in Q1 2014, higher than $4.45 \%$ recorded in the corresponding quarter of 2013, but lower than $6.77 \%$ recorded in the fourth quarter of 2013. 
Table 4: Nigerian poverty rates

\begin{tabular}{|l|l|l|}
\hline \multicolumn{2}{|l|}{ 2013-2014 } & 2009-210 \\
\hline \multicolumn{2}{|c|}{ Per Capita } \\
\hline Poverty Rate & 64.2 & 62.6 \\
\hline Urban Poverty & 52.2 & 51.2 \\
\hline Rural Poverty & 73.4 & 69 \\
\hline Adult equivalence & & \\
\hline Poverty rate & 48.3 & 46.1 \\
\hline Urban Poverty & 36.8 & 34.3 \\
\hline Rural Poverty & 57.4 & 52.9 \\
\hline
\end{tabular}

Source: The World Bank Data on Nigeria Economy Report.

Table 1 show that poverty rates remain high in Nigeria, particularly in rural areas. These rates declined between 2003-2004 and 2009- 2010, although not nearly as fast as would be expected were it to match the pace of economic growth in the country.

\subsection{The creation of States}

Political instability is still evident in the local and state levels. For instance, there were three regions at the inception of federal system in Nigeria, however the number has increased and currently, there are now thirty-six. The local governments and federal territories have also increased from three hundred and six and seven hundred and seventy four respectively as at 2014. Changes in the Nigerian government translate into new formations and policy changes; most alterations usually destroy old political cultures. Enormous institutional, policy and structural changes come from government changes at state, local and federal tiers. 
Government departments, parastatal agencies and ministries have continuously been restructured by consecutive regimes.

The changes have also been reflected in financial regulations, taxation and revenue allocation systems. The contest for political power and resources for development in Nigeria has continuously increased the agitation for the creation of more states to ensure a more inclusive distribution of resource. Based on the earlier analysis of the interactions of ethnic groups in Nigeria, it is apparent that there is consistent political and economic rivalry. State creation is a means of accessing power and resources and it therefore an important aspect of national debate. Since Nigeria attained independence, fragmentation of the federation has occurred six times; $1963 ; 1966 ; 1976 ; 1987 ; 1991$ and 1996. As a result the creation of states and local governments has thrown up issues that impact on political structures and development.

State creation constitutes major conflict among the three major ethnic groups on the one hand, and the conflicts between the major and minority ethnic groups on the other. For example, the minority ethnic groups agitate for separate states to protect themselves against the domination and subjugation by the larger ethnic groups. It appears that the agitation is widespread as the states are the major means of control of power and resources. In response to this notion Suberu (2009) and Suberu (2010) argues that the states, as they are configured, function as the structural and administrative conduits for the devolution of centrally collected revenues, which are allocated to the states mainly on the basis of the dual principles of interunit equality and relative population. The military government fragmented the federation of the four regions to twelve states in 1966, with the goal of curbing the violent ethnic separatism tendencies that had developed around the old regional system. The move, subsequently, provoked civil war over the attempted secession of the Eastern Region as an 
independent Republic of Biafra (Moreno and Colino 2010: 233). In effect, the decision to create twelve states in 1966 was informed by the desire to safeguard Nigeria as a nation. Moreover, Alapiki argues that the creation of the twelve state structure of the federation was a conscious effort to 'balance' the south and north, giving each region six states (Alapiki: 2005).

Campaigning for state creation has been a significant political issue even though some development concerns underlie the campaigns (Suberu 2009). The motivation behind the creation of states has been to bring the government nearer the people while, encouraging participation of the local people, so ensuring equal development within a federal structure of the government (Suberu 2010). Additionally, the demand for more states has been fuelled by rapid economic development (Alapiki: 2005). Essentially, scholars have put forth reasons for creation of more states in Nigeria (Suberu 2010; Alapiki: 2005; Suberu 2009; Suberu 2011). Based on the push for the creation of states two questions emerge. The first is the extent to which the creation of states has enhanced peace, cohesion, equity and justice. In other words, has the creation of states solved the problems of disunity, violence, agitation and secessionist tendencies. The second is the extent to which the creation of states engendered development. Informed opinion answers both of those questions in the negative, (Suberu 2009).

Nonetheless it is important to examine the positive effect of state creation and contrast it with the negative effects. Some scholars have argued that fragmentation of Nigeria over the years has significantly reduced the tendency of secession and disintegration. For instance, Suberu (2010) argues that the present fragmentation has created a situation that no single constituent unit of the federation is large enough to challenge the authority of the federal government, threaten secession, or dominate other states. To this extent, Suberu (2011) argues that the 
initial reason given for state creation has been substantially achieved. Conversely, this attainment does not stop threats of secession and violent ethnic and religious uprisings, Momoh and Adejumobi (1999). In fact the creation of states appears to exacerbate ethnic tension and restiveness amongst the different Nigerian ethnic groups and interests, Musa (2014). Importantly, it appears that as more states are created, the states are becoming weaker and the federal government is correspondingly becoming stronger, Moreno and Colino (2010).

The implications are that the greater the number of states, the weaker and less viable individual states will become. Consequently, the centre regime would actually gather more power and initiative (Diamond, 1987). Further, the condition implies that the creation of more states will make the states so small and will not have the capacity to check the excess of the overbearing centre. This has been playing out in the intergovernmental relationship of Federal-state relationship (Alapiki: 2005). Some suggest that in the Nigerian state creation efforts, winners and losers have emerged. For instance, Alapiki (2005) notes:

“. . . each state creation exercise in Nigeria, significantly, was accompanied by attendant effects that actually exacerbated pre-existing interethnic and intergroup conflicts rather than relieving them. The August 27, 1991, events are particularly interesting in this regard."

He went on to break such events down into three constituent features as follows;

"First, they demonstrate clearly the low level of political integration among the various peoples and communities that make up Nigeria. Second, the exercise was greeted with violence, rampages, and public demonstrations unsurpassed in the history of state creation in Nigeria. Third, the displacement of "non-state indigenous persons" and the subsequent "asset sharing" 
controversies among affected state governments were unprecedented. Instructive, too, is the fact that the violence and public demonstrations took place in all the geopolitical zones of Nigeria."

Ojo and Adebayo (2008) similarly support the argument put by Alapiki (2005). They explain that there is a considerable merit in the demands for an equitable spatial spread of economic development (a) through the creation of more states and local government areas; and (b) through effective engagement in physical (spatial) planning which is sometimes referred to as Urban and Regional Planning. Conversely, from an economic viewpoint, academics argue that there appears to be no justification for the creation of more states in Nigerian in the foreseeable future as virtually all the existing thirty six states are not economically viable (Ojo and Adebayo 2008).

The current fiscal arrangement made states rely on the Federal Government for subvention and allocations to fulfil their constitutional roles. As a consequence most of the states are insolvent so that few states in the federation appear viable on the strength of their secondary and tertiary industries alone (Suberu 2010; Suberu 2011; Suberu 2009). In general, the evaluation on the rationale and actual creation of states reveals that it has further compounded the fear of the minority groups, thereby promoting more agitation, and throwing up new interest groups (Alapiki 2005; Suberu 2010; Ojo and Adebayo 2008; Suberu 2011; Suberu 2009). On the issue of development, Ojo and Adebayo argue that apart from the expansion of bureaucratic and physical infrastructure in the newly established administrative headquarters, the developmental (as distinct from distributive) value of new financial devolution which accrues to the new constituent units from the revenue sharing system is immediately consumed by administrative overheads and new patronage positions, which leaves little resources for real development (Ojo and Adebayo 2008). 
Nigerian nationalism originates from three primary sources. First is the settlement of the slaves in West African coast which group established its own political culture. The second are, the soldiers from the Second World War, following failure to be recognized by the British government, who also formed their own culture and identity. The last element of nationalism originated from Nigerian students who studied overseas. It was these three nationalistic associations that brought forth ethnic groups during struggle for independence.

The current state structure of Nigeria is set out below in Table 2 .

Table 5: Nigerian states

\begin{tabular}{|l|l|l|}
\hline State & Date Created & Preceding Entity \\
\hline Abia State & 27 August 1991 & Imo State \\
\hline Adamawa State & 27 August 1991 & Gongola State \\
\hline Akwa Ibom State & $23 \quad$ September & Cross River State \\
\hline Anambra State & 27 August 1991 & (old) Anambra State \\
\hline Bauchi State & 3 February 1976 & North-Eastern State \\
\hline Bayelsa State & 1 October 1996 & Rivers State \\
\hline Benue State & 3 February 1976 & Benue-Plateau State \\
\hline Borno State & 3 February 1976 & North-Eastern State \\
\hline Cross River State & 27 May 1967 & fastern Region; known as South-Eastern State \\
\hline & & \\
\hline
\end{tabular}




\begin{tabular}{|c|c|c|}
\hline Delta State & 27 August 1991 & Bendel State \\
\hline Ebonyi State & 1 October 1996 & Enugu State and Abia State \\
\hline Edo State & 27 August 1991 & Bendel State \\
\hline Ekiti State & 1 October 1996 & Ondo State \\
\hline Enugu State & 27 August 1991 & (old) Anambra State \\
\hline Gombe State & 1 October 1996 & Bauchi State \\
\hline Imo State & 3 February 1976 & East Central State \\
\hline Jigawa State & 27 August 1991 & Kano State \\
\hline Kaduna State & 27 May 1967 & $\begin{array}{l}\text { Northern Region; known as North-Central State } \\
\text { from } 1967 \text { to } 1976 .\end{array}$ \\
\hline Kano State & 27 May 1967 & Northern Region \\
\hline Katsina State & $\begin{array}{l}23 \text { September } \\
1987\end{array}$ & Kaduna State \\
\hline Kebbi State & 27 August 1991 & Sokoto State \\
\hline Kogi State & 27 August 1991 & Kwara State; Benue State \\
\hline Kwara State & 27 May 1967 & $\begin{array}{l}\text { Northern Region; known as West Central State } \\
\text { from } 1967 \text { to } 1976 .\end{array}$ \\
\hline Lagos State & 27 May 1967 & Federal Territory of Lagos and Colony Province \\
\hline Nasarawa State & 1 October 1996 & Plateau State \\
\hline Niger State & 3 February 1976 & North-Western State \\
\hline
\end{tabular}




\begin{tabular}{|l|l|l|}
\hline Ogun State & 3 February 1976 & Western State \\
\hline Ondo State & 3 February 1976 & Western State \\
\hline Osun State & 27 August 1991 & Oyo State \\
\hline Oyo State & 3 February 1976 & Western State \\
\hline Plateau State & 3 February 1976 & Benue-Plateau State \\
\hline Rivers State & 27 May 1967 & Eastern Region \\
\hline Sokoto State & 3 February 1976 & North-Western State \\
\hline Taraba State & 27 August 1991 & Gongola State \\
\hline Yobe State & 27 August 1991 & Borno State \\
\hline Zamfara State & 1 October 1996 & Sokoto State \\
\hline Abuja Federal Capital & 3 February 1976 & Benue-Plateau, North-Central, and Norn States \\
\hline & & \\
\hline
\end{tabular}

\subsection{Politics and Socio-economic Development}

The relationship between politics and socio-economic development, and the consequences thereof, has been a persistent issue in the debate and analysis of Nigerian federalism (Adejumobi and Kehinde 2007). The debate has several components and perspectives and by reference to a number of opinions Osaghae (2011) categorizes them into five distinct areas, each with differing sub-sets;

(1) ethnicity, ethnic pluralism and ethno-politics; Nnoli (1978); Diamond (1988); Osaghae (1986); and Otitie (1990); 
(2) institutional, process, governance and democratisation: (Awa, 1964; Oyediran, (1979); Mahwood (1980); Oyovbaire (1985); Jinadu (1985); Ayeni and Soremekun(1988); Diamond (1988); Dent (1989); Ekeh and Osaghae (1989); and Bach (1989);

(3) the political economic approach, with emphasis on class and materialist forces, the role of oil in the economy as well as dependency-underdevelopment perspectives: Panter-Brick (1978); Nnoli (1981 and 1993); Ake, (1985);and Onimode, (1982 and, 1983);

(4) the civil military perspectives: Adekanye (1981; Dudley (1973 and 1982; Miners, (1971); Luckman (1971); Odetola (1978 and 1980); and Agbese (1991);

(5) statist and state-society perspectives, including political culture perspectives such as client/patronage politics, prebendalism and the system of values; Okpaku (1972; Oyobaire (1987); Williams (1980; Ekeh(1975 and 1989); Dudley (1973 and 1982; Ajayi and Ikara (1985); Joseph (1987 and 1996); and Lewis(1996).

Each of those perspectives can be discussed in isolation however an assessment of their interaction as a series of inert-related factors is preferred for the purpose of this study.

To this end, the analysis of the politics and development in Nigeria in this section takes a historical approach which provides a general understanding of the issues of the Nigerian politics and development (Adejumobi and Kehinde 2007).The quest for development and oil revenue play significant roles in the structure of the Nigerian federalism and based on this notion Elaigwu (2007:25) indicates that the prospect of decolonization led to competition for power among the different groups in order to control the dispensation of resources. Development presupposes mechanisms and processes for its actualisation, Adejumobi and Kehinde (2007). A sound economic base and effective political processes are therefore 
fundamental mechanisms that drive development and the intersection of politics and development is situate within the conceptual framework of development as a multidimensional process involving reorganization and reorientation of the entire economic and social systems, Rostov (1960: Leys (1996): Pieterse (2001): and Jhingan (2007). Development, therefore, involves the creation and maintenance of institutional, social and administrative structures.

The politics of Nigeria are expressively dictated by the struggle for political and economic control of the available resources of the country, Elaigwu (2008; Nnoli (2008); Wunsch \& Olowu (1990); and Osaghae (2011). Consequently competition has arisen between the players within ethnic and factional politics, Nnoli (2008). The effect of this situation has been and remains a persistent and real threat to the stability of Nigeria as a nation and the many incidences of underdevelopment, Musa (2014). Hence, the observable failure of Nigeria as a cohesive nation capable of building a workable system of government and an economy that is sustainable and effective in the provision of the legitimate and credible process of governance essential for public good is evident Adejumobi and Kehinde (2007; Lewis (2006: 54-85).

Among other things, the USAID (2003) economic report on Nigeria entitled: Nigeria Economic Growth Activities Assessment, states that despite the fact that Nigeria has the advantage of manpower (the largest black population in the world)and enormous natural resources, principally oil (it is the sixth largest oil producing country in the world) there is no corresponding human and social development, rather what obtains is a poorly functioning economy (despite historical increases in GDP referred to in 4.6 of this chapter) and a dearth of development. Osaghae (2011) attributes this overall condition to failed economic policies, manifest in the level of poverty and the poor state of the national infrastructure. The USAID 
report notes that half of the adult population is illiterate; there are apparent gender disparities in education; and high maternal mortality rates. Public utility services are among the worst in the world, with at least two-thirds of households not connected to electricity, with access to water being extremely limited; unreliable urban transportation; and an average of fifty households for each telephone land line. It has disturbing ethnic rivalries that regularly flare into communal violence and Nigeria is rated as the world's most corrupt country.

The key features of democratic governance include rule of law, freedom to choose the leadership, accountability, freedom of expression and elective representation amongst other factors (Adejumobi and Kehinde 2007). Miles (1988) argues that being a government system, democracy seeks to attain overall common good via collective discussion of the policy questions about the public affairs, and the power is given to agents who implement decisions made through the majority vote. Thus, democracy in the modern era involves expressing popular will using elected representatives (Adejumobi and Kehinde 2007; Musa, 2014).

Compared to other nations, the Nigerian democratic government seems disparate (Agbaje and Adejumobi, 2006). From 1999 to 2007 Nigerian citizens never fully experienced the rule of law and respect for the human rights, one of the key attributes of good governance. In Nigeria, election violence and rigging have been prevalent, and barely separating autocracy from democratic governance (Agbaje, 2004). Foreign policy in Nigeria has been based on leadership perception, stressing the significance of responsibility toward development and the liberation in Africa as a continent. Among the educated classes living in urban centres in Nigeria, this perception has been driving political behaviour. 
Current politics in Nigeria are viewed in terms of standards of a civilised nation (Pereira, 2006). In civilized political emancipation, society is ready to leave regimes or political parties that under-perform (Adejumobi and Kehinde 2007). Order transformation, expediency by the government in power and performance puritanism is current in the priorities of government. Nonetheless, backwardness in policy development is still apparent (Lawal, 2004). Historically, policy development in Nigeria is frequently disarticulated from implementation (Adejumobi and Kehinde 2007). The National Executive Council and National Conventions are the examples of available party structures being responsible for formulating polices, but still policies which are implemented only reflect the desires of political leaders rather than those of the organs of state and the majority. Political party life lacks public participation and debate on policy alternatives (Toyo and Aremu, 2003); Party reforms are so challenging because of complex methods used, which lack democracy so political parties must prioritize on policy development to foster good governance and economic development (Miles, 1988).

To a very large number of Nigerian citizens, education is absolutely vital (Adejumobi and Kehinde 2007). They consider attaining degree level education as a prerequisite for social and economic personal progress (Pereira, 2006). While a number of them demand universal education, others do not support the idea, giving rise to conflicts and disagreements in policy. The number of men and women enrolled in educational institutions varies significantly pointing to inequality of opportunity (Toyo and Aremu, 2003). While English is the official language, the majority of the Nigerians consider it as second language, reverting to their own traditional languages and dialects. Pereira (2006) is of the very firm view that to enable individuals to play a significant role in the Nigerian politics, they need education and a good command of English. By contrast, state officials and politicians generally have more access to education and use their elevated status to dominate the less well-educated majority. For 
instance individuals with a formal education can far more easily access government contracts than those without (Adejumobi and Kehinde 2007).

Education has other benefits and according to Pereira (2006) few educated individuals trust the government as they seek to reap the benefits of booming oil economy. In general most citizens still remain cynical about the underlying motives and agendas of politicians while formulating national development policies given that the media portray political life as full of corruption (Pereira, 2006).

\subsection{Service delivery Institutions}

Under the civilian regimes the Nigerian federation has experimented with two types of federal structure since independence, the Westminster-style parliamentary system (1960 to 1966) and the U.S.-presidential system (1979-1983 and 1999-date). In between there were the years of military rule, with its unitary hierarchical structure and intrinsic arbitrariness and authoritarianism (Adamolekun 1991: 5), the process being described as 'military federalism'.

The immediate post-independence Nigeria operated under a parliamentary system. Adamolekun (2005) has highlighted three main features of this era. Firstly, that each regional government was free to determine its own economic and social development policies. Secondly a strong incentive was built into revenue-allocation formulae, with $50 \%$ assigned according to the derivation principle; this meant that each region had to mobilize resources that would be used to implement its development plan (Adejumobi and Kehinde 2007). Thirdly, there was an increasing desire to provide 'life more abundant' for the citizens in their respective regions, leading to the emergence of informal competition (Adamolekun 
2005; 386). For example, the Northern government was determined to match the Western government achievements in terms of education and commerce.

Institutional development was therefore required hence the establishment of tertiary organizations in the regions. An example was the system of Regional Development Boards administering the newly created marketing boards (Adejumobi and Kehinde 2007). Such marketing boards were created to facilitate exports of the principal crops of the country on a world economy competitive basis and their function was to stabilize local cash crop prices to provide some stability for producers. In addition they were given the responsibility of fixing of carrying out price support and stabilization of policies, and the financing of research (Nnoli 2008: 234). Since the principal crops are cocoa, palm oil, groundnut and Cotton, there was a Cocoa Marketing Board in the West, the Palm Oil Marketing Board in the East, and the Groundnut Marketing Board and Cotton Marketing Board in the North. These became some of the institutions designed to standardize and improve production practices and ensure that producers received value for their crops.

\subsection{Political parties, Politicians and elections}

\section{Recent history}

The Military and the political parties are the two central institutions that have influenced and continue to shape the dynamics of the Nigerian federal state (Musa, 2014; Osaghae, 2011). Both institutions have produced political leadership over a number of years, even though the method through which leadership emerges is essentially different (Musa, 2014; Adejumobi and Kehinde 2007). While the military used coup d'états to seize to power, access to leadership in the political arena is premised on an electoral process (Momoh and Adejumobi, 1999; Agbaje and Adejumobi, 2006; Agbaje, 2004). 
According to Osaghae (2011) the role and the impact of the Military on the Nigerian federalism cannot be overstated. It is however, instructive to note that the long years of military incursion into governance has also affected the development of party system in Nigeria (Amuwo, Agbaje, Suberu and Herault 1998). As Agbaje, (1997) argues, all of these has contributed significantly in robbing the party system the opportunity to develop capacities and appetite for its traditional role of deepening democracy and civil activities through political parties. Previous arguments in such research provide analysis of the extent to which the military governments have impacted on the nature, structure and character of Nigeria federalism (Agbaje and Adejumobi, 2006). It is common ground therefore that the centralized and unitary character of Nigerian federalism is essentially of a military heritage. On the other hand, the role of political parties and politicians remain fundamental in analysing the success or failure of federalism in Nigeria (Osaghae 2011). Since military involvement in the Nigerian political scene has now ended, this analysis centres on the Nigerian political parties (Adejumobi and Kehinde 2007).

In this context, Nigeria has had some regimes that permit popular participation but equally others that fail or refuse to allow for such participation. The first and second republics, for instance, introduced provisions for emergency rule, so denying their opponents voting rights or opportunities for political expressions (Kehinde 2007). In other regimes (Babangida and Abacha), Momoh and Adejumobi (1999) noted that the opponents were randomly arrested for criticising the politics of the ruling party who operated akin to a dictatorship. Unlike other third developing country dictatorships, such as Iraq under Saddam Hussein, the media has largely remained free to comment on the political landscape without undue suppression, this has resulted to some extent in a participatory role in the institution of government by the 
press. Furthermore, Suberu and Osaghae (2005) state that successive regimes have allowed interest groups to criticize them politically and publically.

\section{The democratic process}

The essence of liberal democracy is competition for political authority judged by a free electorate exercising free choice from amongst the available platforms offered through political parties whether they be single issue of multi faceted (Amuwo, Agbaje, Suberu and Herault, 1998). It is that competition for power by which representation and participation in the process of democratic governance occurs (Adejumobi and Kehinde 2007). While some people presume that the alignment of political parties is largely directed by the voters the opposing view is that it is the political parties themselves who are responsible for creating visions to mobilize voters by way of their election manifestos (Musa, 2014).

Democracy is the process by which an electorate freely expresses itself against the backdrop of the choices on offer by competing political parties. Inherent in that is that there is more than once choice on offer otherwise the resulting system is likely to be an autocracy, benevolent or otherwise. Democracy produces and results in government likely to represent the wishes of the majority of voters (Agbaje, 2004). Miles (1988), Agbaje and Adejumobi (2006) and Musa (2014) provides the following as the manner by which democracy is expressed through the function of the political parties: (a) generating government policies and programs; (b) encouraging candidates to stand for public office; (c) effective control of government agencies; and (4) societal integration through effective function of government.

In general, political parties are crucial in good governance- centre of democratic governance (Musa, 2014). Political parties provide platforms for collective action, legitimacy, inclusiveness, accountability and popular participation through amalgamated ideologies, 
goals and competing principles (Weingrod, 1977; Adejumobi and Kehinde 2007). So, they mediate agency and personnel affairs with the peoples' affairs (Lawal, 2004).

\section{The party (ies) politic}

Political parties hold a special place in any discussion about democracy (Weingrod, 1977). Their very existence forms an essential part of what defines liberal democracy and how they operate in no small measure determines whether or not democracy will endure. According to Sklar (2004), the basic foundation of political parties in Nigeria is predicated on a multitude of associations devoted to community improvement, political reform and racial liberation. Such diverse interests remain contentious and highly volatile issues within the Nigeria political parties (Adejumobi and Kehinde 2007). According to Amuwo, et al (1998) the majority of Nigerian political parties develop the national system that shares "the national cake" equitably amongst the citizenry.

Political parties are authentic instruments for championing democracy; Nigeria has twentyfive registered parties. Apart from being used to capture political power, political parties are instruments used to satisfy the interests of people through government control. In addition they help sustain democratic governance. Amuwo, et al (1998), further emphasise that the accountability level in public life is determined by; the extent political parties freely represent and articulate citizen' concerns. Coalitions develop between parties of a similar outlook creating a complex system of politics.

From the earlier discussion, it is apparent that there were some highly active political parties before Nigeria achieved independence, increasing number during the first and second republics (Adejumobi and Kehinde 2007). In addition the military government created two new political parties as part of the planned transformation to the third republic that ended 
with the doomed presidential election in 1993 (Momoh and Adejumobi, 1999). The Abacha regime that followed disqualified virtually all opposition and that ban remained effective the constitution was put in place. The death of Abacha in 1998 permitted the creation of new political parties (Adejumobi and Kehinde 2007). They were different from the previous parties established during the second republic and scholarly opinion is generally that they had little in common with the earlier institutions. Some of those differences grew out of the fact that they were permitted to be structurally (if not philosophically) autonomous from the departing military government (Momoh and Adejumobi, 1999).

In total, nine political parties were legally recognized but of them only three recorded good performance in the state and local elections of 1999 for both the presidential and the legislative elections (Adejumobi and Kehinde 2007). Out of those three however certainly two had close associations with the military (Momoh and Adejumobi, 1999). The People's Democratic Party (PDP) was founded by those opposed the Abacha administration in the mid-1990s and though most of them had been imprisoned by the regime they emerged to form this new party. There had been rumours that the PDP also had close ties with the military, particularly to former President Babangida supporters, who is believed to have contributed about \$18 million to the party's reserves (Adejumobi and Kehinde 2007). Others were the All People's Party (APP) and the Alliance for Democracy (AD) which claimed to have had serious democratic credentials.

According to Sklar (2004) political parties represent the social forces that shape and transform the structure of the society, formed to represent diverse interests. These are constituent parts of the political landscape (Musa, 2014). Political parties are the platforms for like-minded people to organize and inaugurate their interests as guidance for government 
action (Amuwo, et al 1998). They set and execute the societal agenda, (Musa, 2014) but according to Schumpeter (1961:279), the primary aim of each political party is to prevail over other parties, win elections in order to acquire political power or mandate to rule.

\section{The electoral process}

Musa (2014) views an election, in the broad sense, as the process by which individuals are selected to occupy organizational, government or institutions positions. Democratically, it is normally expected that candidates chosen via the electoral process exemplify specific policy platforms commanding electorate support (Agbaje, 2004). In this context, Agbaje and Adejumobi (2006: 26) suggest that elections express the sovereign will of the citizenry it being the job of the political parties to provide the platforms for candidates seeking office (Adejumobi and Kehinde 2007; Weingrod, 1977).

The 2015 general election represented a significant shift in attitude in that after losing his reelection bid, President Goodnight Jonathan phoned his rival to concede defeat. Will Ross, of the BBC, report that, "The fact that Goodluck Jonathan phoned the opposition's Muhammadu Buhari to congratulate him is a massive moment for Nigeria." It was widely recognized that that call signaled the country's first peaceful democratic transition of power, ensuring that the tensions of the campaign wouldn't spill over into post-election unrest. Observers commented that Jonathan's gesture also went a long way toward healing Nigeria after an election that took place against a backdrop of violence in which the President was criticized for not responding sooner to the threat of Boko Haram. ${ }^{14}$

\footnotetext{
${ }^{14}$ https://www.pri.org/stories/2015-03-31/goodnight-goodluck-nigerias-president-concedes-election-defeat
} 


\section{Ethnicity}

Ethnic interests continue to play a major role in political parties, in terms of power negotiations and ascent to political offices (Agbaje and Adejumobi, 2006). Conversely the appearance of ethnic conflict in the Nigerian national politics actually masks a more complex struggle between interests that were non-ethnic in nature (Lawal, 2004). Yet another view is that of Musa (2014) who considers that there are still elements of ethnic loyalty and identities attached to the parties, although, such trend appears to be minimal.

\section{Female participation}

Women too have come to assume a varied role in Nigerian politics (Toyo and Aremu, 2003). This however is more apparent in the south as the north, which has Muslim influence, exercised restrictions on the role of women generally (Adejumobi and Kehinde 2007). By contrast in the central east, women still have some rights and if nothing else this illustrates the disparity in culture across the country, a factor which figures greatly in the absence of political unity. Women are enfranchised but overall representation in local politics is extremely low by comparison with their place in federal government (Toyo and Aremu: 2003).

\section{Malpractice}

Adejumobi (2000) notes that vote rigging and other means of coercion have been customarily practiced by all major parties since independence in order to retain power. According to Joseph 1987; Sklar (2004) and Osaghae (2011) the electoral process in Nigeria has always been fraught with challenges, before, during and after the elections, a demonstration of poor participation by the citizens. The challenges range from the use of violence, monetary inducements, outright rigging of election process and results, and 'the elite behaviour that not only used government resources to reward loyalists and punish opposition but show disdain for the voting power of the civil society', (Sklar 2004). There is also the mentality of 
'Whether you vote for us or not we would remain in power' (Agabje 1997:374). This has increased the sense of fear, a lack of confidence in the process and, consequently, the level of participation and apathy on the part of the electorate during elections (Adejumobi 2000). There seems to have been an improvement in the general elections of 2011, although the level of scepticism on the part of the electorate remained high, as the number of challenges to the process after the election underscored the quality of the electoral process (Osaghae 2011). As referred to above (in this section 4.4) the circumstances surrounding the 2015 election might have marked a new milestone in the development of democracy in Nigeria although it is too soon to draw supportable conclusions.

Corruption has dramatically increased because of the oil boom (Adejumobi and Kehinde 2007). Government officials and the politicians use money generated from oil reserves to sustain their extravagant lifestyle (Toyo and Aremu, 2003). The behaviour has made most citizens develop mistrust in the government officials. Some commissions constituted to eradicate crime, for instance, The Economic and Financial Crimes Commission, have ultimately favoured the corrupt officials (Momoh and Adejumobi, 1999).

Overall, it can be argued that the general electorate in Nigeria are excluded from the process of leadership recruitment (Agbaje 1997; Agbaje and Adejumobi 2006; Agbaje 204). This situation impacts on accountability and transparency, translating to poor governance (Osaghae 2011). Despite the positive result of the 2015 election the view of Musa (2014), that there were limited opportunities for participation by the Nigerian people in the decisionmaking processes under the Jonathan regime, remains the general view of the political situation. 


\subsection{Conclusion}

Taking into account structure of Nigeria federalism, the study provides primary data in efforts to examine the structural conflict amongst the three tiers of government, the issue of bordering on the exclusive and concurrent lists, the nervous (of losing control) and overbearing central government, the cost of governance, the politics of proliferation of states and local government, the corruption and culture of impunity within the structure and the principle of derivation as discussed by (Osaghae 2011; Elaigwu 2007; Osayimwese and Iyare 1991: 95; Suberu 2009).

Running through this chapter is a discussion of the essence of the political culture and systems of governance in Nigeria, identifying flaws while acknowledging the positive aspects of the political system, as it impacts on the principles and practice of federalism, where they exist. Political culture encompasses deep-rooted, engrained political and cultural traits that characterize a society. It takes into account the values, beliefs and attitudes that people in a society have about the prevailing political system. The 'quality' of that political culture is relevant, in the sense that it constitutes the growing bed for the seeds of democracy and socio-economic development intended to and actually achieving improvements for the populace of Nigeria.

The chapter demonstrate that the defective design of the contemporary federal structure coupled with the poor 'quality' of the prevailing political culture, are responsible for poor governance and limited socio-economic development. It is clear from the literature that the actions of politicians, and the party system, has produced a culture of leadership in both political and civil society that ensures the persistence of dominant norms, attitudes, practices 
and procedures conducive to behavioural and institutional tendencies that are exploitative, and self-seeking (Suberu 2010; Musa 2014; Kaplan 2001; Momoh and Adejumobi, 1999).

It is widely recognised that Nigeria lacks an appropriate 'quality' of political culture for successful decentralization. This research further illustrates that although the constitution and the structure of government provide a legitimate foundation for good governance and socioeconomic development, evolutionary changes are required if true federalism is to be achieved in Nigeria in the foreseeable future. The author concludes therefore that non-violent political activism is a prerequisite for such change. 


\section{Chapter 5}

\section{$\underline{\text { Report on the Field Experiment in Ondo State, Nigeria }}$}

\subsection{Introduction}

This chapter sets out the report of the fieldwork undertaken for the purpose of this research. It can be seen from the preceding chapters that the bulk of the literature on the Nigerian federal system unambiguously holds that it is dysfunctional and ineffective as a form of government. The fieldwork examines such findings by means of a practical examination of the structure of Nigerian federalism which results poor governance, largely by the performance (whether deliberate or in advertent) of the principal political actors in the process of governance. The issues discussed in this report on the fieldwork are varied; however, they are directly linked to the architecture of Nigerian federalism and the extent of the success or failure of decentralisation in terms of service delivery and participation of the citizenry in governance. This study follows up and augments the previous fieldwork carried out in 2013.

\subsection{Ondo State; a general description}

Ondo state is one of the six states that constitute South West Nigeria. It was created on February 3rd 1976 and then on October 1st 1996 it was split into two, so carving out the present Ekiti state. The diagram below (Figure 3, map of Nigeria) illustrates that Ondo State is bounded in the northwest by Ekiti state, Osun State to the west central area; to the southwest there is Ogun State, and the Edo and Delta states lay in the southeast while the Atlantic Ocean forms the natural southern boundary. Ondo State is about 296.6 kilometres from the Lagos Airport and 437 kilometres from Abuja Airport. It has a landmass of $15,500 \mathrm{~km}^{2}(6,000 \mathrm{sq} \mathrm{mi})$. 

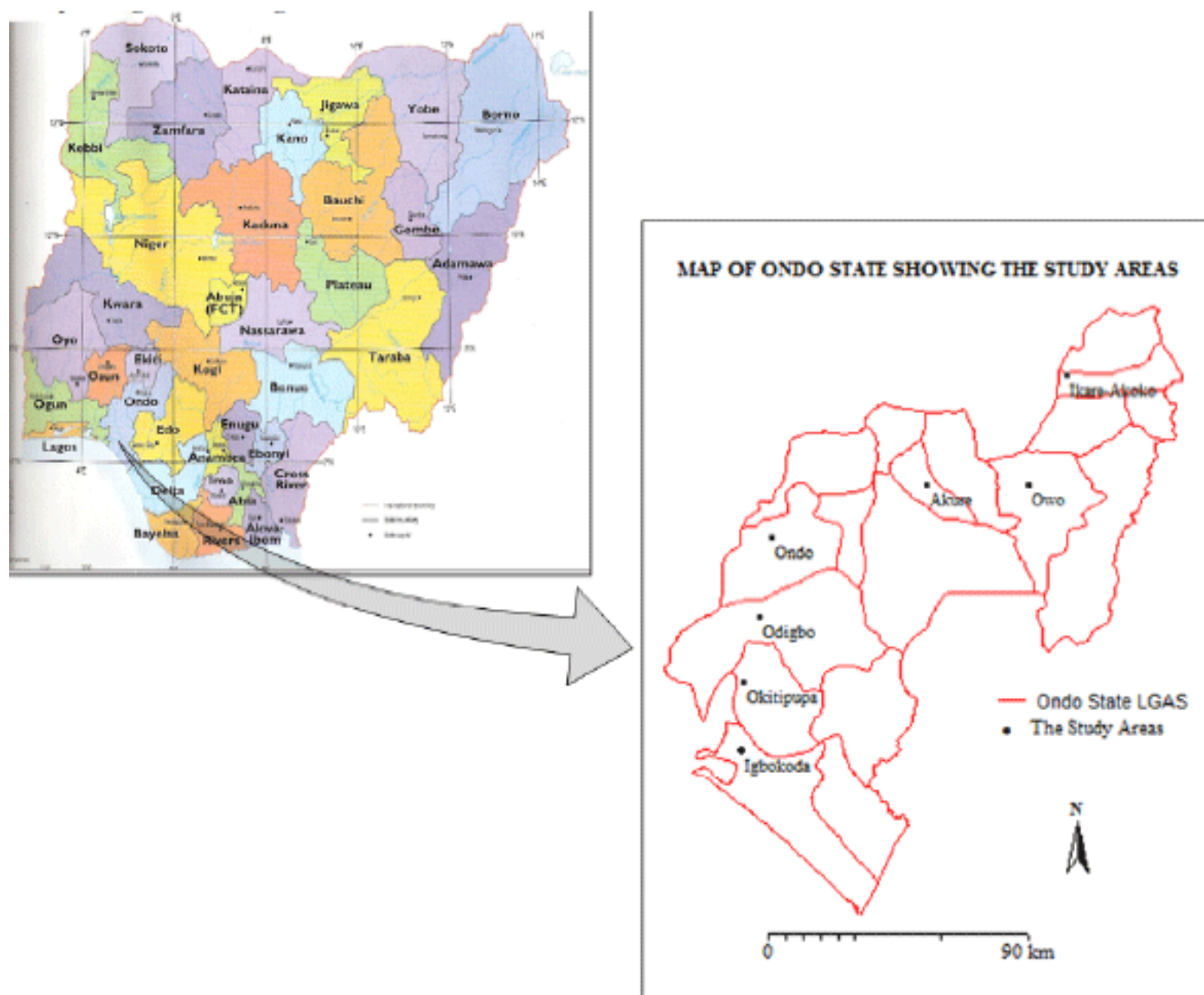

Figure 3: Map of Nigeria; Map of Ondo State.

Table 6: Ondo Population Statistics

\begin{tabular}{|c|c|c|c|c|}
\hline$\underline{\text { Name }}$ & $\underline{\text { Status }}$ & $\begin{array}{l}\text { Population } \\
\text { Census } \\
\text { 1991-11-26 }\end{array}$ & $\begin{array}{l}\text { Population } \\
\text { Census } \\
\text { 2006-03-21 }\end{array}$ & $\begin{array}{l}\text { Population } \\
\text { Projection } \\
2015-03-21\end{array}$ \\
\hline Ondo & State & $2,249,548$ & $3,460,877$ & $4,525,600$ \\
\hline$\underline{\text { Akoko North East }}$ & Local Government Area & $\ldots$ & 179,092 & 234,200 \\
\hline
\end{tabular}




\begin{tabular}{|c|c|c|c|c|}
\hline Name & $\underline{\text { Status }}$ & $\begin{array}{l}\text { Population } \\
\text { Census } \\
\text { 1991-11-26 }\end{array}$ & $\begin{array}{l}\text { Population } \\
\text { Census } \\
\text { 2006-03-21 }\end{array}$ & $\begin{array}{l}\text { Population } \\
\text { Projection } \\
2015-03-21\end{array}$ \\
\hline$\underline{\text { Akoko North West }}$ & Local Government Area & 119,278 & 211,867 & 277,000 \\
\hline$\underline{\text { Akoko South East }}$ & Local Government Area & $\ldots$ & 82,443 & 107,800 \\
\hline Akoko South West & Local Government Area & $\ldots$ & 228,383 & 298,600 \\
\hline$\underline{\text { Akure North }}$ & Local Government Area & $\ldots$ & 130,765 & 171,000 \\
\hline$\underline{\text { Akure South }}$ & Local Government Area & $\ldots$ & 360,268 & 471,100 \\
\hline Ese-Odo & Local Government Area & $\ldots$ & 158,256 & 206,900 \\
\hline$\underline{\text { Idanre }}$ & Local Government Area & 85,776 & 129,795 & 169,700 \\
\hline$\underline{\text { Ifedore }}$ & Local Government Area & 102,617 & 176,372 & 230,600 \\
\hline Ilaje & Local Government Area & $\ldots$ & 289,838 & 379,000 \\
\hline Ile-Oluji-Okeigbo & Local Government Area & 116,094 & 171,876 & 224,800 \\
\hline Irele & Local Government Area & 100,127 & 144,136 & 188,500 \\
\hline$\underline{\text { Odigbo }}$ & Local Government Area & 154,320 & 232,287 & 303,800 \\
\hline Okitipupa & Local Government Area & 176,615 & 234,138 & 306,200 \\
\hline$\underline{\text { Ondo East }}$ & Local Government Area & $\ldots$ & 76,092 & 99,500 \\
\hline
\end{tabular}




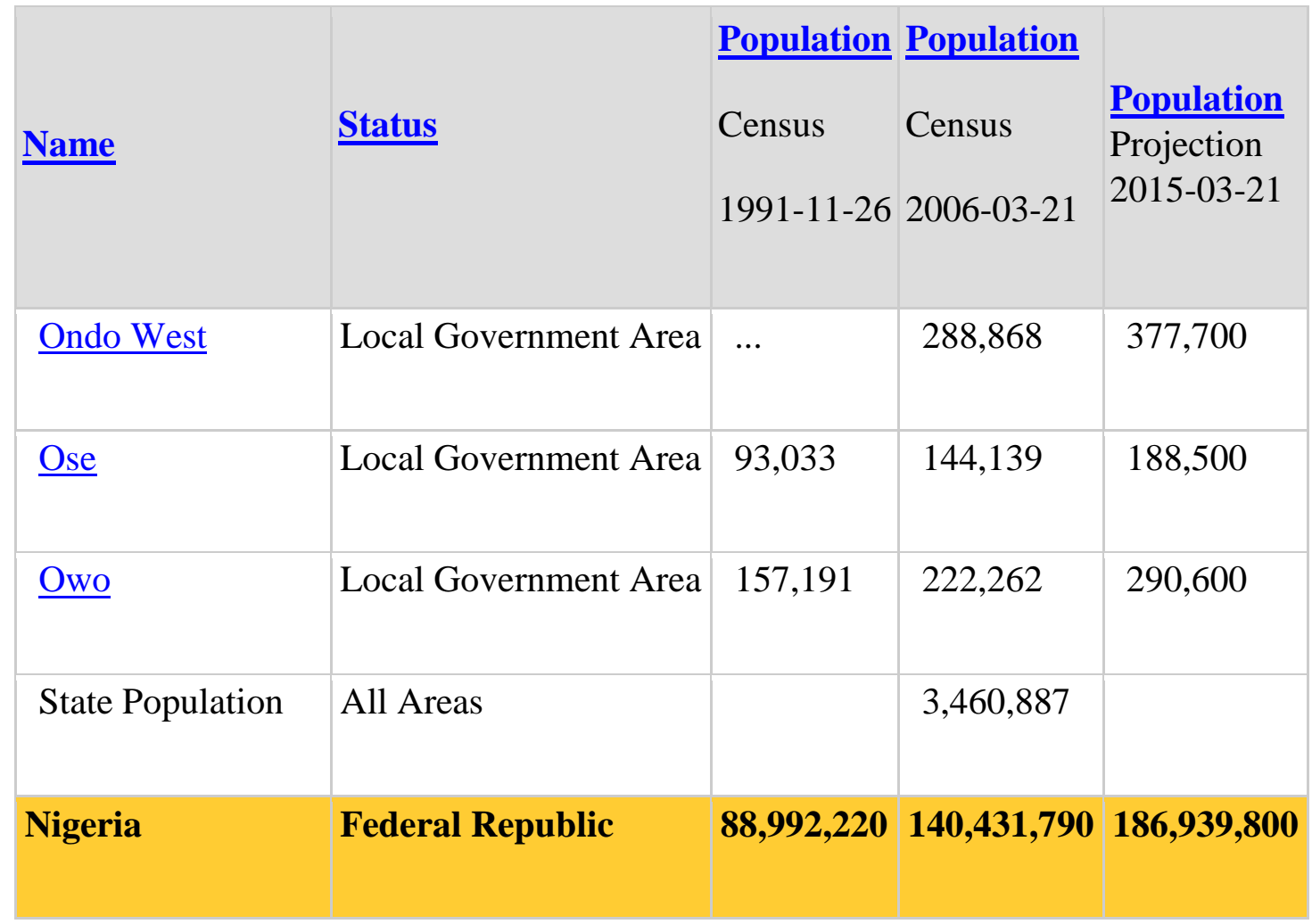

Source: National Population Commission of Nigeria (web), National Bureau of Statistics (web).

The state population as illustrated in Table 5 is about $3,460,887$ with a concentration in the state capital located at Akure and urban areas. It is made up of eighteen local government areas within which are two hundred and three councillorship wards, twenty state electoral constituencies, nine federal constituencies and three federal senatorial constituencies each of which is composed of six local government areas. The senatorial districts are (1) Ondo North, the component Local Governments are: (i) Akoko North East (ii) Akoko North West (iii) Akoko South East (iv) Akoko South West (v) Ose (vi) Owo: (2) Ondo Central, is made of the following Local Governments (i) Akure North (ii) Akure South (iii) Idanre (iv) Ifedore (v) Ondo East (vi) Ondo West: (3) Ondo South , the component Local Governments are EseOdo (ii) Ilaje (iii) Ile-Oluji / Oke-Igbo (iv) Irele (v) Odigbo (vi) Okitipupa. 
Because the number of federal constituency representatives from a state is determined by the population of the state Ondo state only has nine federal constituencies and twenty six state constituencies. The indigenous people are predominantly Yoruba, though they speak other local dialects such as Ikale, Ilaje and Ondo Akoko. There is however, a minority group who are the Ijaws in the coastal area of the state. Its people are predominantly farmers, fishermen and traders. There are also civil servants and some private sector employees. All these features contribute to the cosmopolitan nature of the state especially in Akure.

Table 7: Local government areas in Ondo state and their headquarters

\begin{tabular}{|c|l|l|l|l|}
\hline S/N & \multicolumn{1}{|c|}{$\begin{array}{c}\text { LOCAL } \\
\text { GOVERNMENT } \\
\text { AREA }\end{array}$} & $\begin{array}{c}\text { YEAR } \\
\text { CREATED }\end{array}$ & $\begin{array}{c}\text { LOCAL } \\
\text { GOVERNMENT } \\
\text { HEADQUARTER }\end{array}$ & $\begin{array}{c}\text { DISTANCE OF } \\
\text { LOCAL } \\
\text { GOVERNMENT } \\
\text { HEADQUATERS TO } \\
\text { AKURE, STATE } \\
\text { CAPITAL (KM }\end{array}$ \\
\hline 1 & AKOKO NORTH EAST & 1991 & IKARE & 96 \\
\hline 2 & $\begin{array}{l}\text { AKOKO NORTH } \\
\text { WEST }\end{array}$ & 1991 & OKEAGBE & 121 \\
\hline 3 & AKOKO SOUTH EAST & 1996 & ISUAAKOKO & 102 \\
\hline 4 & $\begin{array}{l}\text { AKOKO SOUTH } \\
\text { WEST }\end{array}$ & 1996 & OKA & 88 \\
\hline 5 & AKURE NORTH & 1997 & IJU/ITAOGBOLU & 18 \\
\hline 6 & AKURE SOUTH & 1976 & AKURE STATE & STATE CAPITAL \\
\hline 7 & ESE ODO & 1996 & OWENA & 168 \\
\hline & & & & \\
\hline
\end{tabular}




\begin{tabular}{|c|l|l|l|l|}
\hline 9 & IFEDORE & 1991 & IGBARA-OKE & 20 \\
\hline 10 & ILAJE & 1991 & IGBOKODA & 152 \\
\hline 11 & ILE-OLUJIOKE IGBO & 1991 & ILE-OLUJI & 54 \\
\hline 12 & IRELE & 1991 & IRELE & 134 \\
\hline 13 & ODIGBO & 1991 & ORE & 83 \\
\hline 14 & OKITIPUPA & 1991 & OKITIPUPA & 126 \\
\hline 15 & ONDO EAST & 1996 & BOLORUNDURO & 46 \\
\hline 16 & ONDO WEST & 1996 & ONDO & \\
\hline 17 & OSE & 1996 & IFON & 92 \\
\hline 18 & & & & 48 \\
\hline
\end{tabular}

\subsection{The Field Survey: subject type, demographics and range}

The scope of the field survey ranged across two communities in each of two local governments areas in each senatorial district of the state. That made a total of twelve communities within six local governments spreading across the three senatorial districts of the state visited for the purpose of the survey. Selection of these local governments and their communities was done randomly; because they all share cultural and occupational affinities within their senatorial zones such random sampling was a safe method to employ. The selected local government areas fully represent the different blocs in the state while the three senatorial districts are structured to accommodate the various indigenous ethnic groupings. Further, the bulk of the population is found in the rural areas. 
The local government areas include Ile - Oluji/Oke Igbo, Ese Odo, Akure North, Akoko South West, Ose and Ifedore. Ile - Oluji/Oke. Igbo local government is located in Ondo Central senatorial district with an estimated population of 171,876 persons. The major occupation is farming and the crop grown mostly is cocoa with the state's main cocoa processing plant located within this area. Other crops grown include vegetables, plantains, rice, yam and cassava. Ese-Odo local government is located in the riverside area of the state with a mixed population of Ijaw and Yoruba. Due to its location, the main occupation of the people is fishing but with some small-scale farming as above. Akure is divided into north and south areas and the southern part houses the seat of local government. Akoko southwest local government area is located in the northern part of the state. Its topography is rocky and this makes the supply of water challenging for the local people. With the state university located in this local government area with a very busy route to Abuja, the federal capital territory, there is an increased business activity. The Ose local government area has its headquarters at Ifon which is located in the eastern part of the state sharing a boundary with Edo state and has a mixed population of both Yoruba and Edo whose main occupations include civil service jobs, lumbering and small scale trading. Ifedore local government has its headquarters in Igbara Oke; its main districts are Ilara, Ipogun and Ijare and the main occupations of its population are in Ifedore local government but include farming and small scale trading. Finally the Ondo North Senatorial zone is significantly made up of the Akoko and Owo. Apart from two towns, Owo and Ikare Akoko, most of the towns and villages are predominantly rural settlements and far removed from the state capital.

From the generalised descriptions set out above the reader will gain a picture of the demographics of Ondo State as being predominantly rural with pockets of more densely occupied areas housing government and commerce while the generality of trade outside those 
centres is small scale and local. Its inhabitants are diverse and comprised of a number of groups with distinct ethnic and racial identities. For instance the Ondo South Senatorial zone includes with its population peoples of Ikale, Ilaje and Ijaws origins.

\subsection{Selection of the study Respondents and conduct of interviews}

To ensure a robust and unbiased information gathering process, the study respondents were selected from both urban and rural areas. The compositions of the first category included those who lived in urban centres and were generally more likely to have had more access to formal education. They included policy makers, civil servants, academics, and self-employed private practitioners, response from many of the respondents in this category was obtained during the first phase of the interview.

The second group included respondents who reside in the rural area who were in general less literate having had less exposure to formal education. In general they comprised community leaders, local politicians, tribal or traditional leaders, traders, farmers, local government workers, artisans and the youth leaders of the communities. Each respondent was selected from within six local government areas in the state and in the view of the researcher formed a fair and sufficient sample taken across the widest possible range. A minimum of twenty-five interviews were conducted in each of the six local government areas by a mixture of informal and semi structured interviews. Taken together with the range of respondents the volume of enquiries is reasonably considered to be adequate and representative. The general factors considered in selecting the respondents for the interviews were that they (a) had lived in the local community for a period not less ten years; (b) were active participants in the community; and (c) were aware of the local development initiatives in the communities. 


\section{$5.4 \quad$ Findings}

\subsubsection{The Constitutional Issues}

Of the issues considered in the literature review of the Nigerian federal system it is appropriate to reiterate (not least for the purpose of establishing the context of the findings of this research) the postulations of Obiinger et al (2005) and Law (2013) (see Chapter 2) that there are five key characteristics of a federal system. They all relationship based and are, in summary; (1) decision-making exists at central governmental level with power of veto; (2) the allocation of policy responsibilities between levels of government; (3) the presence and inter-play of territorially-based actors; (4) inter-governmental fiscal transfer arrangements; and, (5) informal agreements, both at the vertical and horizontal levels, between governments and other actors. There is therefore a compelling reason to examine these differing and competing relationships in this context.

A federal system is fundamentally based on the constitution, which creates and sustains the state institutions and the relationships within the federal system. The highlights of the Nigerian federal system investigated in this fieldwork are; (i) that the present constitution does not deviate from military federalism but, rather, it is a structural arrangement that confers superiority of the central government over the sub-units; (ii) that the constitution is not a consensus document; (iii) that the power and fiscal relations are asymmetrical; (iv) that there are ambiguities in the critical area of the listing of the legislative functions; and (v) that the Local Government's position in the constitution is shrouded in ambiguity, creating more problems than solutions in terms of bringing government closer to the people for the purpose of development. It must be noted however that there is minority opinion that suggests that the problem with Nigerian federalism and the apparent incidence of under development may not be entirely linked to the constitution. 
Notwithstanding that minority view, an assessment of the understanding of the constitutional issues through stratified sampling interviews shows that there seems to be a general opinion that the Nigerian federal structure is dysfunctional and, furthermore, is not adequately responding to the challenges of critical development. For many of those interviewed there was no ambiguity or dispute about the importance of the federal system in a multi-ethnic country like Nigeria and the requirement for an effective constitution which permits its implementation. Indeed it is seen by some as a prerequisite for future development and there seems to be a consensus that the lack of capacity of successive Nigerian governments (at federal, state and local level) to translate the enormous resources in their control into economic growth and development is a consequence of that defective constitution. It follows that state institutions are weak and require to be strengthened legislatively by means of constitutional reform.

\subsubsection{Informal and formal characteristics of a federal System.}

The Nigerian federal constitution has been denounced as lacking the basic prerequisite that puts in place structures and mechanisms that would engender development. As stated above, prevailing opinion is that the constitution must be amended to reflect basic principles of federalism. The constitutional reforms are also meant to set right the wrong notions and understanding of federalism which have influenced the practice of federalism to date. A particular civil activist and development expert agreed in interview with the popular notion that the Nigerian federal system is faulty and noted that:

"The constitution is definitely the problem. The constitution is the centre of everything and if we have to reform our federal system, then it means we must work on the constitution."(SS1/Civil Activist/Development Expert 1/ Abuja/2013) 
All but one of those interviewed about the meaning of federalism as practised in Nigeria agreed that Nigerian federalism is fraught with errors and blamed the constitution. One leading politician who was at the time of the interview a leader of the opposition party in Nigeria but is now part of the leadership of the ruling party agreed with the assertion of the civil activist set out above. Further, in his opinion the problem is that the Nigerian federal system is over centralised and could best be described as a de facto unitary government. He attributed this defect in the system to the many years of military rule in Nigeria. Hence among the first category of interviewees, the term 'military federalism' is used to describe the type of Nigerian federalism in practice today. That politician interviewee was of the view that the basis of federalism has been crafted by and for the military rather than by and for the people. In fact he put it in these terms, “. . . a constitution that has been created by the military, no Nigerian state other than the old Mid West, was created by the people. "(SSI/Politician 1 / London/Lagos/2013).

His position seems to represent the position of a section of Nigerian politicians who clamoured vigorously for the restructure of the Nigerian federal system based on constitutional reform. This perhaps explains the agitation for what is commonly referred to as 'true federalism' as it is called in Nigerian political parlance. During this interview the term 'true federalism' was a recurrent theme. The clamour for 'true federalism' sounded across the board, from citizens in both urban and rural areas who agreed on the need to attain that state. However the term may have differing meanings to western educated people in urban areas as opposed to those from rural areas so caution must be exercised by the general use of the term. In general the urban elites, politicians and academics articulate the meaning of 'true federalism' as a restructuring of the Nigerian federal arrangement in terms of devolution of political and fiscal powers to the lower tiers of government. However the people in the rural 
areas in general were found to have a far more simplistic meaning. For them it is more about infrastructural developments (i.e. schools, primary health facilities, water, electricity and roads) and economic empowerment, (i.e. job opportunities for youths, industries and financial empowerment in terms of soft loans to start small scale businesses). It may be however that each opinion as to what 'true federalism' means is not so different when translated into the basic population requirements for essential support systems, proper and fair governance and a sufficiency and equality of resource distribution.

The major issues emanating from the responses of the interviewees are; (i) the over centralised government that follows the pattern of military command hierarchy which by definition may be overbearing; and (ii) the constitution does not take into full cognisance the diversities that exist amongst the federating units. It is proposed by the author that this state of affairs accrues from the exclusion of people in the process of the drafting of the constitution. This observations corresponds with Riker's (1964) 'Political theory of federal formation' (Chapter Two) that the federal structure arrangement is essentially a bargain between politicians, and between prospective national leaders and officials of constituent governments for the purpose of, aggregating territory, rights to lay taxes and raise armies. It is postulated that Riker is correct to the extent that the process of formation of the Nigerian federal structure, the drafting of constitution, and the implementation of the federal system was not all-inclusive. Rather it was exclusive and focused on the interests of the key participants rather than the generality of the population and its needs, the respondents' view in general was that the Nigerian federal system as a system of government should have been constructed for the benefit of the people, and its constitution drafted for them. In terms of the position of Stepan's (2005) and his typologies of federal states as 'coming together', 'holding together' and 'putting together' Nigeria is seen by a majority of the respondents as falling 
into the 'putting together' category, with its roots in the historic colonial government.

The majority of the interviewees do believe that the present constitution either can enhances effective management or is capable of providing good governance. The response of one interviewee, a civil servant, broadly expresses the view of the majority of the interviewees, that the constitution remains;

“. . . an elite document meant for the elites; if you look at the trend of national events and how leaders are produced, you will realize that the constitution is carefully scripted to protect the interests of the elites who would always have their way through to the political offices and help themselves with the national wealth." (SSI/Civil Servant1/Akure/2016)

This demonstrates the lack of confidence in the constitution and the bylaws of the Nigerian federation. The majority of the respondents were cynical about the position but also recognise the apathy of the majority to defects in the system even though they agreed that many political actors have incapacitated them in terms of good governance for the benefit of the majority. A very common opinion was that the constitution in itself is a fraud so much so that the phrase 'Nigerian Constitution lied against itself' is a popular view and prevalent among the interviewees. This opinion stems from the interpretation of the first line of the Nigerian constitution which states "We the people of the Federal Republic of Nigeria..." This is considered to be a false statement and it is the common view that that there was never a time when Nigerians converged in any sort of 'coming together' to agree on the terms of how they wished their country to be governed. At best, therefore, and in summary of this finding, the constitution is seen largely as the contraption of the military and political elites and questions arise as to the legitimacy of the constitution itself. The consensus view even of the academic, and civil servant interviewees is that the constitution disproportionately favours the 
politicians, public office holders and those with vested interests, a situation which, they say, has very severely undermined good governance and development.

Further consideration of the very forthright views of the politician respondent referred to earlier suggest a considerable degree of consensus about the over-centralisation of the Nigerian federal arrangement. In the classical notion of federalism, a good federal structure allows for a high degree of autonomy, as noted by the federalists such as Wheare (1964), Riker (1964), Adedeji (1971), Eleazar (1976), Stepan (2005) Elaigwu (2007), Obinger et al 2005, Suberu and Osaghae (2005) (Chapter 2),. Observations from the fieldwork indicate that this is far from the reality in Nigeria. Category one respondents commonly referred to the legislative lists of the constitution and are of the opinion that the federal government have too many functions reserved to its own domain, function that ought to be devolved or at least assigned as part of the federal process. One the interviewees, a retired civil servant in one of the urban centres captured this view succinctly and offered the following as one of the consequences of the over centralisation:

"Everything is centralized; a central railway, a central electricity, central water. The system suppresses the development of the units since all people are forced to rely on the federal government in the headquarters in Abuja to give out pee-nuts to the states. (SSI/Retired Civil Servant 1/ Akure/2016/2017)

Common to both categories of respondent was the view that over centralised governance is naturally antithetical to the development of Nigeria as a self-contained and effective sovereign state. As it is, said the above interviewee, the regions and states rely on the federal government for their own survival as economic units because the only means of revenue for infrastructure development and service delivery is the allocation from the federal 
government. Most of the respondents show little interest in the internally generated revenue of the states and the local governments because the focus is on the federal allocation especially in relation to the distribution of oil revenues.

The researcher produced to the interviewees the IGR and the tax income of Ondo State as published by the National Bureau of Statistics (NBS) from 2012 to $2016^{15}$. While the first category of respondents were already aware of this, but perhaps not fully familiar with the figures, the second category of respondents were generally unaware and showed little or no interest in the income coming from within the state but were more interested to observe that the states were obviously not getting their fair share by way of the federal budget allocation. By contrast, to a degree, the second category of the respondents also expressed an interest in having a federal presence in their communities, suggesting approval of federal government intervention in education, health and road infrastructure. The author observed that the many of the respondents in the local communities apparently have more trust and confidence in the central government than the state and local government.

In making another important observation that is contrary to the common view of

15

\begin{tabular}{|l|l|}
\hline 2012 & $10,153,042,597.01$ \\
\hline 2013 & $10,498.697,469.99$ \\
\hline 2014 & $11,718,741,502.49$ \\
\hline 2015 & $10,098,000.000 .00$ \\
\hline Taxes & $7,348,474,927.10$ \\
\hline MDAs Collections & $2,277,317,560.72$ \\
\hline 2016 & $8,884,756,040.35$ \\
\hline
\end{tabular}


centralisation, a very well informed senior lecturer at the University of Ibadan suggested that centralisation is not essentially a problem of Nigerian federalism but, rather it is the values that drive the authors of Nigerian federalism, such as greed and self-interest. He bases his position on a comparative review of different federal systems and argues that there are so many more centralised countries in terms of tax powers than Nigeria and that good governance and the development index of these countries are higher than that of Nigeria. He cited Malaysia as an example thus;

"In Malaysia they have oil and the federal government controls 95\% of the resources from the oil; whilst only about 5\% goes to the state, the level of corruption and the level of dysfunction of the system is not as bad as in Nigeria." (SSI/ Academic 1/ Ibadan/2013)

For this particular respondent, the values that drives the Nigerian federal system include what he openly refers to as; the 'illegal behaviour' of the federal government in the federal-state relations; illegal behaviour of states in state-local government relations; absence of the rule of law; and, more importantly the values that drives the federal government process, which he termed as behavioural pattern of primitive accumulation. He argued that what the politicians do is to manipulate public opinion by drawing the attention of the people always to the constitution, and to the federal structure as a diversionary tactic. To quote this respondent, the irresponsible behaviour of the politicians is the main problem of Nigerian federal system, "it is difficult to defend that popular view that the problem is over centralisation."

That position was referred to other interviewees, about $98 \%$ of whom agreed that there is fundamental problem with the values that drive the process of governance and that sometimes there is flagrant disregard for the constitution by those who operate under its auspices. An 
example of the case between the federal government and Lagos state was referred to; this refers to the disobedience of the federal government of an order of the Supreme Court by withholding the statutory revenue allocation to Lagos State. Informed respondents commonly cited this as an example of the constitution being unable to bring the federal government to account.

\subsubsection{Imperatives of creation states and Local Government as means of good governance and development}

The principle of having a consensus document as the constitution is integral to the federal arrangement. There are strong negative sentiments expressed by the interviewees that not being part of the process of constitutional agreement seem to be affecting the workings of the Nigerian federalism. In other words, there is no sense of ownership or sense of being part of the process of governance. The common sentiment of the respondents about the constitution is that it is skewed to subjugate the composite units and, by extension, the citizens there into the federal government, a government already in the control of the political elites. This sentiment is captured in the interview with a lecturer of political studies at the University of Ibadan:

"If all the composite units came by consensus to form a federation then there must be a federal constitution that means each unit will be coming with a different background and with a different interest and all of those interests must be represented in the constitution. Since 1967 to this present system, we had a unitary constitution, but because they are military constitutions that is one of the bane of Nigeria federalism. Because we cannot have a kind of centralized constitution, dictated from the top this renders the composite units useless and then say you are practicing federalism." (SSI/Academic 2/ Ibadan/2013).

This idea seems, to a degree, to cut across the answers obtained from the other respondents. For example, a high ranking politician, who at different times, was a deputy governor, a 
governor and later an official of the main opposition party, gives an insight into how states were created in Nigeria. He noted that there is no standard formula or definable parameter for creating a state or local government. He reveals that most of the states and the local government were created by the military, and the process is often fraught with bribery and corruption, He gave an example of a friend who bribed some military officers with 250.000 Naira to site a local government headquarters in his own town. Incidents such as this have had a very significant impact on Nigerian federalism and development.

A lecturer interviewed at the University of Ibadan noted that as they are presently constituted states are not reflective of political communities, but that state government has more characteristic of the larger political community than local government. His position aligns with earlier noted assertions of the former governor that the creation of sub units have not followed any standard formula, or set of parameters, he argues that local government was created for the purpose of diverting resources from the central government for the purpose of bringing development to the grassroots. He stated that,

"They are not organised according to certain basic existing accountability structures or mechanisms. They are just demarcated as local government arbitrarily in order to be able to channel money into some areas. As people look for access to governmental power, they are looking for more political offices, so they agitate for more local government and they get it. "(SSI/Politician 2 / Ila Orangun/2013)

From the foregoing it appears that the reasons given for creation of local governments as the means of the equitable distribution of national wealth (Olowu and Wunsch (2004) doesn't reflect the reality. To this effect the creation of more states and local governments simply 
breeds more corruption and does not in any way translate into infrastructural development or economic growth. Consequently the present structure, particularly by reference to the functions of the state and local government as development centres, cannot be sufficiently achieved. A development expert stated in interview:

"When you create a state, you create more politicians and then you create more contractors, you create more corruption the more you have those people, more resources go to overhead ${ }^{16}$ than actually go to capital projects. I don't think it has contributed in any way to the physical structural development." (SS1/Development Expert 2/ Akure/2016)

This assumption may be something of a sweeping statement but from my observations citizens are generally content with the notion of local government because it is a constituent element of successful federalism. They are generally of the opinion that all the development they have seen and are enjoying would not have come to them without the creation of such local government, which, in theory, attracts development. It must be acknowledged however that despite the challenges of the process and operations of these tiers of government, it has served a purpose. There is evidence that the aim of taking government and development closer to the people has been partly fulfilled but the question is whether the local governments and the states have maximized their institutional capacities to bring about higher degree of good governance and development. The respondents seem to agree that via local government, local people seem to have at least some access to development potential. For instance, a former head of service delivery in Ekiti notes that:

\footnotetext{
${ }^{16}$ The growth and magnitude of public spending, in recent years, have tended towards the recurrent side and outstripped the growth of spending on capital projects. Following from the observed trend in aggregate spending, the share of capital expenditure hardly exceeded $30 \%$ of aggregate expenditure due to the growing magnitude of recurrent expenditure which reduces the fiscal space available for spending on developmental projects. Over the 2005-2012 periods, recurrent expenditure almost tripled from N1.2 trillion in 2005 to N3.4 trillion projected for 2012. It is noteworthy that $52 \%$ of the increase from N2.1trillion to N3.2trillion occurred between 2009 and 2010 alone due largely, to a rise in the wage bill. (source; Federal Ministry of Finance)
} 
"No doubt, the creation of states has brought tremendous development in our State (Ekiti State). Not just to our State, but many other states that would not have known development, because the government was far from them. What happens is that the government focuses more on the state capitals and the major towns while neglecting the interiors, but now with the creation of new states, governance is within the reach of the people even to the peripheries. "(SSI/Civil Servant/Head of Service1/Akure/2016)

This view is strongly suggestive of the importance of the creation of more states as a means of engendering development on a local basis. Historical analysis is based on the level of development during the first republic (1957-1966) with the federal structure consisting of four regions and provinces. In this period, the regions and the provinces exercised considerable political and fiscal autonomy. The first republic, with the four regions arrangement, is said to have experienced unprecedented development, with the arrangement of the local council strictly under the regional governments. Local councils built roads, schools and an efficient health sector, particularly in terms of sanitation. From each of the regions exercising considerable power over the resources generated from their regions, development programmes evolved that enhanced the quality of life of the people within their geographical regions and the country at large. One common feature observed during the fieldwork is the romanticising of the first republic as the perfect system or paradigm for development. This is captured in the response of a lawyer respondent when asked about his views on Nigerian federalism, he indicated that while initially the federal structure reflected true federalism, the current system does not reflect any notion of paradigm federalism at all. He stated that:

"Unfortunately when we moved from parliamentary into a federal state at the beginning we had a true federalism when we had three regions . . each region developed it's own central government at it's own level and it was the 
unique opportunity for Nigeria to practise it's federalism, but unfortunately it was truncated by the military regime . . . What we have today cannot truly be called a federal state at best is called a pseudo federal state." (SS1/Lawyer/Akure/2016)

For the majority of the respondents the parliamentary system of the first republic (1957-1966) offered a good platform for citizens' participation in the process of governance, giving, as it did, more autonomy to the regions with special roles for the traditional rulers and the local government police. While describing the Nigerian federal structure and its dominant features, a senior lecturer on political institutions, governance and public policy and administration at the University of Ibadan, argued that the Nigerian system does not permit autonomy of other government tiers because the federal government has taken over the responsibility of the state and the local governments. On that basis, he said, federalism in Nigeria has failed. For him the clamour by some state governors to have state police, calls for self-determination and secessionist threats is a clear indication that the federalism is not working.

\subsubsection{Power relations: asymmetrical power and fiscal relations.}

The idea of the 1976 local government reforms was to strengthen the constitutional status, create an autonomous tier of government with direct funding from the centre, distribute an increased share of federal revenue, establish a permanent system of local government and implement such systematic and uniform reform measures nationwide. However, despite their recognition as a third level of government in practice there have been misgivings about their actual autonomy as a distinct level of government (Chapter Two and Four).An assessment of the notion of asymmetrical power relationships is conducted in two ways; firstly by the exploration of the theoretical understanding of this notion and, secondly, by an investigation within the context of service delivery. By a comparison of current practices in Nigeria and 
other federalist models, the respondent lecturer from the University of Ibadan argues that there is no de facto decentralized federalism in Nigeria but instead that Nigeria practices quasi federalism, as a system without decentralization. He states;

"The kind of federalism we are practising could be best described as
quasi federalism, in other word...there are lot of issues with it, once
there is no decentralization, there is actually no
federalism.(SSI/Academic 2/Ibadan/2013)

A senior civil servant respondent corroborated this assertion when he described the federating units as a sort of administrative units of the federal government. He observed that in practical terms the federating units lack the powers that are required to function properly in terms of fiscal powers and fiscal responsibilities. He therefore suggests that:

“. . . each authority should have a taxation authority to be able to tax people in its jurisdiction; the federal government can tax the people within its federation and each state can tax people within its own jurisdiction so there are two taxation authorities; the third tier should subsist within the state that should depend on each state how it wants to administer its tax." (SSI/Academic 2/ Ibadan/2013)

In the same vein, another respondent, in describing the issues of federalism and the autonomy of the constituent units, advocated decentralization of functions such as social issues, health, and education among the local and state governments. He stated;

"To a large extent to become autonomous in decision-making, is the only thing that federalism centralizes. It is in defence, currency, foreign policy, that is mostly what the central government should be involved;. . . social issues, health, education and the rest of them should be governed by the states and local government. "(SS1/Civil Servant2/Akure/2016) 
The foregoing suggests that absent the control of 'social issues, health, education and the rest of them' at the local level, the principle of autonomy within a federal arrangement is compromised.

Whilst the Nigerian constitution does confer some degree of autonomy on the sub-units for the most part they do seem to lack complete and effective autonomy. Accordingly the powers of the states are intentionally whittled down. A former civil servant respondent in Ondo State noted:

"There is no state or local government in Nigeria that is autonomous from the Federal government. It makes no sense of federalism. For instance at the end of the month we all go to Abuja to converge to share money; right, it is not even sharing money, it is to take our own piece from what is deemed fit by the federal government."(SSI/Retired Civil Servant 2/ Akure/2016).

The majority of respondents seem to agree that the lack of autonomy affects the capacity for creativity and that incentive to promote economic growth and development is lacking in the component units. This notion tallied with the response of one interviewee who claimed that the current federal arrangement suppress development because the federal government is routinely alleged to dictate policy to the sub-units. One implication of exercising this substantial power over the federating units is that some of the decisions and interventions in the state are misplaced. Examples were given of infrastructural projects and infrastructural programmes that are inappropriately sited. The same interviewee noted that, "The Federal Government determines what goes to each state. It determines what states should be a part of something and what states should not be a part of it." (SSI/Retired Civil Servant 2/ Akure/2016)

A further issue arising from this structural arrangement is the dependence of the state and local government governments on the federal government. Although the constitution confers 
considerable power on the states, it appears that these powers are, in practice, tactically withdrawn by other provisions of the constitution. I considered why it is apparently so difficult for the states to exercise this power within the purview of the constitutional provision, and for the federal government to resist what is considered to be undue interference. A former governor respondent of a state in the south west region explained that with the enormous resources at the disposal of the federal government, and the unequal level of reliance on allocations from the federal government by the states, required to survive and carry out even the most basic statutory functions, it remains a very difficult balance to strike absent the political will. He notes that the federal government has the arbitrary power to withhold funds from state government and that creates an inequality of power. The level of the weakness of the state is further expressed by an academic giving as an example based on the powers of the state governor on security matters:

"If we look at the constitution of the country, the Governors are supposed to be the chief security officer of their state; if you are the chief security officer and you don't have the wherewithal to control the security apparatus at your disposal, then what is the whole essence of being autonomous?"'(SSI/Politician 2 / Ila Orangun/2013)

Despite the fact that the state legislators are empowered to make laws for the state, they have little or no coercive authority to enforce the law, having to rely on the federal police to enforce the laws of the state. It is noted that the states are empowered to legislate on residual matters however, the enforcement of such laws is based on the acceptance or convenience of the state commissioner of police, but who doesn't operate under the laws of the state government. The police commissioners take orders from the Inspector General of the Police (IGP). The IGP takes orders from the national president as it is the president who appoints the IGP even though the appointment must be confirmed by the senate. The implication therefore 
is that there are two authorities within the state; the police commissioner is therefore, arguably, an extension of the presence of the federal government hegemony in the states. This particular situation has ripple effects in the Nigerian federation. In the first place it further questions the autonomy of the state governments. This situation leads to inadequate policing of the states and, equally, abuse of security power.

It is helpful to note that there are some reservations expressed by the stakeholders on the issue of state police. There is no consensus among the state governors on the issue; while the states governed by elected officials in political and ideological opposition to the federal government canvassed for state police, the ruling party controlled states are clearly against it. However a fundamental concern in this situation is whether the politicians are reasonable enough to operate the state police properly and without using the as a coercive tool against the population. There was also very significant concern amongst some of the respondents that the politicians would use the police against their political opponents at the state and local government levels in favour of their own political agendas. The author observed that the issue of the police may have political dimensions. In the first strand of interviews, one of the interviewees (a politician then in opposition) was so strongly committed to devolution of the Police Force that he was a fervent advocate for state police. However, in the follow up interview he expressed little interest in the establishment of a state police force because his own party then controlled the federal government and, by extension, the police.

This example shows how the federal government might be taking advantage of what are considered to be federating organs. Enough of the respondents interviewed expressed concern when interviewed about this issue as an example of the difference between 'federating government agencies' and 'federal government organs'. The federating government organs 
are the organs of the mechanisms of the entire nation, while the federal government agencies are those that are directly linked to the bureaucracy of the federal government and distribution of its power through devolved or federal agencies. The lecturer respondent argues that this trend has been a clog in the effective management of Nigerian resources and one which has impeded development. He gives examples to illustrate the meaning of 'federal government organs' and 'federating government organs' thus,

"There are many aberrations in the system, for example, if you take INEC, INEC is supposed to be a federal body, but today INEC is a federal government body, and they are two different things, INEC before Jega ${ }^{17}$ came, was behaving as if it is a federal government organ, not a federating organ, and it is supposed to be a federating organ. Most of our institutions are like that; the institutions become, organs of federal governments, and not federating institutions all because the way the constitution came. It is a military constitution, and you know what the military is about-command and obedience, which in the strict sense of it is part of the bureaucracy of the first tier of the government and not the organ of the federation." (SSI/Academic 2/ Ibadan/2013)

An observation from the communities visited is that the people find it difficult to draw anything but blurred lines between the functions of the federal government, the state government and the local government. They believe that each of the tiers of government is a service provider ranging from the primary education to health care and rural roads. The notion of preferring the federal presence and seeking federal help is prevalent. This situation creates chaos and confusion in the process of good governance and development.

One respondent noted that this situation is responsible for much of the abandoned or nonfunctioning infrastructure around the country. The former head of service in Ekiti State

\footnotetext{
${ }^{17}$ Professor Attahiru Jega, was the Chairman of the Independent Electoral Commission (INEC)..
} 
presented a scenario of such instances:

"Federal Government would say; Ekiti we want to build an agriculture centre, it will be in the Federal Government Budget, the Ministry of Agriculture in the state would not know, the Ministry of intergovernmental relations will not know, the contractor will just get the job in Abuja, gets his money, settle[bribe] some people in Abuja and just disappear. Nobody knows whether a contract has been approved or not in the state.. . You will be surprised to see the number of projects they would have claimed to have been executed in Ondo, through the award of phony contracts" (SSI/Civil Servant/Head of Service1/Akure/2016)

The implication of this position is that local communities are completely left out of the concept stage, planning and implementation of such programmes, notionally designed for the benefit of the local populations.

Beyond the provision of infrastructural access, the author noted the prevailing perception of the federal government amongst the local people in the communities visited. They tend to view the federal government as a remote entity, but with enormous political power and economic resources. Furthermore, it is being perceived as the senior partner and superior to the state, with absolute power exercised on an arbitrary basis. Conversely some people feel more secure with the presence of the Federal government rather than the State government due to a lack of belief and trust in local politics. A former Governor interviewee suggests that this view originates in the military incursion into the federal system arrangement, in a situation where the Head of State and his Military Council had absolute power. An in-depth examination of this notion could be linked to the ways the activities and manner in which the federal government uses some parastatal entities in the exercise of the central authority of the federal government; a good example is the police force. 
Despite the enormous power that all the participants believe the federal government possesses, many are of the opinion that the federal government is of little real practical value in terms of local service delivery. One of the interviewees explained that;

"When we were governed by the Alliance for Democracy Party, (AD) between 1999-2003, our Governor then was Chief Adefarati, we felt we were not reaping the dividends of democracy because we belong to the opposition party. In 2003, we overwhelmingly voted for PDP, with Dr. Agagu as our Governor, between 2003-2007. In a strict sense of it, we wanted to align to the mainstream politics, the party at the centre for the purpose of development. But after four years, we discovered that there was no difference. We realised sooner, that we got a better deal under Governor Adefarati, that was why we voted Agagu out in 2007, although the election was rigged, thanks to the judiciary that restores the mandate."(II/Local Resident 2/ Bolorunduro/2016)

This underscores the conflicting views of the place and function of the Federal government.

It is instructive to mention that in the Ese- Odo local government, the feeling is quite different. There are more overt expression of bitterness, of being cheated and short-changed by the system. This is engendered by the infrastructural development and environmental degradation, despite being an oil producing area. This has resulted in agitation for selfdetermination, resource control, and militancy amongst the youth. One of the interviewees noted that; How do we talk of accountability when the people don't even know the true amount of money accrued from oil derivation?(II//Local Resident 2/Sabomi/2016).

Despite the fact that the work of the OSOPADEC is predominantly commended by the local residents of this local government, there is still some unrest. OSOPADEC was set up to use $40 \%$ of the $13 \%$ oil derivation for the State, to address infrastructural and developmental 
gaps, related to the effect of oil exploration in the area. When the issue of accountability of OSOPADEC was raised by the author with the an official of OSOPADEC, he revealed that even the Commission is not giving information on what that it exactly amounts to every month, after allocation. Neither is such fund remitted to the accounts of the Commission, or any such designated account in the State, and it is equally difficult to access such information from the Accountant Generals' office. Furthermore, when the author probed into how the money from the $13 \%$ is being disbursed and utilised, an official of OSOPADEC elaborated on the politics and difficulties involved in the $13 \%$ derivation to the state as follows

When the new government came in there was an initial intention of remitting funds as appropriate, but they are yet to change that, I guess with paucity of funds, the derivation fund is taken as part of overall earnings for the state, meant for general needs of the State, especially payment of salaries, and servicing of public service. I think that has led to continual increase in gap deficit in the oil region, increasing levels of agitation, lack of trust, and militancy, leading to increasing calls for self determination. (SSI/Civil Servant 3/Akure/2016/2017).

From the interviews conducted in these local governments with local government officials and with the officials of OSOPADEC, the author recorded a reportedly very high level of youth unemployment, resulting in a constant demand for youth employment opportunities, skill acquisitions, and the creation of paths for such disadvantaged sectors of the populace to access the rentier economy and the material benefits it brings (see Karl (2004); Omeje (2008); Collier (2009) chapter four). The way some youths have succeeded in receiving economic support by taking up arms for militancy purposes, has resulted in an increasing willingness to involved oneself in militancy as a way of accessing wealth. 


\subsubsection{Local government as a means of good governance and development.}

Almost all the respondents were of the general view that local government is potentially a force for good and beneficial development. However, there seems also to be the consensus that local governments as they are presently constituted are not functioning to the optimum level. The view of a member of the caretaker committee respondent in one of the local governments captures this succinctly; for him the local governments foster development since they are closer to people. To this extent, he is of the opinion that there should be more local government and development centres and even devolves a little further to town level. He stated:

"If you take a local government, for example, you have smaller units and towns; all of these have being driven in the pre-colonial era by Obas (the local chiefs or the paramount rulers); that is a kind of autonomy so we can move to that by saying you are a local development area within the local government; it's only then we can truly accelerate our development. "(SS1/Politician 4/ Ikaro/ 2016/2017)

Respondents from the local governments were quite enthusiastic about the idea of creation of more local government entities. For example, the interviewees from Akoko South West, Ifedore, Ese Odo and Ose areas were very interested in creating more by partition of existing authorities. For example the respondents from Ose premised their view by reference to the topography and landmass of the present local government area; for them their remit covered too large an area with the consequent difficulties in sharing development evenly.

Development in this instance means accessible schools for children; health care facilities and job opportunities. When asked whether local government should be scrapped, because it is believed that it is not functioning properly, none of the respondents were for the idea because 
of the importance of the local government to the localities. One respondent was of the opinion that the local government should in fact be additionally empowered so as to function properly and foster development. He stated as follows:

"There are those who are saying that local government should be scrapped... there is practically nothing local government can do when their fiscal strength; administrative strength is taken over by the state; we need to see them as autonomous units"(SSI/Local Resident 2/ Iwaro Oka/2016).

Nevertheless that same respondent indicates clearly that there are few independent functions left to local government. The Nigerian constitution does not provide for the independent jurisdictional function of the local government. He expressed it in this way;

"Local government has no clear function and jurisdiction, no independent functions ... In the Nigeria constitution, there are only two . . That is why some constitutional lawyers would continue to say we don't actually have three tiers of government we only have two tiers, the centre and the state because the constitution has nothing for the local government.."(SS1/Lawyer/Akure/2016).

It is important to note that the desire for the creation of more local government has other motivating factors rather than just development. Political motives also underpin such desires. Some of these local governments are home to more than one ethnic group. As such there is a rivalry and struggle for political appointments between the members of the competing factions. This situation could be considered as a microcosm of the nationwide clamour for creation of more states, not just for the purpose of development, but for the purpose of inclusion. A good example is Ese-Odo and Ilaje Local Government Areas. These demonstrate the rivalry between the Ilajes, and Ijaws, and the two ethnic groups: the Ijaw Arogbo and Apoi. Furthermore, within these ethnic groups there are different interest blocs. For example, the appointment of the Chairman and Secretary of OSOPADEC in 2017 became a contentious 
issue amongst the Ilajes who are comprised of predominantly two groups; (1) Ugbo kingdom and (2) Mahin Kingdom. The Ugbo grievance resulted from the appointment of a chairman, from Mahin Kingdom of Ilaje, and the secretary, from Ese_ Odo, were not from the mainstream Ilaje bloc of the Ugbo kingdom, essentially the oil producing area. Despite heated local protest the appointment was confirmed. ${ }^{18}$

\subsubsection{Strength and limitations of local governments}

The general opinion on this question was that local government has been undermined by the state government theoretically to achieve optimum performance. From an interview with a youth leader and a representative of the town development committee in Ose (Ifon), the weakness of the local government lies primarily in the fact that there were no properly elected personnel running the affairs of the local government in his area; he perceived therefore that this did not provide any accountability. The present situation is that the state government uses caretaker committees to run the affairs of the local government. The deduction therefore is that the state government still wants to control the local governments, as explained by a category two community member below;

"Somebody who is voted for and is put in position like that should be responsible to everybody and he will perform. Another area why I think any state government will prefer a care taker committee is the fund coming from above, the federal government pays this money to the state government, the state government may not be disposed to give everything to the council; he would hold up to some out of the money. If it were a local government council elected, the government will not have the right, they will only have to call a sort of meeting and tell them what is allocated to the local government. The state government will not be able to control it fully except

\footnotetext{
${ }^{18}$ Nigerian Tribune: "Chairman of OSOPADEC Inaugurated Despite Protest by Ugbo Youths In Ondo" April 10, 2017 Edition.
} 
there is understanding between the governor and the chairman." (II/Local Resident 2/ Bolorunduro/2016)

At the time this interview was being conducted, there was already a local government chairmen elected into the office six months earlier. When sought, clarification on the difference between a caretaker committee and elected local government officials, the respondent was of the opinion that the local government chairman and the councillors would always do the biddings of the state governor, despite having been democratically elected. This might suggest that many people in the local government areas seem not to appreciate the difference between a caretaker committee and elected officials.

The respondents emphasise the role of the local government as the tier of the government closer to the people in order to address problems such as infrastructure in primary schools and healthcare centres. Bearing in mind all roles mentioned, some of the respondents still feel that the local government is not close to them and that they are not involved in the planning and implementation of the projects. To some extent this might be accounted for by the apathy and failure to engage in the political process (more common in category 2 respondents). One of the respondents in Bolorunduro, Akure North, said that the Nigerian local government is not theirs as it has abandoned the community. He stated thus, "It is unfortunate that the organ that is so far from the people, we don't see the local government officials often. They have the responsibility of taking care of us, but we always feel abandoned at the grassroots." (II/Local Resident 3/Bolorunduro/2016)

Despite the challenges set out above that respondent also agreed that the community has seen the benefit of the work done by the government, including the provision of amenities such as 
police posts and the development of infrastructure projects such as schools and hospitals. However he did emphasise that proximity either to the state capital of the local government headquarters is coincidental in whether development projects are actually carried out. The author observed that in almost all the communities there are community development associations that lobby the government for development projects and also through communal efforts build basic amenities like schools, health centres and similar projects. A respondent member of the caretaker committee in one of the local governments argues that the local government administration in Ondo state has been fairly well managed. According to him, there have been developments in terms of commissioning of health care centres, sinking of boreholes, completion of primary school buildings and creation of market and town halls. In line with the position of the member of caretaker committee, some respondents are of the opinion that local government administration has been well managed since Governor Olusegun Mimiko took over office as Governor in 2009. Even so local government has effectively been administered by a caretaker committee appointed by the state governor, an action contrary to the constitution.

In each of the local government areas visited, there were communities where the state government had recently built new schools and health centres; none of the respondents knew of the cost of the buildings, all the same they were happy that they were the beneficiaries of new development. Evidence such as this illustrates the lack of any clear-cut distinction between the projects of the state government as opposed to projects managed by local government. 


\subsubsection{Effectiveness of Local Government personnel: technocrats and politicians.}

The executive arm of the local government is made up of the chairman, vice Chair, supervisors and the secretary. The management cadre is made up of technocrats who are civil servants. As observed earlier, for seven years the local government in Ondo was administered by the caretaker committees appointed by the governor. In such a case it is easy for state governments to manipulate local authorities to the advantage of the state government and even for the personal gains of state political leaders. In those circumstances the executive arm of the local government can best be describe as a 'surrogate' executive, described by one category two respondent as having been 'handcuffed'.

In Akoko North and at Iwaro Oka the chairman of the community development committee states that most citizens seek help from the local government offices. The state of the roads, for instance, has improved due to the local government initiatives. However, based on his experience, he revealed that the local government does not address complaints; he summarised the position thus, ".. . if you go to the local government and make a complaint they will refer you to the state government,"(II/ Local Resident 4/ Ayegunle Oka/ 2016). In examining as to why local government has failed to address this issue, the respondents seemed to agree that in most cases the local government has no capacity to resolve the problems simply because the local government relies so heavily on the states. Another respondent community leader in Ose accused local authorities of a degree of cruelty since after identifying the needs of community residents, they rarely take initiatives to address pressing problems. He stated, "In the past we go there and tender our intensions then whatever they can do they would assist."(II/Local Resident 1 /Ifon/ 2016). Another respondent community leader asserted that it is true that the community leaders are aware of the challenges facing the community but are impotent to deal with them. One member of a 
caretaker committee of one of the local governments responded during the interview by saying that at present there are no agriculture, health and education programmes that the government is doing, that anyone can benefit from.

There is however one common issue about the local government workforce: it appears that the local government is the highest employer of labour in the community, there is therefore, over staffing and redundancy, hence one of the respondents, who is a retired permanent secretary observes that the staff and workforce in the local government is so enormous that what they get hardly covers salaries and personnel emoluments; with that in place he argued that they cannot fund any meaningful development in local government.

\subsection{8: Level of Participation in Electoral Process}

Respondents from the six local governments stated that they were interested in exercising their franchise during elections. However, for about eight years there was no local government election in Ondo State and the last time the public they had the opportunity of electing candidates into local government council was in April 2016. Nevertheless certain of that the respondents were sufficiently politically aware of their civic duty to vote and about $55 \%$ of the respondents claimed to have voted during the last presidential and gubernatorial elections. It was also observed that there is apathy and cynicism about voting and although certain respondents see voting as an exciting opportunity, they may not be convinced that their votes count. Some were also of the opinion that election time is the time for them to get something back from the politicians in terms of wealth promised by the politicians during the election. This popular notion and attitude reinforces the argument that political clientelism is prevalent in the polity and this shapes the nature of Nigerian federalism. Further examination of the relationship between institutions and actors as posited by Pieterson (ibid) in the review 
of literature in understanding the Nigerian federal system is important. A national newspaper ${ }^{19}$ reported that the last gubernatorial election conducted during and after this fieldwork alleged that voters were induced with money before voting. In addition it is said that community leaders compel community members to vote for community-endorsed candidates.

The election monitor's report of the November 2016 gubernatorial election reveals that that the election turnout was generally quite low across polling stations visited. The voter turnout based on accredited voters was $35.5 \%$. This was compared to other states that had their gubernatorial election within the same time frame. It is reported that the turnout in Ondo State is about $1 \%$ less than for the Bayelsa State; 2\% less than Kogi State 2015 governorship election and about $3 \%$ more than the 2016 Edo governorship election while the turnout based on total votes cast was $35.25 \%$.It is clear that these figures are less than the voter turnout in the 2012 Ondo State governorship election (38.1\%) and the 2015 presidential election in Ondo State $(38.8 \%)$. It is however noted that this is relatively average turnout and should not be interpreted primarily in terms of voter apathy but as a relatively true representation of the voter turnout ${ }^{20}$.

\subsubsection{Decision- making at the community level}

The local government reforms of 1976 anticipated clear and defined relationships between local governments and their communities. Local governments were seen as local institutions of modern government that will be 'responsive to local wishes and initiatives', and provide 'appropriate services' and undertake 'development activities'. They were also expected to

\footnotetext{
${ }^{19}$ Vanguard Newspaper 'Ondo Election: Akeredolu leads' November 27, 2016.

${ }^{20}$ National Daily Newspaper‘Election Monitor report on 2016 Ondo Governorship election’ January 11, 2017.
} 
'mobilise human and material resources through the involvement of members of the public' and provide a 'two way channel of communication' between local communities and the institutions of government. In these responsibilities, local government officials perceive that the difference between local government and government at higher levels is that the latter 'deal with files' while local governments 'deal with people'.

The general response was that the people are not involved in the decision making of the local government; however, more often than not, the local government officials inform the people of some decisions. The principal of a secondary school in Iwaro-Oka stated that the local government and councillors do not generally involve the people from the local community in projects they intend to carry out. It was also noted that the respondents in the local communities were not happy about the fact that they are not carried along in deliberations and decisions, and they expressed hopelessness about the situation. From other respondents across the local government areas it was observed that, there is a platform that gives the community the opportunity to engage with local government officials through a community development forum. However, in two local governments, respondents recollected that there was an attempt in the past by the state government to engage the community in project initiation and implementation. A women's' group leader in one of the local governments, giving her personal testimony based on experience, indicated that before project initiation, the local governments first involved the community. She recounted that:

"The ministry of community and rural development consulted with the community. It is call three I's, they come to the community and go round to ask what they need. The community will gather and they will talk to them. There are different issues mentioned then, but I do not know the parameters that were used to select a priority and do it. Like when they came to my village they built a hall for us. (II/Local Resident 3/Ipogun/2016) 
In an interview with another community leader, it was observed that there were other ways through which the community convey their concerns to the local government chairman or the councillor about their problems. This included written complaints, delegations and making personal contact with the chairman. The respondent however expressed disappointment since the chairman and other local leaders rarely seemed to address the complaints presented. He said, “. . . it is not only during electioneering period that we suppose to see these people, they are supposed to come to us as we normally go to them." (SSI/Local Resident 3/Sabomi/ 2016)

Communication and the lack of transparency were found to be a significant factor in the process. People in the communities were often unaware of how local government is managed and how to approach their representatives or officials. Respondents claimed that the local government officials rarely disclose details of the allocations made by the local government. The response of one them best captures the issue in this succinct response:

"This will not be known to outsiders but in the council because those who are responsible will be called together and discuss how they are going to disburse every money that comes from the federal government through the state government”.(II/Local Resident 4/Bolorunduro/2016)

\subsubsection{Responsiveness of the elected officials}

From the fieldwork it is noted that the chairman and the councillors are perceived as service providers. They are supposed to be part of the society. However, many of the respondents complained that the Chairman of the local government is usually aloof after the election, having abandoned the electorate by breaking election manifesto promises. Some of the respondents claimed that this is usually the case because of the personal demands for 
assistance by huge number of the community. Most of them might not even reside in the local government area but may be in the state capital Akure. One of the interviewees, a youth leader in Ese Odo, at Sabomi/ Igbekebo clarifies the role of elected officials in the local government (in particular the councillors) in planning for the community. After the ward representatives hold discussions in caretaker committees, they then engage the community. Another respondent from another local government commented about the relationship between the councillor and the chairman and the community in general suggesting that in contrast to previous regimes the current caretakers in local government have abandoned the communities. To quote him:

In Mimiko's regime there was no elected local authority except for the caretakers. It was recently they had elections, and now we have the chairman and the councillor in place, so the impact has not been felt much. In the past the councillor do covert, bridges, grade the road to farms, government us to do that in the past, but this present government has not done anything. There is no impact of the council in the town for the past eight years. (SSI/Local Resident 2/ Iwaro Oka/2016)

It might appear that the people are more comfortable with access to local government through local councillors however, they can do little without the approval of the chairman of the local government so the chain of command is often an inhibiting factor in the process of representation.

\subsubsection{Quality of primary health care and primary education.}

\section{Primary Education}

The three issues examined in the quality of free primary education were; (1) the infrastructure; (2) personnel, and, (3) enrolment the schools. In the headquarters of the each 
of the local governments, save for cities such as Akure, Ondo, and Owo, which have a considerable number of primary schools, the average number of primary schools in each community is two, so in total within the local government areas the average number of primary schools is between forty six and forty eight.

The innovation of the previous governor in the building of what is called the 'Caring Heart Mega Schools', built across Ondo State, is generally applauded by the residents of the towns that benefited from them. However, the consensus view is that the quality of primary education is poor, an assertion based on overcrowded classrooms. Random sampling method was used to select fifteen schools in three local government areas for study, namely Ifedore, Akoko North East and Ose. An average of forty to fifty pupils in the classroom is well above the optimum ratio of thirty pupils to a classroom with a single teacher. However the overcrowded situation of the primary school signifies that enrolment in the school is high. There are also private nursery primary schools in almost all the rural communities and the respondents reveal that the existence of private schools is engendered by the lack of confidence in the public school system. Respondents also reveal that parents often withdraw their children from public schools and enrol them in the private school where they feel that they children can access quality education.

All respondents agreed that the quality of primary education is still generally poor. Apart from the insufficient schools and classrooms the respondents also raised the issue of the quality of the teachers in the primary school system and absenteeism in rural communities as reasons for discontent. It is generally acknowledged that poor incentives offered to teachers who work in the remote villages is a negative feature in the system resulting in disenchantment and disappointment. 
One important finding is that despite those negative factors there is an administrative structure in place in local government that helps in the control and management of primary schools that is the local government education authorities, (LGEA) under the general supervision of the area education office (AEO). However the respondents didn't see any particularly beneficial impact of this management structure.

\section{Primary Health care}

The issue here is to investigate if there are functional health care facilities, and to ascertain if they are affordable. Depending on the population of the community the communities have general hospitals, comprehensive health centres, basic health centres and maternity centres. All respondents agreed that the people have benefited from the sitting of these facilities in their communities though it is recognised that the accessibility of such health facilities is not easy for people living in urban and semi urban areas. One important aspect of the effectiveness of primary health care delivery is the relatively low percentage of maternal and infant mortality. The state government programme tagged 'Mother and Child Hospital' is spread across the eighteen local government areas throughout the state and this initiative has drastically reduced maternal and infant mortality. The respondents did however identify two major hindrances in the public sector; the first is the inadequacy of medical personnel and health facilities in the semi urban and rural centres; the second is the limited involvement and participation of the community in primary health.

\subsubsection{Means of improving the function of local government}

To improve the situation and function of local government, numerous suggestions were made by the interviewees, the main one being that of sensitizing the citizens and the community to be more politically engaged and enlightened. This, according to all respondents, would help 
people be of aware of their social responsibilities and encourage them to hold their representatives accountable by using their voting power to recall underperforming leaders. A community leader noted;

"Before anything can be done our citizen/community need to be sensitized you cannot place something on nothing it will not stand we need to be politically enlightened to that people will be conscious of their social responsibilities and we have to wake up to it."(SSI/ Local Resident 5/ Sabomi/2016)

That individual contended forcefully that pressure groups, non-governmental organizations, community leaders and politically empowered individuals should create political awareness among the citizens. He went on to say that creating that awareness is the shared responsibility of enlightened individuals, NGOs and pressure groups. In forcing officials to be responsive to their duties the question of recall of representatives was put to the respondents and while some claim outright ignorance about it, others who claimed to be aware of such constitutional provision feel that it is practically impossible. Aside from the rarely used constitutional provision of recall, respondents offered recommendations on what can be done to improve the function of both local and state government. A member of a caretaker committee of the local government suggested that local government autonomy can improve the effective functioning of the local government. He suggests that without the overbearing nature of state government control, local government can allocate resources appropriately and foster essential development. To cite from his verbatim quote given in interview, "I recommend local government autonomy, Let it be autonomous. "(II/ Local Resident 4/ Ayegunle Oka/ 2016). 


\subsubsection{Performance of Local Government Governance between 1998 and 2015}

Opinions vary greatly on the performance of local governance between 1998 and 2015. Some respondents suggest there are little or no improvements at all in local governance; conversely some argue that local government performance has been good but has not been satisfactory. One discussion with an interviewee revealed that from 1998 to 2016 there have been improvements in Nigeria in terms of technological advancement, reduction in child mortality and improved medical practices. A member of a development committee goes on to suggest that there had been improvement in the functioning of the local government since 1999, but cites the caretaker principle as an obstacle. He stated with confidence that, "there is improvement in any case like a lot of developmental projects taking up by this new present regime through the local government chairman is unprecedented, I believe we are improving. "'SSI/ Local Resident 5/ Sabomi/ 2016).He did however acknowledge that despite the strong local government administration in 1999, the current one has generally achieved relatively little.

\subsubsection{Other community representatives: the role of the traditional institutions in development.}

Traditionally the chiefs and royal heads in Nigeria represented the community. That position remains to an extent in that they continue to lobby and influence local government and where projects are undertaken. Chiefs influence councillors on a personal basis and to some extent that influence percolates upwards into local government. The respondents were unanimous in stating that the local chiefs should be even more involved in the administration of local government. One respondent notes that:

"Another interest outside the council that may help the community is the royal heads by the Oba and the chiefs; the chiefs come from the quarters 
and the wards and they can influence, if it is a possible, a project the local government wants to do.(SSI/Local Resident 2/ Iwaro Oka/2016).

Apparently the respondents agree that traditional councils do influence the elected local authority and that such influence manifests itself at the state and even the federal level. Whereas the traditional council might influence local government operations, the Obas/Baales generally play a neutral role and as such, they cannot hold the government accountable, only exercise subtle influence.

\subsection{Conclusion}

This chapter contrasts some of the fundamental arguments and positions in contemporary literature on Nigeria federalism, political economy and development. As noted in the previous chapters a significant proportion of the literature suggests that the political and economic structure of Nigeria is dysfunctional. That dysfunctionality has been identified as the principal source of poor governance in the country, reflected in lows indices of development. The fieldwork suggests there are two modes of Nigerian federalism, which may be termed formal and informal factors. The formal factors include the architecture within which the federal system operates whilst the informal factors include behavioural patterns of political actors that drive the process of governance. 
Although the informal factor of Nigerian federalism evidence many defects, most notably the influence and self-interest of unscrupulous politicians, the formal factors of structure, rules and normative settings is designed to regulate and control the informal factors so that the formal structure prevails. Based on the evidence however this researcher suggests that that balance is not much in evidence, with the result that the informal factor dominate and regulate the formal factors. 


\section{Chapter Six}

\section{Findings and Discussion}

\subsection{Introduction}

This chapter presents a discussion of the findings resulting from the data set out in chapter five, an analysis of the fieldwork and a comparison of such findings against the literature referred to. It consists of five distinct themes which include; factors perceived to account for the shortcomings in the Nigerian federal structure; institutional and political reasons for the poor performance of decentralisation in Nigeria; problems encountered in the implementation of decentralisation in Nigeria local government system; necessary conditions for effective decentralisation for effective decentralisation in the Nigerian local government system; and, measures to be adopted in improving the decentralisation in the Nigeria local government system.

These principal topics focus on the main research question which revolves around the extent to which the current structure and practice of federalism has contributed to the poor governance and underdevelopment of Nigeria. Subsidiary issues include whether the transfer of authority, resources, accountability and the development of an open local political process and local political and administrative institutions, are working in ways that address local priorities in the manner inherent in genuine federalism. A considered assessment of the issues will include reference to the evidence and a factual assessment, based on that evidence. It will consider whether local governance brings the expected benefits, intangible and tangible, respectively in terms of better schools, health systems and infrastructure and the empowerment of the population and social service delivery that enhances the lives and welfare of the population across the entire state. 
The fieldwork was designed, by scope and content, to elicit from the respondents the impact of the current structure and practice of federalism on governance and development in Nigeria. It focussed on both the immediate and subjective experience of the respondents and, when expressed, their objective assessment of the state of the transfer of political power into the regions by the implementation of federalism based on the constitution. Certain respondents also commented on the constitution itself as the power underlying and fuelling federalism in Nigeria. Following that analysis and discussion the author will come to conclusions as to the central research question.

\subsection{Patterns and Themes}

The primary data, collected by means of the fieldwork disclosed several recurring themes and patterns are conveniently grouped into two categories. The first are those issues which relate directly to the structure and architecture of Nigerian federalism while the second includes the popular perception of the Nigerian experiment with federalism.

\subsubsection{Findings}

The presentation of results is purely qualitative, verbatim quotations gathered by face-to-face interviews and content analysis being used to present such data. Necessary inferences were drawn from some of the findings which corresponded to varying degrees with the literature review, referenced in previous chapters, while observed similarities and differences between the present study and such literature were reconciled using appropriate research tools and methodologies.

In general it is observed that the three main aspects of decentralization (administrative, fiscal and political) involve some level of devolution and sharing of power, resources and 
responsibilities among the three tiers of government, (federal, state and local). The extent of the arrangement of such quasi devolution in theory is based on the constitution, and its practise remains a contentious issue for a number of the respondents, especially those within category one, those perhaps who expresses a more informed view on the topic. The research identified differences between the theory and practise of federalisation which are perceived to be largely the consequence of the intrigues of political and economic rivalry among the constituent units of federation and the defective structural arrangements.

It is informative to note that the debate on Nigerian federalism is intricately woven around political and economic issues of; stability of the polity; cohesion; distribution; allocation; and economic growth focusing fundamentally on the formal institutions as the main means of achieving these ends. At grass root levels however it is far more simply measured by what the citizenry perceives as the benefits delivered by the federal form of government, down through the tiers and onto the ground where the reality of a general lack of infrastructure is felt most keenly. Equally it is right to say that when projects are delivered at such levels there is praise for the delivery process such as by the women's' group leader but in general the spirit of disappointment and the sense of failure of the system prevailed. This is summed by the respondent (Chapter 5) who referred to 'phony contracts' are being let out by state government.

The processes and workings of intergovernmental relations in Nigeria have been adjudged by Freinkman (2007) and Khemani (2001) to be laced with conflicts, fundamentally arising from (i) structural organisational problems, (ii) fiscal relation problems, (iii) shortage of qualified manpower(iv) political and bureaucratic corruption and, (v) the prevailing political culture. The consequences, according to Khemani (2001) are poor service delivery and the dearth of 
development in all sectors of national life. This was generally made out by the field research. An example (Chapter 5) is that of the former head of service delivery in Ekiti state who referred to the mystique surrounding projects that rarely come to fruition because funds perhaps earmarked for such a project is diverted elsewhere.

\subsubsection{The de facto federal structure of Nigeria}

All the evidence shows that Nigerian federalism is overtly centralised. This finding corroborates previous investigations which showed that the Nigerian federalism is more unitary than federal in nature (Onwudiwe and Suberu 2005:94; Elaigwu 1998; 6-7; 2005; 69). This is position is corroborated more by the politicians, technocrats and bureaucrats who were interviewed than the category two respondents who take a more parochial view but nevertheless appears to be valid and provable. There exists a very strong central government and very weak constituent units. One of the interviewee notes that this is based on how Nigerian federalism is conceived and has been operating de facto. He also referred to the bane of the federal system being the constitution out of which federalism was created and the on-going struggle for political reform leading to local autonomy as an impediment to fully functional federal government Such opinions suggest that the principle of autonomy within a federal arrangement is compromised from inception. In principle the constitution confers some degree of autonomy on the sub-units but, in reality, the sub units seem to lack autonomy whether by reason of the failure of effective power sharing by the federal government or the failure of the local government to act efficiently and in harmonious independence from central government. Another interviewee, a former head of service in one of the southern western states, was of the view that because of how Nigerian federalism is conceived, the powers of the federating units are intentionally whittled down. 
That lack of autonomy, and thereby the capacity for creativity based on identified local need, and the incentives to promote economic growth and development is notably lacking in the sub units because it is said that the federal government routinely dictates policy to them. One implication of exercising this dominance over the federating units is that there are some projects and developmental programmes that are inappropriately sited in some states. A senior official of the civil service in one state noted in interview to the effect that it is the federal government that makes decisions about where to site projects. His view, based on close experiences, therefore was that the practice of federalism was token only and therefore arbitrary.

In some of the local government communities there are abandoned projects. For example, the uncompleted primary and health buildings in Ifedore LG and Ifon LG. In Ese Odo there are abandoned roads projects such as the Sabomi- Igbotu road. Such projects are purportedly funded by the federal government and whilst there is speculation about the reasons for such abandonment, the general air of secrecy ensures non-disclosure. Popular opinion amongst the local citizens, evident in the literature is that this is due to the overlapping functions of federal and state agencies in service delivery with the result that control is shared and falls into the gap between the two sides. Again the respondent from Ekiti is cited for his experience in exactly this circumstance where the miscommunication between federal government and the ministry of agriculture resulted in the complete failure of the project to build a centre of excellence for agriculture. a much needed resource.

An obvious feature of the de facto federalism is the dependence of the state governments on the federal government not only for resource distribution but policymaking. Although the constitution confers considerable power to the states in the constitution, it appears that these 
powers are, in practice, tactically withdrawn by other contradictory provisions of the constitution. Reference is made to the respondent who called for the constitution to be scrapped because despite the notion of three tier federal government it purports to create it effectively only delivers two tiers by virtue of the constraints in the constitution itself. A former governor of a state in the South West, Osun State, explained in interview that considering the enormous resources at the disposal of the federal government, it remains a very difficult thing to distribute those resources to the regions. This, he said, was the undeniable political reality of contemporary Nigeria. It results in a significant imbalance in the allocation of legislative powers between the federal government and the states as federating units, with the overloading of the exclusive legislative list at the expense of the concurrent and residual lists (Bolaji Akinyemi 2004:4-7; Jinadu 1994: 57; Elaigwu 2002:78). Second, there is an overlap and duplication of functions which has brought wastage, corruption and a lack of development. An example of the dominance of the federal government was provided by a former governor who lobbied for a series of bridges between Shagamu and Lagos but who failed due to the refusal of the federal government to sanction such expenditure. It is therefore clear, based on the results of the interviews, that there is imbalanced allocation or distribution of legislative powers among the three government tiers in Nigeria. This finding is in line with the studies by Bolaji Akinyemi (2004:4-7), Jinadu (1994: 57) and Elaigwu (2002: 78).

Nigeria federal democracy has witnessed constitutional crisis/conflicts since 1999 due to inherent flaws of the constitution; conflicts range between Governors and their deputies, president and the vice president;on security matters between the governors and the Police Commissioners; crisis of local government creation-between state governments and federal government; conflict between the executive and legislative arms of government and the 
lingering problems of fiscal federalism(Suberu and Osaghae 2005:69;BolajiAkinyemi2004:4; Wunch and Olowu 2010:3). From this it is clear that Nigerian Federalism face numerous challenges. Nigeria has a defective Structure because it is highly centralized government and a situation whereby the federal government exercises enormous powers over the state and local governments. Moreover, the subjugation of local governments under the state government reveals a defective federal structure.

Amongst those interviewed, there appeared to be little ambiguity about the importance of the federal constitution as the prerequisite for any successful federal arrangement. In the same vein, there seems to be a consensus, that the lack of capacity of Nigerian governments (federal and state) to translate the enormous resources in their control into economic growth and development is a consequence of a defective constitution. Section 5(3) of the Constitution of the Federation of Nigeria 1999 for instance, still contains the original first republic limitation on executive power of the state so that its executive authority shall extend to all matters with respect to which the legislature of the Region has for the time being power to make laws but shall not impede or prejudice the exercise of the executive authority of the Federation or to endanger the continuance of federal government in Nigeria. As stated in Chapter 5 that provision contains an in-built veto without definition of what is meant by impeding the federal government or who judges whether any act by a state is deemed to have done so and by reference to what standard.

An example of the exercise of the overbearing power of the federal government was the manipulation of the gubernatorial election of 2007 in Ondo State. The leading contestants were Dr. Mimiko of the Labour Party (in opposition to the incumbent party) and Dr. Agagu of the People's Democratic Party (the ruling party at the federal level). The generally held 
view of the citizens of Ondo State and the reports of the Election observers was that the Independent Electoral Commission (INEC) plainly rigged the electoral process in favour of Dr. Agagu. This became evident when his victory was announced in Abuja while the voting slips were still being counted in Ondo State. Dr. Mimiko challenged the outcome and it was declared to be unlawful by both the Election Tribunal and then the High Court. The Appeal Court upheld the first instance decisions of both, during which time Dr. Agagu acted as de facto governor of Ondo State without lawful mandate.

In another instance, in Osun State, the former Governor, Chief Bisi Akande (interviewed by the author) reported on use of the police force in support of the federal ruling party candidate. By his account, his opponent had one hundred and fifty anti-riot policemen who caused intimidation amongst opposition party voters at the point of the polling booth. In his view such intimidation was an obstruction in the process of a free and fair election and unlawful using the federal government organs and agencies.

Such incidents went some way to justifying the demands of the then opposition party, that the police forces be decentralized so as to limit the power of the federal government in such matters. However, it is notable that after the historical opposition electoral victory of 2015, this item has apparently disappeared from their legislative agenda.

The overbearing posture of the federal government is not however limited to the conduct of elections. For instance, under former President Obasanjo, in 2003 withheld the Lagos State fiscal allocation for two years. It was supposedly justified on the basis that the decision of the Lagos State government to create 37 local government development areas, (LCDAs) was unconstitutional. These actions on the part of the state government and the federal 
government put to test in a very practical way the relative powers of the two tiers of government and their relationship arising under the constitution. The matter went to the Supreme Court which made two principal findings. The first was that it upheld the constitutional legality of the LCDAs; the second finding (the natural consequence of the first) was that the withholding of the allocation was constitutionally illegal and the Federal Government was therefore ordered to release the funds. The federal government disobeyed the rulings of the Supreme Court, and when it disobeyed the matter, the federal government went back to the Supreme Court to insist on withholding the allocation however, the allocation was eventually released under the Presidency of Late President Umaru Yar'Adua.

As noted in the fieldwork report, the practice of the federal government gives the impression at the grass root level that it is a behemoth. Such is the de facto state of federalism in Nigeria. To make it work the general opinion is that the constitution must be amended to reflect basic principles of federalism, i.e. true devolved autonomous local government. One of the respondents, a civil activist and development expert, agreed with the popular notion that the constitution is at the heart of the failure of federalism, and added a new dimension to the debate by arguing for a fourth tier of government to ensure that resources find their way equitably into all parts of the country. Whilst that is outside the scope of this study it is illustrative of how the problem of delivering federalism on the basis of the current constitution is perceived.

\subsubsection{The prevailing political culture}

The findings of this study show that federalism has translated into at least, a degree of political stability in which some socio-economic development has occurred. To suppose otherwise, when Nigeria has oil wealth would be manifestly false, but the debate remains 
about the extent of that development as against what was reasonably anticipated. This view is supported by several studies that found that federalism in Nigeria has achieved the purpose of promoting political stability and cohesion (Diamond 1999:152; Horowith 1985 602-613). Olowu too has found that political federalism, through the creation of the sub units, has reduced the tendency of secession and reduced threat of political instability (Olowu 1991).

The political objectives of the state are manifest in the powers that are devolved to the local government or the administrative units and they assume greater participation in development planning and management, so promoting national unity by giving groups in different regions in a country a greater ability to participate in planning and decision making, and thus increase their stake in their own political stability. This view is supported by (Rondinelli et al 1984: 10). Conversely some scholars have argued that fragmentation of Nigeria over the years have considerably reduced the tendency of secession and disintegration this creating a more settled political climate. For example, Suberu (2010) suggests that the fragmentation inherent in the federal system has created a situation where no single constituent unit of the federation is large enough to challenge the authority of the federal government, threaten secession, or dominate other states. However the existence of very vocal and sometimes militant insurgent groups, which threaten secession and violent ethnic and religious uprisings, run contrary to that supposition but even so an argument exists that the rationale behind state creation has delivered some political stability, Another important issue is that it may appear that as more states are created, such states are becoming smaller and weaker with the central government becoming comparatively stronger (Diamond, 1987).

The level of engagement in the political process depends very much on the individual's political culture, (see Chambers and Kymlicka (2002) in Chapter 2.8.) Factors that adversely 
influence the political culture include, apathy, fear, and a lack of conviction that any engagement in the political process is meaningless in a system, which is essentially corrupt, and whilst promises much delivers little. Almond and Verba (1963) talk of political culture being influenced by 'parochial' and 'political' orientations. Parochial political culture describes those participants in the process in terms of disengagement and naivety. Participant political culture suggests a greater deal of involvement in and between specialized institutions and the citizen or active groups of citizens interested and engaged in the political process because it affects them directly. There is the third class of political culture and that is the civil culture as a subset of political culture, considered as a participant group culture such as that of political parties or activists, the common feature being engagement in the political process.

Elaigwu, (2007) indicates that it is almost impossible to generalize in describing the prevailing political culture due to the diversity of cultures, ethnicity and religions in Nigeria. The self-interest of political actors is a factor that has a dramatic effect on the political landscape and culture and breeds a culture of corruption and expectations of poor service delivery and 'phony contracts'. It is the view of this researcher therefore that the political landscape in Nigeria has reached some level of maturity but that the failure of the system itself (and the principal participants in the process) engenders unrest and the rise of political instability.

\subsubsection{Extent of administrative decentralization}

Administrative decentralization involves the transfer of responsibility for planning, financing and management of public functions; the structure of governance, public personnel, administration and intergovernmental relations to devolve entitles charged with the administration of such functions, properly accountable to its citizenry. The essential rationale 
for administrative decentralization is to move such functions to those tiers of government for a better and qualitative service delivery where is it most needed. Among the supporters of decentralization are, Adamolekun \& Ayo (1989: 157-176) and Afigbo (1991: 13-29).

This research shows that degree of transfer of authority to the local government of Ondo State is both incomplete and badly managed. This calls into question the type of decentralisation that is in operation and although the constitution envisaged full devolution of powers, in practice the type of administrative decentralisation in operation more resembles delegation of duties with accountability facing backwards to central government. It is a political fact that local government in Ondo State was administered by the caretaker committees appointed by the Governor for more than seven years. That meant that almost all the functions of the local government were taken over by a combination of the federal and state government. In light of this some scholars (and particularly technocrats) have argued that the principle of local government should be scrapped because during that period it was shown to have no effective purpose. In addition Nwabueze's (2003:123) submission that an inclusive model of intergovernmental relations which features a hierarchical relationship between the central government and the other tiers of government, as well as dependence of lower tier of government on the higher tier, is largely absent in Nigeria.

Fiscal decentralization (as opposed to just administrative decentralisation) leads to enhanced balanced distribution of resources amongst the units of the federation and promote distributive justice through the devolution and redistribution of resources (Galadima 2007: 59-72). This is a state that Nigeria has not attained because of the view that the present situation is on of quasi federalism. This study illustrates that proper and equitable fiscal decentralization faces numerous challenges, leading almost inevitably to the absence of fiscal 
autonomy in local government. It is noteworthy a simple majority of the participants in the research expressed ignorance about the fiscal matters of their local government which is suggestive either or both of a lack of engagement or a lack of transparency at local government level about such matters.

The opinion of the author, based on the results of the interviews, support previous researchers that the arrangement of fiscal allocation in Nigeria threatens initiatives, innovation and modern ideas of generating money for sustainable development (Diamond 1987: 21; Omeje 2008:78; Suberu \& Osagahae 2010;10). Other authors cite the centralization of revenue allocation within the context of Article 162 of the 1999 Constitution of the Federal Republic of Nigeria that leaves the States at the mercy of the Federal Government in terms of their ability to meet the needs of their electorate. (Ben Nwabueze 2003: 124-130; Suberu 2008: 451-485). Moreover, the financial incapability of the Nigerian Government at the state and local government levels to carry out their assigned responsibilities, without recourse to the centre, as a result of their financial constraints, demonstrates a failed fiscal decentralization effort ( Nwabueze 2003: 124-130).

The analysis of the principle of decentralization in this research shows that it is an essential mechanism for good governance and socio-economic development. For instance administrative and management objectives are expressed on the de-concentration of authority to react quickly to un-anticipated problems at local level, thereby doing away with multi level bureaucracy. 


\subsubsection{Institutional reforms required to improve socio-economic growth}

This study shows that Nigerian decentralisation at state and local government levels, is not necessarily reflective of the political communities at all levels. The narratives provided by most participants indicate that local government fails to meet expectations or represent the community in either a political or cultural sense. It is evident that what the political leaders have done is to expand local government so that resources may be diverted to diverse destinations and have done so in such a way, under military rule, that their political preferences have affected the entire process. This research aligns with the literature that recommends decentralization as a means of achieving good governance and development (Rondinelli and Cheema 1983; Smith 1985; Litvack, Ahmad, \& Bird; 1998; Hutchcrorft 2001 Prud'homme 1995; Wunsch \&Olowu 1990).

The results of this research represent the views of a number of the respondents (however eloquently or not, they were expressed) that Nigeria has not evolved into a non-extractive system of government because of the legacy of a colonial extractive system that failed to establish enduring governmental institutions. Based on the literature, it is clear that the colonial legacy may have laid the foundation for the corrupt attitude and mentality of a number of Nigerian political leaders, who see governance as a means of self-enrichment, selfaggrandizement, the opportunity to build personal empires and the exercise of power over others. As a consequence institutional change is required and this research aligns with some of the literature recommending the restructuring of Nigerian federalism, focussing on the imbalances which have been identified. Nwabueze (2007) captures the aggregate view on the institutional restructuring of the federal arrangement when he points out that restructuring would fundamentally involve constitutional and statutory changes. 
In summary such institutional changes would involve the preservation of the federal system as the best option for government in the Nigerian context. Constitutional reform would be a critical part of such restructuring leading to a review of the division of powers and revenue between central government and the localities. At the extreme, what Nwabueze $(2007 ; 391$ 443) termed the coercive forces supporting the present central government, would need to be dispelled. Such large-scale institutional changes undoubtedly constitute a major restructuring of the architecture of Nigerian federalism but unless and until achieved true federalism will not be achieved.

This research further focuses on the economic imperatives of the renter state as an adverse feature of Nigeria's institutional economy. Rent economy has not only changed the structure of revenue derivation and allocation, it has also affected the mentality of the people, i.e. 'renter behaviour' or 'renter mentality' (Beblawi 1990). The 'Renter mentality' is evidence of the State being over dependent on export resources, with low or absence of revenue from domestic taxation so that citizens have less incentive to place pressure on the government to become responsive to their needs. Instead, the government essentially 'bribes' the citizenry with social welfare programs, becoming an allocation or distributive state, (Beblawi et al 1990: 87-88). To this extent, the renter economy changed the ideal and idea of federalism in Nigeria, in terms of revenue generation and equitable distribution leading to socio-economic development.

\subsubsection{The evolution of federalism in Nigeria}

In the paradigm federal state, as posited by Wheare (1964) the sub-units must be solvent enough to support the central government (Suberu 2010). The findings of this research show 
that reliance of the sub-units of the federation on the central government and the state government is counterproductive. It is noted that it not only kills initiative for revenue generation, it also stalls appropriate developmental plans for the sub-units, and diminishes the political and economic space of the people. Based on responses provided by majority of the interviewees this study recommends political education in addressing failed decentralization in Nigeria. Apathy in voting patterns is reflected most in the voice and accountability indicator. The trend can be attributed to two main factors. The first factor is that the political culture of democratic political activism (apart from extreme groups) is lacking in Nigeria. The second is that the effects of centralization do not confer legitimacy on government and do not direct the involvement of the people in governance.

One of the major problems identified by this research is the lack of understanding or deliberate distortion of what federalism entails in Nigeria. In the discussion about political participation, one of the interviewees complained that if people didn't know or understand what was wrong, they not know how to vote. One of his mantras was that people have to be educated to take any meaningful part in the process but without development such education will not be freely available. It is noted that political education and enlightenment of the citizens is essential. This would help erase negative thoughts and scepticism of the political system in general (Amuwo, Suberu et al: 29). To this end, an emergence of new leadership with a new orientation and the right attitude will be of great importance in achieving the peace and stability that the introduction of federalism seeks to achieve.

Elaigwu (2007: 313) argues that the future threat to the survival of Nigeria may not come from the vertical relations between the federal centre and sub-national states, but from the horizontal relations amongst Nigerians as the centre becomes increasingly a bigger political 
prize, especially as the crises of allocation of scarce resources increases in tempo and aggressiveness. In a regional arrangement of government, there would be more cooperation among the provinces, where there is a cultural affinity and socio-political identity. To this extent, emphasis is placed on decentralization of not only the functions of government but of economic activity.

The research does not entirely support the fact that the restructuring of the architecture of Nigerian federalism might be a difficult task to achieve, an argument other previous researchers have advanced. Suberu (2010) argues that past and recent efforts to achieve comprehensive constitutional change have proved unproductive in a context of rigid constitutional amendment rules and deep ethno-regional divisions over the precise modalities and specifics of reform. To this extent, he advocates non-constitutional renewal as an alternative path to political reform. This research does not, however, support the opinion that non-constitutional reform would genuinely transform the state. The constitution remains the bedrock of a successful federal state and this researcher therefore argues that structural (constitutional) reform and social reforms must be aligned.

\subsection{Key performance indicators in moving de facto federalism to fruition}

\subsubsection{Leadership and political will}

One important factor that plays out in the present analysis is the divergent leadership culture. The problem of leadership in Nigeria has contributed greatly to the shortcomings of federalism for reasons ranging from tribal loyalties, ethnic differences and personal ambition. Virtually all its leaders, since independence, have acted in a way or that portrays them as advancing ethnic or sectional interest. Even the citizens, in most cases, analyse and perceive 
the actions of those in governance through the lens of ethnicity or other sectional affiliations. The tendency towards poor political will is further reinforced by the attitudes of Nigeria's political class who, in their inter and intra class struggles for political power and to consolidate their accumulation of wealth, aggravate existing or historic divisions by interpreting politics in terms of survival of ethnic or regional entities. Indeed, the series of leadership crises experienced since independence reflect this perspective. Also in this context, the practice of federalism only serves to advance individual rather than communal interests (Muhammed 2007).

Considering the importance of good leadership in governance and development, most participants suggest that Nigerians must focus on effective leadership as a pre or co requisite to almost all other reforms. To support this argument, Elaigwu (2008) argues that federalism is not a sort of magic that will automatically usher in the values essential to peace, good governance and development, as he notes that what federalism cannot supply are values of fairness, justice and the accommodation of all such values in the system. Nigerian political leaders must hold these values at their core values.

However, federalism may provide a conducive medium for realizing, in relative forms, the values of fairness and justice in public life, and political leaders must effectively use this medium (Elaigwu2007: 314-315). In this way, the leadership recruitment process must be tailored towards bringing out leaders that will be accountable to the people. For this to occur, the participatory space of the people must be enhanced, giving them genuine involvement in the processes of leadership recruitment and government and enabling their basic control of their politics, environment and economy. Although decentralization is instrumental in good governance and development, its application in Nigeria, based on most responses, has been 
ineffective and has failed to bring inclusive development to Nigeria, let alone turn the country into a global economic force. Through historical institutionalist analysis, this study accentuated the ambiguous mix of devolution and de-concentration as a major source of decentralization's governmental and economic underperformance in Nigeria.

The desire for development, as indicated by most participants in this study, seems to underpin the competition for control of the state political apparatus and fiscal powers. To support the argument, Suberu (2011) proposes that access to political and economic powers seems to guarantee development. Hence there has been a consistent struggle amongst the sub units/regions to gain access to political and economic power. In achieving control of political and economic advantage over the years, other variables outside of the political process have been deployed. These variables fundamentally are religion, tribal sentiments and prejudices.

The clamour for development appears to necessitate the struggles for political and economic advantages amongst the different sub units and regions within the framework of Nigerian Federalism. Despite this, most participants show that Nigeria has not witnessed the type of development that could commensurate with the kind of resources accruing to it. To this effect, it appears that the economic and political control of governance may not necessarily translate into development, as supported by Suberu (2009). Even at that, there is a consistent struggle for political and economic advantage of the central government. The political and fiscal evolution therefore raise fundamental questions in relation to the propriety of the federal structure and the extent to which the present structural arrangement can particularly serve the purpose of development. 


\subsubsection{Socio-economic development}

The overtly centralised and overbearing character of the federal government is argued to be responsible for the poor performance of socio-economic development of which education and health are key features. Further research suggests that it may not just be a constitutional issue but, also, an issue of perception and values. Indeed, these values and perceptions seem to actually drive the mechanisms of the Nigerian federal system. It should be noted that the federal government was able to take over all service delivery institutions through its takeover of the economic resources of the federation. The federal government has more resources than all the states and, invariably, the centre is financially strong, while the federating units are very weak. The strength of the federal government and the weakness of the state is more often expressed in the welfare packages/salaries of the federal workers and the state workers. The federal workers are better paid than the state workers. This gives the perception that it is better to work with the federal government than the state. This has strengthened the perception that the federal government is essentially more capable of dealing with financial issues than the state government. As a result, the trappings of the federal arrangement in relation to capacity and functions are lost on the general public.

Most participants in this study suggest that the present profile of Nigeria on politics and socioeconomic development is at odds with the rich human and natural resources of the country. Per capita Nigeria is one of the richest countries in the world (Suberu, 2009) and is ranked as the sixth country in the world crude oil production and the fourth world ranking country for Liquefied Natural Gas and several other mineral resources such as gold, tin, columbite, lead, coal and gemstones. Conversely it now ranks amongst the poorest countries 
in the world in terms of the quality of life of the people (Suberu, 2011) and that gap requires both explanation and remedy.

\subsubsection{Education}

By section 18(1) of the 1999 Constitution primary education is fundamentally the responsibility of the state and local government, the legislative aim being that Government shall direct its policy towards ensuring that there are equal and adequate educational opportunities at all levels. The general public seems to have implicit confidence in the federal government to respond to their needs, whereas, they seem to have less confidence in the state government to provide education, perhaps because they were not mandated to so by the constitution and have unclear devolved powers to do so.

One fundamental flaw in the process is that teachers are better paid under the federal government that state or local. This is arguably borne out of the confusion that is created by the intervention of the federal government in the primary school education via provisions in the Universal Basic Education Programme. This confusion has led to critical failures in relation to the capacity of the system to adequately respond to this critical stage in the education of children. Instead of federal government involvement or partnership with the states in order to enhance growth in the education sector, the present approach has only brought about failure.

\subsubsection{Improvements between 1998 to 2014}

For Nigerians the transition of 1999 was essentially the disengagement of the military from the political governance of the country. This disengagement signifies the emergence of a more decentralised system of governance based on a liberal democracy and federal 
principles. In turn, this implies inter-governmental relations, based on constitutional provisions, rather than military decrees. It is clear that the institutional changes in Nigeria during 1998 and 1999 present a substantial and viable basis for the assessment of the outcomes of such changes and reforms.

In assessing the political conditions and the institutional structures as a hinge for economic growth and development, most of the literature on Nigerian federalism seems to suggest that the structural and institutional factors that are embedded within the social and political histories of the nation are vital in the understanding of the process of governance development countries (Tirtosudarmo 2008; Lewis 2007; Akinyoade 2008). The histories include the colonialism and nationalism, ethnicity and religion, the role of the military, the role of the elites (including the politicians, the technocrats and the political parties) and international factors (foreign loans, aids and investment).

The Nigeria federal structure remains a complex architecture. The complexity of this structure of governance is derived from the intrigues on which its foundation was laid, and the very peculiar heterogeneous circumstances of the Nigerian state (Suberu, 2010). From the colonial foundation to the present configuration of the structure of government, there have been unresolved issues, as most participants suggested. To support this finding, Lewis (2007) asserts that these issues appear to border on the interplay of desire for political and economic survival and relevance amongst the ethnic nationalities. Consequently, this is played out in the struggle for economic advantage and political control of the state on one hand, and resistance of control and dominion on the other hand, amongst the ethnic nationalities that made up the federation. It is instructive, as Tirtosudarmo (2008) argues, to take into 
cognisance that the ethnic struggle for political and economic superiority predates the colonial intervention and administration.

In terms of the foundation for economic growth and development, Kohli (2004:327) argues that the failures in Nigeria's industrialisation process can be traced back to the colonial period, in which British "effortless" colonialism laid the foundation of a distorted state and a commodity-dependent economy. Even worse, such effortless colonialism took place in a country that had not experienced the order and prosperity of a centralised state, with centuries of slavery having robbed it of their best, and having existed in relative isolation with a barely used written language, important for public administration (Kohli, 2004:326). To this effect, Lewis (2007) and Tirtosudarmo (2008) argue that the travails of development as responses to challenges and opportunities brought about by political independence, more often than not reflect particular circumstances that the country and its leaders have had to confront.

\subsubsection{Institutional Arrangements}

Nigerian decentralization can be best described as a mixture of devolution and deconcentration of administrative, political and fiscal powers to the lower levels of government. Based on the responses provided by the interviewees, the practice is called quasi federalism. The legal and institutional framework of the Nigerian decentralization is ambiguous; the local government arrangement being the most problematic in Nigeria's federal structure. The contentious nature of the Nigerian decentralised federal arrangement is particularly noticeable in the areas of constitutional provisions for the local government. As noted in the previous research, scholars like Olowu (1991); Elaigwu (2007); Nwabueze (2003); Diamond (1987); Suberu \& Osaghae (2010) note that the ambiguity lies in the provisions of the 1999 
constitution. On the one hand, a section of the constitution grants autonomy to the local government whilst, on the other, another section of the constitution removes the autonomy.

Section 7(1) of the 1999 Nigerian Constitution purports to guarantee the system of local government by democratically elected local government councils. By this provision the constitution puts the local government directly under the state government. Section 7 further empowers the state government to enact legislation with regard to the establishment, structure, composition, finance and functions of democratically elected local government councils. Additionally, the Fourth Schedule of constitution assigns some roles to local governments in the provision of critical basic services including primary education, health services and the development of agriculture. However, in practice, state governments exercise virtually unlimited jurisdiction in these same arenas. In many cases, the role of local government is largely relegated to mere participation in the execution of functions. Based on this provision, many state governors in collaboration with the states' legislatures have dissolved local government councils, appointing instead their cronies and party loyalists while simultaneously refusing to hold elections for the local government councils. The results based on narrations provided by the interviewees indicate that the participation of the populace in governance at the lowest level of society is not guaranteed.

The legislation in Nigeria largely hinders decentralization and development as described by the participants. Based on the narratives provided, it is clear that there is a severe imbalance in the allocation of legislative powers between the federal government and the states as federating units, with the overloading of the exclusive legislative list at the expense of the concurrent and residual list of legislative subjects, in addition to an overlap and duplication of functions which has brought wastages, corruption and a lack of development. These finding 
corroborates the previous investigations by Bolaji Akinyemi (2004:4-7), Jinadu 1(994: 57) and Elaigwu (2002:78).

From the results provided, it is clear that the federal government is involved in almost all the spheres of governance, suggesting excessive control. Respondents suggested that even when it shares responsibilities with the sub-units, there is a tendency toward domination by the centre. Consequently the legislative list has been a contentious issue. A study by Bolaji Akinyemi (2004:4-7) found that the activities assigned to the federal government and the shared responsibilities with the state and local government add some support to the view that Nigerian federalism is more of a centralised system of government, thus corroborating the present study. It also shows that there are various areas of conflict. Sometimes, the areas of conflict have resulted in the federal government and the state government getting involved in a game of passing off responsibility.

Okojie (2009) notes that even though the Nigerian local government has been in existence since independence, local government councils have not been explicitly treated as autonomous, independent entities. Instead, they have been treated largely as subordinate to the regional governments in the first republic and subsequent state governments in succeeding republics. The states are supposed to take care of the interest of local governments under the portfolios of a minister or commissioner of local government. The case for autonomous local governments is made based on the narrations by the majority of the respondents. 


\subsection{Good Governance}

Good governance within any defined system of government is comprised of a number of factors which operate on an symbiotic basis and which combine to engender a system that functions in accordance with its design and objectives. A number of such factors are considered below; several of them being synonymous with many of the issues in part 6.2 above, However principle of good governance justifies a section to itself because of its special importance. It is largely through good governance, which implies honesty and the faithful performance by political actors of their electoral mandate, all of which goes to create trust between government and the people.

\subsubsection{Accountability}

Nigeria's voice for accountability is very quiet. Voice accountability is significantly premised on the extent to which a country's citizens are able to participate in selecting their government through democratic institutions and democratic practices. These include independent electoral institutions, free and fair elections, the roles of political parties and an active civil society, freedom of speech and an independent judicial system. In Nigeria, the political elites control political parties, and the civil society is not very active in opposition. Based on the narrations provided by the respondents, poor voice accountability in Nigeria could be seen within the context of a weak democratic culture and non-adherence to democratic values. In the context of local accountability the respondent from Bolorunduro, Akure North talked of being abandoned by local government. Others talked of access to elected official being very poor so that the possibility of holding them to account were very limited. This was particularly the experience recorded by category two respondents, generally those at the outer reaches of governmental influence and coincidentally those perhaps with no voice at all. 


\subsubsection{The Electoral process}

This study reveals that the Nigerian electoral processes are flawed due to the political influence of the politicians themselves who seem to have embraced power for the benefit of the powerful minority rather than the powerless majority. For instance one of the interviewees referred to Nigeria having a presidential style of government in complete contradiction to the constitution. That observation corresponds with a study by Elaigwu (2007:9), which noted that the electoral process has been crisis-ridden since 1999 when successive governments failed to achieve legitimacy through the electoral process. In support of that same finding, other investigators found that Nigeria continues to witness with growing disappointment and apprehension the inability to conduct peaceful, free and fair open elections whose results are widely accepted and respected across the country (Igbuzor, 2010; Osama \& Aghemelo, (2010), Ekweremadu, (2011). Although the 2011 election was adjudged to be better than the previous two by both local and international observers, it was not completely free from corruption, controversy and violence and far from the ideal set out in Section 15(5) of the 1999 constitution whereby the State shall abolish all corrupt practices and abuse of power.

It is commonly reported that political violence often erupts during Nigerian elections. Some candidates apparently hire young people to engage in violent acts, including intimidation of their opponents' supporters or of voters believed to support opponents. Violence can also occur during the polling process, with the theft of ballot boxes and clashes at or near polling stations. The murder of political opponents and the kidnapping of family members of political opponents is also said to have taken place. 


\subsubsection{Political instability, civil unrest and violence}

It is informative to note that based on the findings in this investigation, Nigeria has a better rating of political stability than has been witnessed during previous elections in the midst of political upheaval and national change. Nonetheless, the upsurge of violence in the oil rich region of the Niger-Delta, which has a very poor development index, sectarian and religious violence and, lately, the activities of the Boko Haram terrorist group has exacerbated political instability, violence and terrorism in Nigeria.

\subsubsection{Government Effectiveness}

Government effectiveness, based on the previous studies, is linked to the conflicting, overlap and duplication of legislative functions assigned to the tiers of government. These have brought about wastages, lack of coordination, corruption and lack of development. In particular the federal government has appropriated to itself functions and responsibilities that can be better implemented by the lower tiers of government. These include basic services like education, agriculture, housing, health and road construction.

Overall, government effectiveness is determined by the measure of institutional strength and the quality of the Civil Service, assessed by the bureaucrats' strength and expertise and how they are able to manage political alterations without drastic policy changes. Factors that could militate against government effectiveness include; government instability and government ineffectiveness due to the low quality of personnel in conjunction with excessive bureaucracy and red tape, all evident in Nigeria based on the results provided by the respondents. The testimony of the former head of service respondents in one of the southwest state was to the effect that in Nigeria there is no effective devolution to the councils.

Existing research provides support for the assertion that the Nigerian civil service and 
bureaucracy have problems arising from the federal structure and fiscal decentralization. These give rise to conflict in intergovernmental relations, and hamper effective planning and execution of government policies. The processes and workings of Inter-Governmental Relations in Nigeria have been pronounced to be laced with conflicts (Freinkman 2007; Khemani, 2001). These conflicts fundamentally arise from (i) structural organisational problems; (ii) financial problems; (iii) shortage of qualified manpower; and (iv) political and bureaucratic corruption. The attendant consequence is poor service delivery and a dearth of development in all sectors of national life (Khemani 2001). In trying to exercise their autonomy, the different tiers of government work almost at cross-purposes.

The existing arrangements for policy coordination between the federal and state governments remain inadequate. Although there are organs for the planning of shared responsibilities, there is always conflict in the implementation of the programs. The prevailing coordination effort tends to remain at the planning level rather than in actual implementation. Because of this lack of coordination, the impact of joint responsibility does not engender the intended development results. To this end the lack of coordination has brought about corruption in the bureaucratic process and, furthermore, has been the source of conflict between the federal and state governments. Federal/State conflicts have invariably involved litigation and arbitration by the Supreme Court but seemingly without resolution.

\subsubsection{Regulatory Quality}

Many institutional and governance reforms have been carried out in Nigeria. However, instead of focusing on reforms largely based on regulatory policy and a legal framework affecting national and sub national government in taxation powers and charges, Nigeria's reforms were more at economic reform, the civil service, the banking sector, trade policy, 
micro and macroeconomics, public procurement, public expenditure management and privatisation (OkonjoIweala and Kwaako 2007). Although these reforms introduced some new policies aimed at improving good governance, economic growth and development, they did not necessarily touch on the legal framework of decentralisation.

The Due Process Mechanism introduced in 2001, but taking effect in 2003, is the mechanism for ensuring strict compliance with the principles of openness, competition, cost accuracy, rules and procedures that guide contract award by the government. Due Process Policy is an agenda to ensure and sustain an open, transparent and competitive Federal Procurement System (Fayomi 2013). The present study confirms that poor public expenditure management has significantly hampered the quality of government capital projects, resulting in poor service delivery to citizens.

That observation was made by one of the civil servant interviewees who was of the opinion that the states system did not provide the strength needed by the country as whole. Previous studies also support this view and show that oversight of public expenditure was further made difficult due to fiscal decentralization in Nigeria, which allocated about half of total government revenues to state and local government, with the remainder being allocated to the federal government (Igbuzor, 2010; Osumah \& Aghemelo, 2010, Ekweremadu, 2011; OkonjoIweala and Kwaako 2007). While increased resource allocation to state and local government may potentially encourage more direct intervention in pro-poor programs, capacity constraints and the lack of transparency at sub-national level posed serious challenges (Ekweremadu, 2011). 


\subsubsection{The Rule of law}

Previous researchers indicate that there were serious questions about the constitution as it related to functions of the federal and state governments, one of the major problems being the penchant of the federal government to flout the judgement of the courts. In doing so they place themselves above the law, thereby flouting the rule of law, as it is generally understood, that is that no one (including the government) is above the law. A major case during this period was that between the Lagos state government and the federal government. Mbaba (2005) reports that, despite the judgement of the Supreme Court on the matter the federal government, was defiant of the judgment and effectively in contempt of court. This type of precedent creates a sense of immunity from the rule of law in many entities or persons with any authority over others. Such practices can oust the jurisdiction of courts so that nobody, not even the court can question such conduct.

The findings reveal that the Nigerian judiciary is weaker in carrying out its constitutional functions. As a support, there was a general opinion the politicians cannot take the federal government to court to address federal government seizure of the funds allocated to the state government. This poor performance, based on supportive existing research, has therefore mainly been linked to this institution (Chukuma and Ebai 2012; Nwabueze 2007). Based on the Governance Assessment Framework, it is also clear that the score of Nigeria in the realm of the rule of law has been consistently poor and without signs of improvement. The percentile rank has fallen from 14.83 in 2000 to 12.32 in 2013 . The weakness of the judiciary is linked to its dependence on the executive in fiscal matters, poor funding and disregard of judicial orders by the executive (Nwabueze 2007). 
Although the constitution of the federal republic provides for the independence of the judiciary, the executive arm of the government has overbearing power over it. Researchers also support this finding, arguing that with this dependence on the executive arm of government it is difficult to guarantee the autonomy of the judiciary and this has resulted in poor and inadequate judicial infrastructure, low morale amongst judicial personnel, alleged corruption, delays in administration of justice and judicial services delivery and general low quality and poor output (Nwabueze 2007). This situation has to some degree affected the quality of the judgements of the courts (Chukuma and Ebai 2012).

\subsubsection{Corruption Control}

In furtherance of this principle the results of this research reveal that endemic corruption remains an enormous challenge for Nigeria. For instance, one interviewee, a civil activist, suggested that corruption was a major crisis point. This finding is also supported by existing research on Nigerian corruption such as that conducted by The Institute for Development Research of Ahmadu Bello University Zaria (IDR, ABU Zaria) in its final report on the survey of corruption in Nigeria (2003) notes that the main institutions of government in Nigeria are deeply and historically rooted in corruption and this fact has affected their performance in bringing about good governance and development. The report lists the following institutions as most corrupt in the country in descending order; (1) the Police, (2) political parties; (3) national and state assemblies; (4) local and municipal governments; (5) federal and state executive councils. Corruption is therefore endemic at all levels of government, depriving the three tiers of government of a substantial amount of revenue for development. Mandela stated to the effect that corruption is was order of the day. 
Given that the internal revenue generation of most of the states is too low for the states to be self-supporting (Collier 2009; Omeje 2007; Elaigwu 2007; Adamolekun 1991; Suberu 2010; Olowu 2001; Suberu 2010) they depend therefore on the federal government allocation. Corruption at the top however limits the amount of resource available for distribution so that a reduced amount of money percolating down to the states not therefore translating into socio-economic development. At the state and local government levels, most participants agree that there have been recorded cases of corruption and mismanagement of resources levied against the state governors and chairmen of local government. In summary corruption in the states and local governments, significantly deprives the states and local government of resources of the opportunity to fund developmental projects.

\subsection{Conclusion}

An important observation in the debate on Nigerian federalism is the way scholars argue for practise of federalism, and at the same time critique the mechanisms of federalism within the Nigeria context, dubbing it an overall failure. However the conclusion of a majority of scholars on Nigerian federalism is not for it to be abandoned, rather how it is to be strengthened so as to engender political stability, unity and cohesion within the framework of political federalism and equity, justice, economic growth and development within the framework of fiscal decentralization. This is notwithstanding all of the identified weaknesses ranging from corrupt practices and all the factors which account for the lack of good governance on a national scale and accounting for an enormous reduction in available resources which should be distributed amongst the population.

From the analysis of decentralization in Nigeria, this accords with the general perception amongst scholars and others. The limited developmental trajectories spring from poor design and practice of decentralization and the lack of devolution to local government results in poor 
accountability and limited transparency, the principal causes underlying Nigeria's failure. The hazy mix of devolution and de-concentration engenders excessive public spending, corruption, and wastage of state resources, ultimately explaining Nigeria's socio-economic underperformance. Decentralization however would have many positive effects in the Nigerian context if performed in accordance with the constitution serving as an essential tool in diffusing social and political tensions and ensuring local cultural and political autonomy in a world of rampant ethnic conflicts and separatist movements.

In general political theory, and proven by the examples quoted in this research, such as the Unites States of America, decentralization and federalisation, though not devoid of weaknesses, is an efficient structural mechanism for good governance and socio-economic development. However, if ambiguously applied, as is the case in Nigeria with its overlapping central and local government responsibilities, economic productivity becomes restricted, irrespective of human and natural resource wealth. An informed political culture and an increased level of education of the people would enhance the capacity to demand transparency and accountability. To this extent, decentralization of governance involves the empowering of sub-national levels of the society to ensure that local people participate in and benefit from their own governance institutions and development services. The central government must therefore be relieved of many shared functions. For example, the government should devolve services such as health, education and culture, public works, environment, land management and capital investment to the local government.

In summary, the debate on Nigerian federalism, and based on the narrations provided by the participants in the field study, concludes that the practice of federalism in Nigeria enjoys some limited success because of its potential system of sound government, albeit worthy of 
improvement by changes to the constitution. Conversely the literature suggests that the practise of federalism has significantly failed, or that it has not sufficiently addressed the challenges of good governance and development (Suberu, 2010). This position seems to enjoy broad based support because it is perceived that the Nigerian federal structure has not responded sufficiently to the four classic challenges of the post-colonial world, namely (i) national unity; (ii) democratic stability (iii) socioeconomic development; and (d) endemic corruption.

If therefore federalism is to succeed in Nigeria it is the informed view of the author that those challenges must be met and overcome by the institutional capacity to promote stronger leadership, accountability, transparency and development in Nigeria. In conclusion, the current challenges facing Nigerian federalism, in its present form render it dysfunctional and unfit for purpose and it will remain so until the prevailing political culture permits effective reforms 


\section{Chapter 7}

\section{Summary and Findings}

\subsection{Introduction}

This chapter outlines the summary and findings of the research, and reflects on the substantive theoretical, conceptual and empirical issues arising from the relationships between decentralization, governance and development, as revealed in the analysis of the primary data collected from the respondents in Ondo State, Nigeria. The theoretical and conceptual argument that the form and design of decentralization has the capacity to engender, that is good governance and development, is verified by empirical means by the application of the research results to the analytical tools and research methods considered in chapter two. However, the research goes further to argue that although the structure of government plays a significant role in achieving good governance and development, an appropriate political culture and activism is a pre-requisite for successful decentralization leading to full federalism; this was considered in detail Chapter 2.2 and Chapter 2.3 in which the forms of decentralisation were examined. The author concludes with a discussion of the findings and the contribution of this research to governance and development, and the scope for future study originating from this study.

In so doing regard has been paid to the history of the country, and the nation, in which colonial and military rule has featured so significantly. Important events in the national psyche of Nigeria (and which have directed and perhaps accounted for the nation's development) are highlighted as moments to which critical juncture analysis applies and from which path dependency illustrates the future development of political institutions. What also emerges from this study, by application of historical institutionalism approach, is how current 
state of federalism and its institution can be attributed to the ways in which such events structure and shape political behavior and outcomes. Against such a background, and the fractured national identity that accounts for civil unrest and disobedience in certain parts of the country, there is an exploration of the multitudinous challenges which stand in the way of successful implementation of the of the Nigerian system of federalism. Such challenges appear to result in the failure of government to engender political and national stability and socio-economic development throughout the nation as a whole. A detailed study of the history of Nigeria's political and social development thus far is critical not only to identify the adaptive paths taken by its political institutions, but so as to direct with the benefit of historical reactions to prevailing circumstances the next steps. In addition the impact of the transition from an agricultural based economy to an oil based economy on the country generally has been considered with an assessment of how that seismic event shaped the course of the national development. It is particularly in this context that devolution of political rule in and out of military and colonial rule, the fundamental shift in the essence of the economy away from traditional national product to the oil economy with all the benefits (and (dis)benefits) experienced by the nation as a consequence, have impacted on the development of Nigeria as an effective federal country.

The research highlights areas of weaknesses in the Nigerian federal system by means of empirical analysis of the primary data and a detailed review of the existing literature. To some extent it reflects on the ability of Nigeria to cope with and adapt to change. Historical political institutions were faced with change for which they may not have been inherently equipped to deal with. The obvious example was the shift in the shape and nature of political institutions to manage the change from military rule to civil self-determination. Having reached that critical juncture in the development of Nigeria as a nation, an application of path 
dependency theory illustrates what has been done with such ability, power and right by means of the process adopted by the political culture to implement change, namely federalism. An example is the genesis of the current constitution, born out of the first attempt at mature self determination within the principles of federalism, evolved by pragmatism and empirical judgments based on fact and national experience. The premise of this study is that Nigeria has failed to fully implement its model of federalism, which is intended to be constructive and instructive rather than destructive and indicates the value of this work to the debate generally.

In that context the author adopts the historical institutionalism approach to identify reasons for the failure of the process of Nigerian decentralization following which he provides new thought on the means by which such underperformance can be reconsidered from different perspectives. Such perspectives include (rather than exclude) the standpoints of the key participants in the system of government by reference to the three tiers of government, the de facto form of governance and the intended recipients of the distribution of wealth by means of the process of federalism. Finally this thesis concludes with an assessment of what is achievable by the adoption of a shift in policy whether such shift be considered radical or simply based on the process of evolution.

\subsection{Summary}

Broadly speaking the Nigerian federation has experienced four phases, namely, colonial, civilian, military and post-military rule and civilian administration. Each of these phases (critical junctures in its history) has left indelible marks on both the nature and the operation of the country's federation and programme of decentralization. Each phase caused stress which, in some cases, resulted in adjustments to the process as a whole, and not always for 
the better. Each of the developing constitutions served its immediate and limited purpose and context but none produced the formula for effective management of the coalition of states in the Nigerian federation. Such a constitutional form is realised when individuals (be they states or the population at large) are prepared to cede limited powers to the central government who draws positive conclusions that such reform is both essential and achievable by an on-going process of political participation at all levels of government.

It is an obvious truth that decentralisation can occur without federalism but the converse, that federalism cannot exist without decentralisation, is perhaps less often appreciated; that fact emerged from the interview process generally and is a theme which the author has exploited in his analysis of the findings of his research, specifically in Chapter 2.2, and in Chapter 6 in general. The principal underlying the research question is to the extent to which the current structure and practice of federalism has contributed to the poor governance and underdevelopment of Nigeria. A central premise of federalism is that all levels of government are equally empowered to perform their functions, a principle which requires the essential ingredient of effective central government. In Nigeria however the autonomy of each tier of government is often misconstrued resulting in competition with each other and seeking to frustrate the others. This may be a feature of the relative immaturity of the Nigerian political system though conversely it may be a result of the failure of federalism which breeds suspicion and a general lack of the cooperation essential for the working of a truly federal state. From such divisions can come the failure of federalism at all levels, perhaps the most obvious feature being revenue allocation which has evoked intense controversy in Nigeria. Revenue allocation however is a function of good governance and even relatively small improvements in the means of governance and the more equitable distribution of national resource can go some way towards addressing such complaints. 
In pursuit of a definitive view from which conclusions can properly and reasonably be drawn, the study has examined:

1. the major shortcomings in the structure of Nigerian federal structure; see Chapters 5.4 and 6.3 in particular;

2. the institutional reforms that could transform the poor trends of socio-economic growth to a vibrant economy and sustainable development; such as is explored in Chapter 6.1; and,

3. the extent to which decentralization can influence the effective operation of the different tiers of government; see Chapter 5.4.

A study of these concepts and related theoretical issues constituted the foundation for the contextual analysis, the main theoretical foundations employed being functional theory per (Brown and Oates 1986; Burns 1994; Oates 1972; Stein 1990; Paterson, Rabe and Wong 1986; Elazar 1991) and legislative theory (Peterson 1995) as expounded within Chapter 2.

A comprehensive analysis of the Nigerian system was carried out, articulating arguments for and against Nigeria's form of federalism both by reference to the literature and by an analysis of the interviews with the respondents in field. An exploration of the successful decentralization problems resulting from decentralized governance in Nigeria was also performed. Some scholars argue that Nigerian federalism has achieved the purpose of promoting political stability and cohesion, and forestalling the tendency for secession by different ethnic groups, per (Diamond 1999:152; Horowith 1985 602-613; Olowu 1991:3) as set out in Chapter 2. That however suggests that the most positive gloss is being placed on a system which is riddled with mediocrity and endemic with corruption. There are those, in the majority, who argue very forcefully that Nigerian federalism has failed to achieve its purpose resulting in a nation that is divided not only politically but in apparently irreconcilable 
nationalistic terms. For them the Nigerian federal system is more of a unitary rather than federal system (Onwudiwe and Suberu; 2005:94: Elaigwu 1998; 6-7; 2005; 69). They hold that this is due to a severe imbalance in the allocation of legislative powers between the central government and the state and the local governments.

In part this is based on the Nigerian Constitution itself (so that the issue is structural), which is said, in Chapter 4, to inherently weaken the process of the distribution of power between the principal and subservient tiers of government by the reservation of ultimate power to the central government. That imbalance in the distribution of power has contributed to a system of politics in which ethnicity plays such a large part. This is evident in the pressure from ethnic groups ranging from major players such as Boko Haram, Indigenous People of Biafra, to the minor and less vocal groups militating peacefully via the process of democracy for national sovereignty per, for instance (Elaigwu 1994: Nnoli 2008; 101: Osaghae 2011) as discussed in Chapter 2 and elsewhere. Such issues were very much in the forefront of the minds of all respondents in interview and illustrate that such problems have both resulted in, and are the result of, poor governance and the poor record of development at the far end of the distributive process.

In Nigeria, Africa's most populous country, decentralization has routinely failed to produce good governance and socio-economic development. Scale is a feature of that failure and with that in mind the researcher analysed the institutional and political contexts within which the federal system operates in the terms specifically of Chapter 5.4. To evaluate the performance of local governments, Ondo State was used as a representative sample population. The major shortcomings in Ondo are taken as typical of the lack of institutional reforms likely to transform the poorest regions into vibrant economies, so ensuring sustainable development. 
In that regard the level of good governance and the participation of local government was scrutinised in detail (particularly in Chapters 5.4.5 to 5.4.10) and found to be wanting.

The starting point was the assessment of the supposition that the form of the Nigerian federal structure is considered to be a principal reason for Nigeria's inability to achieve good governance and development (Elaigwu 2007; Ekeh and Osaghae 1989; Adamolekun 1991; Nnoli 2008; Elaigwu 2007; Suberu 2010; Okpanachi 2010; Osagahae, 2010; Adebanwi and Obadare 2010), see Chapter 2. The research examines the critical factors that are responsible for the failure of the Nigerian federal structure to sufficiently fulfil the rationale for its adoption, which includes a framework for national development, cohesion and peaceful coexistence. There is focus on the formal and informal factors that are responsible for the poor performance of federalism in Nigeria, the formal factor being the legal and institutional framework of the federal arrangement as enshrined in the constitution. The informal factors include military heritage, religion, tribal sentiments/ affiliations, and class interests. These factors could be described as the bedrock and values that shape the institutional framework and drives Nigerian federalism.

An examination of these factors was carried out using Ondo State as representative entity within Nigeria by comparing the preponderance of current research with empirical data collected using interviews as set out in Chapter 3. By the use of an historical institutional critical juncture approach, the research conceptualises the relationship between the structure of government (federalism and the type of decentralization; delegation or devolution) and good governance and development. Similarly, the author analysed the effects of politics and politicians on Nigerian federalism and the impact of the oil economy. Findings show that politicians, the military, and the oil economy all impact heavily on the nature and 
developmental performance of Nigerian political and fiscal federalism. From those matters set out in Chapter 4.1, it can be seen that the roots of political unrest, ethnic and religious divisions and civic discontent in Nigeria are deep and historic. Many of the major disrupting factors that are so challenging of contemporary politics in the Nigerian political system are cyclical, having been the same compelling forces that so tumultuously led Nigeria out of colonial rule, through military domination and into the civil administrations that followed. A number of those factors have diverged, for instance in the way that the Boko Haram agenda is based on religion, ethnicity and a very fundamental difference in its view of politics and the way in which civil society is organised and ordered. A number of the respondents were of the view that such divisions were not capable of remedy leading to a sense of hopelessness and disillusionment in the system of government at all levels, see Chapter 5.

Some of the literature referred to in Chapter 2 supports the view that despite the obvious and extensive challenges, the Nigerian federal arrangement has brought about good governance and development; further that the federal system has fundamentally been the bedrock for appreciable national unity and cohesion in Nigeria. It must be said also that when surveyed $57 \%$ in the Igbo southeast to $87 \%$ in the northeast, agreed that Nigeria should remain united as one country on the present basis. Overall, about three quarters of Nigerians affirm a desire for national unity, while an equally overwhelming majority of the citizenry professes firm commitments to both group and national (Nigerian) identities. However the majority of informed commentators insist that such very significant issues regarding poor governance and the development record of Nigeria, which questions the suitability and the capacity of the present decentralised system to engender good governance and development. From the above it might be inferred that while most Nigerians might express the commitment to national unity, it is to a paradigm version of their society to which they refer, one which is corruption 
free and effective in equal distribution of the national resource, by means of a Federal system that would substantially fulfil the good governance and developmental rationale for the adoption of a federal system of governance. This research analysed in Chapter 5 results therefore in new insights that might be used to transform the Nigerian federal state into a more viable structure for good governance and development.

Since the introduction of federalism in Nigeria in 1945 there have been some significant changes to meet the challenges of governance. From the analysis in Chapter 4 of the legal and constitutional framework of Nigerian decentralization, the ambiguities in the constitutional provisions of the legislative functions of local government are obvious factors in the imbalance in the allocation of legislative powers between the Federal Government and the States as federating units, with the consequent overloading of the exclusive legislative list at the expense of the national interest. There is also an overlap and a duplication of functions which has engendered wastage, corruption and constrained development. From the assessment of Nigerian federalism, this research argues that the Nigerian decentralization is de jure devolution and de facto de-concentration because of quasi federalism practices. This is made out as a theme running throughout the entirety of this study and is examined in detail in Chapters 2, 4 and 6.

The implication of this mixed decentralization arrangement is that the sub-units are not sufficiently empowered politically, administratively and fiscally to perform efficiently the constitutional functions allotted to them. This is due to inadequate constitutional force and political subversion of the constitution so that the political arrangement does not give opportunities for the conditions that could engender good governance and development, such as voice and accountability, rule of law and public sector management. The situation makes 
the states and the local governments to be mere appendages or subsidiaries of the central government. This arrangement questions the foundation of Nigerian federalism, because it contradicts some of the basic doctrines of federalism. A system by which the state authorities have to revert to central government for funding for assistance for development projects does not create equality and the full entitlement to federalised autonomy. This illustrates the problem in de-centralisation very comprehensively, where the central government fails to relinquish control over development finance, a position reinforced by the analysis of the fieldwork in Chapter 5, especially by interviews of category one respondents who had some specialist knowledge of such matters.

The contemporary debates about Nigeria's political and economic failures have routinely implicated the presumed pathologies, incongruities and liabilities of the country's federalism. Federalism also assumes that within a federation, there would be differences in the capacity of sub units to raise revenue for their functions and services for reasons that are beyond their control. The provision of fiscal equalisation serves to remedy inequalities that may arise from varying revenue-generation capacities of sub national units of government. The provision, however, does not make the sub-national government subordinate to the central government. This then necessitates an investigation of the relationship of governmental tiers within a federal or decentralised state as was conducted within Chapter 2.

The study therefore conceptualises the interrelationship between the structure of government, governance and development in what is purportedly a decentralised country. It is argued that both formal institutions (structure of government) and informal institutions (political values or behaviour that drive governance) affect the outcome of decentralization, which in this context is good governance and development. Corruption is still so fundamental in the 
Nigerian political culture that it is difficult to see the means by which it might be eradicated. There was consideration of the problem of corruption throughout this study with some particular focus in Chapter 6.3 in the context of good governance. The Nigerian political space has always been monopolised by a personalised and ethnically fragmented political elite that informs the behaviour that propels the process of government in Nigeria. So too is the Rentier economy, explained in detail in Chapter 4.1, an enormously significant factor in the continuity of the ethic of corruption, if that is not a contradiction in terms.

So too is the rentier economy a factor which has reduced the value of traditional production by means of agriculture in favour of the low hanging fruit of oil which, despite being in the hands of the state, is effectively controlled by outside national and private interests and the global market which is presently in decline or has reached a stage of stagnation. All of such factors contribute to the instability of the political and civil cultures on a national basis with the position being further exacerbated by continuing strife between competing religio-ethnic elements. Whilst there is constitutional provision for devolution, de-concentration and delegation, delineation of function remains a critical issue in system. This uncertainty at all levels affects good governance and development. It follows therefore that both state and local government authorities must have autonomy deriving from devolved powers to have access to and to control its own financial resources. Absent that situation the better description of Federalism in Nigeria is quasi federalism, which suggests partial only commitment to the general principle of effective federalism.

In Ondo State (typical of all Nigerian states in terms of its governance structures) those features which typify the failure of decentralisation and power sharing were noted from the research and the literature. The author's own statement at Chapter 1.4 'If, despite the huge 
revenue allocation from the centre there is still poverty, the relevance of local governments to the people in terms of good governance must be called into question' becomes of particular significance in the context of measuring the ideals of federalism against the manifestation of its results on the ground in Ondo State. Those differences are signified by dysfunctionality and disconnects between all levels of government, from Federal to State links and trickling down through subsidiary levels of local government. Such disconnects have very real consequences, such as in the failure of service delivery which typify the inequality in distribution of the national reserve to the grass roots. It is reasonably postulated that such findings typify the national condition and nothing in the literature is suggestive otherwise or indicative of prevailing conditions in which such deficiencies are not present. An example from the public domain ${ }^{21}$ is that of the Oluwa Glass enterprise which was established by the Ondo State government with the support of the Federal government. It failed for the lack of funds to pay its workers but fundamental to that were the Nigerian diseases of corruption, a failure to distribute national resources, inefficiency at local levels and the failure of central government to prevent the loss of important local industry.

\subsection{Findings}

A limited comparison with decentralisation in, for instance Indonesia, is instructive where an assessment of the transition from 'New Order' to 'Reformasi' was that Indonesia achieved a regime that established new political elements in the interests of the whole nation. It was done without displacing the incumbent elite; rather such political transition produced an atmosphere in which there was a shift in what had previously contentious popular interests so

\footnotetext{
${ }^{21}$ The Nation Newspaper "Oluwa Glass Industry As Metaphor" http://thenationonlineng.net/oluwa-glassmetaphor/ Dec. 28, 2016 Edition.
} 
there was 'room for all'. Such should be the paradigm state in Nigeria but for the reasons set out in this study there are significant points of differences between the two situations.

The scope of the research question set out in the abstract ensured a detailed examination of the relationship between federalism, or decentralisation, and effective governance of the process of implementation of federalism in accordance with the 1999 Nigerian constitution. That examination threaded through the entire study and allowed for the conclusions drawn herein to the supported. In addition it prompted an enquiry into the extent of socio-economic development in Nigeria arising from such political and social imperatives. The main aspects evaluated, by reference to the literature and fieldwork, were governance, socio-economic development, the development of federalism against the background of the Nigerian political culture, to include reference to the prevailing political economy, and the operation of fiscal federalism and development of democracy and decentralisation.

The literature on federalism, governance and decentralisation is inclined towards the traditional approach that narrowly focused on government institutions, concentrating on the historic political machinery as the instruments of good governance and development. Specifically the literature seems to concentrate on the structure, the technicality of policymaking and the division of functions at each tier of devolved government, generally limiting comment on the informal sector and context in which the federal system operates. To this extent the increasing complexity of the interactions between central and sub-national levels of government and the need to explore the complex structures of powers, values and interests mean that there is need for more participatory approach to local governance by the people. This can only be cultivated through a new paradigm of a political culture which is inclusive of the population at large rather than exclusive. In this context what is notably 
lacking is the impact of any equivalent doctrine amongst the Nigerians of 'Pancasila', (see Chapter 4.2) the cohesive philosophy that united rather than divided the Indonesian people, and served as the building blocks of the new political culture of activism that enhanced the practise of decentralisation in Indonesia. Absent such an intangible cohesive force Nigeria will continue to be managed by the largely unaccountable political elite who inevitably fail to unite the populace.

That present approach, of exclusion of the citizenry, based on the structural relationships and traditional approaches to local government in general, and central-local relations in particular, requires justification if local government is to survive. One basis for its continued existence, its raison d'etre, is by reference to the practical advantages to be offered to a majority of the citizenry. This does however require some 'buy in' by a greater proportion of the population than is witnessed at present where ignorance of the political system founds the political culture. The alternative to the practical advantage approach is the abstract principle of 'legitimacy' (originating in the constitution) and a popular acceptance and support flowing from an acknowledgement of the advantages of federalism. That however requires an even greater leap of faith by the citizens, that the principle of federalism will be achieved at grass roots without evidence that it is actually delivering. All of these points to an appreciation of the need for a better balance between the state at any level and its clients, the local populace. The problem of failed local development cannot satisfactorily be addressed from a ruling class perspective; in Africa the problems plaguing the majority of the population cannot be fully understood at the level of the ruling class alone. Therein lays one of the critical obstacles to full and effective federalism and it is not until there is political, and constitutional, reform that the objectives of the constitution will be realised. 
In terms of constitutional reform there is little doubt that further decentralisation of local government is necessary for more effective grassroots reach or, seen the other way, better linkage of community level structures up to the institutions of modern government. It was said authoritatively that in rural areas with poor infrastructure and communications a large local authority reduces the pace of development. In response to this remoteness, there has been speculation that a 'fourth-tier' of government to provide that additional mechanism for delivery might improve service delivery. In this context it is noted (see Chapter 4.10 in particular) that the existing traditional patterns of territorial organisation provide ready-made machinery for extension of development responsibilities and planning down to the community level. Indeed it is evident from the findings of this study that where legitimacy is accorded and local leadership is accountable, traditional rulers remain a veritable link between local communities and local government. This suggestion reflects what has been termed the statutory incorporation of autonomous communities. One informed voice suggests that changing structure is easier than bringing about a radical change of the underlying defects in government. Structures however do not change overnight and recognition for the requirement for change and the adoption of the means of such change is a matter for institutional and democratic development.

The creation of a fourth tier of government may however do no more than recreate the conditions which gave rise to it, and inevitably point to the necessity for a fifth tier as exists in the decentralised system in Indonesia. In Nigeria the remoteness of local government from their clients is much less a matter of distance in physical terms than in value terms. What may be needed is the de-concentration of the existing third tier of state activity in line with existing traditional structures and institutions down to village community level. By reference to the example of Indonesia where the system of governance has five tiers and operates 
successfully there might be merit in such a proposal. However, as stressed throughout this study, the resulting political structure depends on the context and circumstances of each subject system and country.

A practical solution to enable local government to sustain a local environment conducive to local development might be by not 'doing business' with local leaders discredited by their own communities or found to have been colluding with local leaders of whatever description to corruptly misappropriate local resources. It is however acknowledged that historic and inherent weaknesses in having the traditional ruler as the representative of the community might not fit into the concept of modern government. Nevertheless the use of existing structures will obviously assist in implementing change and an example is the Community Development Committees are a ready structure for this purpose. As presently constituted they are unrepresentative of community interests and have little influence in planning at the community level. It is in this context that the author considers that the integration of traditional structures into the formal sub-structure of local government might offer an effective channel of communication.

The emphasis on the blend of traditional and modern structures derives from the proven relevance of such structures in participation and development in local communities as well as in conditions in the modern political sector where they have ably substituted for the formal structures. It is known that under conditions of local elections on non-party basis, for instance, modern and traditional structures within civil society can function as 'structural equivalents' performing the necessary functions in the modern political system which would otherwise be performed by political parties. 
When villages become centres for local development, they will also become centres for the systematic moderation of the articulated values through accommodation. This will be valuable in diffusing the destructive political pressures presently focussed on the institution of local government. Local institutions with which local clients can easily identify would also have been created. This is the true meaning of bringing government closer to the people. These suggestions reflect a degree of pragmatism which consciously avoids the danger of analysis contributing to paralysis powerlessness and hopelessness for local clients of the state who are underprivileged. It is also evident that the insights drawn from the debate on the articulation of modes of production, as this relates to the ultimate impact of informal values on formal structures and functions, provide ideas with which to further explore, more systematically, different dimensions of the problem of local development in Nigeria. In respect of the overall institutional intervention of the local state in local community development, for instance, the centrality of power suggests the need to focus on aspects of local development that are amenable to influence and intervention. The community development committee is means of achieving participation and improving good governance at the local level. Such committees are very active in the different communities where they exist. The main problem however may be that of representation in the committees is not freely and democratically available to the larger population.

Perhaps the two most important and fundamental factors which require resolution are those of the corruption endemic in the political system and the definition of good governance. The first of those two elements will require a paradigm shift in the mentality of political actors across the whole political spectrum but it must be acknowledged that without that shift the future of the implementation of federalism in Nigeria might almost be said to be doomed. The second element, that of good governance of project delivery, which includes the delivery of 
federalism itself, is a resource that can be acquired and managed by external agencies. There needs therefore to be a clear definition of what constitutes good governance by reference to established but such standards are widely recognised and can be only be applied given the political will.

This however is intricately entwined with the prevailing political culture in Nigeria, considered in depth in Chapter 4. In the conclusion to that chapter the author observed a perceived lack of 'quality' of political culture requisite for successful decentralization. That lack of 'quality' might account for the lack of trust in the political institutions themselves and it is postulated from the research, and from the literature, that lack of trust is in turn a by product of the perceived lack of integrity of the institutions of state. It was not difficult to conclude in that context that non-violent political activism is a prerequisite for the changes required in both the political institutions and the political culture.

From the literature one derives the general principle that federalism, as a constitutional form, is brought about when competing factions surrender certain powers to a coordinated central authority. One of the functions of that central authority is to operate for the benefit of such factions as a whole, which comprise the nation state. A cardinal principle of federalism therefore is the functional arrangement between states for living and working together nationally while presenting a measure of separate identity. In this way the religion/ethnic/political differences are preserved and honoured as distinct features of the nation. The author appreciates that the scope for the improvements identified herein, particularly socio-economic growth resulting in a vibrant economy based on sustainable development, can only be incrementally achieved over a significant period of time, especially when faced with endemic resistance to change from entrenched interests. However the 
political history of Nigeria is a story of incremental change during recent history at critical junctures in Nigerian history, brought about by the exercise of democracy inspired by the desire to achieve a political culture that delivers benefits for everyone on an equitable basis. In addition such changes must happen, in conventional parlance, from the bottom up and from the top down, concurrently rather than consecutively particularly by way of a fundamental shift in prevailing political culture. Nigeria will not become a viable federation unless and until the constituent parts (the states) are adequately empowered by enabling practices enshrined in the constitution that conform to acknowledged principles of federalism. The value of this study is that it identifies those issues that need to be addressed and offers some indicators of how the present socio-economic system of politics and political culture might be improved. The author has conducted a thorough examination of the specialised literature and provided a key into comparative studies into similar political systems that warrants further study. Such studies might identify points of similarity, and divergence, from which the design of the future of the political culture in Nigeria might be designed. It is submitted that the approach to the research and the study from an historical institutionalist perspective provides an original approach and an important and new contribution to the topic.

The federalist debate in Nigeria is longstanding, passionate and inconclusive and is driven by a relentless focus on its failures rather than its successes. In the meantime little in the political structure of Nigeria (legislative and administrative) points to it being a fully functioning federal entity, paying lip service only to its self proclaimed description as such. In fact, it may be that it is only the de facto existence of the states that creates the semblance of federalism; in all other respects the country is a unitary state. It is that perception which must change, based inevitably on the underlying performance of the federalist model, which must improve. Put even more forcefully: absent such change and Nigeria will fail as a federalist state. 


\section{BIBLIOGRPAHY}

Abdulhamid, O.S. and Chima, P., (2016). Local Government Administration in Nigeria: The Search for Relevance. Commonwealth Journal of Local Governance, (18), pp.181-195.

Abimboye, D. (2010) 'The Years of Despondency' Newswatch Magazine Online Publication: Nigeria at 50 Special Edition.

http://www.newswatchngr.com/index.php?option=com_content\&task=view\&id=2443\&Itemi $d=1$.

Abonyi, N. N., (2010) "Local Government Administration in Nigeria and Ghana: A comparative Analysis" in Obi, E. A. Comparative Local Government: An Ecological Approach. Onitsha: Bookpoint Educational Ltd.

Acemoglu, D., (2003). Why not a Political Coase Theorem? Social Conflict, Commitment, and Politics. Journal of Comparative Economics, 31(4), pp.620-652.

Acemoglu, D., Robinson, and D. Woren: (2012) Why nations fail: the origins of power, prosperity and poverty, Vol. 4. SciELO Chile.

Adamolekun, L. (1979) “The Idea of Local Government as a Third Level of Government." Ibadan: Heinemann Educational Books.

Adamolekun, L. (2002) Public Administration in Africa, Lagos: Spectrum Books.

Adamolekun, L. (2005) The Nigerian Federation at Crossroads: The Way

Forward. Oxford Journals Publius.http://publius.oxfordjournals.org/content/35/3/383.

Adamolekun, L (1991) .Federalism in Nigeria Toward Federal Democracy (Oxford Journals Autumn 1991) Vol. 21. No 4. http://www.jstor.org/stable/3330307.

Adebanwi, W., \& Obadare, E. (2010) Introducing Nigeria at Fifty; The Nation in Narration: Journal of Contemporary African Studies 2010 28:4.

Adebayo, A. (1971) 'Federalism and Development Planning in Nigeria', in Ayida, A. and Onitiri, H (eds.) Reconstruction and Development in Nigeria: Proceedings of a Conference. Ibadan: Oxford University Press, 1971.

Adedotun, P. (1991) 'Managing Fiscal Federalism: Revenue Allocation'. Publius Volume21, Issue 4 Pp. 103-111. http://www.jstor.org/stable/3330313.

Adejumobi, S., (2000). Elections in Africa: A Fading Shadow of Democracy?. International Political Science Review, 21(1), pp.59-73.

Adejumobi,S. \& Momoh, A. (eds. 2002) The National Question in Nigeria, Comparative Perspectives. London: Ashgate Publishing Limited. 
Adejumobi, S. and Kehinde, M., 2007. Building Democracy without Democrats?: Political Parties and Threats of Democratic Reversal in Nigeria. Journal of African Elections, 6(2), pp.95-113.

Ademola, A. (2011) 'Endangering Good Governance for Sustainable Democracy: The Continuity Struggle against Corruption in Nigeria'. Journal of Research in Peace, Gender and Development, volume 1 (11), pp. 307 - 314 December, 2011.

Adesina, O. (1998) 'Revenue Allocation Commission and Contradiction in Nigeria', in Amuwo K (ed.) Federalism and Political Restructuring in Nigeria.Ibadan: Spectrum Books Limited.

Agba, M.S., Akwara, A.F. and Idu, A., (2013). Local Government and Social Service Delivery in Nigeria: a Content Analysis. Academic Journal of Interdisciplinary Studies, 2(2), p.455.

Agbaje, A. (1994) 'Beyond the Generals: Twilight of Democracy in Nigeria'. Africa Demos, 3:4-5.

Agbaje, A. (1997) 'Party Systems and Civil Societies' in Beckett P, \& Crawford Y (eds.), Dilemmas of Democracy in Nigeria.361-387Rochester: University of Rochester Press.

Agbaje, A. and Adejumobi, S., (2006). Do Votes Count? 1 The Travails of Electoral Politics in Nigeria. Africa Development, 31(3), pp.25-44.

Agbese, D., (2012). Ibrahim Babangisa: The Military, Politics and Power in Nigeria. Adonis \& Abbey Publishers.

Aghion, P., \& Bolton P. (1997) A Theory of Trickle-Down Growth and Development.Review of Economic Studies (1997) 64, 151-172.

Agu. S, Okeke, V., \& Idike. A. (2003) "Voters Apathy and Revival of Genuine Political Participation in Nigeria" Mediterranean Journal of Social Sciences. Rome, Italy.

Aiyede, E.(2009) 'The Political Economy of Fiscal Federalism and Dilemma of Constructing A Developmental State in Nigeria'.International Political Science Review 2009. 30: 249. http://ips.sagepub.com/content/30/3/249.

Ajakaiye, Olu (2004), "Centrality of Planning to Alternative Development Paradigm in Africa”, In: Bade Onimode (ed.), African Development and Paradigm in Africa”, in: Bade Onimode (ed.), African Development and Governance Strategies in the 21st Century: Essays in Honour of Adebayo Adedeji at Seventy, London and New York: Zed Books, chapter 5.

Akindele, S., \& Olaopa, R. (2002) 'Fiscal Federalism and Local Government Finance in Nigeria'.http://unpan1.un.org/intradoc/groups/public/documents/CAFRAD/UNPAN008121

Akinyemi, B. (2004) "Corruption: A Battle Nigeria must Win" This Day August 22, p. 22. 
Akpan, E. (2004) 'Intergovernmental Fiscal Relations: The Nigerian Experience'. Paper presented at the 10 Year Anniversary of Financial and Fiscal Commission of South Africa. Capetown, 10-12 August 2004. http://www.ffc.co.za/conf/papers/nigeria-igfr.pdf.

Alapiki, H.E., (2005). State Creation in Nigeria: Failed Approaches to National Integration and Local Autonomy. African Studies Review, 48(3), pp.49-65.

Almond, G. and Coleman, J., (1960).Politics of Developing Nations. Princeton, NJ: Princeton University.

Almond, G. and Verba, S., (1963). The Civic Culture: Political Attitudes and Democracy in Five Country Baba, I., 2015. Political Culture and Democratic Transition in West Africa: The Nigerian Experience. Universal Journal of Management, 3(3), pp.115-121.es. Princeton: Princeton university, 3.

Amar, B., \& Hamdi, M T. (2012) 'Global Competitiveness and Economic Growth: Empirical Verification for African Countries'. International Journal of Economics and Finance.

Canadian Center for Science and Education. Vol. 4, No. 6; 2012.

Ames, B, (2001) "The Deadlock of Democracy in Brazil”, Ann Arbor, MI. University of Michigan Press.

Amoretti, M. U. \& Berneo, N. (eds.) (2004). Federalism and Territorial Cleavages. Baltimore and London: The John Hopkins University Press.

Amuwo K, S., Agbaje, A., \& Herault, G (eds. 1998) Federalism and Political Restructuring in Nigeria. Ibadan: Spectrum Books Limited.

Anand, S., \& Amartya S. (1996) 'Sustainable Development: Concepts and Priorities'. United Nations Development Programme, Office Development Studies Discussion Paper Series.

Ananta, A., Arifin, E., \& Suryadinata, L. (2005), Emerging Democracy in Indonesia, Singapore: Institute of Southeast Asian Studies

Anazodo, R.O., Okoye, J.C. and Emma, E.O., J. \& Chukwuemeka, E.(2012)“CCivil service reforms in Nigeria: The Journey so far in Service Delivery.". American Journal of Social and Management Sciences, ISSN Print.

Anderson, W. (1960). Intergovernmental Relations in Review, Minneapolis: University of Minnesota Press.

Andrews, M. and Shah, A., (2005). Citizen-Centered Governance: A New Approach to Public Sector Reform. Public Expenditure Analysis, pp.153-182.

Anugwom, E. (2001) 'Federalism, Fiscal Centralism and the Realities of Democratization in Nigeria: the case Study of Nigeria Niger Delta'. UNESCO/ENA,

2001.www.uniesco.org/shs/most.

Aspinall, E. (2010) 'Assessing Democracy Assistance in Indonesia'. UNDP: http://fride.org/download/IP_WMD_Indonesia_ENG_jul10.pdf. 
Aribigbola, A., Folami, O.M., Williams-Adewinle, A. and Karimu, O., (2013). Urban Governance in Sub Saharan Africa: an Evaluation of its Effectiveness for Sustainability in Akure, Ondo State, Nigeria. European Scientific Journal, esj, 9(8).

Awolowo, O. (1947) Path to Nigeria Freedom. London: Faber and Faber, Ltd.

Awopeju, A. (2011) 'Election Rigging and The Problems of Electoral Act in Nigeria' Afro Asia Journal of Social Sciences, Volume 2, No 2.4 Quarter IV.

Axelrod, R., (1997). The Dissemination of Culture: A Model with Local Convergence and Global Polarization. Journal of Conflict Resolution, 41(2), pp.203-226.

Ayoade, J. (1998) Nigeria and the Squandering of Hope. Ibadan, Vantage Publishers Ltd.

Ayodele, B. and Bolaji, K., (2007). Public Service and Democracy in Developing Societies: The Nigerian Experience. Journal of Social Science, 15(2), pp.105-110.

Babawale, T. (2006) 'Nigeria in the Crisis of Governance and Development'. Lagos: Political and Administrative Resource Center (PARC)

Bamidele, G. (2013) The Role of Local Government in Federal Systems. Available at: https://www.newsdiaryonline.com

Barabra, A., Bardes, M., \& Shelley, S. (2011) American Government and Politics Today: (2011-2012 Student Edition) Boston: Wadsworth.

Bardhan, P., (2002).Decentralization of Governance and Development. The Journal of Economic Perspectives, 16(4), pp.185-205.

Barro, R.J., 2000. Inequality and Growth in a Panel of Countries. Journal of Economic Growth, 5(1), pp.5-32.

Bayart, Jean-François (1993). The state in Africa: the politics of the belly (2nd ed.). London: Longman.

Beblawi, H., \& Luciani, G (eds. 1987) THE RENTIER STATE 51.

Beblawi, H., \& Luciani, G. (1990) 'The Rentier State in the Arab World', in Luciani, G. (ed.) The Arab State. London: Routledge, p.87-88.

Bernet, R. (2010) 'Decentralizing Authority after Suharto: Indonesia's 'Big Bang' 19982010. Princeton University. www.princeton.edu/successfulsocieties.

Besley, T. and Ghatak, M., (2007). Reforming Public Service Delivery 1. Journal of African Economies, 16(suppl_1), pp.127-156.

Bird, R. (2000) 'Fiscal Decentralization and Competitive Government', in Gianluigi, G., Pierre, S., \& Wintrobe, R. (eds) Competition and Structure: The Political Economy of 
Collective Decisions: Essay in Homer of Albert Breton, New York Cambridge University Press.

Bird. R.M, (1994) 'A Comparative Perspective on Federal Finance' in Banting, K., Brown, D., \& Courchene, T. (1994) The Future of Fiscal Federalism.Kingston School of Policy Studies, Queen's University 1994.

Birdsall, N., Vaishnav, M., \& Ayres R. L. (eds. 2006) Short of the Goal U.S. Policy and Poorly Performing States. Washington DC: Brookings Institution Press.

Bjørnskov, C., Gupta, N.D. and Pedersen, P.J., (2008). Analysing Trends in Subjective Wellbeing in 15 European Countries, 1973-2002. Journal of Happiness Studies, 9(2), pp.317-330 Black, K. (1999) Development in Theory and Practice; Paradigms and Paradoxes. Westview Press.

Blair, H. (2000) 'Participation and Accountability at the Periphery: Democratic Local Governance in Six Countries’ World Development, Vol. 28, No.1, pp. 21-39.

Brancati, D. (2005) Decentralization: Fueling the Fire or Dampening the Flames of Ethnic Conflict and Secessionism. Institute for Quantitative Political Science Center for Government and International Studies, North Building Cambridge, Massachusetts 02138 http://www.nyu.edu/gsas/dept/politics/seminars/brancati_f05_paper.pdf.

Braun, D., \& Hunter, S. (2014) 'Political Trust, Extra-Representation and the Openness of Political Systems’. International Political Science Review, November, 2014. SAGE Journals.

Bratton, M., 2008. 'Vote buying and violence in Nigerian election campaigns'. Electoral studies, 27(4), pp.621-632.

Budiati, P. (2013) Policy and Participatory Local Governance in Indonesia. UNDP Indonesia Program Manager Decentralization and Local Governance.

http://www.pk.undp.org/content/dam/pakistan/docs/Democratic\%20Governance/Federalism/I nternational\%20Conference\%20Sept13/presentations/Day2/3rd\%20Ms.\%20Budiati\%20pdf.p df

Bunte, M., \& Ufen A. (eds.) (2009) Democratization in Post-Suharto Indonesia.Oxon: Routledge Contemporary Southeast Asia Series.

Burges, M. (2006) Comparative federalism: Theory and Practice. London: Routledge.

Capoccia, G. and Kelemen, R.D., (2007). The study of critical junctures: Theory, narrative, and counterfactuals in historical institutionalism. World politics, 59(3), pp.341-369.

Cappocia, G (2016) "Critical Junctures and Institutional Change", in Mahoney, J. and K. Thelen, eds., Advances in Comparative Historical Analysis, Cambridge, Cambridge University Press, 2015, pp. 147-179. 
Charlick, R. (1992) 'The Concept of Governance and its Implications for A.I.D Development Assistance in Africa'. ARD, Washington D.C

Cheena, G., \& Rodinelli, D. (eds.) (1983) Decentralization and Development: Policy

Implementation in Developing Countries, Beverly Hills: Sage Publications

Clarke, T. and Clegg, S., (1999). Changing Paradigms in Public Service

Management. Administrative Theory \& Praxis, 21(4), pp.485-490.

Cohen, S. (1981) Decentralization: A Framework for Policy. California: University Press of California.

Cole, T \& Robert O. (eds.) (1962) The Nigeria Political Scene.Durham, N.C; Duke University Press.

Coleman, J. (1986) Nigeria: Background to Nationalism. Benin City \& Katrineholm: Broburg \& Wsitrom.

Colino, C., \& Moreno, L. (2010) 'Diversity and Unity in Federal Countries. '(A Global Dialogue on Federalism Volume 7).Forum of Federations. Montreal and Kingston: McGillQueen's University Press.

Collier, P \& Hoeffier, A. (2004) "Greed and Grievance in Civil Wars", Oxford Economic Papers 56, pp.663-695.

Commonwealth Secretariat (2011) "Decentralization and Development", in Z. Scott and M. Alam, Resource Guide on Decentralization and Local Government, Commonwealth Secretariat, London.

Conyers, D. (1985) 'Decentralization: A Framework for Discussion,' in Hasnat Abdul Hye, (ed.) Decentralization, Local Government Institutions and Resource Mobilization (Dhaka: Bangladesh Academy for Rural Development,), pp. 22-42.

Conyers, D. (1986) Decentralization and Development: A framework for Analysis (Downloaded from cdj. Oxforjournals.org.

Corbin, J., \& Strauss, A. (2008) Basics of Qualitative Research: Techniques and Procedures for Developing Grounded Theory. London: Sage Publications.

Corkey, J. (1997) 'International Experience with Institutional Development and Administrative Reform: Some Pointers for Success'. Working Paper No. 15. Maasricht: ECPDPM.

Crawford, G., \& Hartmann, C. (eds.) (2008) Decentralization in Africa: A Pathway out of Poverty and Conflict? Amsterdam University Press.

Creswell, J. W. (2013). Qualitative Inquiry and Research Design. Thousand Oaks, CA: Sage

Creswell, J.W., (2013). Research Design: Qualitative, Quantitative, and Mixed Methods Approaches. Sage publications. 
Crook, R., \& Manor, J. (1998) Democracy and Decentralization in South Asia and West Africa; Participation, Accountability and Performance, New York: Cambridge University Press.

Crowder, M. (1962) The Story of Nigeria, London: Faber and Faber.

Cuadrado-Ballesteros, B., García-Sánchez, I.M. and Prado-Lorenzo, J.M., (2013).

Effect of Modes of Public Services Delivery on the Efficiency of Local Governments:

A Two-stage Approach. Utilities Policy, 26, pp.23-35.

Cyr, A., \& Deleon, P. (1975) Comparative Policy Analysis. Policy Sciences, 6, 375-384.

Dadzie, K. (1993) 'The UN and the Problem of Economic Development', in Roberts, A. and Kingsbury, B., (eds.) United Nations, Divided World. Oxford: Claredon Press.

Dalton, R.J. and Shin, D.C., (2014). Reassessing the Civic Culture Model. The Civic Culture Transformed: From Allegiant to Assertive Citizens, pp.91-115.

Darma, N.A. and Ali, M., (2014). An Assessment of Public Sector Service Delivery in Nigeria: A Case Study of Federal Capital Territory Area Councils, 2007-2011. International Journal of Development and Sustainability, 3(8), pp.1756-1776.

Degutis, M., Urbonavičius, S. and Gaižutis, A., (2010). Relation between Life Satisfaction and GDP in the European Union. Ekonomika, 89.

Dethier, J, (2000). Some Remarks on Fiscal Decentralization and Governance: Paper prepared for Presentation at the Conference on Decentralization Sequencing, Jakarta, Indonesia, March 20, 2000

https://www.imf.org/external/pubs/ft/seminar/2000/idn/dethier.pdf

Devarajan, S., Dollar, D., \& Holmgren, T. (eds.) (2001) Aid and Reforms in Africa. Washington, DC: The World Bank.

Diamond, L (1988) 'Nigeria: Pluralism, Statism and Struggle for Democracy' in L. Diamond, J.J. Linz, and S.M. Lipset (eds.) (1988), Democracy in Developing Countries: Africa; 33-91. Boulder: Lynne Rienner Publishers.

Dike, V. E. (2005) Corruption in Nigeria: A New Paradigm for Effective Control, Africa Economic Analysis. Retrieved from: http://www.AfricaEconomyAnalysis.Org.

Diplomacy and The Polio Immunization Boycott In Northern Nigeria

Judith R. Kaufmann and Harley Feldbaum Health Affairs, 28, no.4 (2009):10911101http://content.healthaffairs.org/content/28/4/1091.full.html

Domingo, P. (2009) Why Rule of Law Matters for Development. Overseas Development Institute. London.

Dunmoye, R.A., (2002). Resource Control: Which way forward. The Nigerian Social Scientist, 5(1), pp.49-53.

Eaton, K., Kaiser, K., \& Smoke P. (2010) The Political Economy of Decentralization Reforms: Implications for Aid Effectiveness. The Word Bank, Washington, DC 
Ebel, Robert D. and Serdar Yilmaz (2003) "On the Measurement and Impact of Fiscal Decentralization," in James Alm and Jorge Martinez-Vazquez, eds. (2003) Public Finance in Developing and Transitional Countries: Essays in Honour of Richard M. Bird (Cheltenham, UK: Edward Elgar).

Egwu, S. (1998) 'Structural Adjustment, Agrarian Change and Rural Ethnicity in Nigeria'. Research Report No. 103. Uppsala, Sweden, The Nordic Africa Institute.

Ekeh, P., Cole, D. (eds.)(1989) Nigeria since Independence, the First 25 years/Volume One. Ibadan: Heinemann Educational Books Limited.

Ekeh, P. \& Osaghae, E. (eds.1989) Federal Character and Federalism in Nigeria.Ibadan: Heinemann Educational Books Limited.

Ekundare, O.(1971) An Economic History of Nigeria 1860-1960.London: Methuen \& Co Ltd. 1971. Pgs.15-17.

Ekpo, A.H and Ndebbio, J.E.U. (1998). Local Government Fiscal Operations in Nigeria. African Economic Research Consortium Research Paper 73, Nairobi

Elaigwu, J.I. and Galadima, H., (2003). The Shadow of Sharia over Nigerian Federalism. Publius: The Journal of Federalism, 33(3), pp.123-144.

Elaigwu, I. (2007) 'Nigeria: The Current State of the Federation: Some Basic Challenges'. Paper presented at International Conference Daniel J (1995): From Statism to Federalism - A Paradigm Shift, in Publius Vol. 25, No. 2. on Federalism in Honour of Professor Ronald Watts, Organized by the Institute of Intergovernmental Relations, Queens University, Kingston, Canada, October 18-21, 2007.

Elaigwu, I. (2007) The Politics of Federalism in Nigeria.London: Adonis and Abbey Publishers.

Elazar, D. (1987) Exploring Federalism, Tuscaloosa: University of Alabama Press.

Elliot, J. (2006) An Introduction to Sustainable Development. London: Routledge.

Engel, A. (1997). Decentralization, Local Capacity and Regional Rural Development: Experiences from GTZ-Supported Initiatives in Africa Southern Africa Region GTZ

Enikolopov, R., Zhuravskaya, E. (2007) Decentralization and Political Institutions, Journal of Public Economics, Volume 91, Issue 11.

ESG Business Intelligence (February 2014) Special Report on MINT Countries: ESG Issues in Mexico, Indonesia, Nigeria\& Turkey.

Falola, T. (1994) The Military Factor in Nigeria: 1966-1985. New York Lewiston press..

Falola, T., \& Heaton, M. (2008) A History of Nigeria.Cambridge University Press.

Fesler, J. (1968) 'Centralization and Decentralization' in David L Sills (ed.) International Encyclopaedia of Social Sciences, Vol.2, New York: The Macmillan Company and The Free Press. 
Fisman, R, \& Gatti, R, (2000). "Decentralization and Corruption - evidence across countries," Policy Research Working Paper Series 2290, The World Bank.

Franceschet, S., Krook, M. L., \& Piscopo, J. M. (Eds.). (2012). The Impact of Gender Quotas. New York, NY: Oxford University Press

Friedrich, C. (1968) Trends of Federalism in Theory and Practice. New York: Praeger.

Friscttak, L. (1994) 'Governance Capacity and Economic Reform in Developing Countries'. World Bank Technical Paper 254, Washington.

Fuglie, K. (2003) 'Productivity Growth in Indonesian Agriculture, 1961-2000'.

Contributed Paper presented to the 47th Annual Conference of the Australian Agricultural and Resource Economics Society at Fremantle, February 12-14, 2003

Gboyega, A., 1987. Political Values and Local Government in Nigeria. Malthouse press.

George, M. (2010) The Looting of Local Government in Nigeria. Available at: https://newsmailonline.wordpress.com/2010/10/03/hello-world/.

Gerson, K., \& Horowith, R. (2002) 'Options and Choices in Qualitative Research' in May, T. (ed. 2002) Qualitative Research in Action, London: Sage Publications.

Giddings, B., Hopwood, B., \& O’Brien, G. (2002) 'Environment, Economy and Society: Fitting Them Together Into Sustainable Development Sustainable'. Polity Press in Association Basil Blackwell. Dev. 10, pp. 187 - 196.

Graf, W.D., (1988). The Nigerian State: Political Economy, State Class and Political System in the Post-Colonial Era. Heinemann.

Green, K. (2005) 'Decentralization and Good Governance: The Case of Indonesia'. MPRA Paper No. 18097 posted 26. October 2009 14:02 UTC Online at http://mpra.ub.unimuenchen.de/18097/

Griffiths, M. (2005) Encyclopaedia of international Relation and Global Politics. New York: Routledge.

Gupta, M.D., Gauri, V. and Khemani, S., 2003. Decentralized Delivery of Primary Health Services in Nigeria. Africa Region Human Development Working Paper Series. Washington, DC, The World Bank.

Guryer, J. (1997) Local Government Chiefs and Office Holders in a Rural Area. Ibadan: Vantage Press.

Hadiz, V. R. (2004) Decentralization and Democracy in Indonesia: A Critique of NeoInstitutionalist Perspectives. Development and Change 35(4): 697-718 (2004).Institute of Social Studies 2004. Published by Blackwell Publishing, 9600 Garsington Road, Oxford OX4 2DQ, UK and 350 Main St., Malden, MA 02148, USA. 
Hakim, C. (1987) Research Design: Successful Designs for Social and Economic Research. London: Allen \& Uwnwin Publishers.

Harris, J. (2000) 'Basic Principles of Sustainable Development' (Global Development and Environment Institute) Tufts University .http://ase.tufts.edu/gdae.

Harrison, L., and Huntington, S, (2001). Culture Matters: How Values Shape Human Progress. New York: Basic Books.

Head, I. (1991) On a Hinge of History-The Mutual Vulnerability of South and North. Toronto: University of Toronto Press.

Huntington, S. (1987) 'The Goals of Development' in M. Weiner and S.P Huntington (eds. 1987) Understanding Political Development (Boston, MA, Little Brown and Co.), pp. 3-32.

Human Right Watch (2014) ttp://www.hrw.org/news/2014/03/14/nigeria-boko-haramattacks-cause-humanitarian-crisis

Hussaini, A. (2010) Clash of Identities, State, Society and Ethno-Religious Conflict in Northern Nigeria. Kaduna: DevReach Publishers Nigeria.

Hutchcroft, P. (2001) 'Centralization and Decentralization in Administration and Politics Assessing Territorial Dimensions of Authority and Power' in McCoy, A., \& Scarano, F. (eds. 2009) Colonial in Crucible: Empire in the Making of the Modern American State. The University of Wisconsin Press. Pp. 23-53.

Hyden, G., Olowu, D., \& Okotie Ogendo, H. (eds.) (2000) African Perspectives on Governance.African World Press, Incoporation.

Ihonvbere, J. (2011) 'Economic Crisis, Structural Adjustment and Social Crisis in Nigeria'. World Development Journal, 21(1), 141-153.

Ikeanyibe, O.M. (2009) Local Government and Constitutional Elasticity. In: Odion-Akhaine, S (ed) Local Government Administration in Nigeria. Abuja: Panaf Press.

Jacobs, G. and Slaus, I., 2010. Indicators of Economics Progress: the Power of Measurement and Human Welfare. Cadmus, 1(1), p.53.

Javier, G. (2012) Instability Factors in Indonesia, In: Majer, M., Ondrejcsák, R., Tarasovič, V. (eds.): Panorama of Global Security Environment 2012. Bratislava: CENAA, pp. 525-439.

Jevons, M. (2008) 'Why World Bank's Governance Indicators Suck?' http://bayesianheresy.blogspot.co.uk/2008/06/why-world-banks-governance-indicators.html Jhingan, M. (2007) The Economics of Development And Planning. Delhi, Vrinda Publications.

Johnson, C, and Start D, (2001) Rights, Claims and Capture: Understanding the Politics of Pro-poor Policy. Overseas Development Institute 111 Westminster Bridge Road London 
Joseph, R. (1987) Democracy and Prebendal Politics in Nigeria. Ibadan: Spectrum Books Limited.

Joshi, S. (2005) 'Theories of development: Modernisation vs Dependency'

Retrieved from http://infochangeindia.org/defining-development/theories-of-developmentmodernisation-vs-dependency.html

Jutting, J., Kauffmann, C., McDonnel I., Osterrrieder H., Pinaud N., \& Wegner L (2004) 'Decentralization and Poverty in Developing Countries: Exploring the Impact'. OECD Development Center.

http://www.oecd.org/dataoecd/40/19/33648213.pdf.http://biblioteca.unmsm.edu.pe/redlieds/R ecursos/archivos/gestionestado/overview-decentralization-worldwide-paper.pdf.

Kalipossa, F. P. (2004).'Decentralization and Democracy in Developing Countries' Development in Practice. Vol. 14. No 16 pp.768-779. http://www.jstor.org/stable/4030022.

Kampen, J.K., De Walle, S.V. and Bouckaert, G., (2006). Assessing the Relation between Satisfaction with Public Service Delivery and Trust in Government. The Impact of the Predisposition of Citizens toward Government on Evaluations of its Performance. Public Performance \& Management Review, 29(4), pp.387-404.

Kaplan, Seth (2008) Fixing Fragile States A New Paradigm for Development. London: Praeger Security International.

Kathmandu Final Workshop Report (2009). Governance and Infrastructure Development Challenges in the Kathmandu Valley.Sponsored by the East-West Center's Urban Dialogue and Kathmandu Metropolitan City Government. Sponsored by the East-West Center's Urban Dialogue and Kathmandu Metropolitan City Government.

Kaufmann, D. (2003a) 'Rethinking Governance, Empirical Lessons Challenge Orthodoxy'. Discussion Paper, Washington DC: World Bank Institute, available at http://www.worldbank.org/wbi/governance.

Kaufmann, D. (2003b) 'Governance Crossroads' in Cornelius, P., Schwab, K., and Porter, M. (eds.), Global Competitiveness Report 2002-2003, New York: Oxford University Press.

Kaufmann, D., \& Kraay, A. (2003) 'Growth without Governance'. The Journal of the Latin American and Caribbean Economic Association, 3 (1): 169- 215.

Kaufmann, D., Kraay, A., \& Mastruzzi, M. (2004) Governance Matters III: Governance Indicators for 1996-2002., World Bank Policy Research Working Paper No. 3106, Washington DC: World Bank.

Kaufmann, D., Kraay, A. \& Mastruzzi, M. (2005) Governance Matters IV: Governance Indicators for 1996-2004., World Bank Policy Research Working Paper No.3630, Washington DC: World Bank.

Kaufmann, D., Kraay, A., \& Mastruzzi, M., (2008) Governance Matters VII: Aggregate and Individual Working Paper 4654, Washington: 2008 
Kaufmann, D., Kraay, A., \& Zoido-Lobaton, P. (1999) Aggregating Governance Indicators. World Bank PolicyGovernance Indicators 1996-2007, Policy Research Research Working Paper No. 2195, Washington DC: World Bank.

Kaufmann, D., Kraay, A., \& Zoido-Lobaton, P. (2000) Governance Matters: From Measurement to Action, Finance and Development, 37 (2). Washington DC:

International Monetary Fund.

Kaufmann, D., Kraay, A., \& Zoido-Lobaton, P. (2002) Governance Matters II: Updated Indicators for 2000-01., World Bank Policy Research Working Paper No. 2772, Washington DC: World Bank.

Kemp, R., Parto, S. and Gibson, R.B., 2005. Governance for Sustainable Development: Moving from Theory to Practice. International Journal of Sustainable Development, 8(1-2), pp.12-30.

Kesner-Skreb, M. (2009)."Fiscal Federalism: Financial Theory and Practice”. 33(2), 235-237.

King, D. (2003) USAID/Nigeria Economic Growth Activities Assessment; Transition Period Summary Report'. http://pdf.usaid.gov/pdf_docs/PDACG556.pdf

Kingsbury, D. (2002) The Politics of Indonesia. Oxford University Press.

Kirk-Greene A (1997); "Northern Nigeria from c. 1900 until Independence" in John Middleton et al (eds.) Africa South of Sahara, Vol 3, New York: Simon and Schuster Macmillan, 1997.

Knack, S. (2002), .Governance and Growth: Measurement and Evidence., Paper prepared for the Forum Series on the Role of Institutions in Promoting Growth, IRIS Center and USAID, Washington DC, February 2002.

Knack, S. (Ed.) (2003), Democracy, Governance and Growth, Ann Arbor: The University of Michigan Press.

Koehn, $P$. (1991) 'Development and Administration in Nigeria: Inclinations and Results' in Ali Farazmand (ed.) Handbook of Comparative and Development Administration. New York: Marcel Dekker.

Kofele-Kale, N., 2006. Change or the Illusion of Change: the War against Official Corruption in Africa. Geo. Wash. Int'l L. Rev., 38, p.697.

Krasner, S. (1985) Structural Conflict: The Third World Against Global Liberalism. Becklay CA, University of California Press.

Landell-Mills, P., \& Serageldin, I. (1991) Governance and the External Factor, Washington: World Bank Annual Conference. 
Larbi, G.A., (2003). Overview of Public Sector Management Reform. United Nations Research Institute for Social development.

Larson, B. (ed.) (2007) Sustainable Development Advances. New York: Nova Sciences Publisher Inc.

Law (2013) “How Can We Define Federalism?” Perspectives on Federalism. Vol. 5. Issue 3.

Lawal, T. and Oladunjoye, A., 2010.Local government, Corruption and Democracy in Nigeria. Journal of Sustainable Development in Africa, 12(5), pp.227-235.

Leftwich, A., 2007.The Political Approach to Institutional Formation, Maintenance and Change. IPPG Discussion papers series, (14).

Leftwich, A., 2008.Developmental States, Effective States and Poverty Reduction.

Lerner, D., 1958. The Passing of Traditional Society: Modernizing the Middle East.

Lev, S. (2009) The Transition to Guided Democracy: Indonesian Politics 1957-1959.

Singapore: Equinox Publishing (Asia) PTE Ltd.

Lewis, P., Robinson, P., \& Rubin, B.(1998). Stabilizing Nigeria, Sanctions, Incentives and Support for Civil Society. New York: The Century Foundation Press.

Leys, C. (1996) The Rise and fall of Development Theory. Bloomington \& Indianapolis: Indiana University Press.

Lopes, C. (1994) Enough is Enough! For an Alternative Diagnosis of African Crisis. Uppsala: Nordiska Afrikainstituet.

Lopes, C. (1999) Are Structural Adjustment Programmes an Adequate response to Globalisation? UNESCO. Oxford: Blackwell Publishers.

Maddick, H. (1963) Democracy, Decentralization and Development. London: Asia Publishing House.

Mahoney, J. and Villegas, C.M., 2007. Historical Enquiry and Comparative Politics. In The Oxford Handbook of Comparative Politics.

Maja-Pearse, A. (1999) From Khaki to Agbada (1999): a Handbook for the February 1999 Elections in Nigeria, Lagos: Civil Liberty Organisation.

Maman, S., \& Hidayat, A. (2006) Fiscal Decentralization in Indonesia: Current Status and Future Challenges Published at Jurnal Keuangan Publik, Ministry of Finance RI, September 2006.

Manor J. (1999) The Political Economy of Democratic Decentralization, World Bank, Washington DC.

Maxwell, J.A. (2013). Qualitative Research Design: An Interactive Approach. Thousand, Oaks, CA: Sage. 
Macarthur, J., \& Sachs, J. (2002) The Growth Competitiveness Index: Measuring Technological Advancement and the Stages of Development, in: M.E. Porter, J.D. Sachs.

Macarthur, W., Cornelius, P., \& Schwab, K. (eds.) The Global Competitiveness Report 20012002, New York: Oxford University Press.

McCullough J. Johnson R. \& Rondinelli D.A. (1989) 'Analysing Decentralization Policies in Developing Countries': A Political-Economy Framework. (Development and Change Vol. 20), London: Sage.

Mcgee, R., \& Gaventa, J. (2010) Review of Impact and Effectiveness of Transparency and Accountability Initiatives: Synthensis Report. Institute of Development Studies, ttps://www.ids.ac.uk/files/dmfile/IETASynthesisReportMcGeeGaventaFinal28Oct2010.pdf

Mcgrew, A. (2000) 'Sustainable Globalisation?The Global Politics of Development and Exclusion in the New World Order' in Allen, T., \& Thomas, A. (eds.), Poverty and Development into the $21^{\text {st }}$ Century. New York, Oxford University Press Inc.

Momoh, A. and Adejumobi, S., 1999. The Nigerian Military and the Crisis of Democratic Transition: a Study in the Monopoly of Power. Civil Liberties Organisation.

Moreno, L. and Colino, C., 2010. Diversity and Unity in Federal Countries (Vol. 7).McGillQueen's Press-MQUP.

Muhammad, A. (2007) 'Federalism and Political Stability in Nigeria: Current Peril and Future Hopes'. Journal of Sustainable Development in Africa (Vol.9, No.4, 2007).

Neuman, W.L. and Robson, K., 2012. Qualitative interviewing. Basics of Social Research Qualitative and Quantitative Approaches, pp.187-203.

Ndegwa, S. N. (2002) 'Decentralization in Africa: A Stocktaking Survey’ (World Bank, African Working paper Series) ttp://www.worldbank.org/afr/wps/wp40.pdf

Ndibe, O. (1999) "Nigeria" in Appiah Anthony Kwame, Gates Henry Louis (eds) Africana The Encyclopaedia of the African and African American Experience. New York: Perseus Books, 1999.

Ngou, C. (1989) 'The 1959 Elections and Formation of the Independence Government' in P.P Ekeh (eds.) Nigeria since Independence: The First 25 years. Vol.v: Politics of Constitutions (Ibadan: Heinman).

Niven, R. (1967) Nigeria: London: Ernest Benn Limited.

Nnoli, O. (2008) Ethnic Politics in Nigeria.Enugu: Fourth Dimension Publishers.

North, D. C.: 1990, Institutions, institutional change and economic performance.Cambridge university press. 
North, D. C.: 1994, 'Economic performance through time'. The American economic review 84(3), 359-368.

Norgaard, R. (1994) Development Betrayed: The End of Progress and a Co evolutionary Revisioning of the Future. New York and London: Routledge.

Norris, P. and Inglehart, R., 2009. Cosmopolitan Communications: Cultural Diversity in a Globalized World. Cambridge University Press.

Numa, S.E., 2015. Political Participation and Political Apathy in Nigeria (2011-2015): Case Study of Undergraduate Students of the University of Jos. A Publication of Brics International Resource Solutions, Eylül.

Nwabueze, B. (1982).A Constitutional History of Nigeria. London: Oxford Press.

Nwabueze, B. (2007) How President Obasanjo Subverted Nigeria's Federal System. Ibadan: Gold Press Limited.

Oates, W. (1972) Fiscal Federalism, Harcourt Brace, New York.

Oates, W. (1993) The Role of Fiscal Decentralization in Economic Growth.http://pdf.usaid.gov/pdf_docs/PNABP362.pdf

Oates, W. (1999). 'An Essay on Fiscal federalism', America: Journal of Economic Literature, JSTOR.37(3):1120-49.

Obinger, H., Leibfried, S. and Castles, F.G. eds., (2005). Federalism and the Welfare State: New World and European Experiences. Cambridge University Press.

Oduwobi, T., (2011). From Conquest to Independence: the Nigerian Colonial Experience. Historia Actual Online, (25), pp.19-29.

OECD: Reviews of Regulatory Reforms: Indonesia (2012): Strengthening Coordination and Connecting Markets.

https://www.google.co.uk/search?tbm=bks\&hl=en\&q=Reviews+of +Regulatory+Reforms\%3 A+Indonesia+2012\%3A+Strengthening+Coordnation+and+Connecting+Markets.

Ofeimun, O. (2005) Resource Control and Beyond (2) The Guardian Newspaper Lagos.

Ogunna, A. (1996). A Handbook on Local Government in Nigeria, Owerri: Versatile Publishers.

Ogunrotifa, A.B., (2012). Millennium Development Goals in sub-Saharan Africa: A critical assessment. Radix International Journal of Research in Social Science, 1(10), pp.1-22.

Ojo, E.O. and Adebayo, P.F., 2008. The Politics of States\Local Governments\'Creation and Nigerial's Search for Geo-Political Balancing. African Research Review, 2(3), pp.334-367.

Okoli,F.. (2000).Theory and Practice of Local Government: A Nigerian Perspective, Enugu:J ohn Jacobs Classic Publishers Ltd

Okotoni, O., 2001. Problems and Prospects of Nigerian Bureaucracy. Journal of Social Sciences, 7(3), pp.223-229. 
Okunrounmu, T. 0 (1997), 'Fiscal Federalism: Revenue Allocation System in the Federal Republic of Nigeria' in CBNIWorld Bank's Nigeria: Prospects for Development. Abuja: CBNIWorld Bank. Pp.157-162.

Olanipekun, J.M. (1988) Local Government in Nigeria. Paper presented at African Leadership Forum, Ibarapa Local Government Area, Oyo State, Nigeria 27 October 1988.

Olarinmoye, O.(2008) 'Godfathers, Political Parties and Electoral Corruption in Nigeria'. African Journal of Political Science and International Relations 2(4), 67 - 73.

Olasupo, F., Fayomi, M. (2012). Historical Epochs of Local Government Administration in Nigeria: Women and the Poor. Global Journal Of Human-Social Science Research, 12(9-A)

Olowu, B. (2001) 'African Decentralization and Policies and Practices from 1980s and Beyond’, ISS Working Papers Series No.334, The Hague: Institute of Social Studies.

Olusanya, G.O. (1980) Constitutional Development in Nigeria, 1861-1960, in Ikime (ed.) Groundwork of Nigerian History. Heinemann.

Omeje, K. (2006) High Stakes and Stakeholders: Oil Conflict and Security in Nigeria. Hampshire: Ashgate Publishing Limited.

Omeje, K (ed. 2007) State-Society Relations In Nigeria.London: Adonis and Abbey Publishers Limited.

Omeje, K (ed. 2008) Extractive Economies and Conflicts in the Global South. Multi-Regional Perspectives on Rentier Politics.London: Adonis \& Abbey Publishers.

Omokhoa I. (2015) Revisiting the Peace-Building Efforts in Post Conflict Niger Delta, Nigeria: A Case Study of the Amnesty Programme. Mediterranean Journal of Social Sciences. MCSER Publishing, Rome-Italy. Vol. 6 No 6 S1

Omotoso, F., (2010). Nigerian Fiscal Federalism and Revenue Allocation Formula for Sustainable Development in Niger Delta. The Social Sciences, 5(3), pp.246-253.

Omotoso, F., (2014).Public-service Ethics and Accountability for Effective Service Delivery in Nigeria. Africa Today, 60(3), pp.118-139.

Oni, S., Oni, A.A.and Gberevbie, D., (2015). Electronic Mediated Administration and Public Service Delivery in Nigeria. Acta Universitatis Danubius. Administratio, 7(2).

Onimode, B (2000) Fiscal Federalism in Nigeria: Options for the $21^{\text {st }}$ Century. A Research Report. Ibadan: NISER.

Organization for Economic Co-operation and Development (OECD) Principles for Good International Engagement in Fragile States Preamble (Paris France: OECD) April 7 2005).2

Osaghae, E, (1997) 'Comment’ Regional Development Dialogue 18(2); 107-117.

Osaghae, E. (1998) Crippled Giant: Nigeria since Independence. London: Hurst \& Company. 
Osaghae, E. (2011) Crippled Giant, Nigeria since Independence. Ibadan: John Archives Publishers.

Osayinwese, I., \& Iyare, S. (1991) The Economics of Nigerian Federalism: Selected Issues in Economic Management. Oxford Journals. Publius, Vol 21. No 4.

http://www.jstor.org/stable/3330323. Pp. 89-101.

Pereira, R., (2014).International Developments of States in Africa. In Recipient States in Global Health Politics (pp. 47-65). Palgrave Macmillan UK.

Peters, B.G., 1998. Comparative politics: Theory and Methods. New York: University Press.

Peterson, E. (1995) The Price of Federalism. Washington D.C: The Brooking Institutions.

Pierson, P (2000) 'Increasing returns, path dependence, and the study of politics'. American political science review.

Pierson P. (2004). Politics in Time History, Institutions, and Social Analysis. Princeton/Oxford: Princeton University Press.

Pierson, P., and T. Skocpol. (2002). "Historical Institutionalism in Contemporary Political Science." In Political Science: State of the Discipline, (eds). I. Katznelson and Milner H.V. New York: Norton. 3, pp.693-721

Pieterse, J.N., (2001). Participatory Democratization Reconceived. Futures, 33(5), pp.407422.

Post K.W., \& Vickers, M. (1973) Structure and Conflict in Nigeria 1960-65.London: Heinemann Educational Books Ltd.

Priyambud, E. (ed. 2009) 'Deepening Democracy in Indonesia: Direct Elections for Local Leaders (Pilkada)'. ISEAS Publishers, Singapore.

Protais, M. (2004) "Innovations in Governance and Public Administration for Poverty Reduction in Post-Conflict Countries in a Globalized World: the Experience of Rwanda" in UNDESA, Searching for Innovations in Governance and Public Administration for Poverty Reduction, (United Nations, New York.)

Prud'Homme, R. (1995) 'The Dangers of Decentralization. 'The World Bank Research Observer. Vol.10, no. (2): 201-220.

Pye, L.W. and Verba, S., 1965. Introduction, Political Culture and Political Development (pp. 3-26).Princeton University Press.

Rahman, Tunde and Achi, Louis (2005), 'Project Nigeria at 45: The Uncovered Grounds .... ' in Thisday Newspaper. Lagos: Leaders and Company. October 2 nd Edition, Pp. 1112-3

Ramphal, Sh. (1979). The Commonwealth Secretary General, "Keynote Address to the International Conference on Federalism", at the Nigerian Institute of International Affairs, Lagos. Published in Akinyemi, B., Cole, P., \& Ofonagoro, W. (eds.) Readings on Federalism Lagos: N.I.I.A., 
Rhodes, R. (2000) 'The Governance Narrative: Key Findings and Lessons from the Erc's Whitehall Programme' Public Administration, 78: 345-363.doi: 10.1111/1467-9299.00209

Richard, O.C., (2000). Racial Diversity, Business Strategy, and Firm Performance: A Resource-based View. Academy of Management Journal, 43(2), pp.164-177.

Ricklefs, M. (2001) A History of Modern Indonesia since c.1200.Palgrave (Third Edition)

Riker, W.H. (1975). "Federalism." In Handbook of Political Science, eds. F. Greenstain and N. Polsby. Massachusetts: Addison-Wesley Publishing Company.

Riker, W. (1964) Federalism: Origin, Operation, Significance. Boston: Little, Brown and Company.

Ritchie, J, \& Lewis J. (eds.) (2003). Qualitative Research Practice: A Guide For Social Science Students and Researchers. London: Sage Publications.

Rodeen J. (2004). Comparative Federalism and Decentralization: On Meaning and Measurement. Comparative Politics 36 (4): 481-500.

Rondinelli, D. (1981) 'Government Decentralization in Comparative Perspective: Theory and Practice in Developing Countries'. International Review of Administrative Science, vol. 47, 1981, pp. 136-45.

Rondinell, D. (1981) 'Government Decentralization in Comparative Perspective: Theory and Practice in Developing Countries'. International Review of Administrative Science.

Rondinelli, D. (1990) 'Decentralization, Territorial Power and the State: A Critical Response'. (Development and Change Vol. 21), London: Sage.

Rondinelli, D., \& Nellis J. (1986) 'Assessing Democratization Policies in Developing Countries: A case of Cautious Optimism’.Development Policy Review 4(1)

Rondinelli, D., Nellis J., \& Chenna.S. (1983) 'Decentralization in Developing Countries: A Review of Recent Experience’. World Bank Working Paper No. 581. Washington DC:

World Bank (Assessed on 11/07/11) http://wwwwds.worldbank.org/external/default/WDSContentServer/WDSP/IB/1983/07/01/000009265_3 980928162717/Rendered/PDF/multiOpage.pdf.

Sachs, W. (1993) The Development Dictionary.London: Zed Books.

Samuel, D., (2000) "Reinventing Local Government? Municipalities and Intergovernmental Relations in Democratic Brazil" in Amoretti M. U. \& Berneo, N. (eds.) (2004). Federalism and Territorial Cleavages. Baltimore and London: The John Hopkins University Press.

Sanders, E., 2006. Historical institutionalism. In The Oxford handbook of political institutions.

Sekwat, A., (2002). Civil service reform in post-independence Nigeria: Issues and challenges. Public Administration Quarterly, pp.498-517.

Schiavo-Campo, S., (1996) 'Reforming the Civil Service'. Finance and Development 33(3): 10-14. 
Schneider, A. (2003). "Decentralisation: Conceptualisation and Measurement." Studies in Comparative International Development 38(3): 32-56

Schou, A., \& Haug, M. (2005) 'Decentralization in Conflict and Post-Conflict Situations', Working Paper no 139, NIBR.

Schumpeter, J.A. (1961) Capitalism, Socialism and Democracy, London: Harper.

Schwarz, F. (1965) NIGERIA, The Tribes, The Nation, or the Race-The Politics of Independence.Cambridge: The M.I.T Press.

Scott, W.R., 1987. The Adolescence of Institutional Theory. Administrative Science Quarterly, pp.493-511.

Scott, Z. (2009) 'Decentralization, Local Government and Social Cohesion: An Analytical Review'. GSDRC Governance and Social Development Resource Center. International Development Department, University of Birmingham.

Shah, A., (ed.) (2007) 'Performance Accountability and Combating Corruption'. The International Bank for Reconstruction and Development/ World Bank Public Sector GOVERNANCE and Accountability Series. Washington DC.

Shah, Anwar. (1997). Fostering Responsive and Accountable Governance: Lessons from Decentralization Experience. World Bank, Washington, D.C.

Shah, A., Thompson, T. (2004) "Implementing Decentralized Local Governance: A Treacheriou Road with Potholes Detour and Road Closures" in World Bank Policy Research Working Paper 3353, Washington, D.C: World Bank.

Sharma, C.K. (2005) 'The Federal Approach to Fiscal Decentralization: Conceptual Contours for Policy Makers’.Loyola Journal of Social Sciences, XIX (2): 169-88.

Sharma, C. K. (1995) 'When Does decentralization Deliver?The Dilemma of Design'. South Asian Journal of Socio-Political Studies, 6(1):38-45

Sklar, R.L., (2004). On the Study of Constitutional Government in Africa. Constitutionalism and Society in Africa. Aldershot, UK: Ashgate.

Slater, D. (1989) 'Territorial Power and Peripheral State: The Issue of Decentralization'. (Development and Change Vol.20) London: Sage

Smith, B. (1985) Decentralization: The Territorial Dimension of the State. London: George Allen \& Unwin.

Smith, B. (1992) 'Introduction: Development Administration in the Third Development Decade' in Brian Smith (ed.) Progress in Development Administration, 1981-1991, Chichester: John Wiley.

Smith, B. (1996), ‘Sustainable Local Democracy’ Public Administration and Development Vol.16, No. 2, pp.163-178 
Smoke, P. (2001) 'Overview of Decentralization and Workshop Theme Llinkages'. In UNCDF (ed.) Decentralization and Local Governance in Africa: proceedings from Participatory Symposium, New York: UNCDF. www.uncdf.org.

Smoke, P. (2003) 'Decentralization in Africa: Goals Dimensions, Myths and Challenges' Public Administration and Development, Vol. 23, No. 1, pp. 7-16.

Soares Jr, J. and Quintella, R.H., 2008. Development: an Analysis of Concepts, Measurement and Indicators. BAR-Brazilian Administration Review, 5(2), pp.104-124.

Soesastro , H., SMITH, A., \& LING, H. (eds.) (2003) 'Governance in Indonesia: Challenges Facing the Megawati Presidency’ Institute of Southeast Asian Studies. Singapore.

Stake, R. (1995) The Art of Case Study Research. Newbury Park, CA: Sage Publications.

Stepan, A. (2005) 'Federalism and Democracy: Beyond the US Model', in Karmis, D. \& Norman, W. (eds.) Theories of Federalism: A Reader, New York and Basingstoke: Palgrave Macmillan.

Stewart, F., (2005). Horizontal Inequalities: A Neglected Dimension of Development. In WIDER Perspectives on Global Development (pp. 101-135). Palgrave Macmillan UK.

Stoker, G., (1998). Governance as Theory: Five Propositions. International Social Science Journal, 50(155), pp.17-28.

Suberu, R. (1992) 'Federalism ad the Transition to Democratic Governance in Nigeria' in Caron, B., Gboyega, A., \& Osaghae E (eds.), Democratic Transition in Africa: 319-29. Ibadan: CREDU

Suberu, R. (1994) 'The Democratic Recession in Nigeria'Current History, 93: 213-18.

Suberu, R, (2001) Federalism and Ethnic Conflict in Nigeria. Washington, DC: United States Institute of Peace Press. 2001.

Suberu, R. \& Osaghae, E. (2005) 'History of Identities, Violence and Stability in Nigeria'. Center for Research on Inequality, Human Security and Ethnicity: Queen Elizabeth House, University of Oxford January.

Suberu, R., (2009). Federalism in Africa: The Nigerian experience in comparative perspective. Ethnopolitics, 8(1), pp.67-86.

Suberu, R., (2009). Religion and institutions: Federalism and the management of conflicts over Sharia in Nigeria. Journal of International Development, 21(4), pp.547-560.

Suk Kim, P., Halligan, J., Cho, N., OH, C., \& Eikenberry, A. (2005) 'Toward Participatory and Transparent Governance: Report on the Sixth Global Forum on Reinventing Government.' Public Administration Review 65(6): 646-54. 
Tavares de Almeida, M. H. (2006). Decentralization and Centralization in a Federal System: The Case of Democratic Brazil. Revista de Sociologia e Politica 1:29_

44.socialsciences.scielo.org/pdf/s_rsocp/v1nse/scs_a02.pdf.

Tanzi, V, (2002) Pitfalls on the Road to Fiscal Decentralization Economic Reform Project GLOBAL POLICY PROGRAM Number 19 April 2002.

Thede, N., (2008) 'Decentralization, Democracy and Human Rights: A Human Rights based Analysis of the Impact of Local Democratic Reforms on Development.

Thompson, E. (1999) 'Indonesian in Transition: The 1999 Presidential Elections' NBR Briefing. Policy Report, No.9

.http://profile.nus.edu.sg/fass/socect/Thompson\%201999\%20NBR\%20Briefing.pdf.

Tilman, R., \& Cole, T. (eds.) (1962) 'The Nigerian Political Scene'.Durham, N.C.: Duke University Commonwealth Center 1962. p.46

Todaro, M., \& Smith, C. (2006) Economic Development: Harlow, Pearson Education

Tonwe, D. (2012) Fluidity in democratic local governance: the Achilles' heel of Nigerian Local Government. Journal of Human and Social Sciences, 4 (2), 75-82. Available at: http://www.ajol.info/index.php/ijhss/article/viewFile/86869/76658

Toyo, Nkoyo. (2003). "Why Entryism for Nigerian Women in Politics?" in Bassey, E. and Toyo, N. (eds.) Nigerian Women and Political Entryism: Power, Intrigues and Obstacles around the 2003 Elections. Lagos: Gender and Development Action.

Treisman D. (2002) Defining and Measuring Decentralization: A Global Perspective; (unpublished) http://www.sscnet.ucla.edu/polisci/faculty/treisman/Papers/defin.pdf.

UJNDP (1999) Human Development Report, 1999. Oxford University Press, New York.

United Nations Development Program, Human Development Program Report 1996.

http://web.ng.undp.org/documents/NHDR1996/NHDR_MAIN-REPORT1996.pdf.

United Nations Development Programme (UNDP), 1997.Governance for Sustainable Human Development: A UNDP Policy Document, New York: UNDP.

United Nations Development Program 2004: Decentralization Governance for Development: A Combined Practise Note on Decentralisation, Local Governance and Urban/Rural Development.

http://www.undp.org/content/dam/aplaws/publication/en/publications/democraticgovernance/dg-publications-for-website/decentralised-governance-for-development-acombined-practice-note-on-decentralization-local-governance-and-urban-ruraldevelopment/DLGUD_PN_English.pdf.

UNITED Nations Development Programme (UNDP), 2004, Decentralised Government for Development, New York: UNDP

USAID (2009).Democratic Decentralization Strategic Assessment Indonesia Final Report.http://pdf.usaid.gov/pdf_docs/PNADQ231.pdf 
van Dok, G., (1998) Good Governance-vom Papiertiger zum Hoffnungsträger?, Kritische Anmerkungen zum Erfolg eines Aussenpolitischen Konzeptes. Caritas-Verlag. discussion paper No 6 Lucerne.

Verba, S. and Pye, L., (1965). Political Culture and Political Development. Studies on Political Development.

Vickers, A. (2013). A History of Modern Indonesia.Cambridge.

Victor, E., (2002).Barriers to True Democracy in Nigeria. Abuja: Spectrum Books Limited.

Wang, T. and Di, Y., (2010), August. Fiscal Decentralization and Targeting of Antipoverty Program in Developing Countries. In Management and Service Science (MASS), 2010 International Conference on (pp. 1-4). IEEE.

Watts, R., (1995) The Contemporary Relevance of the Federal Idea' African Journal of Federal Studies. Vol.1 No.1 pp. 2-18.

Watts, R., (1970) Administration of in Federal System. Hutchinson Educational Limited. London.

Weingrod, A., 1977.Patronage and power. Patrons and Clients in Mediterranean Societies, pp.41-51.

Wheare, K.C. (1964) Federal Government, New York: Oxford University Press.

Williams, G. (ed.) (1970) Nigeria: Economy and Society. London: Rex Collins Ltd.

William, F., \& Robert L. (eds.) (1993) Indonesia: A Country Study. Washington: GPO for the Library of Congress.

Wilson, J. (1992) American Government, Lexington: DC Health.

Wilson, R (2000), Understanding Governance: an International Perspective. Revista de Administração de Empresas.vol.40, n²0, pp. 51-63.

Winston, T. (1997) 'Application of a Case Study Methodology The Qualitative Report’.Volume 3, Number 3, September, 1997 (http://www.nova.edu/ssss/QR/QR33/tellis2.html).

Wood, G. (1985) 'The Politics of Development Policy Labelling' in Wood, G. (ed.) Labelling in Development Policy: Essays in Honour of Bernard Schaffer, 5-31. London: Sage: The Hague: Institute of Social Studies.

Work, R. (2002) 'Overview Of Decentralization Worldwide: A Stepping Stone to Improved Governance and Human Development' ( $2^{\text {nd }}$ International Conference on Decentralization Federalism: The Future of Decentralizing States?) United Nations Development Programme.

World Bank (1991) The Reform of Public Sector Management, Lessons from Experience, Policy and Research. Series 18. Washington: The World Bank.

World Bank (1992) Governance and Development. Washington: The World Bank. 
World Bank (1994) Governance, The World Bank's Experience. Washington: The World Bank.

World Bank (1997) The State in a Changing World, World Development Report.

Washington: The World Bank.

World Bank (1997) Annual Report.Washington D.C: The World Bank 1997

World Bank (1998) Sub-Saharan Africa, From Crisis to Sustainable Growth: A Long Term Perspective Study.

World Bank (2003a) World Development Report 2004: Making Services Work for Poor People, World Bank and Oxford University Press, Washington, D.C.

World Bank (2003b), Decentralizing Indonesia: A Regional Public Expenditure Review Overview Report, World Bank, Jakarta.

World Bank (2004) Initiatives in Legal and Judicial Reform, Washington: The World Bank 2004

World Bank (2005), Papua Public Expenditure Analysis: Regional Finance and Service Delivery in Indonesia's most Remote Region, World Bank, Jakarta.

World Bank (2006) Equity and Development, World Development Report 2005. Washington: The World Bank.

World Bank (2007) Strengthening World Bank Group Engagement on Governance and Anticorruption Washington: The World Bank 2007

world Bank (2007) Spending for Development: Making the most of Indonesia's New Opportunities, World Bank, Jakarta.

World Bank (2008), Investing in Indonesia's Health: Challenges and Opportunities for Future Public Spending, World Bank, Jakarta.

World Economic Forum: The Global Competitiveness Report 2009-2010. http://www.weforum.org/pdf/GCR09/GCR20092010fullreport.pdf.

Wunsch, J. (2008) 'Why has Decentralization failed in Africa? Assessing the Lessons of SelfOrganized, Local Governance Initiatives'. A Paper presented at the Workshop for political theory and Policy Analysis.

Wunsch, J., \& Olowu, D. (1990) The Failure of the Centralized State (Institutions and Self Governance in Africa).Westview Press. Boulder.

Yin, R.K., 2015. Qualitative Research from Start to Finish. Guilford Publications. 


\section{$\underline{\text { Appendix }}$}

\section{$\underline{\text { List of Interviewees }}$}

\section{Type of Interview/Identity/Location/Year}

II/Local Resident 1 /Ifon/ 2016

II/Local Resident 2/Ifon/2016

II/Local Resident 3/Ifon/2016

II/Local Resident 4/Ifon/2017

II/Local Resident 5/ Bolorundoru/2016

II/Local Resident 6/Bolorunduro/2016

II/Local Resident 7/Bolorunduro/2016

II/ Local Resident 8/ Ayegunle Oka/ 2016

II/Local Resident 9/ Alayere/2016

II/Local Resident 10/Ipogun/2016

II/Local Resident 11/Ijare/2016

II/Local Resident 12/Igbara-Oke/2016

II/Local Resident 13/Igbara-Oke/2016

II/Local Resident14/Igbara-oke/2017

II/Local Resident 15/Igbara-Oke/2016

II/Local Resident 16/Igbara-Oke/Ibuji/2016

II/Local Resident116/Igbotu/2017

II/Local Resident17/Iwaro-Oka/2016

II/Local Resident 18/Ikotun/2016

II/Local Resident 19/Ikotun/2016
A former LG worker

Chairman CDC

A Local Resident (Chief)

Youth Leader

Member of CDC

Member of CDC Farmer

Teacher in the community

Member of CDC Farmer

Head of Idoma Community

Woman leader of a Community

Woman leader of a community

Chairman CDC

Youth Leader

Youth Leader

Member of CDC, Farmer

A woman petty trader

Youth Leader

Youth Leader

Religious leader(Christian)

Member of CDC 
SSI/ Academic 1/ Ibadan/2013

SSI/Academic 2/ Ibadan/2013

SS1/Civil Activist/Development Expert 1/ Abuja/2013

SSI/Civil Servant/Head of Service1/Akure/2016

SSI/Retired Civil Servant 2/ Akure/2016/2017

SSI/Retired Civil Servant 3/Sabomi/2016

SS1/Retired Civil Servant 4/Sabomi/2016

SS1/Civil Servant 1/Akure/2016

SSI/Civil Servant 2/Akure/ 2016/2017

SSI/Civil Servant 3/Akure/2016/2017

SS1/Civil Servant 4/Akure/2016/2017

SS1/ Civil Servant 5/Igbara-Oke/2016

SS1/Civil Servant 6/Igbara-Oke/2016

SS1/Civil Servant 7/Oka/ 2016

SSI/Civil Servant 7/Oka/2016

SS1/Civil Servant 8/Igbekebo/2017

SSI Civil Servant 9/Igbekebo/2017

SS1/Civil Servant 10/Iju-Itaogbolu/2016

SSI Civil Servant 11/Iju-Itaogbolu/2016

SS1 Civil Servant 12/Owo/2016

SS1 Civil Servant 13/0wo/2016

SS1/Development Expert 2/ Akure/2016
Senior Lecturer University of

Ibadan

Senior Lecturer, University of Ibadan

Country Director of an NGO

Retired Head of Service

Civil Servant

Civil Servant

Secretary OSOPADEC

Director OSOPADEC

Ifedore LG

Teacher

Akoko South-West LG

Akoko South-West LG

Ese -Odo LG

Ese-Odo LG

Akure North LG

Akure South LG

Owo LG

Owo LG

Program Officer of an NGO 
SS1/Lawyer1/Akure/2016

SSI/Lawyer2/Akure/2016/2017

SS1/Local Resident1/Alayere/Ogbese/2016

SSI/Local Resident 2/ Iwaro Oka/2016

SSI/Local Resident 3/Sabomi/ 2016

SSI/ Local Resident 4/ Iwaro/ 2016

SSI/ Local Resident 5/ Sabomi/ 2016

SSI/Local Resident 6/Sabomi/2016

SSI/Local Resident 7/ Igbotu/2017

SSI/Local Resident 8/Igbotu/2017

SSI/Local Resident9/Igbekebo/2017

SSI/Local Resident 10/Ode-Irele/2016

SSI/Local Resident 11/ Ode-Irele/2016

SSI/Local Resident 12/Ode-Irele/Kiribo/2016

SSI/Politician 1 / London/Lagos/2013

SSI/Politician 2 / Ila Orangun/2013

SS1/Politician 3/Abuja/2013

SSI/Politician 4/ Igbara-Oke/2016

SSI/Politician 5/Owo/2013

SSI/Politician 6/Owo/2013

SS/1/Politician 7/Ipogun/2016/2017

SS1/Politician 8/Ikaro/ 2016
Private Legal Practitioner

Lawyer and former Legislator

Religious leader (Christian)

Principal of a school

Member of CDC

Youth Leader

Member of CDC

A traditional Chief

Community member

CDC Chairperson

Local Chief

A Community leader

A Community leader

Youth Leader

National Leader of political Party

Former State Governor

Senator of Federal Republic

Member of LG Caretaker committee

A female gubernatorial aspirant

A member of Yoruba Sociopolitical organisation (Afenifere)

Local politician

Member of LG. Caretaker Committee. 
SSI/Politician 9/Akure/2016

SSI/Politician 10/Akure/2016
Member House of Assembly

Former Chairman Akure South

LG. 